\title{
Triple oxygen isotope variations in natural and anthropogenic carbon dioxide
}

\author{
Dissertation \\ zur Erlangung des Doktorgrades \\ der Mathematisch-Naturwissenschaftlichen Fakultäten \\ der Georg-August-Universität zu Göttingen
}

vorgelegt von

Magdalena Else Gabriele Hofmann aus Roßdorf (bei Darmstadt)

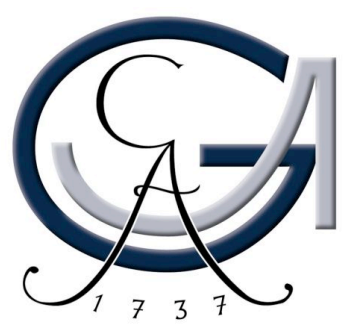

Göttingen 2012 
Referent:

Prof. Dr. Andreas Pack

Korreferent:

Prof. Dr. Jochen Hoefs

Tag der mündlichen Prüfung: $\quad$ 21.09.2012 


\section{Abstract}

The oxygen and carbon isotope composition $\left({ }^{18} \mathrm{O} /{ }^{16} \mathrm{O}\right.$ and $\left.{ }^{13} \mathrm{C} /{ }^{12} \mathrm{C}\right)$ of atmospheric carbon dioxide is an excellent tool to investigate the atmospheric $\mathrm{CO}_{2}$ cycle. In recent years, it has been suggested that the triple oxygen isotope composition $\left({ }^{17} \mathrm{O} /{ }^{16} \mathrm{O}\right.$ and $\left.{ }^{18} \mathrm{O} /{ }^{16} \mathrm{O}\right)$ of tropospheric $\mathrm{CO}_{2}$ might be a potential new tracer for the terrestrial gross primary production. This study investigates whether and to which extent this new tracer might complement conventional stable isotope investigations of tropospheric $\mathrm{CO}_{2}$.

This thesis presents (i) a new high-precision technique for triple oxygen isotope analysis in carbon dioxide; (ii) an experimental study on triple oxygen isotope exchange between $\mathrm{CO}_{2}$ and water, the most important process controlling the triple oxygen isotope composition of tropospheric $\mathrm{CO}_{2}$; (iii) experimental data on the triple oxygen isotope composition of combustion $\mathrm{CO}_{2}$, in particular anthropogenic $\mathrm{CO}_{2}$ emissions; (iv) observational data of tropospheric $\mathrm{CO}_{2}$ and a global mass balance model.

In chapter 2, we describe the new high-precision analytical technique that allows detecting small variations in near-surface tropospheric $\mathrm{CO}_{2}$ and in the various $\mathrm{CO}_{2}$ sources to the troposphere. The method is based on $\mathrm{CO}_{2}-\mathrm{CeO}_{2}$ equilibration at elevated temperature $\left(\mathrm{T}=685^{\circ} \mathrm{C}\right.$ ) and subsequent laser fluorination of the equilibrated $\mathrm{CeO}_{2}$. The released molecular oxygen is then analyzed for its triple oxygen isotope composition on a mass spectrometer. The oxygen isotope composition of the sample $\mathrm{CO}_{2}$ can be inferred from the triple oxygen isotope composition of the equilibrated $\mathrm{CeO}_{2}$. The analytical uncertainty of triple oxygen isotope analysis of $\mathrm{CO}_{2}$ has been improved by about an order of magnitude compared to former techniques.

The triple oxygen isotope composition of tropospheric $\mathrm{CO}_{2}$ is largely controlled by $\mathrm{CO}_{2}$ water exchange in plant leaves, soils and in ocean surface water. Thus, chapter 3 presents a laboratory study on the equilibrium fractionation exponent for oxygen isotope exchange between $\mathrm{CO}_{2}$ and water at three different temperatures $\left(2{ }^{\circ} \mathrm{C}, 23{ }^{\circ} \mathrm{C}\right.$ and $\left.37^{\circ} \mathrm{C}\right)$. Our experimental results agree well with theoretical calculations. Knowledge of this equilibrium fractionation process is a prerequisite for estimating the triple oxygen isotope composition of natural $\mathrm{CO}_{2}$ gross fluxes from the bio- and hydrosphere.

In chapter 4 , we investigate the triple oxygen isotope composition of $\mathrm{CO}_{2}$ from propanebutane and wood combustion, car exhaust and human breath. The experimental studies show that high-temperature combustion $\mathrm{CO}_{2}$ largely inherits its distinct triple oxygen 
isotope signature from ambient air $\mathrm{O}_{2}$. For low-temperature combustion, such as wood combustion, the triple oxygen isotope signature of the released $\mathrm{CO}_{2}$ is also affected by $\mathrm{CO}_{2}$-water equilibration or other oxygen sources, such as wood inherent oxygen. The oxygen isotope composition of human breath is solely controlled by isotope exchange with body water. The experimental data demonstrate that the triple oxygen isotope composition of anthropogenic $\mathrm{CO}_{2}$ emissions can be clearly distinguished from natural $\mathrm{CO}_{2}$ sources.

In chapter 5, we present the first high-precision triple oxygen isotope data of tropospheric $\mathrm{CO}_{2}$. The data set of ambient air $\mathrm{CO}_{2}$ sampled in Göttingen shows a significant temporal variation, which only in part follows the seasonal cycle of the ${ }^{18} \mathrm{O} /{ }^{16} \mathrm{O}$ ratio of tropospheric $\mathrm{CO}_{2}$. The triple oxygen isotope composition of tropospheric $\mathrm{CO}_{2}$ sampled on top of the Brocken Mountain (1140 m, Harz Mountains, Germany) falls within the range observed in Göttingen. The mass balance prediction for the triple oxygen isotope composition of global tropospheric $\mathrm{CO}_{2}$ only in part agrees with the observational data. The modeling results suggest that the observed temporal variation in $\Delta^{17} \mathrm{O}$ cannot be attributed to seasonal variations in plant activity, but it may be that the influx of stratospheric $\mathrm{CO}_{2}$ significantly affects the temporal $\Delta^{17} \mathrm{O}$ variations of tropospheric $\mathrm{CO}_{2}$.

This study presents the basis for triple oxygen isotope analysis in tropospheric $\mathrm{CO}_{2}$ and its meaningful interpretation. Yet, not all characteristics of the triple oxygen isotope signature of tropospheric $\mathrm{CO}_{2}$ can be explained calling for future studies. 


\section{Kurzfassung}

Die stabilen Isotopenverhältnisse von Sauerstoff und Kohlenstoff $\left({ }^{18} \mathrm{O} /{ }^{16} \mathrm{O}\right.$ und $\left.{ }^{13} \mathrm{C} /{ }^{12} \mathrm{C}\right)$ in atmosphärischem Kohlendioxid sind besonders geeignet, um den $\mathrm{CO}_{2}$ Kreislauf zu untersuchen. Vor einigen Jahren wurde die Hypothese aufgestellt, dass die 3Sauerstoffisotopen-Verhältnisse $\quad\left({ }^{17} \mathrm{O} /{ }^{16} \mathrm{O}\right.$ und $\left.\quad{ }^{18} \mathrm{O} /{ }^{16} \mathrm{O}\right)$ von troposphärischem Kohlendioxid ein neuer Isotopenindikator für die terrestrische Bruttoprimärproduktion ist. In dieser Arbeit wird untersucht, ob und inwieweit dieser neuartige Isotopenindikator konventionelle stabile Isotopenuntersuchungen von troposphärischem Kohlendioxid ergänzen kann.

Die vorliegende Arbeit gliedert sich in vier Teile: (i) Die Entwicklung einer analytischen Methode, mit der die Sauerstoffisotopie $\left({ }^{17} \mathrm{O} /{ }^{16} \mathrm{O},{ }^{18} \mathrm{O} /{ }^{16} \mathrm{O}\right)$ von Kohlendioxid mit höchster Präzision gemessen werden kann. (ii) Eine experimentelle Untersuchung zum 3Sauerstoffisotopen-Austausch zwischen $\mathrm{CO}_{2}$ und Wasser. Dieser Austauschprozess ist von grundlegender Bedeutung für die Isotopen-Signatur von troposphärischem $\mathrm{CO}_{2}$. (iii) Eine Studie zur 3-Sauerstoffisotopen-Zusammensetzung von Kohlendioxid aus Verbrennung mit einem besonderen Fokus auf anthropogene $\mathrm{CO}_{2}$ Emissionen. (iv) Abschließend werden troposphärische $\mathrm{CO}_{2}$ Daten vorgestellt und mit einem globalen Massenbilanzmodell verglichen.

In Kapitel 2 wird die neuartige Methode zur 3-Sauerstoffisotopen-Analyse von $\mathrm{CO}_{2}$ beschrieben. Diese Methode ermöglicht es, kleinste Variationen in troposphärischem Kohlendioxid und den unterschiedlichen $\mathrm{CO}_{2}$ Quellen zur Troposphäre zu untersuchen. Die Methode beruht auf Isotopenäquilibrierung zwischen $\mathrm{CO}_{2}$ und $\mathrm{CeO}_{2}$ bei erhöhter Temperatur $\left(\mathrm{T}=685^{\circ} \mathrm{C}\right)$ und anschließender Laser-Fluorinierung des äquilibrierten Cerdioxids. Der freigesetzte Sauerstoff wird anschließend massenspektrometrisch auf seine 3-Sauerstoffisotopen-Zusammensetzung untersucht. Die Sauerstoffisotopie $\left({ }^{17} \mathrm{O} /{ }^{16} \mathrm{O}\right.$, $\left.{ }^{18} \mathrm{O} /{ }^{16} \mathrm{O}\right)$ der Kohlendioxid Probe kann aus der Isotopie des $\mathrm{CeO}_{2}$ berechnet werden. Die Messgenauigkeit konnte im Vergleich zu früheren Methoden um etwa eine Größenordnung verbessert werden.

Die Sauerstoffisotopie $\left({ }^{17} \mathrm{O} /{ }^{16} \mathrm{O},{ }^{18} \mathrm{O} /{ }^{16} \mathrm{O}\right)$ von troposphärischem Kohlendioxid wird hauptsächlich durch den Isotopenaustausch zwischen $\mathrm{CO}_{2}$ und Wasser in Pflanzenblättern, Böden und in der obersten Meeresschicht bestimmt. Daher widmet sich Kapitel 3 der experimentellen Bestimmung der Gleichgewichtsfraktionierung $\left({ }^{17} \mathrm{O} /{ }^{16} \mathrm{O},{ }^{18} \mathrm{O} /{ }^{16} \mathrm{O}\right)$ zwischen $\mathrm{CO}_{2}$ und Wasser bei drei unterschiedlichen Temperaturen $\left(2{ }^{\circ} \mathrm{C}, 23^{\circ} \mathrm{C}\right.$ und 
$37^{\circ} \mathrm{C}$ ). Die experimentellen Ergebnisse stimmen mit theoretischen Berechnungen überein. Die Kenntnis dieses Gleichgewichtsfraktionierungsprozesses ist eine Grundvoraussetzung, um die 3-Sauerstoffisotopen-Zusammensetzung der natürlichen $\mathrm{CO}_{2}$ Quellen aus der Biound Hydrosphäre abzuschätzen.

In Kapitel 4 werden die experimentellen Ergebnisse zur 3-SauerstoffisotopenZusammensetzung von Kohlendioxid aus Verbrennung dargestellt (Propan-ButanVerbrennung, Holzverbrennung, Autoabgase und $\mathrm{CO}_{2}$ aus Atemluft). Die Ergebnisse zeigen, dass bei Hochtemperatur-Verbrennungsprozessen die Sauerstoffisotopie von Luft$\mathrm{O}_{2}\left({ }^{17} \mathrm{O} /{ }^{16} \mathrm{O},{ }^{18} \mathrm{O} /{ }^{16} \mathrm{O}\right)$ größtenteils auf das Kohlendioxid übertragen wird. Bei niedrigen Verbrennungstemperaturen, wie der Holzverbrennung, wird die SauerstoffisotopenZusammensetzung des freigesetzten Kohlendioxids auch durch $\mathrm{CO}_{2}$-Wasser Äquilibrierung und andere Sauerstoffquellen, wie z.B. im Holz gebundener Sauerstoff, beeinflusst. Die Sauerstoffisotopen-Zusammensetzung von Kohlendioxid aus Atemluft wird hingegen nur durch den Isotopenaustausch mit Körperwasser bestimmt. Die experimentellen Daten zeigen, dass man anthropogenes Kohlendioxid anhand seiner Sauerstoffisotopie $\left({ }^{17} \mathrm{O} /{ }^{16} \mathrm{O},{ }^{18} \mathrm{O} /{ }^{16} \mathrm{O}\right)$ eindeutig von Kohlendioxid aus natürlichen Quellen unterscheiden kann.

In Kapitel 5 werden die ersten hoch-präzisen 3-Sauerstoffisotopen-Analysen von troposphärischem Kohlendioxid vorgestellt. Der Datensatz von $\mathrm{CO}_{2}$ Proben aus Göttingen zeigt eine deutliche zeitliche Variation in der 3-Sauerstoffisotopen-Zusammensetzung. Diese zeitliche Schwankung stimmt nur teilweise mit der saisonalen Variation des ${ }^{18} \mathrm{O} /{ }^{16} \mathrm{O}$ Verhältnisses von troposphärischem $\mathrm{CO}_{2}$ überein. Messungen von $\mathrm{CO}_{2}$ Proben vom Brocken (1140 m, Harz, Deutschland) stimmen mit den gemessen Daten in Göttingen überein. Die Massenbilanz Vorhersage für die 3-Sauerstoffisotopen-Zusammensetzung von troposphärischem $\mathrm{CO}_{2}$ stimmt nur teilweise mit den gemessenen Daten überein. Die Modellierung legt nahe, dass die zeitlichen Variationen in der 3-SauerstoffisotopenZusammensetzung nicht durch saisonale Schwankungen der biologischen Aktivität erklärt werden können, stattdessen könnte der Zustrom von stratosphärischem $\mathrm{CO}_{2}$ die zeitlichen Schwankungen verursachen.

Diese Untersuchung bereitet die Grundlage für 3-Sauerstoffisotopen Analysen von troposphärischem Kohlendioxid und deren aussagekräftige Interpretation. Allerdings können nicht alle Merkmale der gemessenen Isotopendaten erklärt werden, es werden künftig weitere Untersuchungen notwendig sein. 


\section{Acknowledgments}

Above all, I thank my supervisor Prof. Dr. Andreas Pack for providing me with this topic and his continuous support during my time as a $\mathrm{PhD}$ student. I enjoyed the various discussions, which were always characterized by his scientific curiosity. I also thank Prof. Dr. Jochen Hoefs for being my co-supervisor.

I thank Balázs Horváth for being a very helpful colleague at all times. Working on the same project with him and sharing the same office was crucial for the day-to-day motivation!

I thank my two $\mathrm{PhD}$ fellows, Alexander Gehler and Verena Bendel, for sharing the ups and downs of a dissertation project. I wish you all the best for finishing your dissertations!

I thank Reinhold Przybilla, Ingrid Reuber and Axel Dierschke for their technical support in the laboratory.

I also thank our student assistants, especially Maximilian Troche and Andres Höweling, for helping me in the lab.

I am thankful to the INTRAMIF organizers, in particular Thomas Röckmann, Jan Kaiser and Amaelle Landais, who initiate two great summer schools on stable isotopes and beyond. It was always a pleasure for me meeting all the INTRAMIF PhD students!

Moreover, I thank Hauke Vollstaedt for an ongoing friendship from the first introductory lectures in geology to the highly specialized world of geochemistry. The conversations on academia in general and specific scientific problems were always a welcome change!

In particular, I enjoyed the rehearsals and concerts with the AOV Göttingen during my time as a $\mathrm{PhD}$ student, which were always a valuable balance to daily work. Especially, I thank Liane Lühmann for many cheerful moments!

I also thank my mother Heidelore Hofmann for always listening and giving a fresh perspective on life!

Finally, I am grateful to my beloved Christian for his scientific advice and for being a wonderful companion! 


\section{Table of contents}

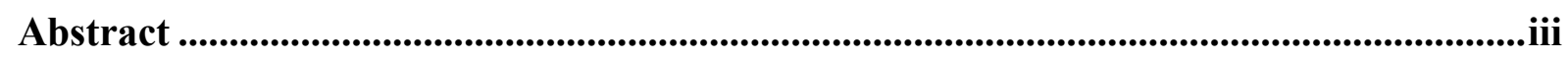

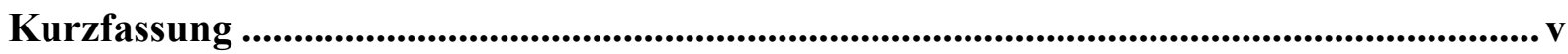

Acknowledgments ........................................................................................................................ vii

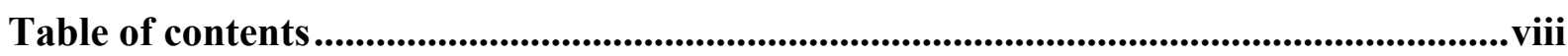

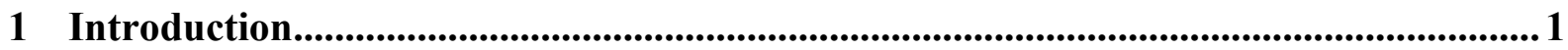

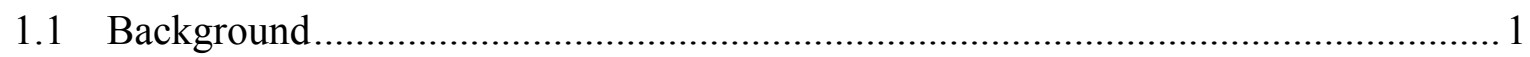

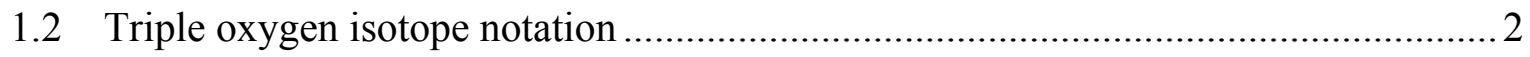

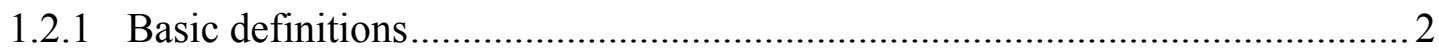

1.2.2 The $\Delta^{17} \mathrm{O}$ value and the reference line ........................................................ 4

1.2.3 Triple oxygen isotope exponents: $\lambda$ and $\theta$ values ....................................... 6

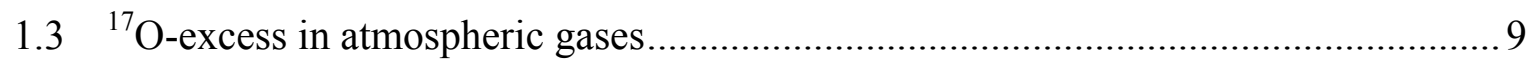

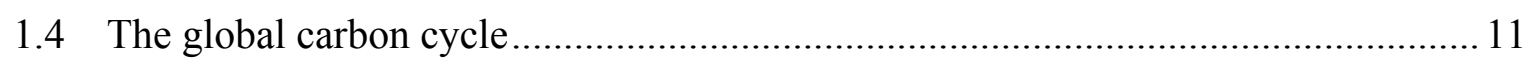

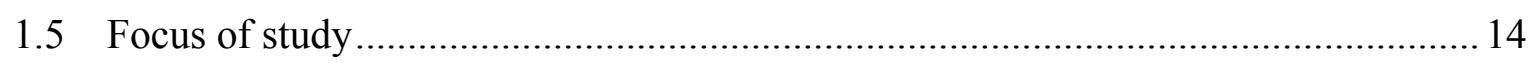

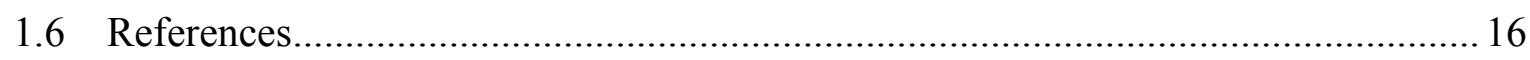

2 Technique for high-precision analysis of triple oxygen isotope ratios in

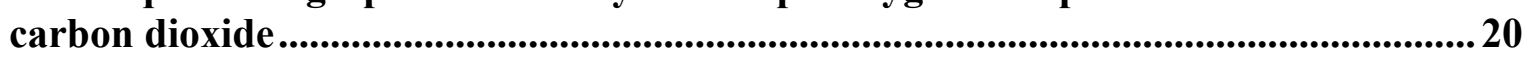

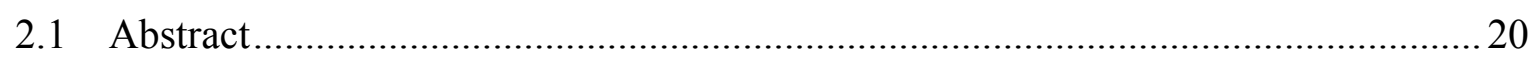

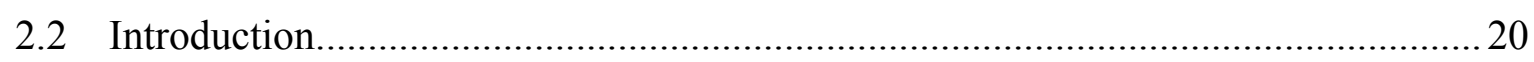

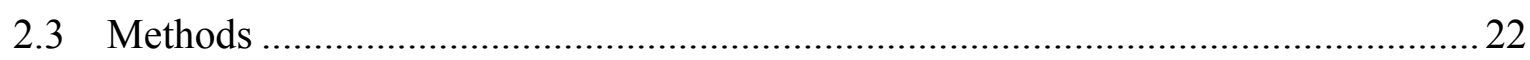

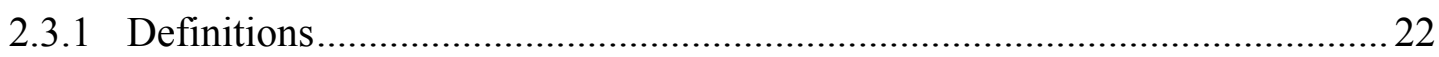

2.3.2 Oxygen and carbon isotope analyses ........................................................ 22

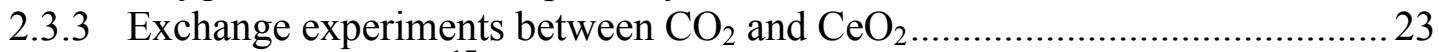

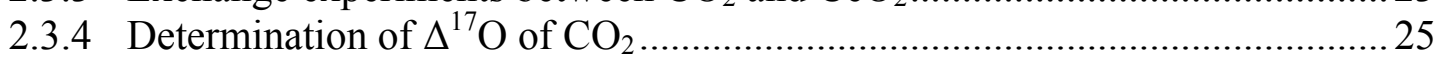

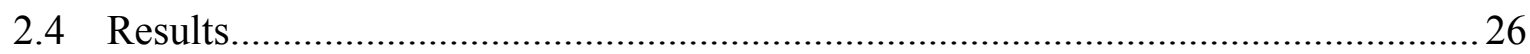

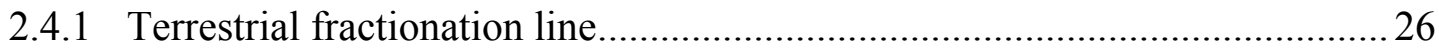

2.4.2 Isotopic composition of the starting materials ........................................... 27

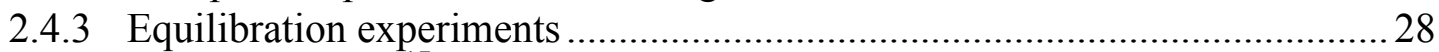

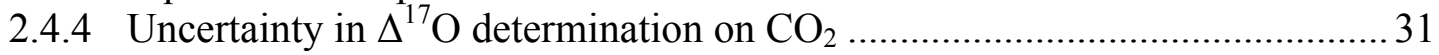

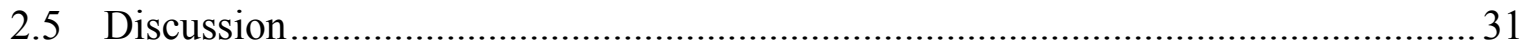

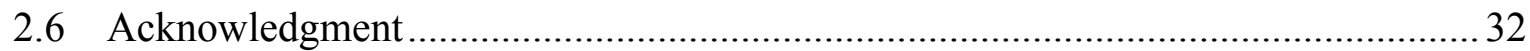

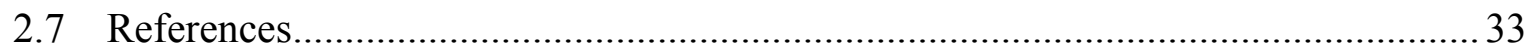


3 Triple oxygen isotope equilibrium fractionation between carbon dioxide

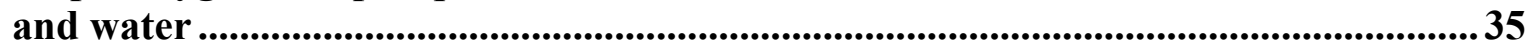

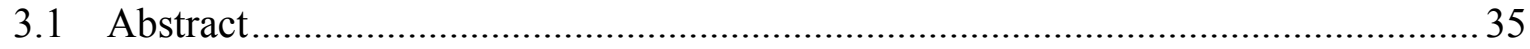

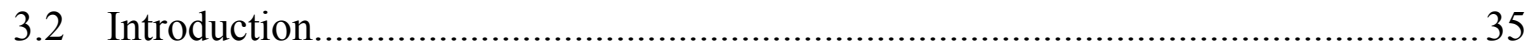

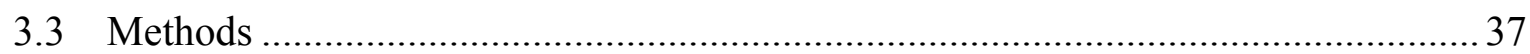

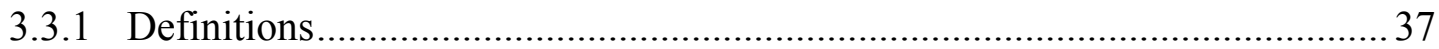

3.3.2 Isotope exchange experiments between $\mathrm{CO}_{2}$ and water .................................37

3.3.3 Triple oxygen isotope analyses of $\mathrm{CO}_{2}$ and water ...................................... 39

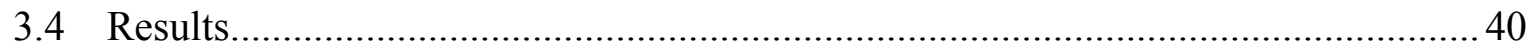

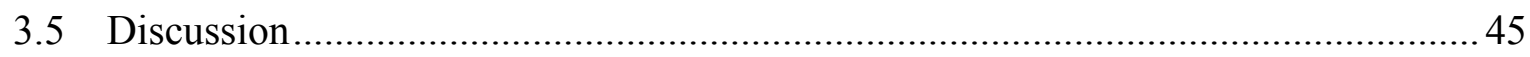

3.5.1 The triple oxygen isotope equilibrium fractionation exponent $\theta_{\mathrm{CO} 2 \text {-water }}$ in the context of experimental and theoretical literature

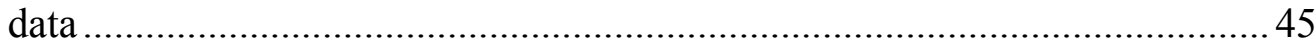

3.5.2 Relevance of the $\theta_{\mathrm{CO} 2 \text {-water }}$ value for the identification of major $\mathrm{CO}_{2}$ sources to the troposphere ..................................................................... 49

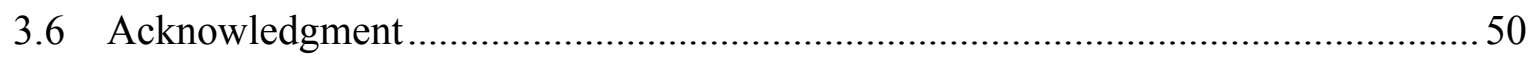

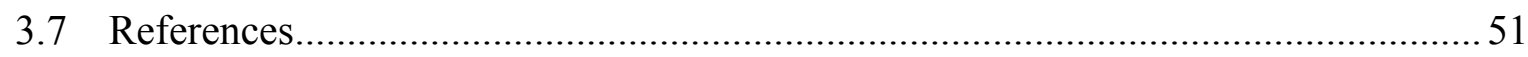

4 On the triple oxygen isotope composition of carbon dioxide from some

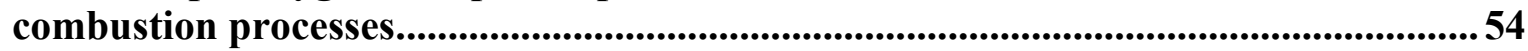

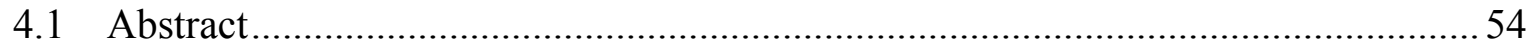

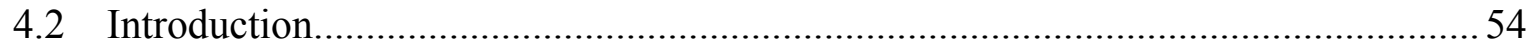

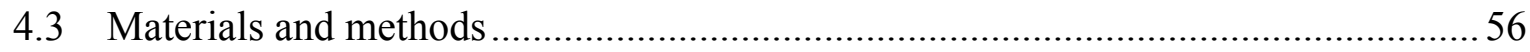

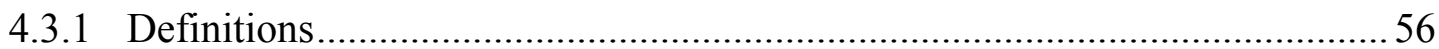

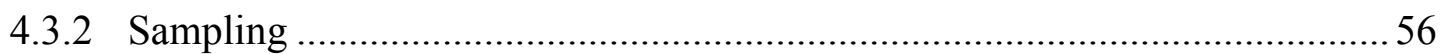

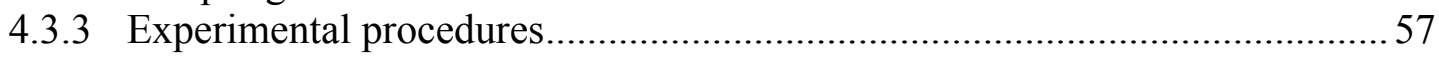

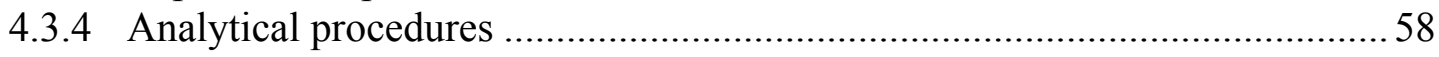

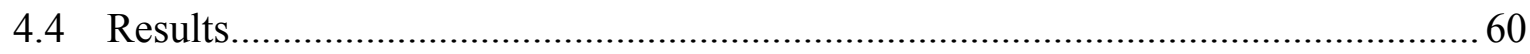

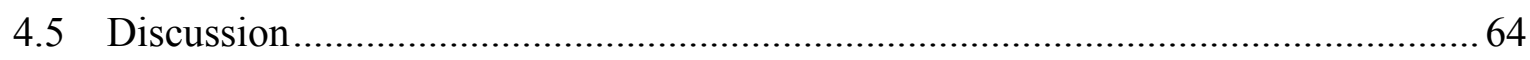

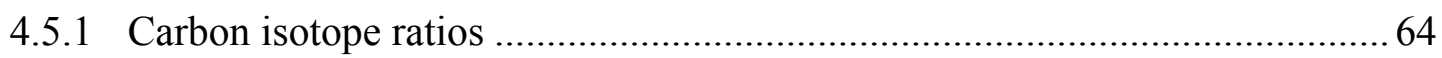

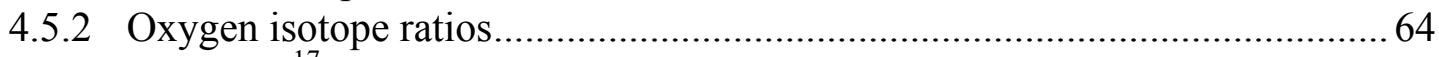

4.5.3 Can the $\Delta^{17} \mathrm{O}$ value of $\mathrm{CO}_{2}$ be used as a tracer to distinguish
between different $\mathrm{CO}_{2}$ sources? .............................................................. 71

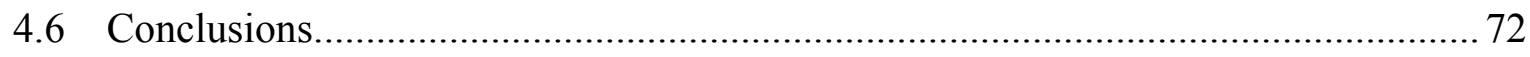

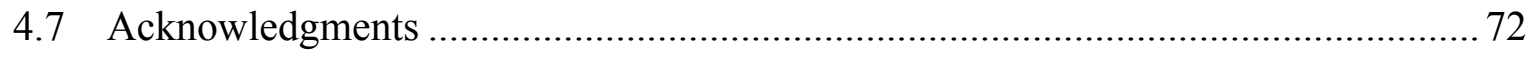

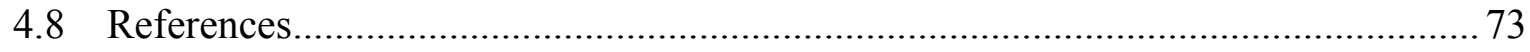

5 Triple oxygen isotope composition of tropospheric $\mathrm{CO}_{2}$ : Observational data and model simulation ............................................................................................................. 78

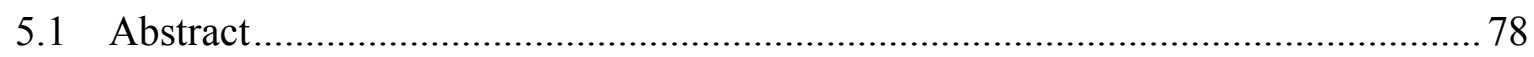

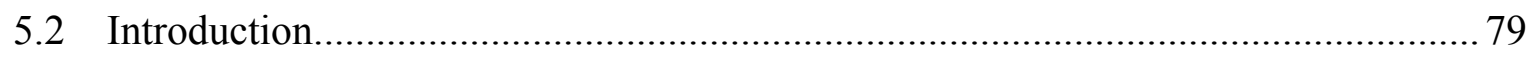




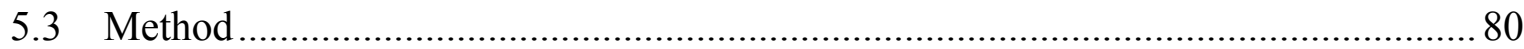

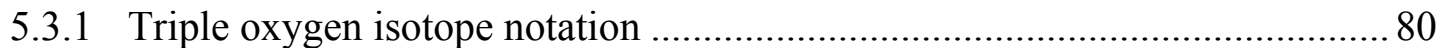

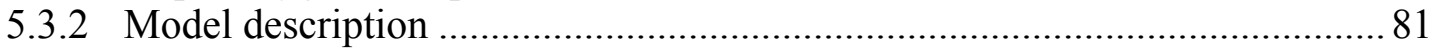

5.3.3 Sampling of tropospheric $\mathrm{CO}_{2}$ and isotope analyses ................................. 97

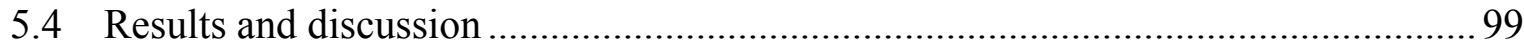

5.4.1 Modeled triple oxygen isotope composition of tropospheric $\mathrm{CO}_{2} \ldots \ldots \ldots \ldots \ldots . . . .99$

5.4.2 Impact of the major $\mathrm{CO}_{2}$ sources and sinks on the global mean $\Delta^{17} \mathrm{O}$ value of tropospheric $\mathrm{CO}_{2}$

5.4.3 Is $\Delta^{17} \mathrm{O}$ of tropospheric $\mathrm{CO}_{2}$ a potential tracer for the terrestrial

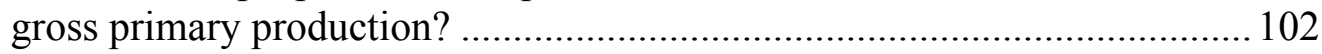

5.4.4 Observational triple oxygen isotope data of tropospheric $\mathrm{CO}_{2} \ldots \ldots \ldots \ldots \ldots \ldots . . . . . . .103$

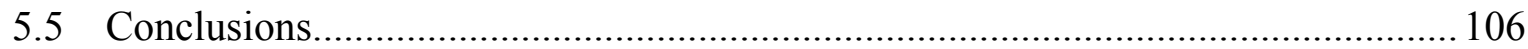

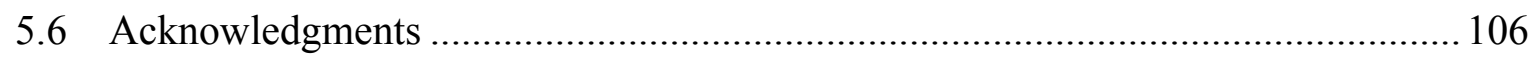

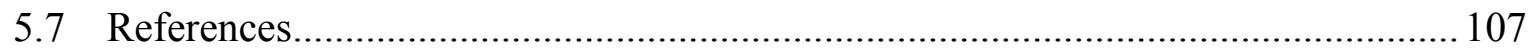

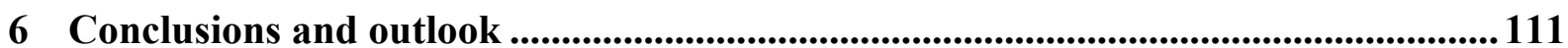

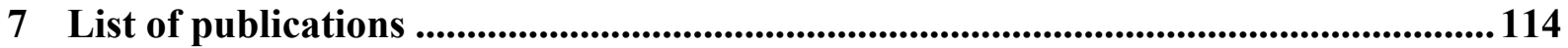

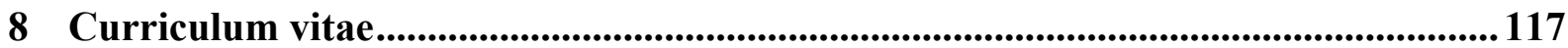




\section{Introduction}

\subsection{Background}

Today, the increase in atmospheric $\mathrm{CO}_{2}$ concentration and the concomitant climate change is one of the most pressing environmental challenges that society is facing (IPCC, 2007). Stable isotope geochemistry has traditionally played an important role in unraveling the magnitude of anthropogenic and natural $\mathrm{CO}_{2}$ sources and sinks to the atmosphere. Assessing and understanding the mechanisms of the disturbed current global carbon cycle is a prerequisite for meaningful future climate change predictions.

During the late 1950s and the 1960s, Charles Keeling was the first to investigate simultaneously variations in the atmospheric $\mathrm{CO}_{2}$ concentration and in the ${ }^{13} \mathrm{C} /{ }^{12} \mathrm{C}$ isotope ratio of atmospheric $\mathrm{CO}_{2}$, and thus, he was able to ascribe seasonal variations in $\mathrm{CO}_{2}$ concentration to seasonal variations in plant activity (Keeling, 1958; Keeling, 1960; Keeling, 1961). Since then, various studies on the stable carbon isotope ratio of atmospheric $\mathrm{CO}_{2}$ followed, and ultimately, allowed to partition the global net $\mathrm{CO}_{2}$ uptake between the terrestrial biosphere and the ocean (e.g. Ciais et al., 1995). The underlying principle is that plants preferentially take up the light ${ }^{12} \mathrm{C}$ isotope compared to the heavy ${ }^{13} \mathrm{C}$ isotope, whereas dilution of $\mathrm{CO}_{2}$ in the ocean hardly affects the ${ }^{13} \mathrm{C} /{ }^{12} \mathrm{C}$ ratio of the residual atmospheric $\mathrm{CO}_{2}$.

Since the late 1970s, stable oxygen isotope analysis of atmospheric $\mathrm{CO}_{2}$ gained in importance. At that time, the main focus was on analyzing the ${ }^{18} \mathrm{O} /{ }^{16} \mathrm{O}$ ratio ${ }^{1}$. In contrast to the stable carbon isotope composition of atmospheric $\mathrm{CO}_{2}$, the stable oxygen isotope composition of tropospheric $\mathrm{CO}_{2}$ is largely controlled by $\mathrm{CO}_{2}$-water exchange in leaves, soils and ocean surface water (Farquhar et al., 1993; Francey and Tans, 1987). Thus, investigating the ${ }^{18} \mathrm{O} /{ }^{16} \mathrm{O}$ ratio of atmospheric $\mathrm{CO}_{2}$ allows inferring the $\mathrm{CO}_{2}$ gross fluxes from the terrestrial biosphere and soil respiration (Ciais et al., 1997; Cuntz et al., 2003a; Cuntz et al., 2003b; Peylin et al., 1999). Recently, it has been suggested that interannual variations in the ${ }^{18} \mathrm{O} /{ }^{16} \mathrm{O}$ ratio of atmospheric $\mathrm{CO}_{2}$ could also trace changes in the

${ }^{1}$ Oxygen has three stable isotopes: ${ }^{16} \mathrm{O},{ }^{17} \mathrm{O}$ and ${ }^{18} \mathrm{O}$. Oxygen with mass $16 \mathrm{u}$ is the far most abundant isotope accounting for about $99.76 \%$. The rare isotopes ${ }^{17} \mathrm{O}$ and ${ }^{18} \mathrm{O}$ have an abundance of only $0.039 \%$ and $0.201 \%$, respectively. 
terrestrial gross primary production (Welp et al., 2011).

During the 1980s, Thiemens and Heidenreich (Thiemens and Heidenreich, 1983; Heidenreich and Thiemens, 1986) were the first to identify large enrichments in ${ }^{17} \mathrm{O}$ in an atmospheric tracer gas, namely ozone. The reason for this large enrichment in ${ }^{17} \mathrm{O}$ were socalled mass-independent fractionation effects during the formation process of ozone. Subsequent, this large enrichment in the rare ${ }^{17} \mathrm{O}$ isotope was discovered in stratospheric $\mathrm{CO}_{2}$ (Thiemens et al., 1995a; Thiemens and Jackson, 1991; Thiemens et al., 1995b), and it was found that this excess in ${ }^{17} \mathrm{O}$ was also passed on to almost all other oxygen-bearing trace gases in the atmosphere. Thus, exploring the triple oxygen isotope composition of atmospheric gases became a powerful tool to investigate atmospheric chemistry or atmosphere-biosphere interactions (e.g. Luz et al., 1999).

Nowadays, high-precision measurement of triple oxygen isotope ratios in tropospheric carbon dioxide is a promising tracer to complement the traditional stable oxygen and carbon isotope analyses. In 2005, Hoag et al. pointed out that the triple oxygen isotope composition of tropospheric $\mathrm{CO}_{2}$ might contain information on the current-day terrestrial gross primary production. It is the ultimate goal of this study to test the potential of this new tracer for the global carbon cycle.

\subsection{Triple oxygen isotope notation}

\subsubsection{Basic definitions}

In general, variations of stable isotope ratios in natural terrestrial materials are small. Thus, the isotopic ratio of a sample is not given as an absolute value, but as a deviation from an international reference material. The small isotopic variations are given as $\delta$-values describing the relative isotopic enrichment of a sample to a reference material:

$$
\delta=\left[\frac{R_{\text {sample }}}{R_{\text {reference }}}-1\right]
$$

The variable $R$ describes the ratio of the heavy to light stable isotope in the sample and the reference material.

\footnotetext{
${ }^{2}$ Note that the $\delta$-notation in Eq.1-1 often contains a numerical factor of 1000 . However, recently Coplen (2011) recommended to omit this factor for consistent stable isotope notation.
} 
For the case of oxygen, there are three stable isotopes $\left({ }^{16} \mathrm{O},{ }^{17} \mathrm{O},{ }^{18} \mathrm{O}\right)$ so that one can define $\delta^{18} \mathrm{O}$ - and $\delta^{17} \mathrm{O}$-values:

$$
\delta^{17} O=\left[\frac{\left({ }^{17} O /{ }^{16} O\right)_{\text {sample }}}{\left({ }^{17} O /{ }^{16} O\right)_{\text {VSMOW }}}-1\right]
$$

and

$$
\delta^{18} O=\left[\frac{\left({ }^{18} O /{ }^{16} O\right)_{\text {sample }}}{\left({ }^{18} O /{ }^{16} O\right)_{\text {VSMOW }}}-1\right]
$$

For oxygen isotope notation, the primary reference material is Vienna Standard Mean Ocean Water (VSMOW). Alternatively, oxygen isotope ratios are given relative to Vienna Pee Dee Belemnite (VPDB), which is also the most common reference material for carbon isotope ratios. Note, that conversion from one oxygen isotope reference scale to the other can be easily done applying the relationship given in Coplen et al. (1983).

For mass-dependent fractionation processes, i.e. equilibrium and kinetic isotope exchange reactions, the ratios of multi isotope species are related via a power law function. For the triple oxygen isotope ratios, the mass-dependent fractionation law can be given by the following relationship (Young et al., 2002):

$$
\frac{\left({ }^{17} \mathrm{O} /{ }^{16} \mathrm{O}\right)_{\text {sample }}}{\left({ }^{17} \mathrm{O} /{ }^{16} \mathrm{O}\right)_{\text {VSMOW }}}=\left[\frac{\left({ }^{18} \mathrm{O} /{ }^{16} \mathrm{O}\right)_{\text {sample }}}{\left({ }^{18} \mathrm{O} /{ }^{16} \mathrm{O}\right)_{\text {VSMOW }}}\right]^{\lambda}
$$

The exponent $\lambda$ differs for equilibrium and kinetic fractionation processes. In theory, the exponent $\lambda$ for oxygen isotope fractionation can vary between 0.509 and 0.530 for kinetic and equilibrium fractionation processes (Young et al., 2002). Note that the exponent is generally denoted with $\lambda$ if one is reporting isotope variations of a certain reservoir (e.g. meteoric water or terrestrial rocks and minerals) representing a statistical triple oxygen isotope distribution in this reservoir. However, the exponent for pure equilibrium fractionation between two phases $\mathrm{A}$ and $\mathrm{B}$, e.g. oxygen isotope exchange between $\mathrm{CO}_{2}$ and water, is denoted with the greek symbol $\theta$ in this study: 


$$
\frac{\delta^{17} O^{A}+1}{\delta^{17} O^{B}+1}=\left[\frac{\delta^{18} O^{A}+1}{\delta^{18} O^{B}+1}\right]^{\theta}
$$

where $\delta^{17} \mathrm{O}^{\mathrm{A}}$ and $\delta^{18} \mathrm{O}^{\mathrm{A}}$ are the isotopic values of a phase $\mathrm{A}$ and $\delta^{17} \mathrm{O}^{\mathrm{B}}$ and $\delta^{18} \mathrm{O}^{\mathrm{B}}$ are the isotopic values of phase B. Nowadays, it is possible to detect slight variations in the exponent $\theta$ for equilibrium fractionation between compounds due to a steady increase in analytical precision. A short literature review on different theoretical and experimental $\lambda$ and $\theta$ values will be given below (see section 1.2.3).

In order to obtain a linear relationship between $\delta^{18} \mathrm{O}$ and $\delta^{17} \mathrm{O}$ values, the equations Eq. 1-2 and Eq. 1-3 can be rearranged to give

$$
\delta^{, 17,18} \mathrm{O}=\ln \left(\delta^{17,18} \mathrm{O}+1\right)
$$

From Eq. 1-4 it follows that the two new variables $\delta^{, 18} \mathrm{O}$ and $\delta^{17} \mathrm{O}$ describe a linear relationship with the variable $\lambda$ as coefficient:

$$
\delta^{117} \mathrm{O}=\lambda \times \delta^{118} \mathrm{O}
$$

Thus, the variable $\lambda$ corresponds to a slope in a $\delta^{, 18} \mathrm{O}$ vs. $\delta^{, 17} \mathrm{O}$ plot and the $\theta$ value represents a line connecting two points: the $\delta{ }^{, 18} \mathrm{O}$ and $\delta{ }^{17} \mathrm{O}$ value of a phase A (e.g. $\left.\mathrm{CO}_{2}\right)$ and the $\delta^{, 18} \mathrm{O}$ and $\delta{ }^{, 17} \mathrm{O}$ value of a phase $\mathrm{B}$ (e.g. water).

\subsubsection{The $\Delta^{17} \mathrm{O}$ value and the reference line}

In general, triple oxygen isotope ratios are given relative to a reference line in a triple oxygen isotope plot (Fig. 1-1). Deviations from a mass-dependent reference line (RL) are defined as $\Delta^{17} \mathrm{O}$ values according to Eq. 1-7:

$$
\Delta^{17} \mathrm{O}=\delta^{17} \mathrm{O}-\lambda_{R L} \times \delta^{18} \mathrm{O}+\gamma_{R L}
$$

The variables $\lambda_{\mathrm{RL}}$ and $\gamma_{\mathrm{RL}}$ describe the slope and the intercept of the reference line in a triple oxygen isotope plot. Deviations from a mass-dependent reference line, expressed as $\Delta^{17} \mathrm{O}$ value, are most often called oxygen isotope anomaly or ${ }^{17} \mathrm{O}$-excess. 


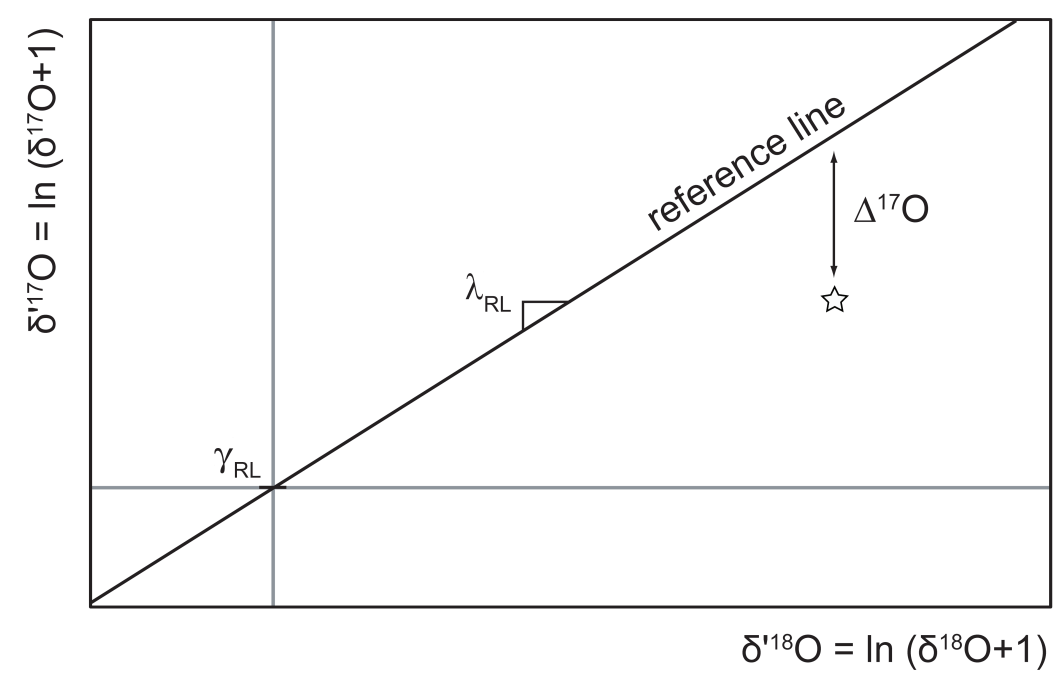

Fig. 1-1: Notation of triple oxygen isotope data. Small variations of triple oxygen isotope data are generally reported as a deviation from a reference line $\left(\Delta^{17} \mathrm{O}\right.$ values) with a slope $\lambda_{\mathrm{RL}}$ and an intercept $\gamma_{\mathrm{RL}}$.

Different reference lines were used within this dissertation (Table 1-1). At the beginning of this $\mathrm{PhD}$ project, a terrestrial fractionation line (TFL) was chosen as reference line because the main focus of the stable isotope laboratory in Göttingen lies on the analysis of rocks and minerals. During the course of this $\mathrm{PhD}$ project, the equilibrium exponent for $\mathrm{CO}_{2}$ water exchange was determined (Chapter 3). Subsequently, triple oxygen isotope data of tropospheric $\mathrm{CO}_{2}$ are given relative to a $\mathrm{CO}_{2}$-water equilibrium line with a slope of 0.522 and zero intercept (Chapter 4 and 5). The $\mathrm{CO}_{2}$-water equilibrium line was chosen as the new reference line because equilibrium exchange between $\mathrm{CO}_{2}$ and water in the bio- and hydrosphere is the dominant process controlling the triple oxygen isotope composition of tropospheric $\mathrm{CO}_{2}$. The zero intercept was chosen for simplicity.

Table 1-1: Overview of the different reference lines used within this dissertation.

\begin{tabular}{llll}
\hline & type & slope & $\begin{array}{l}\text { intercept } \\
{[\%]}\end{array}$ \\
\hline Chapter 2 & TFL & 0.5252 & -0.015 \\
Chapter 3 & TFL & 0.5251 & 0.00 \\
Chapter 4 & $\mathrm{CO}_{2}$-water line & 0.522 & 0.00 \\
Chapter 5 & $\mathrm{CO}_{2}$-water line & 0.522 & 0.00 \\
\hline
\end{tabular}




\subsubsection{Triple oxygen isotope exponents: $\lambda$ and $\theta$ values}

Understanding slight variations in triple oxygen isotope ratios in terrestrial compounds requires knowledge of the exponent $\lambda$ or $\theta$ for the involved exchange mechanisms. The exponent differs for kinetic and equilibrium fractionation because kinetic fractionation results from differences in the effective molecular mass of the involved gases (or liquids) whereas equilibrium fractionation depends on the atomic masses of the involved isotopes.

\section{Equilibrium fractionation}

The exponent $\theta$ for equilibrium fractionation depends on the partition function ratio of the oxygen-bearing isotopologues. The overall partition function ratio describes the translational, rotational and vibrational energy of a molecule, and thus, the equilibrium exponent $\theta$ can be derived from quantum mechanical calculations. The exponent for hightemperature exchange (temperatures exceeding about $500^{\circ} \mathrm{C}$ ) can be approximated for any exchange reaction between two oxygen-bearing compounds from the mass ratios of the stable oxygen isotopes (Young et al., 2002):

$$
\theta=\frac{1 / m_{16}-1 / m_{{ }^{17} O}}{1 / m_{16}-1 / m_{18} O}
$$

From this it follows that equilibrium fractionation at high-temperatures proceeds with $\theta=$ 0.53. For low temperature equilibration processes, the approximation in Eq. 1-8 is not valid anymore, and thus, the exponent $\theta$ can be significantly lower than the high temperature limit of 0.53 (see Cao and Liu, 2011).

Experimental results on $\theta$ values for equilibrium fractionation processes are still scarce (Fig. 1-2). Barkan and Luz (2005) determined an exponent $\theta$ for water-water vapor exchange of $0.529 \pm 0.001$ in the temperature range from 11 to $42{ }^{\circ} \mathrm{C}$, which was also confirmed by theory (Cao and Liu, 2011). Simultaneous to this dissertation, several other $\theta$ values for equilibrium exchange reactions were determined experimentally within the stable isotope group in Göttingen: $\theta_{\text {apatite-water }}=0.526 \pm 0.002$ at about $37^{\circ} \mathrm{C}, \theta_{\text {quartz-fayalite- }}$ magnetite $=0.530 \pm 0.002$ at $\mathrm{T} \geq 700^{\circ} \mathrm{C}$ and $\theta_{\mathrm{SiO} \text { (opal)-water }}=0.521 \pm 0.001$ for temperatures between 2 and $10{ }^{\circ} \mathrm{C}$ (Pack et al., 2012). 
Recently, Cao and Liu (2011) presented theoretical estimates for different equilibrium exponents (Fig. 1-2). The authors confirm that the equilibrium exponent for water-water vapor exchange at low temperatures is identical to the high-temperature limit of 0.53 . Additionally, they also give estimates for various other equilibrium exponents including $\theta_{\text {quartz-water }}=0.525$ and $\theta_{\text {calcite-water }}=0.524$ at room temperature.

It is an integral part of this study to determine experimentally the exponent $\theta$ for $\mathrm{CO}_{2}$ water exchange which is the dominant process controlling the triple oxygen isotope composition of tropospheric $\mathrm{CO}_{2}$ (see chapter 3).

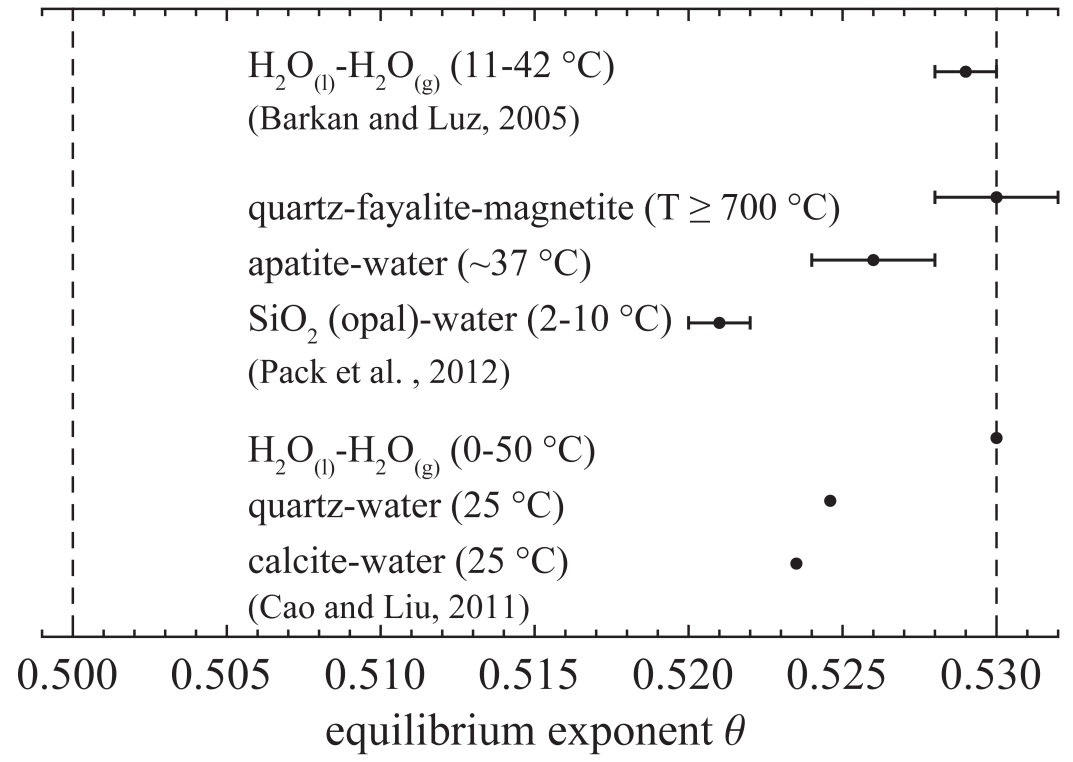

Fig. 1-2: Overview of equilibrium exponents. Data points with error bars are based on experimental studies; data points without error bars are based on theoretical studies. All equilibrium exponents must fall between the high temperature limit of 0.53 and the lower limit of 0.509 typical for kinetic fractionation (Young et al., 2002). 


\section{Kinetic fractionation}

In theory, the exponent $\lambda$ for kinetic fractionation processes (e.g. diffusion of a water vapor molecule in vacuo) depends on the kinetic energy of the involved molecules, and thus, it depends solely on the masses $m$ of the oxygen isotopologues (Young et al., 2002):

$$
\lambda=\frac{\ln \left(m_{1} / m_{2}\right)}{\ln \left(m_{1} / m_{3}\right)}=\frac{\ln \alpha_{2 / 1}}{\ln \alpha_{3 / 1}}
$$

where $\mathrm{m}_{1}, \mathrm{~m}_{2}$ and $\mathrm{m}_{3}$ denote the masses of the isotopologues in ascending order. This relationship can be simplified replacing the mass ratios with the fractionation factors $\alpha_{2 / 1}$ and $\alpha_{3 / 1}$. For example, for water vapor diffusion $\mathrm{m}_{1}=18, \mathrm{~m}_{2}=19$ and $\mathrm{m}_{3}=20$ resulting in a $\lambda$ value of 0.513 and for diffusion of $\mathrm{O}_{2}$, the exponent $\lambda$ is equal to 0.509 .

For gas mixtures, e.g. water vapor diffusion in air, the mass $\mathrm{m}$ of the isotopologue is replaced by the reduced mass $\mu$ :

$$
\mu_{1}=\frac{m^{B} m_{1}^{A}}{m^{B}+m_{1}^{A}}
$$

where the superscript denotes the two gases A and B and the subscript denotes the involved isotopologue. Inserting the reduced masses for all isotopologues in Eq. 1-10 gives:

$$
\lambda=\frac{\ln \left(\mu_{1} / \mu_{2}\right)}{\ln \left(\mu_{1} / \mu_{3}\right)}=\frac{\ln \left(\frac{m^{B} m_{1}^{A}}{m^{B}+m_{1}^{A}} \frac{m^{B} m_{2}^{A}}{m^{B}+m_{2}^{A}}\right)}{\ln \left(\frac{m^{B} m_{1}^{A}}{m^{B}+m_{1}^{A}} \frac{m^{B} m_{3}^{A}}{m^{B}+m_{3}^{A}}\right)}
$$

For water vapor diffusion in air, for example, where $\mathrm{m}_{\text {air }}=29 \mathrm{~g} / \mathrm{mol}$, the theoretical $\lambda$ value is 0.518 . 


\section{Oxygen isotope reservoirs: TFL and GMWL}

The most extensive studies on triple oxygen isotope reservoirs on Earth have been carried out on terrestrial rocks and minerals and on meteoric water. Various studies showed that for terrestrial rocks and minerals the slope $\lambda_{\mathrm{TFL}}$ for a terrestrial fractionation line (TFL) falls between 0.524 to 0.526 (Miller et al., 1999b; Pack et al., 2007; Rumble et al., 2007). The exact slope seems to depend on the choice of rocks and minerals reflecting the formation process. Luz and Barkan (2010) analyzed a great number of meteoric waters from all over the world and found that these water fall on a line with a slope $\lambda_{\mathrm{GMWL}}=$ $0.528 \pm 0.001$ and an intercept of $\gamma_{\mathrm{GMWL}}=+0.033 \pm 0.003 \%$ in a $\delta{ }^{18} \mathrm{O}$ vs. $\delta^{, 17} \mathrm{O}$ plot. This line is known as the global meteoric water line (GMWL). Recently, Tanaka and Nakamura (2012) simultaneously analyzed terrestrial rocks and minerals and meteoric waters and found that their TFL and GMWL differ both in their slope and in their intercept: $\lambda_{\mathrm{TFL}}=0.5270 \pm 0.0005 \quad$ and $\quad \gamma_{\mathrm{TFL}}=-0.070 \pm 0.005 \%$ os. $\quad \lambda_{\mathrm{GMWL}}=0.5281 \pm 0.0004 \quad$ and $\gamma_{\text {GMWL }}=-0.011 \pm 0.015 \%$.

\section{$1.3 \quad{ }^{17} \mathrm{O}$-excess in atmospheric gases}

All oxygen bearing trace gases from the strato- and mesosphere (except water) show a large oxygen isotope anomaly (Fig. 1-3). This anomaly has its origin in the formation of ozone in the upper atmosphere, and subsequently, is passed on to other trace gases by a variety of reaction mechanisms.

Ozone is formed in the upper atmosphere due to a recombination reaction between atomic oxygen and molecular oxygen:

$$
\mathrm{O}+\mathrm{O}_{2}+\mathrm{M} \longrightarrow \mathrm{O}_{3}+\mathrm{M} \quad\left(\mathrm{M}=\mathrm{N}_{2}, \mathrm{O}_{2} \text {, etc. }\right)
$$

The third collision partner $\mathrm{M}$ is required to carry away the excess energy. Ultimately, this reaction, which is part of the so-called Chapman cycle, produces ozone that has a large positive oxygen isotope anomaly $\left(\delta^{, 18} \mathrm{O} \approx 80-150 \%\right.$, $\Delta^{17} \mathrm{O} \approx 40 \%$ ) (Krankowsky et al., 2000; Lämmerzahl et al., 2002; Mauersberger, 1981), see Fig. 1-3.

Thiemens and Heidenreich (1983) were the first to reproduce these stratospheric observations in a simple experiment where ozone was produced by electrical discharge. They postulated that the formation of ${ }^{17} \mathrm{O}^{16} \mathrm{O}^{16} \mathrm{O}$ was equally fast as the formation of ${ }^{18} \mathrm{O}^{16} \mathrm{O}^{16} \mathrm{O}$, and thus, giving rise to an exponent $\lambda=1$. 
Subsequent to ozone formation, the ozone molecule is decomposed due to photolysis and the oxygen isotope anomaly is transferred to stratospheric $\mathrm{CO}_{2}$ via the electronically excited singlet oxygen $O\left({ }^{1} \mathrm{D}\right)$ (Yung et al., 1991):

$$
\begin{aligned}
& \mathrm{O}_{3}+h v \longrightarrow \mathrm{O}_{2}+\mathrm{O}\left({ }^{1} \mathrm{D}\right) \\
& \mathrm{O}\left({ }^{1} \mathrm{D}\right)+\mathrm{CO}_{2} \longrightarrow \mathrm{CO}_{3}{ }^{*} \longrightarrow \mathrm{CO}_{2}+\mathrm{O}\left({ }^{3} \mathrm{P}\right)
\end{aligned}
$$

As a result, carbon dioxide from the strato- and mesosphere shows a large positive oxygen isotope anomaly (Boering et al., 2004; Kawagucci et al., 2008; Lämmerzahl et al., 2002; Thiemens et al., 1995b) (see Fig. 1-4). Tropospheric $\mathrm{O}_{2}$, however, is depleted in its ${ }^{17} \mathrm{O}$ composition with $\Delta^{17} \mathrm{O}=-0.365$ (relative to $\lambda_{\mathrm{RL}}=0.522$ ) (Barkan and Luz, 2011; Luz and Barkan, 2005).

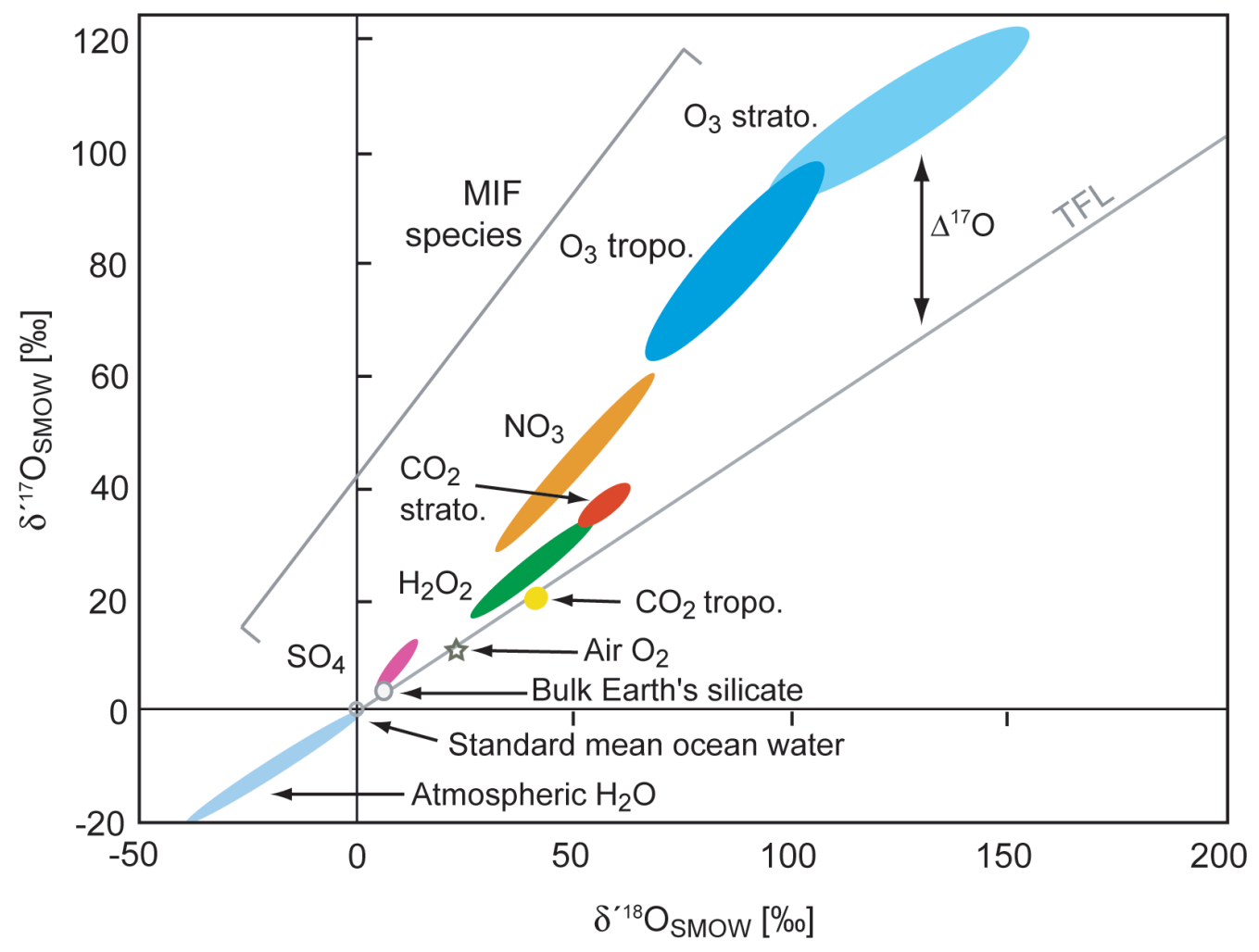

Fig. 1-3: Triple oxygen isotope ratios of atmospheric species (adapted from Thiemens, 2006). Stratospheric gases show distinct deviations from the terrestrial fractionation line, whereas tropospheric gases, namely $\mathrm{O}_{2}$ and $\mathrm{CO}_{2}$ show only a small or no deviation from a mass-dependent reference line, such as the terrestrial fractionation line. 


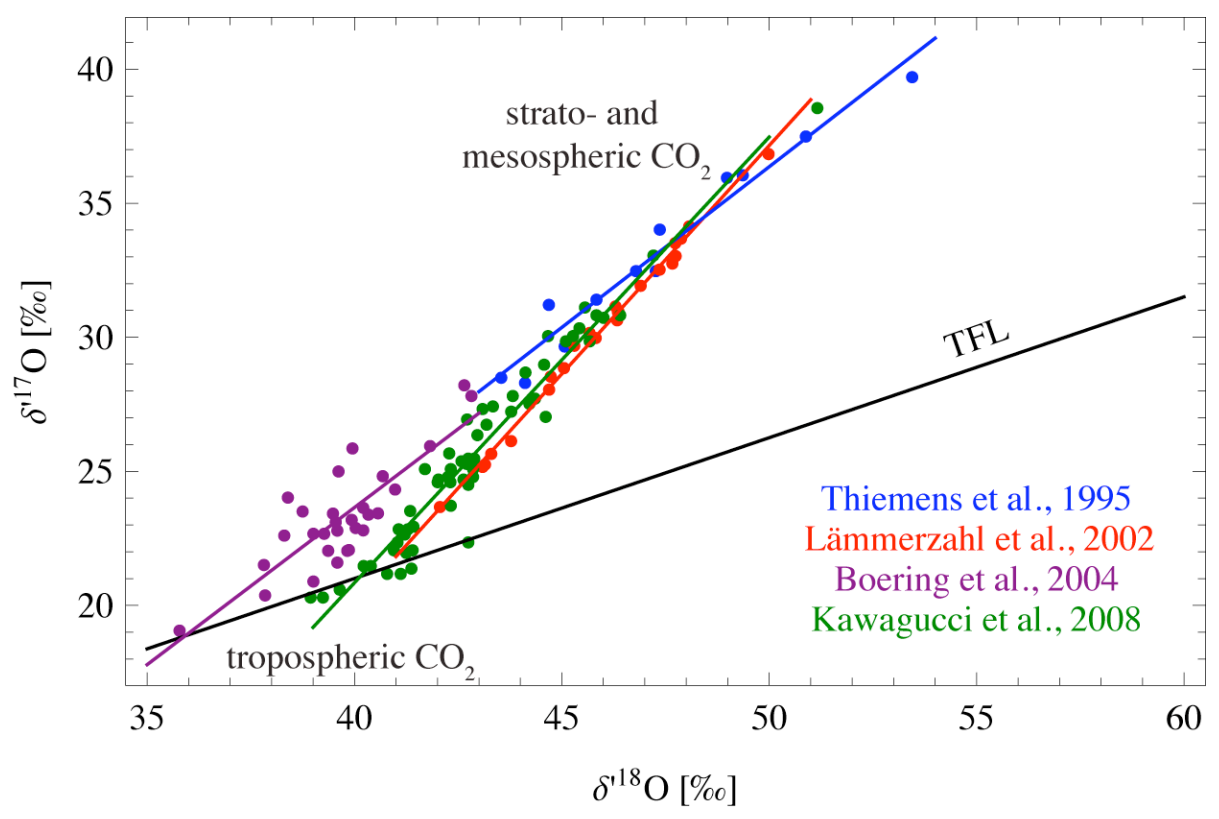

Fig. 1-4: Triple oxygen isotope composition of atmospheric $\mathrm{CO}_{2}$. Strato- and mesospheric carbon dioxide shows a large oxygen isotope anomaly with $\Delta{ }^{17} \mathrm{O}$ values of up to $10 \%$. The distinct anomaly is a result of atmospheric reaction mechanisms. Note that the Boering et al. (2004) dataset slightly deviates from the other datasets (Kawagucci et al., 2008; Lämmerzahl et al., 2002; Thiemens et al., 1995b). Most likely, these $\mathrm{CO}_{2}$ samples were affected by exchange with water during storage (see Boering et al., 2004). Tropospheric $\mathrm{CO}_{2}$ shows $\delta^{18} \mathrm{O}$ values of approximately 39 to $42 \%$ (corresponding to $\delta^{18} \mathrm{O}$ values of about 40 to $43 \%$ ) and $\Delta^{17} \mathrm{O}$ values close to zero. It is the aim of this project to determine the exact magnitude and variability of the $\Delta^{17} \mathrm{O}$ signature of a tropospheric end-member.

\subsection{The global carbon cycle}

Almost all carbon in the atmosphere is present as carbon dioxide. The tropospheric $\mathrm{CO}_{2}$ concentration and its isotopic composition are controlled by various gross fluxes between the atmosphere and the bio- and hydrosphere: photosynthesis, respiration, soil invasion, oceanic carbon uptake and release, stratosphere-troposphere exchange and anthropogenic $\mathrm{CO}_{2}$ emissions (Fig. 1-5). In the pre-industrial era, the carbon cycle was in steady state, i.e. the $\mathrm{CO}_{2}$ sources were balanced by equivalent $\mathrm{CO}_{2}$ sinks and the carbon dioxide concentration remained constant at about $270 \mathrm{ppm}$. Since about 1850, the atmospheric carbon cycle is not in a steady state anymore but the $\mathrm{CO}_{2}$ concentration increases at about $1.9 \mathrm{ppm}$ per year, corresponding to a carbon flux of about $4.1 \mathrm{PgC} / \mathrm{yr}$ (Canadell et al., 2007; Le Quéré et al., 2009). At present, the atmospheric $\mathrm{CO}_{2}$ concentration is approximately at $390 \mathrm{ppm}$, corresponding to an atmospheric reservoir size of about 830 PgC (Canadell et al., 2007; Le Quéré et al., 2009). 
The largest gross fluxes are carbon uptake and release by the biosphere. Terrestrial plants take up carbon dioxide and water to produce organic matter, and as a by-product, release molecular oxygen:

$$
6 \mathrm{CO}_{2}+6 \mathrm{H}_{2} \mathrm{O} \stackrel{\text { light }}{\longrightarrow} \mathrm{C}_{6} \mathrm{H}_{12} \mathrm{O}_{6}+6 \mathrm{O}_{2}
$$

This process is well known as photosynthesis. The overall rate of photosynthetic carbon fixation is referred to as gross primary production. Today, about $120 \mathrm{PgC} / \mathrm{yr}$ are fixed by the terrestrial ecosystem (Beer et al., 2010). A fraction of the organic matter is decomposed by respiration.

Besides terrestrial respiration, there is also an abiotic flux coming from soils named soil invasion (Miller et al., 1999a; Tans, 1998). This term describes the process where $\mathrm{CO}_{2}$ diffuses into the uppermost soil column, and after a certain residence time diffuses back to the atmosphere. Overall, the soil invasion flux has no effect on the atmospheric $\mathrm{CO}_{2}$ concentration but due to isotope exchange between the carbon dioxide and soil water it might have a significant effect on the oxygen isotope composition of atmospheric $\mathrm{CO}_{2}$ (Wingate et al., 2009). In the first place, it was thought that only about $20 \mathrm{PgC} / \mathrm{yr}$ diffuse from the troposphere into the upper soil layer and vice versa, but recent estimates from Wingate et al. (2009) suggest this exchange flux might be as large as $450 \mathrm{PgC} / \mathrm{yr}$.

Carbon dioxide exchange between the ocean and the atmosphere amounts to about $90 \mathrm{PgC} / \mathrm{yr}$ (Heimann and Maier-Reimer, 1996). Overall, there is a small oceanic net sink of about 2 PgC/yr (Canadell et al., 2007; Le Quéré et al., 2009).

Due to atmospheric mixing processes, about $100 \mathrm{PgC} / \mathrm{yr}$ are exchanged between the tropoand stratosphere (Appenzeller et al., 1996). Overall, the mixing process does not affect the $\mathrm{CO}_{2}$ concentration, but it might be of importance to the triple oxygen isotope composition of tropospheric $\mathrm{CO}_{2}$ (Hoag et al., 2005).

Anthropogenic $\mathrm{CO}_{2}$ emissions are small ( 9 PgC/yr, see Canadell et al., 2007; Le Quéré et al., 2009) compared to the large gross fluxes from the bio- and hydrosphere. However, as they constantly accumulate in the atmosphere these emissions lead to an alarming increase in $\mathrm{CO}_{2}$ concentration in the global atmosphere. 


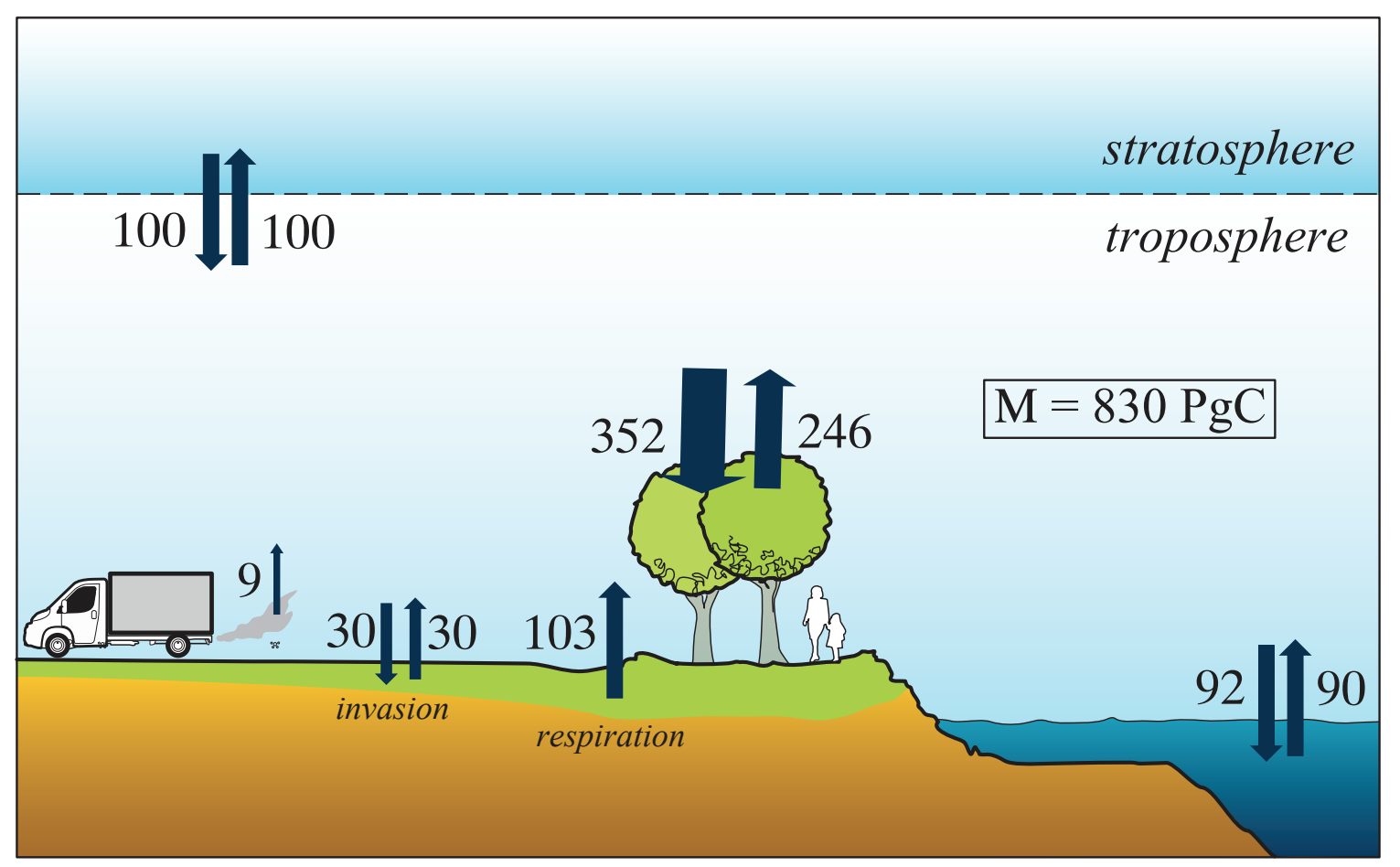

Fig. 1-5: The current day global carbon cycle. Various biogeochemical processes in the bio- and hydrosphere control the atmospheric $\mathrm{CO}_{2}$ concentration and its carbon and oxygen isotopic composition. The sketch illustrates the major gross fluxes (for a detailed description also see chapter 5). The terrestrial respiration and assimilation fluxes are based on a gross primary production (GPP) of $120 \mathrm{PgC} / \mathrm{yr}$ (Beer et al., 2010) and a chloroplast to atmosphere $\mathrm{CO}_{2}$ concentration ratio of 0.70 (see chapter 5). Since the industrial era, anthropogenic $\mathrm{CO}_{2}$ emissions have a major effect on atmospheric $\mathrm{CO}_{2}$ concentrations. 


\subsection{Focus of study}

The aim of this study is to test the potential of ${ }^{17} \mathrm{O}$-excess as a new tracer in the global and regional carbon cycle. In order to do so, the project was divided into four sub-topics:

- Chapter 2: Technique for high-precision analysis of triple oxygen isotope ratios in carbon dioxide

Originally, the triple oxygen isotope analysis of carbon dioxide aimed at detecting large variations in ${ }^{17} \mathrm{O}$-excess in stratospheric $\mathrm{CO}_{2}$ samples. As a consequence, state-of-the-art techniques had an analytical uncertainty that was appropriate for the object of study. However, in order to detect small variations in ${ }^{17} O$-excess in tropospheric $\mathrm{CO}_{2}$, a new technique for high-precision triple oxygen isotope analysis was developed.

- Chapter 3: Triple oxygen isotope equilibrium fractionation between carbon dioxide and water

The triple oxygen isotope composition of tropospheric $\mathrm{CO}_{2}$ is largely controlled by mass-dependent equilibrium fractionation between $\mathrm{CO}_{2}$ and water in the hydroand biosphere. Thus, in order to understand small-scale variations in ${ }^{17} O$-excess of tropospheric $\mathrm{CO}_{2}$ it is crucial to know the exact triple oxygen isotope equilibrium fractionation factor described by the exponent $\theta$ in the power law function for mass-dependent fractionation.

- Chapter 4: On the triple oxygen isotope composition of carbon dioxide from some combustion processes

Anthropogenic $\mathrm{CO}_{2}$ emissions lead to a steady increase in atmospheric $\mathrm{CO}_{2}$ concentration on a global scale. In particular, they have a significant influence on the $\mathrm{CO}_{2}$ concentration and carbon isotope composition of urban air $\mathrm{CO}_{2}$. Chapter 4 investigates if and to which extent anthropogenic $\mathrm{CO}_{2}$ inherits the oxygen isotope anomaly of ambient air $\mathrm{O}_{2}$. Carbon dioxide from natural gas and propane-butane combustion, wood chips burning, car exhaust and human breath were investigated. The aim of this project was to test if the triple oxygen isotope composition of $\mathrm{CO}_{2}$ (denoted with $\triangle^{17} \mathrm{O}$ ) could act as a tracer for anthropogenic $\mathrm{CO}_{2}$ emissions in urban air studies. 
- Chapter 5: Triple oxygen isotope composition of tropospheric $\mathrm{CO}_{2}$ : Observational data and model simulation

Chapter 5 presents triple oxygen isotope data of ambient air $\mathrm{CO}_{2}$ sampled in Göttingen over the course of 2 years and on top of the Brocken Mountain. The experimental data are compared to a global mass balance model for the triple oxygen isotope composition of tropospheric $\mathrm{CO}_{2}$. In particular, the mass balance model investigates the sensitivity of $\triangle^{17} \mathrm{O}$ of tropospheric $\mathrm{CO}_{2}$ to changes in the terrestrial gross primary production. 


\subsection{References}

Appenzeller, C., Holton, J. R., Rosenlof, K. H., 1996. Seasonal variation of mass transport across the tropopause. J. Geophys. Res.-Atmos. 101, 15071-15078.

Barkan, A., Luz, B., 2011. The relationship among the three stable isotopes of oxygen in air, seawater and marine photosynthesis. Rapid Commun. Mass Spec. 25, 23672369.

Barkan, E., Luz, B., 2005. High precision measurements of ${ }^{17} \mathrm{O} /{ }^{16} \mathrm{O}$ and ${ }^{18} \mathrm{O} /{ }^{16} \mathrm{O}$ ratios in $\mathrm{H}_{2} \mathrm{O}$. Rapid Commun. Mass Spec. 19, 3737-3742.

Beer, C., Reichstein, M., Tomelleri, E., Ciais, P., Jung, M., Carvalhais, N., Rödenbeck, C., Arain, M. A., Baldocchi, D., Bonan, G. B., Bondeau, A., Cescatti, A., Lasslop, G., Lindroth, A., Lomas, M., Luyssaert, S., Margolis, H., Oleson, K. W., Roupsard, O., Veenendaal, E., Viovy, N., Williams, C., Woodward, F. I., Papale, D., 2010. Terrestrial gross carbon dioxide uptake: global distribution and covariation with climate. Science 329, 834-838.

Boering, K. A., Jackson, T., Hoag, K. J., Cole, A. S., Perri, M. J., Thiemens, M., Atlas, E., 2004. Observations of the anomalous oxygen isotopic composition of carbon dioxide in the lower stratosphere and the flux of the anomaly to the troposphere. Geophys. Res. Lett. 31.

Canadell, J. G., Le Quéré, C., Raupach, M. R., Field, C. B., Buitenhuis, E. T., Ciais, P., Conway, T. J., Gillett, N. P., Houghton, R. A., Marland, G., 2007. Contributions to accelerating atmospheric $\mathrm{CO}_{2}$ growth from economic activity, carbon intensity, and efficiency of natural sinks. Proc. Natl. Acad. Sci. 104, 18866-18870.

Cao, X., Liu, Y., 2011. Equilibrium mass-dependent fractionation relationships for triple oxygen isotopes. Geochim. Cosmochim. Acta 75, 7435-7445.

Ciais, P., Denning, A. S., Tans, P. P., Berry, J. A., Randall, D., Collatz, J. G., Sellers, P. J., White, J. W., Trolier, M., Meijer, H. A. J., Francey, R. J., Monfray, P., Heimann, M., 1997. A three-dimensional synthesis study of $\delta^{18} \mathrm{O}$ in atmospheric $\mathrm{CO}_{2}$ : Part 1 Surface fluxes. J. Geophys. Res. 102, 5857-5872.

Ciais, P., Tans, P. P., Trolier, M., White, J. W. C., Francey, R. J., 1995. A large northern hemisphere terrestrial $\mathrm{CO}_{2}$ sink indicated by the ${ }^{13} \mathrm{C} /{ }^{12} \mathrm{C}$ ratio of atmospheric $\mathrm{CO}_{2}$. Science 269, 1098-1102.

Coplen, T. B., 2011. Guidelines and recommended terms for expression of stable-isotoperatio and gas-ratio measurement results. Rapid Commun. Mass Spec. 25, 25382560 .

Coplen, T. B., Kendall, C., Hopple, J., 1983. Comparison of stable isotope reference samples. Nature 302, 236-238. 
Cuntz, M., Ciais, P., Hoffmann, G., Allison, C. E., Francey, R. J., Knorr, W., Tans, P. P., White, J. W. C., Levin, I., 2003a. A comprehensive global three-dimensional model of $\delta^{18} \mathrm{O}$ in atmospheric $\mathrm{CO}_{2}:$ 2. Mapping the atmospheric signal. J. Geophys. Res. 108, ACH2.1-ACH2.19.

Cuntz, M., Ciais, P., Hoffmann, G., Knorr, W., 2003b. A comprehensive global threedimensional model of $\delta^{18} \mathrm{O}$ in atmospheric $\mathrm{CO}_{2}: 1$. Validation of surface processes. J. Geophys. Res. 108, ACH1-ACH23.

Farquhar, G. D., Lloyd, J., Taylor, J. A., Flanagan, L. B., Syvertsen, J. P., Hubick, K. T., Wong, S. C., Ehleringer, J. R., 1993. Vegetation effects on the isotope composition of oxygen in atmospheric $\mathrm{CO}_{2}$. Nature $363,439-443$.

Francey, R. J., Tans, P. P., 1987. Latitudinal variation in oxygen-18 of atmospheric $\mathrm{CO}_{2}$. Nature 327, 495-497.

Heimann, M., Maier-Reimer, E., 1996. On the relations between the oceanic uptake of $\mathrm{CO}_{2}$ and its carbon isotopes. Global Biogeochem. Cy. 10, 89-110.

Hoag, K. J., Still, C. J., Fung, I. Y., Boering, K. A., 2005. Triple oxygen isotope composition of tropospheric carbon dioxide as a tracer of terrestrial gross carbon fluxes. Geophys. Res. Lett. 32, 1-5.

IPCC, 2007. Climate change 2007: The physical science basis: Contribution of Working Group I to the Fourth Assessment Report of the Intergovernmental Panel on Climate Change. Cambridge University Press, New York, p. 996.

Kawagucci, S., Tsunogai, U., Kudo, S., Nakagawa, F., Honda, H., Aoki, S., Nakazawa, T., Tsutsumi, M., Gamo, T., 2008. Long-term observation of mass-independent oxygen isotope anomaly in stratospheric $\mathrm{CO}_{2}$. Atmos. Chem. Phys. 8, 6189-6197.

Keeling, C. D., 1958. The concentration and isotopic abundances of atmospheric carbon dioxide in rural areas. Geochim. Cosmochim. Acta 13, 322-334.

Keeling, C. D., 1960. The concentration and isotopic abundances of carbon dioxide in the atmosphere. Tellus 12, 200-203.

Keeling, C. D., 1961. The concentration and isotopic abundances of carbon dioxide in rural and marine air. Geochim. Cosmochim. Acta 24, 277-298.

Krankowsky, D., Lämmerzahl, P., Mauersberger, K., 2000. Isotopic measurements of stratospheric ozone. Geophys. Res. Lett. 27, 2593-2595.

Lämmerzahl, P., Röckmann, T., Brenninkmeijer, C. A. M., Krankowsky, D., Mauersberger, K., 2002. Oxygen isotope composition of stratospheric carbon dioxide. Geophys. Res. Lett. 29, 1582. 
Le Quéré, C., Raupach, M. R., Canadell, J. G., Marland, G., et al., 2009. Trends in the sources and sinks of carbon dioxide. Nature Geosci. 2, 831-836.

Luz, B., Barkan, E., 2005. The isotopic ratios ${ }^{17} \mathrm{O} /{ }^{16} \mathrm{O}$ and ${ }^{18} \mathrm{O} /{ }^{16} \mathrm{O}$ in molecular oxygen and their significance in biogeochemistry. Geochim. Cosmochim. Acta 69, 1099-1110.

Luz, B., Barkan, E., 2010. Variations of ${ }^{17} \mathrm{O} /{ }^{16} \mathrm{O}$ and ${ }^{18} \mathrm{O} /{ }^{16} \mathrm{O}$ in meteoric waters. Geochim. Cosmochim. Acta 74, 6276-6286.

Luz, B., Barkan, E., Bender, M. L., Thiemens, M. H., Boering, K. A., 1999. Triple-isotope composition of atmospheric oxygen as a tracer of biosphere productivity. Nature $400,547-550$.

Mauersberger, K., 1981. Measurement of heavy ozone in the stratosphere. Geophys. Res. Lett. 8, 935-937.

Miller, J. B., Yakir, D., White, J. W. C., Tans, P. P., 1999a. Measurement of ${ }^{18} \mathrm{O} /{ }^{16} \mathrm{O}$ in the soil-atmosphere $\mathrm{CO}_{2}$ flux. Global Biogeochem. Cy. 13, 761-774.

Miller, M. F., Franchi, I. A., Sexton, A. S., Pillinger, C. T., 1999b. High precision $\delta^{17}$ O isotope measurements of oxygen from silicates and other oxides: method and applications. Rapid Commun. Mass Spec. 13, 1211-1217.

Pack, A., Albrecht, N., Hofmann, M. E. G., Horváth, B., Gehler, A., 2012. Experimental data on variations in triple oxygen isotope equilibrium fractionation exponents. ISI, Washington DC.

Pack, A., Toulouse, C., Przybilla, R., 2007. Determination of oxygen triple isotope ratios of silicates without cryogenic separation of $\mathrm{NF}_{3}$ - technique with application to analyses of technical $\mathrm{O}_{2}$ gas and meteorite classification. Rapid Commun. Mass Spec. 21, 3721-3728.

Peylin, P., Ciais, P., Denning, A. S., Tans, P. P., Berry, J. A., White, J. W. C., 1999. A 3dimensional study of delta O-18 in atmospheric $\mathrm{CO} 2$ : contribution of different land ecosystems. Tellus B 51, 642-667.

Rumble, D., Miller, M. F., Franchi, I. A., Greenwood, R. C., 2007. Oxygen three-isotope fractionation lines in terrestrial silicate minerals: An inter-laboratory comparison of hydrothermal quartz and eclogitic garnet. Geochim. Cosmochim. Acta 71, 35923600 .

Tanaka, R., Nakamura, E., 2012. Kinetic isotope fractionation effect observed in oxygen triple isotope ratios in terrestrial silicate minerals. Sixth International Symposium on Isotopomers, Washington DC.

Tans, P. P., 1998. Oxygen isotopic equilibrium between carbon dioxide and water in soils. Tellus B 50, 163-178. 
Thiemens, M., Jackson, T., Brenninkmeijer, C. A. M., 1995a. Observation of a mass independent oxygen isotopic composition in terrestrial stratospheric $\mathrm{CO}_{2}$, the link to ozone chemistry, and the possible occurrence in the Martian atmosphere. Geophys. Res. Lett. 22, 255-257.

Thiemens, M. H., 2006. History and applications of mass-independent isotope effects. Annu. Rev. Earth Planet. Sci. 34, 217-262.

Thiemens, M. H., Heidenreich, J. E. I., 1983. The mass-independent fractionation of oxygen: A novel isotope effect and its possible cosmochemical implications. Science 219, 1073-1075.

Thiemens, M. H., Jackson, T., 1991. Oxygen isotope fractionation in stratospheric $\mathrm{CO}_{2}$. Geophys. Res. Lett. 18, 669-672.

Thiemens, M. H., Jackson, T., Zipf, E. C., Erdman, P. W., van Egmond, C., 1995b. Carbon dioxide and oxygen isotope anomalies in the mesosphere and stratosphere. Science 270, 969-972.

Welp, L. R., Keeling, R. F., Meijer, H. A. J., Bollenbacher, A. F., Piper, S. C., Yoshimura, K., Francey, R. J., Allison, C. E., Wahlen, M., 2011. Interannual variability in the oxygen isotopes of atmospheric $\mathrm{CO}_{2}$ driven by El Nino. Nature 477, 579-582.

Wingate, L., Ogée, J., Cuntz, M., Genty, B., Reiter, I., Seibt, U., Yakir, D., Maseyk, K., Pendall, E. G., Barbour, M. M., Mortazavi, B., Burlett, R. g., Peylin, P., Miller, J., Mencuccini, M., Shim, J. H., Hunt, J., Grace, J., 2009. The impact of soil microorganisms on the global budget of $\delta^{18} \mathrm{O}$ in atmospheric $\mathrm{CO}_{2}$. Proc. Natl. Acad. Sci. 106, 22411-22415.

Young, E. D., Galy, A., Nagahara, H., 2002. Kinetic and equilibrium mass-dependent isotope fractionation laws in nature and their geochemical and cosmochemical significance. Geochim. Cosmochim. Acta 66, 1095-1104.

Yung, Y. L., Demore, W. B., Pinto, J. P., 1991. Isotopic exchange between carbon dioxide and ozone via $\mathrm{O}\left({ }^{1} \mathrm{D}\right)$ in the stratosphere. Geophys. Res. Lett. 18, 13-16. 


\section{Technique for high-precision analysis of triple oxygen isotope ratios in carbon dioxide}

Hofmann, M.E.G. and Pack, A., 2010. Technique for high-precision analysis of triple oxygen isotope ratios in carbon dioxide. Anal. Chem. 82, 4357-4361

\subsection{Abstract}

Since the discovery of mass-independent isotope effects in stratospheric and tropospheric gases, the analysis of triple oxygen isotope abundance in carbon dioxide gained in importance. However, precise triple oxygen isotope determination in carbon dioxide is a challenging task due to mass-interference of ${ }^{17} \mathrm{O}$ and ${ }^{13} \mathrm{C}$ variations. Here, we present a novel analytical technique that allows us to determine slight deviations of $\mathrm{CO}_{2}$ from the terrestrial fractionation line (TFL). Our approach is based on isotopic equilibration between $\mathrm{CO}_{2}$ gas and $\mathrm{CeO}_{2}$ powder at $685^{\circ} \mathrm{C}$ and subsequent mass spectrometric analysis of ceria powder by infrared-laser fluorination. We found that $\beta_{\mathrm{CO} 2-\mathrm{CeO} 2}$, the exponent in the relation $\alpha^{17 / 16}=\left(\alpha^{18 / 16}\right)^{\beta}$, amounts to $0.5240 \pm 0.0011$ at $685^{\circ} \mathrm{C} .{ }^{1}$ The oxygen isotope anomaly of $\mathrm{CO}_{2}\left(\Delta^{17} \mathrm{O}\right)$ can be determined for a single analysis of $\mathrm{CeO}_{2}$ with a precision of $\pm 0.05 \%$ o $(1 \sigma)$. Our $\mathrm{CO}_{2}-\mathrm{CeO}_{2}$ equilibration procedure is performed with an excess of $\mathrm{CO}_{2}$ so that one analysis of $\Delta^{17} \mathrm{O}$ on $\mathrm{CO}_{2}$ requires at least $3.5 \mathrm{mmol}$ of $\mathrm{CO}_{2}$ gas. Our new technique allows accurate and precise determination of $\Delta^{17} \mathrm{O}$ in $\mathrm{CO}_{2}$ and opens up a new field for investigating triple oxygen isotope abundance in various types of natural $\mathrm{CO}_{2}$.

\subsection{Introduction}

Oxygen isotope anomalies of atmospheric trace gases $\left(\mathrm{O}_{3}, \mathrm{NO}_{3}, \mathrm{CO}_{2}, \mathrm{H}_{2} \mathrm{O}_{2}, \mathrm{SO}_{4}, \mathrm{CO}\right.$, $\mathrm{N}_{2} \mathrm{O}$ ) (Thiemens, 2006) originate from UV-induced photoreactions (Thiemens and

\footnotetext{
${ }^{1}$ Note that in this chapter the exponent for $\mathrm{CO}_{2}-\mathrm{CeO}_{2}$ isotope exchange and the slope of the terrestrial fractionation line are both denoted with $\beta$. Apart from this chapter, triple oxygen isotope exponents are defined as $\lambda$ and $\theta$ values as introduced in section 1.2.2 and 1.2.3.
} 
Heidenreich, 1983), namely, in association with the formation of $\mathrm{O}_{3}$. Stratospheric $\mathrm{CO}_{2}$ inherits its oxygen isotope anomaly of $\Delta^{17} \mathrm{O} \approx+10 \%$ from isotopic exchange of electronically excited oxygen, $\mathrm{O}\left({ }^{1} \mathrm{D}\right)$ and $\mathrm{CO}_{2}$ (Perri et al., 2003; Yung et al., 1991). The distinct anomaly of stratospheric $\mathrm{CO}_{2}$ is diluted with isotopically normal $\mathrm{CO}_{2}$ when it enters the troposphere so that ground level $\mathrm{CO}_{2}$ shows little if any anomaly (Thiemens and Jackson, 1991; Thiemens et al., 1995b). Hoag et al. (2005), however, predicted an oxygen isotope anomaly of tropospheric $\mathrm{CO}_{2}$ of $\Delta^{17} \mathrm{O}=+0.15 \%$ (relative to the TFL with a slope of $\beta=0.516)$. They suggest that high-precision data on $\Delta^{17} \mathrm{O}$ of tropospheric $\mathrm{CO}_{2}$ will improve geochemical modeling of terrestrial gross carbon fluxes.

Published data on the triple oxygen isotope composition of tropospheric $\mathrm{CO}_{2}$ are too imprecise to verify the presence of such a small anomaly as predicted by Hoag et al (2005). Precise determination of oxygen isotope anomalies in $\mathrm{CO}_{2}$ is a challenging task, namely, due to mass-interference of ${ }^{12} \mathrm{C}^{17} \mathrm{O}^{16} \mathrm{O}$ on ${ }^{13} \mathrm{C}^{16} \mathrm{O}_{2}$.

To date, four techniques have been developed to determine $\Delta^{17} \mathrm{O}$ in $\mathrm{CO}_{2}$. Thiemens and Jackson (1991) fluorinated $\mathrm{CO}_{2}$ at $800{ }^{\circ} \mathrm{C}$ for $48 \mathrm{~h}$ using $\mathrm{BrF}_{5}$ as the reactant. The oxygen isotope ratios are measured on the resulting molecular oxygen. The measurement error of $\Delta^{17} \mathrm{O}$ amounts to about $0.1 \%$. Brenninkmeijer and Röckmann (1998) described a procedure where $\mathrm{CO}_{2}$ reacts with $\mathrm{H}_{2}$ to methane and water. The latter is fluorinated, and the oxygen isotope anomaly is analyzed on the resulting $\mathrm{O}_{2}$. The precision and accuracy of $\Delta^{17} \mathrm{O}$ analysis is specified as $\pm 0.2 \%$. Assonov and Brenninkmeijer (2001) described an alternative approach that is based on oxygen isotope exchange of $\mathrm{CO}_{2}$ with solid $\mathrm{CeO}_{2}$. The $\Delta^{17} \mathrm{O}$ of $\mathrm{CO}_{2}$ can be deduced by comparing the mass ratios $45 / 44$ and $46 / 44$ of the $\mathrm{CO}_{2}$ before and after equilibrating the gas sample with $\mathrm{CeO}_{2}$. The procedure goes along with a relatively large error of $\Delta^{17} \mathrm{O}$ of $\pm 0.33 \%$. Kawagucci et al. (2005) developed a simple analytical system where one $\mathrm{CO}_{2}$ aliquot is measured directly in the mass spectrometer, the other aliquot exchanges its oxygen isotopes with $\mathrm{CuO}$ at $900{ }^{\circ} \mathrm{C}$ prior to mass spectrometric analysis. As in the case of the technique described by Assonov and Brenninkmeijer (2001), the $\Delta^{17} \mathrm{O}$ of $\mathrm{CO}_{2}$ is determined by comparison of the mass ratios $45 / 44$ and $46 / 44$ of the two subsamples. This procedure requires only nanomole quantities of sample $\mathrm{CO}_{2}$, but the standard deviation of $\Delta^{17} \mathrm{O}$ is $\pm 0.35 \%$.

Despite these recent advancements in $\Delta^{17} \mathrm{O}$ analysis, the uncertainties remain too large to reveal the predicted oxygen isotope anomaly of tropospheric $\mathrm{CO}_{2}$. This study aims at establishing a new analytical technique that allows accurate and precise determination of $\Delta^{17} \mathrm{O}$ in $\mathrm{CO}_{2}$ with an uncertainty better than $\pm 0.1 \%$. 


\subsection{Methods}

\subsubsection{Definitions}

In this study, $\delta^{17} \mathrm{O}$ and $\delta^{18} \mathrm{O}$ values are given relative to SMOW. $\Delta^{17} \mathrm{O}$ values are reported relative to the rocks- and minerals-defined TFL with a slope of 0.52520 and an intercept of $-0.015 \pm 0.019 \%$. The $\Delta^{17} \mathrm{O}$-value is defined by the vertical deviation of a sample from the TFL in a $\delta^{\prime 17} \mathrm{O}$ vs. $\delta^{18} \mathrm{O}$ diagram (Miller, 2002; Miller et al., 2002; Pack et al., 2007), where $\delta^{\prime 17} \mathrm{O}=10^{3} \ln \left(\delta^{17} \mathrm{O} / 10^{3}+1\right)$ and $\delta^{\prime 18} \mathrm{O}=10^{3} \ln \left(\delta^{18} \mathrm{O} / 10^{3}+1\right)$ (Miller et al., 2002; Young et al., 2002). All data on $\Delta^{17} \mathrm{O}_{\mathrm{TFL}}$ (Table 2-1 and 2-2) can be converted to any other reference line $(\mathrm{RL})$, e.g. the meteoric water line (Barkan and Luz, 2005; Meijer and Li, 1998), according to the relation: $\Delta^{17} \mathrm{O}_{\mathrm{RL}}=\delta^{\prime 17} \mathrm{O}-\delta^{\prime 18} \mathrm{O} \times \beta_{\mathrm{RL}}$, given that the reference line passes through the origin. The TFL was defined by a large number of analyses of rocks and minerals (MORB glass, Bushveld complex chromite, UWG-2 garnet, NBS-28 quartz, Dörentrup quartz and sapphire) in Göttingen during the period of June 2008 to January 2009 (data shown in section 2.4).

\subsubsection{Oxygen and carbon isotope analyses}

All triple oxygen isotope data on $\mathrm{CeO}_{2}$ were measured by laser fluorination (Sharp, 1990) in combination with continuous flow isotope ratio monitoring mass spectrometry (CFirmMS). Our in-house reference $\mathrm{O}_{2}$ gas was calibrated relative to SMOW by E. Barkan (Institute of Earth Sciences, Hebrew University of Jerusalem) and has a $\delta^{18} \mathrm{O}_{\text {SMOW }}=+13.472 \%$ and a $\delta^{17} \mathrm{O}_{\text {SMOW }}=+6.702 \%$. Positively charged $\mathrm{O}_{2}$ ions were analyzed on three Faraday cups in a Thermo MAT 253 gas mass spectrometer. We used $\sim 20$ mbar purified $F_{2}$ gas (Asprey, 1976) as the oxidation agent. Excess $F_{2}$ was reacted with $\mathrm{NaCl}$ to $\mathrm{Cl}_{2}$, which was trapped at $-196{ }^{\circ} \mathrm{C}$ in a cold trap. Interference of $\mathrm{NF}$ $(\mathrm{m} / \mathrm{z}=33)$ on ${ }^{17} \mathrm{O}^{16} \mathrm{O}$ was eliminated by means of a $5 \AA$ gas chromatography column (Pack et al., 2007).

In the continuous flow mode, the reference gas was injected via an open split valve using a Thermo Gasbench II. The reference gas peaks were $\sim 10 \mathrm{~V}$ high and $\sim 40 \mathrm{~s}$ wide. The peak shape was rectangular. The sample peaks were injected by releasing $\mathrm{O}_{2}$ from a $5 \AA$ molecular sieve trap that was placed in the helium gas stream. The resultant smooth peaks were slightly asymmetric with an amplitude of $\sim 20-30 \mathrm{~V}$ and full width at half-maximum of $\sim 15 \mathrm{~s}$. Accuracy and precision of the continuous flow method has been tested by repeated analyses of reference $\mathrm{O}_{2}$. The reference gas was expanded into the extraction line and treated as if it had been released from fluorination. The $\delta^{18} \mathrm{O}$ of the analyzed gas was 
within $\pm 0.2 \%$ identical to the reference gas value. The $\delta^{17} \mathrm{O}$ showed a small systematic offset of $+0.080 \%$, which is due to limitations in linearity of the ion source. All data have been corrected in $\delta^{17} \mathrm{O}$ by $0.080 \%$. Tests with dual inlet did not show any systematic deviation from the expected values.

The error of $\Delta^{17} \mathrm{O}$ was $\pm 0.05 \%$ o $(1 \sigma)$ for a single analysis, and the error in $\delta^{18} \mathrm{O}$ was typically $\pm 0.25 \%$ o $(1 \sigma)$. One run generally contained eight $\mathrm{CeO}_{2}$ samples $(\sim 2.5-3.1 \mathrm{mg}$ per sample) and four terrestrial reference silicates ( 1.0-1.2 mg per sample). All samples were placed on a nickel sample holder and were baked out overnight in a fluorine atmosphere at $70{ }^{\circ} \mathrm{C}$. The terrestrial rocks with $-1 \%<\delta^{18} \mathrm{O}<+24 \%$ were used to determine the TFL.

Bottle $\mathrm{O}_{2}$ that was used for $\mathrm{O}_{2}$ to $\mathrm{CO}_{2}$ conversion was analyzed by means of dual inlet mass spectrometry using the Thermo MAT 253 relative to the in-house reference $\mathrm{O}_{2}$ gas $\left(\delta^{18} \mathrm{O}_{\text {SMOW }}=13.472 \%, \delta^{17} \mathrm{O}_{\text {SMOW }}=6.702 \%\right)$. The $\Delta^{17} \mathrm{O}$ of the in-house reference $\mathrm{O}_{2}$ was determined by comparison with rock and mineral data that define the TFL. The uncertainty in $\Delta^{17} \mathrm{O}$ is $\pm 0.02 \%$.

Analyses of $\delta^{18} \mathrm{O}$ and $\delta^{13} \mathrm{C}$ (relative to $\mathrm{PDB}$ ) of $\mathrm{CO}_{2}$ gas were performed on a Finnigan Delta plus mass spectrometer. The $\mathrm{CO}_{2}$ samples were analyzed in a dual inlet mode. Values of $\delta^{13} \mathrm{C}$ and $\delta^{18} \mathrm{O}$ were standardized by comparison with $\mathrm{CO}_{2}$ generated by phosphoric acid decomposition of NBS-19 $\left(\delta^{18} \mathrm{O}_{\mathrm{SMOW}}=+28.65 \%\right.$; $\delta^{13} \mathrm{C}_{\mathrm{PDB}}=+1.95 \%$ ). The uncertainty in $\delta^{18} \mathrm{O}$ and $\delta^{13} \mathrm{C}$ is in the range of $\pm 0.1 \%$.

\subsubsection{Exchange experiments between $\mathrm{CO}_{2}$ and $\mathrm{CeO}_{2}$}

It has been demonstrated by Assonov and Brenninkmeijer (2001) that $\mathrm{CeO}_{2}$ exchanges oxygen with $\mathrm{CO}_{2}$ gas at temperatures in the range of $650{ }^{\circ} \mathrm{C}$ in less than $30 \mathrm{~min}$. In our approach, we analyze small amounts of $\mathrm{CeO}_{2}$ after equilibration with large excesses of gaseous $\mathrm{CO}_{2}$.

The equilibration system consists of a quartz glass tube $\left(\mathrm{V} \approx 650 \mathrm{~cm}^{3}\right)$ that is inserted in a horizontal tube furnace (Fig. 2-1). The glass tube can be evacuated by a rotary vane pump (Pfeiffer DUO 005M). The reaction tube can be opened on both endings in order to place the sample shuttle with the $\mathrm{CeO}_{2}$ powder inside the furnace. Ceria powder was placed on a small platinum plate in order to avoid any exchange with the ceramic shuttle. After insertion of the sample, the line was evacuated and heated to the experimental temperature. Subsequent to evacuation, the reaction tube was filled with sample $\mathrm{CO}_{2}$. We admitted $\sim 1000$ mbar to the reactor. After equilibration, $\mathrm{CO}_{2}$ was pumped to waste and the furnace 
was switched off to cool down $\mathrm{CeO}_{2}$ to room temperature. This procedure avoided equilibration with ambient air oxygen.

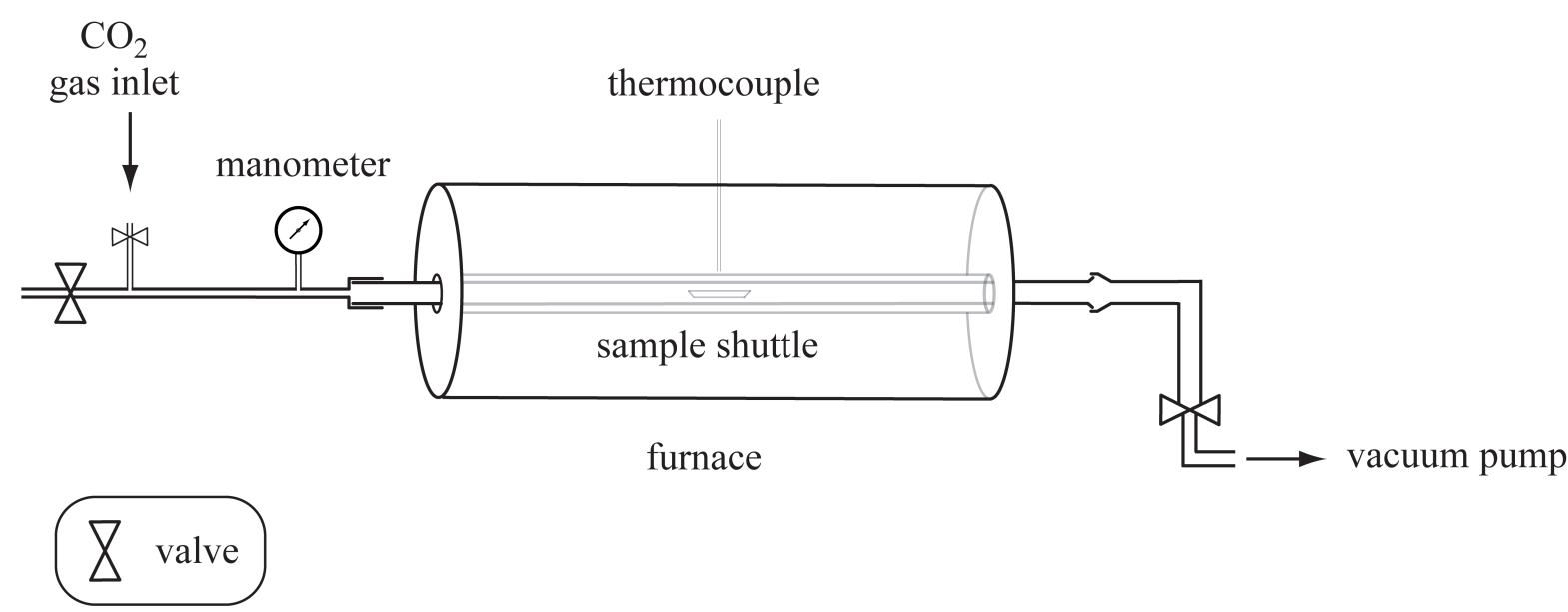

Fig. 2-1: Schematic illustration showing the equilibration apparatus. The apparatus consists of a quartz glass reaction tube that can be opened on both endings to load the sample shuttle, a tube furnace and a furnace thermocouple, a metal gas inlet, a manometer, and a vacuum pump. The isotopic equilibration system $\left(\approx 650 \mathrm{~cm}^{3}\right)$ is used to equilibrate ceria and $\mathrm{CO}_{2}$ at $685{ }^{\circ} \mathrm{C}$.

We ran time-dependent $\mathrm{CO}_{2}-\mathrm{CeO}_{2}$ equilibration experiments at $635,685,735$, and $935^{\circ} \mathrm{C}$ to test if equilibrium is reached within $30 \mathrm{~min}$ (Assonov and Brenninkmeijer, 2001). The $\delta^{18} \mathrm{O}$ and $\Delta^{17} \mathrm{O}$ values of $\mathrm{CeO}_{2}$ of these experiments showed that equilibrium was reached within $<10 \mathrm{~min}$ for all temperatures investigated. Subsequently, $\mathrm{CO}_{2}-\mathrm{CeO}_{2}$ exchange experiments were carried out at $685^{\circ} \mathrm{C}$ for $30 \mathrm{~min}$ to $1 \mathrm{~h}$. The experimental temperature was chosen with respect to earlier research showing that exchange experiments are best carried out at temperatures above $550{ }^{\circ} \mathrm{C}$ (Assonov and Brenninkmeijer, 2001; Holmgren et al., 1999). Temperatures exceeding $900^{\circ} \mathrm{C}$ were avoided due to possible oxygen isotope exchange between the quartz glass reaction tube and the gaseous sample (Barkan and Luz, 1996).

Granulated $\mathrm{CeO}_{2}$ (Merck no. 2263) was ground to a powder in order to facilitate diffusive isotopic exchange. Equilibration experiments were carried out with untreated ceria (as supplied by Merck) and with the same ceria but after heating it in air for $7 \mathrm{~h}$ at $1035^{\circ} \mathrm{C}$. For each equilibration experiment, $12-24 \mathrm{mg}$ of $\mathrm{CeO}_{2}(\sim 70-140 \mu \mathrm{mol})$ exchanged with $\sim 18 \mathrm{mmol}$ of gas. The molar $\mathrm{CO}_{2} / \mathrm{CeO}_{2}$ ratios always exceeded $\sim 130$. The $\delta^{18} \mathrm{O}$ analyses of $\mathrm{CO}_{2}$ before and after equilibration showed that the influence of $\mathrm{CeO}_{2}$ oxygen on the isotopic composition of the bulk system was negligible. Mass balance calculations confirm that the initial isotopic signature of $\mathrm{CeO}_{2}$ did not affect the isotopic signature of $\mathrm{CO}_{2}$, that 
is the theoretical shifts in $\delta^{18} \mathrm{O}$ and $\Delta^{17} \mathrm{O}$ values of $\mathrm{CO}_{2}$ are $<0.1 \%$ and $<0.0005 \%$, respectively. The amount of ceria was chosen to be as low as possible, but it should allow several measurements on the mass spectrometer, each measurement requiring $\sim 2.5-3.1 \mathrm{mg}$ of ceria.

In order to determine the triple oxygen isotope fractionation, we equilibrated $\mathrm{CeO}_{2}$ with $\mathrm{CO}_{2}$ with known $\delta^{18} \mathrm{O}$ and $\Delta^{17} \mathrm{O}$ at $685^{\circ} \mathrm{C}$. The $\mathrm{CO}_{2}$ with known $\Delta^{17} \mathrm{O}$ was produced by combustion of electrically heated graphite in pure $\mathrm{O}_{2}$ with known $\delta^{18} \mathrm{O}$ and $\Delta^{17} \mathrm{O}$. Complete conversion was checked by pressure monitoring $\left(\mathrm{CO}_{2}\right.$ was cryotrapped during the conversion). The $\delta^{18} \mathrm{O}$ values of the produced $\mathrm{CO}_{2}$ were also compared with the $\delta^{18} \mathrm{O}$ value of the starting $\mathrm{O}_{2}$.

\subsubsection{Determination of $\Delta^{17} \mathrm{O}$ of $\mathrm{CO}_{2}$}

In order to use $\mathrm{CeO}_{2}$ as proxy for the $\Delta^{17} \mathrm{O}$ value of $\mathrm{CO}_{2}$, we must know the exponent $\beta_{\mathrm{CO} 2-\mathrm{CeO} 2}$ for the equilibration reaction. $\beta_{\mathrm{CO} 2-\mathrm{CeO} 2}$ is calculated according to

$$
\beta_{\mathrm{CO}_{2}-\mathrm{CeO}_{2}}=\frac{\Delta^{17} \mathrm{O}_{\mathrm{CO}_{2}}-\Delta^{17} O_{\mathrm{CeO}_{2}}}{\delta^{18} O_{\mathrm{CO}_{2}}-\delta^{18} O_{\mathrm{CeO}_{2}}}+\beta_{T F L}
$$

The $\beta_{\mathrm{TFL}}$ value denotes the slope of the TFL, and the $\Delta^{17} \mathrm{O}$ values describe deviations from the TFL (Fig. 2-2). The $\Delta^{17} \mathrm{O}$ and $\delta^{\prime 18} \mathrm{O}$ values of $\mathrm{CO}_{2}$ and $\mathrm{CeO}_{2}$ denote the isotopic composition of $\mathrm{CO}_{2}$ and $\mathrm{CeO}_{2}$ after equilibration. The exponent $\beta_{\mathrm{CO} 2-\mathrm{CeO} 2}$ was determined in equilibrium exchange experiments between $\mathrm{CeO}_{2}$ and $\mathrm{CO}_{2}$ with known $\Delta^{17} \mathrm{O}$.

The oxygen isotope anomaly of $\mathrm{CO}_{2}$ gas is determined from the isotope composition of $\mathrm{CeO}_{2}$ :

$$
\Delta^{17} O_{\mathrm{CO}_{2}}=\Delta^{17} \mathrm{O}_{\mathrm{CeO}_{2}}+\left(\beta_{\mathrm{CO}_{2}-\mathrm{CeO}_{2}}-\beta_{\mathrm{TFL}}\right)\left(\delta^{18} \mathrm{O}_{\mathrm{CO}_{2}}-\delta^{18} \mathrm{O}_{\mathrm{CeO}_{2}}\right)
$$

Again, $\beta_{\mathrm{TFL}}$ denotes the slope of the TFL and $\Delta^{17} \mathrm{O}$ the deviations from the TFL (Fig. 2-2). The $\delta^{\prime 18} \mathrm{O}$ values denote the isotopic signature of $\mathrm{CO}_{2}$ and $\mathrm{CeO}_{2}$ brought to equilibrium, whereby $\delta^{\prime 18} \mathrm{O}$ does not change during the equilibration process as equilibration is conducted under excess $\mathrm{CO}_{2}$ conditions. 


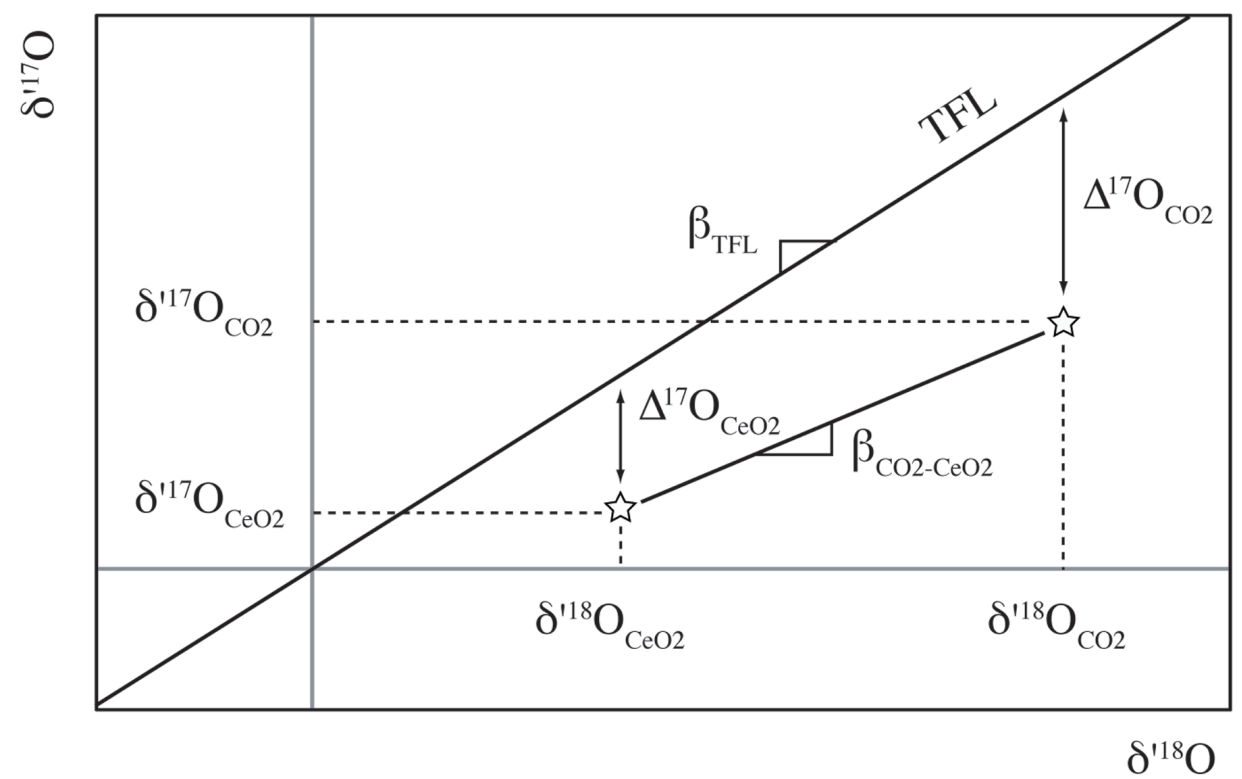

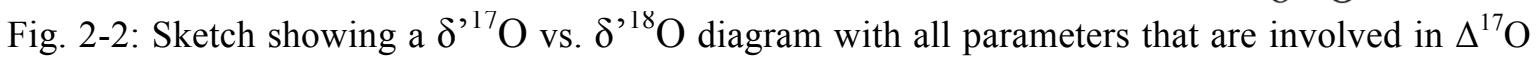
determination of $\mathrm{CO}_{2}$.

\subsection{Results}

\subsubsection{Terrestrial fractionation line}

The TFL was defined by 161 analyses of rocks and minerals (Fig. 2-3). A WilliamsonYork regression yielded a TFL with a slope of $0.52520 \pm 0.00085$ and an intercept of $-0.015 \pm 0.019 \%$. The regression parameters were calculated using an Excel spreadsheet set up by Cantrell (2008). 


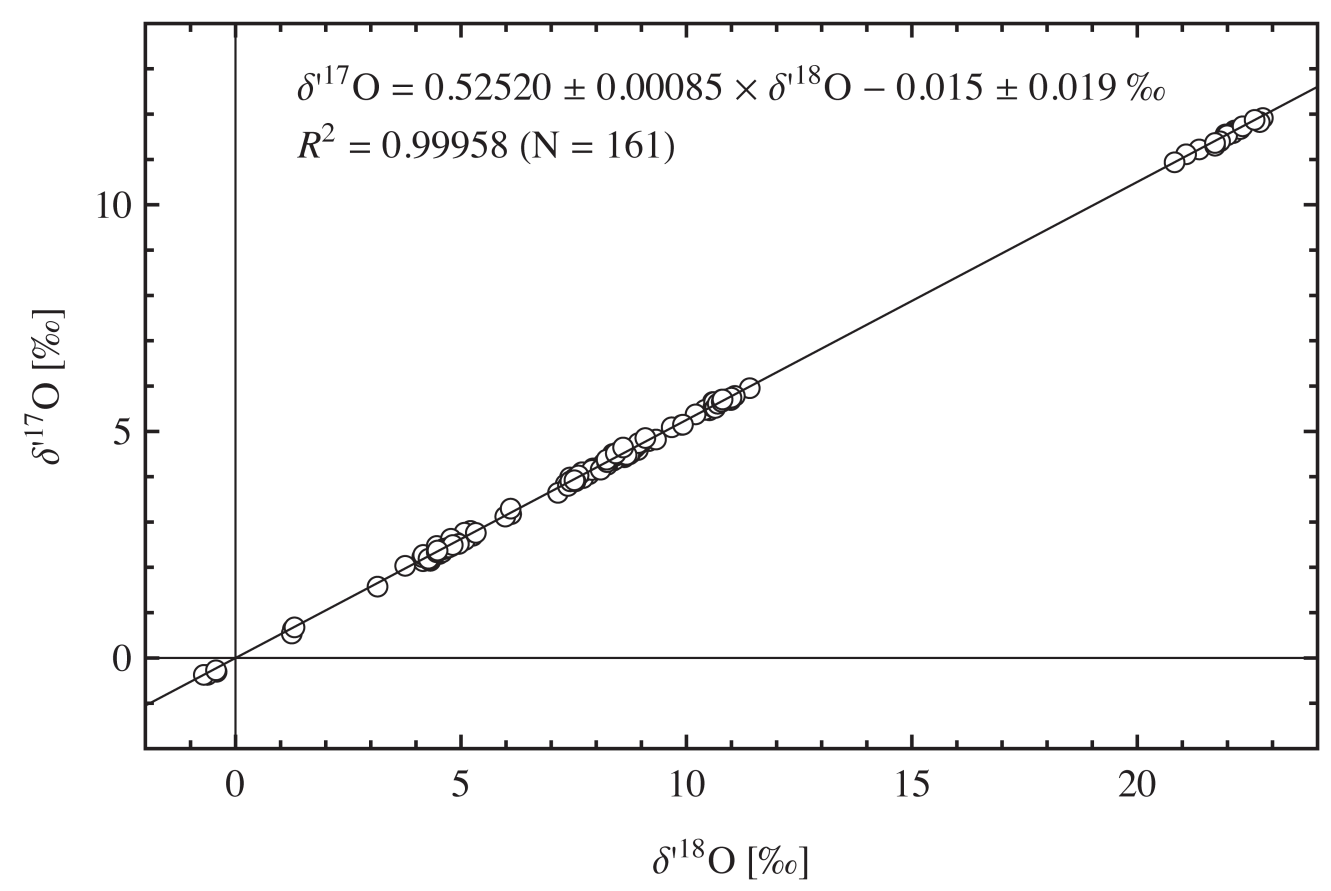

Fig. 2-3: Terrestrial fractionation line. A total of 161 analyses of terrestrial rocks and minerals define the TFL. The bivariate regression line is based on a Williamson-York approach (Cantrell, 2008).

\subsubsection{Isotopic composition of the starting materials}

Two types of $\mathrm{CeO}_{2}$ were used as starting material (Table 2-1). Untreated $\mathrm{CeO}_{2}$ from Merck had a $\delta^{\prime 18} \mathrm{O}$ value of $+3.78 \pm 0.27 \%$ and a $\Delta^{17} \mathrm{O}$ value of $-0.23 \pm 0.01 \%$. A fraction of the Merck $\mathrm{CeO}_{2}$ was preheated in air resulting in a $\delta^{\prime 18} \mathrm{O}$ value of $+19.64 \pm 0.08 \%$ and a $\Delta^{17} \mathrm{O}$ value of $-0.37 \pm 0.02 \%$. For determination of $\beta_{\mathrm{CO} 2-\mathrm{CeO} 2}$, bottle $\mathrm{O}_{2}$ with $\delta^{\prime 18} \mathrm{O}=11.45$ $\pm 0.03 \%$ o, $\delta^{\prime 17} \mathrm{O}=5.62 \pm 0.02 \%$, and $\Delta^{17} \mathrm{O}_{\mathrm{TFL}}=-0.38 \pm 0.01 \%$ was used for $\mathrm{O}_{2}$ to $\mathrm{CO}_{2}$ conversion and subsequent $\mathrm{CO}_{2}-\mathrm{CeO}_{2}$ equilibration. 
Table 2-1: Isotopic composition of the two types of $\mathrm{CeO}_{2}$ starting materials. The $\Delta^{17} \mathrm{O}_{\mathrm{TFL}}$ values are reported relative to the terrestrial fractionation line with a slope of 0.52520 and an intercept of $-0.015 \%$.

\begin{tabular}{|c|c|c|c|}
\hline sample material & $\delta^{, 18} \mathbf{O}_{\text {SMOW }}[\%$ ] & $\delta^{, 17} \mathbf{O}_{\text {SMOW }}[\%$ ] & $\Delta^{17} \mathbf{O}_{\text {TFL }}[\% 0]$ \\
\hline \multirow[t]{4}{*}{$\mathrm{CeO}_{2}$ untreated } & 3.340 & 1.494 & -0.246 \\
\hline & 3.560 & 1.611 & -0.243 \\
\hline & 3.666 & 1.718 & -0.192 \\
\hline & 4.555 & 2.143 & -0.234 \\
\hline average \pm std error & $3.780 \pm 0.267$ & $1.742 \pm 0.142$ & $-0.229 \pm 0.013$ \\
\hline \multirow[t]{4}{*}{$\mathrm{CeO}_{2}$ preheated in $\operatorname{air}\left(1035^{\circ} \mathrm{C}, 7 \mathrm{~h}\right)$} & 19.690 & 10.002 & -0.324 \\
\hline & 19.774 & 10.012 & -0.358 \\
\hline & 19.704 & 9.919 & -0.414 \\
\hline & 19.410 & 9.810 & -0.369 \\
\hline average \pm std error & $19.644 \pm 0.080$ & $9.936 \pm 0.047$ & $-0.367 \pm 0.019$ \\
\hline
\end{tabular}

\subsubsection{Equilibration experiments}

Four $\mathrm{CO}_{2}-\mathrm{CeO}_{2}$ equilibration experiments were carried out in order to determine $\beta_{\mathrm{CO} 2-\mathrm{CeO} 2}$ at $685{ }^{\circ} \mathrm{C}$ (Table 2-2). For each experiment, the equilibrated $\mathrm{CeO}_{2}$ was analyzed three or four times. The equilibration experiments are based on quantitative conversion of $\mathrm{O}_{2}$ $\left(\delta^{\prime 18} \mathrm{O}=11.45 \% ; \delta^{\prime 17} \mathrm{O}=5.62 \% ; \Delta^{17} \mathrm{O}=-0.38 \%\right.$ ) to $\mathrm{CO}_{2}$ and subsequent exchange of oxygen-atoms between $\mathrm{CeO}_{2}$ and $\mathrm{CO}_{2}$ with known $\Delta^{17} \mathrm{O}$. Conversion of $\mathrm{O}_{2}\left(\delta^{\prime 18} \mathrm{O}=\right.$ $11.45 \pm 0.03 \%)$ to $\mathrm{CO}_{2}\left(\delta^{\prime 18} \mathrm{O}=11.42 \pm 0.08 \%\right)$ did not result in fractionation in $\delta^{18} \mathrm{O}$, and thus, the $\Delta^{17} \mathrm{O}$ value of the produced $\mathrm{CO}_{2}$ must equal the $\Delta{ }^{17} \mathrm{O}$ of the initial $\mathrm{O}_{2}$ gas. The slope $\beta_{\mathrm{CO} 2-\mathrm{CeO} 2}$ for the $\mathrm{CO}_{2}-\mathrm{CeO}_{2}$ equilibrium was determined to $0.5240 \pm 0.0011$ at $685^{\circ} \mathrm{C}$ (Fig. 2-4). The fractionation factor $1000 \ln \alpha$ between $\mathrm{CO}_{2}$ and $\mathrm{CeO}_{2}$ was determined as $10.89 \pm 0.44 \%$. 
Table 2-2: Data obtained from four $\mathrm{CeO}_{2}-\mathrm{CO}_{2}$ equilibration experiments. The $\Delta^{17} \mathrm{O}_{\mathrm{TFL}}$ values are reported relative to the terrestrial fractionation line with a slope of 0.52520 and an intercept of $-0.015 \%$.

\begin{tabular}{|c|c|c|c|c|c|c|c|}
\hline no. & $\mathbf{T}$ & $\begin{array}{l}\text { equili- } \\
\text { bration } \\
\text { time } \\
\end{array}$ & sample material & $\begin{array}{l}\delta^{, 18} \mathbf{O}_{\text {Sмоw }} \\
{[\% \text { \% }}\end{array}$ & $\begin{array}{l}\boldsymbol{\delta}^{, 17} \mathbf{O}_{\text {Sмош }} \\
{[\% \text { \% }}\end{array}$ & $\begin{array}{l}\Delta^{17} \mathbf{O}_{\mathrm{TFL}} \\
{[\% \text { ] }}\end{array}$ & $\begin{array}{l}\beta_{\mathrm{CO} 2-\mathrm{CeO} 2} \\
\pm \text { std } \\
\text { error } \\
\end{array}$ \\
\hline \multirow[t]{6}{*}{1} & $685^{\circ} \mathrm{C}$ & $1 \mathrm{~h}$ & $\begin{array}{l}\mathrm{CeO}_{2}(\text { preheated })+ \\
\mathrm{CO}_{2}\left(\delta^{18} \mathrm{O}=11.6 \% 0\right)\end{array}$ & 0.720 & 0.731 & 0.338 & \\
\hline & & & & 0.593 & 0.597 & 0.270 & \\
\hline & & & & 0.722 & 0.765 & 0.371 & \\
\hline & & & & 0.538 & 0.614 & 0.316 & \\
\hline & & & & 0.720 & 0.731 & 0.338 & \\
\hline & & & average \pm std error & $\begin{array}{l}-0.643 \\
\pm 0.046 \\
\end{array}$ & $\begin{array}{l}-0.677 \\
\pm 0.042 \\
\end{array}$ & $\begin{array}{l}-0.324 \\
\pm 0.021 \\
\end{array}$ & $\begin{array}{l}0.5209 \\
\pm 0.0021\end{array}$ \\
\hline \multirow[t]{5}{*}{2} & $685^{\circ} \mathrm{C}$ & $30 \mathrm{~min}$ & $\begin{array}{l}\mathrm{CeO}_{2} \text { (untreated) }+ \\
\mathrm{CO}_{2}\left(\delta^{18} \mathrm{O}=11.6 \% 0\right)\end{array}$ & 0.516 & 0.196 & 0.452 & \\
\hline & & & & 0.511 & 0.102 & 0.355 & \\
\hline & & & & 0.482 & 0.017 & 0.255 & \\
\hline & & & & 0.591 & 0.128 & 0.423 & \\
\hline & & & average \pm std error & $\begin{array}{l}0.525 \\
\pm 0.023 \\
\end{array}$ & $\begin{array}{l}-0.111 \\
\pm 0.037\end{array}$ & $\begin{array}{l}-0.371 \\
\pm 0.044\end{array}$ & $\begin{array}{l}0.5248 \\
\pm 0.0021 \\
\end{array}$ \\
\hline \multirow[t]{5}{*}{3} & $685^{\circ} \mathrm{C}$ & $30 \mathrm{~min}$ & $\begin{array}{l}\mathrm{CeO}_{2}(\text { untreated })+ \\
\mathrm{CO}_{2}\left(\delta^{18} \mathrm{O}=11.6 \% 0\right)\end{array}$ & 1.007 & 0.208 & -0.307 & \\
\hline & & & & 0.914 & 0.050 & -0.415 & \\
\hline & & & & 0.889 & 0.079 & -0.372 & \\
\hline & & & & 0.854 & 0.021 & -0.412 & \\
\hline & & & average \pm std error & $\begin{array}{l}0.916 \\
\pm 0.033\end{array}$ & $\begin{array}{l}0.089 \\
\pm 0.041 \\
\end{array}$ & $\begin{array}{l}-0.377 \\
\pm 0.025 \\
\end{array}$ & $\begin{array}{l}0.5252 \\
\pm 0.0021 \\
\end{array}$ \\
\hline \multirow[t]{4}{*}{4} & $685^{\circ} \mathrm{C}$ & $30 \mathrm{~min}$ & $\begin{array}{l}\mathrm{CeO}_{2} \text { (untreated) }+ \\
\mathrm{CO}_{2}\left(\delta^{18} \mathrm{O}=11.6 \% 0\right)\end{array}$ & 1.449 & 0.400 & -0.345 & \\
\hline & & & & 1.609 & 0.405 & -0.425 & \\
\hline & & & & 1.571 & 0.445 & -0.365 & \\
\hline & & & average \pm std error & $\begin{array}{l}1.543 \\
\pm 0.042\end{array}$ & $\begin{array}{l}0.417 \\
\pm 0.012\end{array}$ & $\begin{array}{l}-0.378 \\
\pm 0.021\end{array}$ & $\begin{array}{l}0.5254 \\
\pm 0.0021\end{array}$ \\
\hline
\end{tabular}




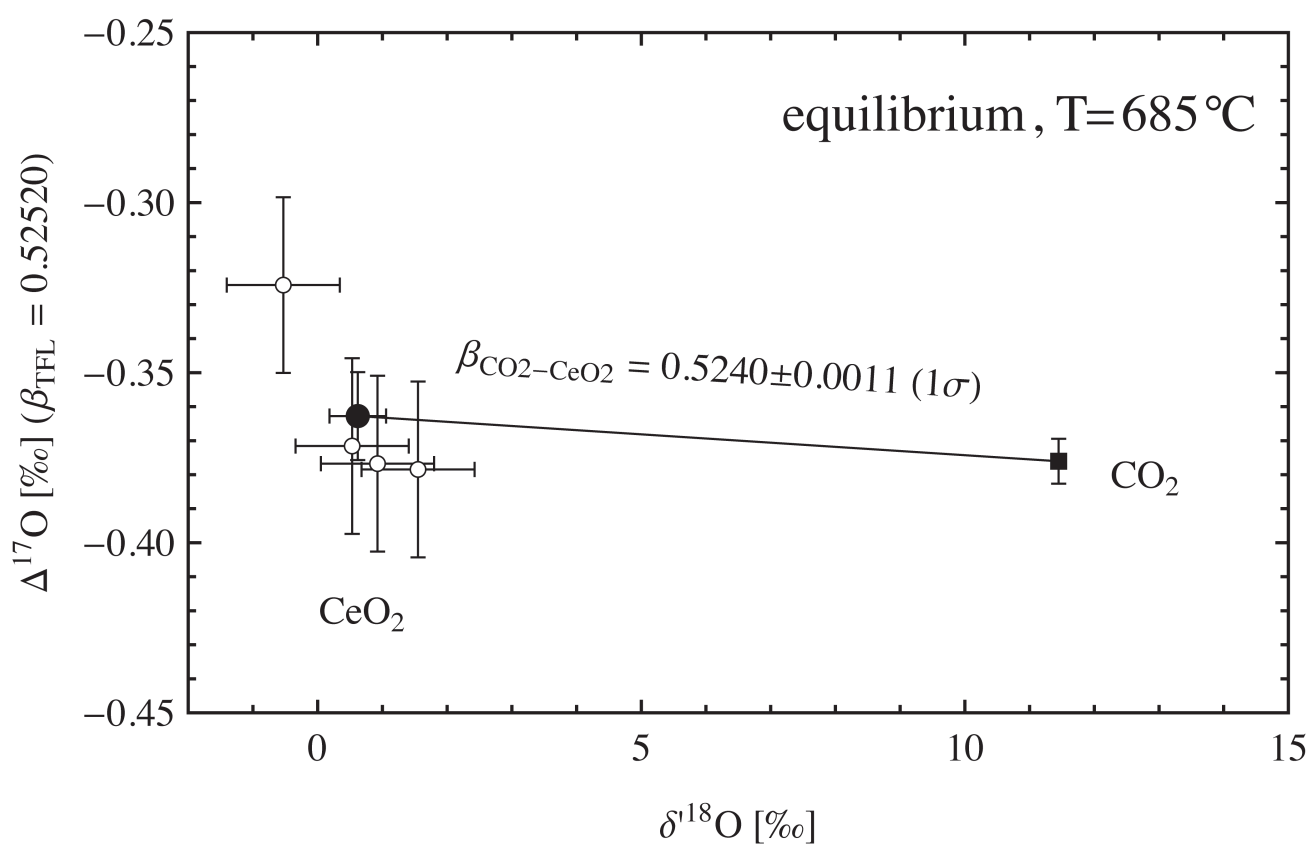

Fig. 2-4: Plot of $\Delta^{17} \mathrm{O}$ vs. $\delta^{18} \mathrm{O}$ showing the composition of $\mathrm{CeO}_{2}$ and $\mathrm{CO}_{2}$ at equilibrium (T $=685{ }^{\circ} \mathrm{C}$, four experiments, $\mathrm{O}$ ). Determination of $\beta_{\mathrm{CO} 2-\mathrm{CeO} 2}$ is based on mean $\delta^{18} \mathrm{O}$ and $\Delta{ }^{17} \mathrm{O}$ values of the four equilibration experiments $(\bullet)$ and the data point for $\mathrm{CO}_{2}(\boldsymbol{\square}, \mathrm{N}=7)$ 


\subsubsection{Uncertainty in $\Delta^{17} \mathrm{O}$ determination on $\mathrm{CO}_{2}$}

The uncertainty of $\Delta^{17} \mathrm{O}_{\mathrm{CO} 2}$ was determined for a single analysis to $\pm 0.05 \%$ o $(1 \sigma)$. The uncertainty is based on error propagation for Eq. 2-2. The uncertainty in $\Delta^{17} \mathrm{O}$ of $\mathrm{CeO}_{2}$ is $\pm 0.05 \%$ and dominates the overall uncertainty in $\Delta^{17} \mathrm{O}$ analysis of $\mathrm{CO}_{2}$ since the influence of the uncertainties of $\beta_{\mathrm{TFL}}, \beta_{\mathrm{CO} 2-\mathrm{CeO} 2}, \delta^{\prime 18} \mathrm{O}_{\mathrm{CO} 2}$, and $\delta^{\prime 18} \mathrm{O}_{\mathrm{CeO} 2}$ on the overall uncertainty $\Delta \Delta^{17} \mathrm{O}_{\mathrm{CO} 2}$ is an order of magnitude smaller than the uncertainty of $\Delta \Delta^{17} \mathrm{O}_{\mathrm{CeO} 2}$.

\subsection{Discussion}

Our data show that full equilibrium is reached within $30 \mathrm{~min}$ at $685^{\circ} \mathrm{C}$. The equilibration experiments confirm earlier findings of Assonov and Brenninkmeijer (2001) that ceria is an excellent oxygen exchange medium in $\mathrm{CO}_{2}$ exchange experiments.

We determined $\beta_{\mathrm{CO} 2-\mathrm{CeO} 2}$ to $0.5240 \pm 0.0011$ at $685^{\circ} \mathrm{C}$. Our $\beta$ value for equilibrium fractionation between $\mathrm{CO}_{2}-\mathrm{CeO}_{2}$ is lower than the high-temperature limit of $\beta$ given as 0.529 (Young et al., 2002). This demonstrates that $\beta=0.529$ is not a universal value even for equilibration at $685{ }^{\circ} \mathrm{C}$. For $\mathrm{CO}_{2}-\mathrm{H}_{2} \mathrm{O}$ equilibrium, Matsuhisa et al. (1978) predicted also a $\beta$ value $<0.529$. The authors also demonstrate that the exponent $\beta$ for $\mathrm{CO}_{2}-\mathrm{H}_{2} \mathrm{O}$ equilibrium is temperature dependent. For water-steam fractionation, however, $\beta$ is identical to the high-temperature approximation of 0.529 (Barkan and Luz, 2005).

We show that measurement of ceria that has been in equilibrium with $\mathrm{CO}_{2}$ is a suitable proxy for $\Delta^{17} \mathrm{O}$ of $\mathrm{CO}_{2}$. On the basis of the $\beta_{\mathrm{CO} 2-\mathrm{CeO} 2}$ value determined in this study, $\Delta^{17} \mathrm{O}$ of $\mathrm{CO}_{2}$ can be deduced from $\mathrm{CO}_{2}-\mathrm{CeO}_{2}$ equilibration at $685^{\circ} \mathrm{C}$ according to:

$$
\Delta^{17} O_{\mathrm{CO}_{2}}=\Delta^{17} O_{\mathrm{CeO}_{2}}+(0.5240-0.5252) \times 10.90 \%
$$

Since the relative errors of $\beta_{\mathrm{TFL}}, \beta_{\mathrm{CO} 2-\mathrm{CeO} 2}$, and $\delta^{\prime 18} \mathrm{O}$ on both $\mathrm{CO}_{2}$ and $\mathrm{CeO}_{2}$ are comparatively small, the uncertainty largely depends on the uncertainty in $\Delta^{17} \mathrm{O}$ analysis of $\mathrm{CeO}_{2}$. As $\Delta^{17} \mathrm{O}$ of $\mathrm{CeO}_{2}$ can be analyzed with a precision of $\pm 0.05 \%$ o $(1 \sigma), \Delta^{17} \mathrm{O}$ of $\mathrm{CO}_{2}$ can be determined with a precision of $\pm 0.05 \%$ o $(1 \sigma)$ for a single analysis.

The analytical error of our approach is by a factor of 3-5 smaller than the analytical uncertainty indicated by Kawagucci et al. (2005), Assonov and Brenninkmeijer (2001), and Brenninkmeijer and Röckmann (1998). It is by a factor of $\sim 2$ better than the analytical error indicated by Thiemens and Jackson (1991). 
A clear disadvantage of our procedure is that it requires a large amount of $\mathrm{CO}_{2}$ because we need a high molar $\mathrm{CO}_{2} / \mathrm{CeO}_{2}$ ratio $(>200)$. For $\mathrm{CO}_{2}$ samples whose $\delta^{18} \mathrm{O}$ composition falls between $\sim 10$ and $\sim 50 \%$ and whose $\Delta^{17} \mathrm{O}$ value is $-1 \%$ o $\leq \Delta^{17} \mathrm{O} \leq+1 \%$, at least $3.5 \mathrm{mmol}$ of $\mathrm{CO}_{2}(\sim 80 \mathrm{~mL} \mathrm{STP})$ are required for equilibration with $\sim 3 \mathrm{mg}$ of $\mathrm{CeO}_{2}$.

Sampling of millimole quantities of natural $\mathrm{CO}_{2}$ might be difficult and time-consuming because $\mathrm{CO}_{2}$ is a trace gas in the atmosphere. However, Brenninkmeijer and Röckmann (Brenninkmeijer, 1991; Brenninkmeijer and Röckmann, 1996) present a cryogenic trap that is suitable for extracting millimole quantities of $\mathrm{CO}_{2}$ from natural gas mixtures.

Our analytical technique opens up a new field for investigating the triple oxygen isotope abundance of various types of natural and anthropogenic $\mathrm{CO}_{2}$ in the lowermost troposphere and biosphere. The most promising application is high-precision analysis of tropospheric $\mathrm{CO}_{2}$, which will be useful to investigate carbon circulation between the atmosphere and the biosphere (Hoag et al., 2005). $\Delta^{17} \mathrm{O}$ analysis of ambient air $\mathrm{CO}_{2}$ allows us to verify the prediction of Hoag et al (2005) that tropospheric $\mathrm{CO}_{2}$ should have an oxygen isotope anomaly of $-0.22 \%$ (relative to TFL with $\beta_{\mathrm{TFL}}=0.525$ ). The precision of our new technique is by a factor of 4 smaller than the predicted oxygen isotope anomaly of tropospheric $\mathrm{CO}_{2}$, and thus, we will be able to resolve such small deviations from the TFL. Future data are likely to elucidate the potential of $\Delta^{17} \mathrm{O}$ as a tracer of biosphere-atmosphere interaction.

\subsection{Acknowledgment}

We thank E. Barkan for calibration of our in-house reference $\mathrm{O}_{2}$ gas relative to SMOW. We also thank the anonymous reviewers for their helpful comments. This project was partly funded by the German Science Foundation (AP, Project PA909/4-1). 


\subsection{References}

Asprey, L. B., 1976. Preparation of very pure fluorine gas. J. Fluor. Chem. 7, 359-361.

Assonov, S. S., Brenninkmeijer, C. A. M., 2001. A new method to determine the ${ }^{17} \mathrm{O}$ isotopic abundance in $\mathrm{CO}_{2}$ using oxygen isotope exchange with a solid oxide. Rapid Commun. Mass Spec. 15, 2426-2437.

Barkan, E., Luz, B., 1996. Conversion of $\mathrm{O}_{2}$ into $\mathrm{CO}_{2}$ for high-precision oxygen isotope measurements. Anal. Chem. 68, 3507-3510.

Barkan, E., Luz, B., 2005. High precision measurements of ${ }^{17} \mathrm{O} /{ }^{16} \mathrm{O}$ and ${ }^{18} \mathrm{O} /{ }^{16} \mathrm{O}$ ratios in $\mathrm{H}_{2}$ O. Rapid Commun. Mass Spec. 19, 3737-3742.

Brenninkmeijer, C. A. M., 1991. Robust, high-efficiency, high-capacity cryogenic trap. Anal. Chem. 63, 1182-1184.

Brenninkmeijer, C. A. M., Röckmann, T., 1996. Russian doll type cryogenic traps: improved design and isotope separation effects. Anal. Chem. 68, 3050-3053.

Brenninkmeijer, C. A. M., Röckmann, T., 1998. A rapid method for the preparation of $\mathrm{O}_{2}$ from $\mathrm{CO}_{2}$ for mass spectrometric measurement of ${ }^{17} \mathrm{O} /{ }^{16} \mathrm{O}$ ratios. Rapid Commun. Mass Spec. 12, 479-483.

Cantrell, C. A., 2008. Technical Note: Review of methods for linear least-squares fitting of data and application to atmospheric chemistry problems. Atmos. Chem. Phys. 8, 5477-5487.

Hoag, K. J., Still, C. J., Fung, I. Y., Boering, K. A., 2005. Triple oxygen isotope composition of tropospheric carbon dioxide as a tracer of terrestrial gross carbon fluxes. Geophys. Res. Lett. 32, 1-5.

Holmgren, A., Duprez, D., Andersson, B., 1999. A model of oxygen transport in Pt/ceria catalysts from isotope exchange. J. Cat. 182, 441-448.

Kawagucci, S., Tsunogai, U., Kudo, S., Nakagawa, F., Honda, H., Aoki, S., Nakazawa, T., Gamo, T., 2005. An analytical system for determining $\delta^{17} \mathrm{O}$ in $\mathrm{CO}_{2}$ using continuous flow-isotope ratio MS. Anal. Chem. 77, 4509-4514.

Matsuhisa, Y., Goldsmith, J. R., Clayton, R. N., 1978. Mechanisms of hydrothermal crystallization of quartz at $250^{\circ} \mathrm{C}$ and $15 \mathrm{kbar}$. Geochim. Cosmochim. Acta $42,173-$ 182.

Meijer, H. A. J., Li, W. J., 1998. The use of electrolysis for accurate $\delta^{17} \mathrm{O}$ and $\delta^{18} \mathrm{O}$ isotope measurements in water. Isot. Environ. Healt. S. 34, 349 - 369. 
Miller, M. F., 2002. Isotopic fractionation and the quantification of ${ }^{17} \mathrm{O}$ anomalies in the oxygen three-isotope system: an appraisal and geochemical significance. Geochim. Cosmochim. Acta 66, 1881-1889.

Miller, M. F., Franchi, I. A., Thiemens, M. H., Jackson, T. L., Brack, A., Kurat, G., Pillinger, C. T., 2002. Mass-independent fractionation of oxygen isotopes during thermal decomposition of carbonates. Proc. Natl. Acad. Sci. USA 99, 10988-10993.

Pack, A., Toulouse, C., Przybilla, R., 2007. Determination of oxygen triple isotope ratios of silicates without cryogenic separation of $\mathrm{NF}_{3}$ - technique with application to analyses of technical $\mathrm{O}_{2}$ gas and meteorite classification. Rapid Commun. Mass Spec. 21, 3721-3728.

Perri, M. J., Van Wyngarden, A. L., Boering, K. A., Lin, J. H., Lee, Y. T., 2003. Dynamics of the $\mathrm{O}\left({ }^{1} \mathrm{D}\right)+\mathrm{CO}_{2}$ oxygen isotope exchange reaction. J. Chem. Phys. 119, 82138216.

Sharp, Z. D., 1990. A laser-based microanalytical method for the in situ determination of oxygen isotope ratios of silicates and oxides. Geochim. Cosmochim. Acta 54, 13531357.

Thiemens, M. H., 2006. History and applications of mass-independent isotope effects. Annu. Rev. Earth Planet. Sci. 34, 217-262.

Thiemens, M. H., Heidenreich, J. E. I., 1983. The mass-independent fractionation of oxygen: A novel isotope effect and its possible cosmochemical implications. Science 219, 1073-1075.

Thiemens, M. H., Jackson, T., 1991. Oxygen isotope fractionation in stratospheric $\mathrm{CO}_{2}$. Geophys. Res. Lett. 18, 669-672.

Thiemens, M. H., Jackson, T., Zipf, E. C., Erdman, P. W., van Egmond, C., 1995b. Carbon dioxide and oxygen isotope anomalies in the mesosphere and stratosphere. Science 270, 969-972.

Young, E. D., Galy, A., Nagahara, H., 2002. Kinetic and equilibrium mass-dependent isotope fractionation laws in nature and their geochemical and cosmochemical significance. Geochim. Cosmochim. Acta 66, 1095-1104.

Yung, Y. L., Demore, W. B., Pinto, J. P., 1991. Isotopic exchange between carbon dioxide and ozone via $\mathrm{O}\left({ }^{1} \mathrm{D}\right)$ in the stratosphere. Geophys. Res. Lett. 18, 13-16. 


\title{
3 Triple oxygen isotope equilibrium fractionation between carbon dioxide and water
}

\author{
Hofmann, M.E.G., Horváth, B. and Pack, A., 2012. \\ Triple oxygen isotope equilibrium fractionation between carbon dioxide and water.
}

Earth Planet. Sci. Lett. 319-320, 159-164

\subsection{Abstract}

The growing number of recent high precision triple oxygen isotope data of water and atmospheric gases requires the reinvestigation of the major isotope fractionation processes between the hydro-, bio- and atmosphere. Here we present the experimental triple oxygen isotope fractionation factor between $\mathrm{CO}_{2}$ gas and water in the temperature range between 2 and $37^{\circ} \mathrm{C}$. We have determined the triple oxygen isotope fractionation factor, $\theta=$ $\ln ^{17} \alpha / \ln ^{18} \alpha$, for $\mathrm{CO}_{2}$-water equilibrium and found that $\theta_{\mathrm{CO} 2 \text {-water }}=0.522 \pm 0.002$ $\left(\mathrm{t}_{0.95} \times \mathrm{SEM}\right)$. No temperature dependence was resolved. Knowledge on the triple oxygen isotope equilibrium fractionation between $\mathrm{CO}_{2}$ and water is crucial for estimating the triple oxygen isotope composition of tropospheric $\mathrm{CO}_{2}$. Model predictions combined with highprecision $\Delta^{17} \mathrm{O}$ analysis of tropospheric $\mathrm{CO}_{2}$ might reveal new information on biosphereatmosphere interactions or the influx of anomalous stratospheric $\mathrm{CO}_{2}$.

\subsection{Introduction}

Oxygen isotope exchange between $\mathrm{CO}_{2}$ and water is a ubiquitous process in the bio- and hydrosphere due to rapid hydration and dehydration of $\mathrm{CO}_{2}$ in water. The steady exchange between $\mathrm{CO}_{2}$ and water in leaves, soils and the ocean largely controls the ${ }^{18} \mathrm{O} /{ }^{16} \mathrm{O}$ ratio of tropospheric $\mathrm{CO}_{2}$ (Ciais et al., 1997; Farquhar et al., 1993; Francey and Tans, 1987; Friedli et al., 1987; Yakir and Wang, 1996), and as a consequence, it also determines to a great extent the ${ }^{17} \mathrm{O} /{ }^{16} \mathrm{O}$ ratio of tropospheric $\mathrm{CO}_{2}$.

Hoag et al. (2005) proposed that the triple oxygen isotope ratios $\left({ }^{17} \mathrm{O} /{ }^{16} \mathrm{O},{ }^{18} \mathrm{O} /{ }^{16} \mathrm{O}\right)$ of tropospheric $\mathrm{CO}_{2}$ might be a tracer of bio-, hydro- and atmosphere interaction. According to their mass balance model, variations in the terrestrial biosphere productivity might induce seasonal variations in the triple oxygen isotope signature of tropospheric $\mathrm{CO}_{2}$. Moreover, the influx of mass-independently fractionated stratospheric $\mathrm{CO}_{2}$ (Lämmerzahl 
et al., 2002; Thiemens et al., 1995a; Thiemens and Jackson, 1991) suggested to have a measurable impact on the oxygen isotope composition of tropospheric $\mathrm{CO}_{2}$.

A comprehensive understanding of the triple oxygen isotope composition of tropospheric $\mathrm{CO}_{2}$ requires the knowledge of the triple oxygen isotope fractionation between $\mathrm{CO}_{2}$ and water. The triple oxygen isotope fractionation is expressed in terms of $\alpha_{\mathrm{CO} 2-\text { water }}$ and $\theta_{\mathrm{CO} 2}$ water (Young et al., 2002) with:

$$
{ }^{17} \alpha_{\mathrm{CO}_{2} \text {-water }}=\frac{\left(\frac{{ }^{17} \mathrm{O}}{{ }^{16} \mathrm{O}}\right)_{\mathrm{CO}_{2}}}{\left(\frac{{ }^{17} \mathrm{O}}{{ }^{16} \mathrm{O}}\right)_{\text {water }}} \text { and }{ }^{18} \alpha_{\mathrm{CO}_{2} \text {-water }}=\frac{\left(\frac{{ }^{18} \mathrm{O}}{{ }^{16} \mathrm{O}}\right)_{\mathrm{CO}_{2}}}{\left(\frac{{ }^{18} \mathrm{O}}{{ }^{16} \mathrm{O}}\right)_{\text {water }}}
$$

The relationship between the fractionation factors ${ }^{17} \alpha$ and ${ }^{18} \alpha$ is given by a power law function that can be expressed as

$$
\ln { }^{17} \alpha_{\mathrm{CO}_{2} \text {-water }}=\theta_{\mathrm{CO}_{2} \text {-water }} \times \ln { }^{18} \alpha_{\mathrm{CO}_{2} \text {-water }}
$$

In the mass balance model for tropospheric $\mathrm{CO}_{2}$, Hoag et al. (2005) assume that the exponent $\theta$ for $\mathrm{CO}_{2}$-water equilibrium is equal to 0.516 without giving an explanation for the choice of their equilibrium $\theta$ value. However, the choice of $\theta_{\mathrm{CO} 2 \text {-water }}$ is crucial when modeling the triple oxygen isotope composition of tropospheric $\mathrm{CO}_{2}$ because of the large ${ }^{18} \mathrm{O} /{ }^{16} \mathrm{O}$ equilibrium fractionation between $\mathrm{CO}_{2}$ and water $\left(1000 \ln ^{18} \alpha \approx+41\right.$ at $\left.20{ }^{\circ} \mathrm{C}\right)$.

Improvements in measurement precision of triple oxygen isotope ratios in $\mathrm{CO}_{2}$ (Hofmann and Pack, 2010) provide the opportunity to determine experimentally the value $\theta_{\mathrm{CO} 2 \text {-water }}$ for equilibrium isotope exchange and to test if the triple oxygen isotope composition of tropospheric $\mathrm{CO}_{2}$ can be used as an additional tracer of bio-, hydro- and atmosphere interaction (Hoag et al., 2005).

Here, we present the first experimental data on the triple oxygen isotope fractionation factor $\theta$ for equilibrium isotope exchange between $\mathrm{CO}_{2}$ and water. 


\subsection{Methods}

\subsubsection{Definitions}

All oxygen isotope data on $\delta^{17} \mathrm{O}$ and $\delta^{18} \mathrm{O}$ are reported relative to VSMOW. The $\delta$ values are defined as:

$$
\delta^{17} O=\left[\frac{\left({ }^{17} \mathrm{O} /{ }^{16} O\right)_{\text {sample }}}{\left({ }^{17} \mathrm{O} /{ }^{16} \mathrm{O}\right)_{\text {VSMOW }}}-1\right] \text { and } \delta^{18} O=\left[\frac{\left({ }^{18} \mathrm{O} /{ }^{16} \mathrm{O}\right)_{\text {sample }}}{\left({ }^{18} \mathrm{O} /{ }^{16} \mathrm{O}\right)_{\text {VSMOW }}}-1\right]
$$

The $\delta^{\prime 17} \mathrm{O}$ and $\delta^{\prime 18} \mathrm{O}$ notation were introduced as the linearized version of the $\delta$-notation, with $\delta^{\prime 17} \mathrm{O}=\ln \left(\delta^{17} \mathrm{O}+1\right)$ and $\delta^{\prime 18} \mathrm{O}=\ln \left(\delta^{18} \mathrm{O}+1\right)$ (Hulston and Thode, 1965; Miller, 2002; Young et al., 2002). $\Delta^{17} \mathrm{O}_{\mathrm{TFL}}$ values denote deviations in $\delta^{17} \mathrm{O}$ from the terrestrial fractionation line (TFL) of the form $\delta^{\prime 17} \mathrm{O}=\lambda_{\mathrm{TFL}} \times \delta^{\prime 18} \mathrm{O}$. We are using the TFL as reference line because we are analyzing rocks. On the basis of $>700$ analyses of rocks and minerals, we determined a slope $\lambda_{\mathrm{TFL}}=0.5251 \pm 0.0014\left(\mathrm{t}_{0.95} \times \mathrm{SEM}\right)$. The slope $\lambda_{\mathrm{TFL}}$ is, within analytical uncertainty, identical to slopes reported for rocks and minerals in other studies (Kusakabe and Matsuhisa, 2008; Miller, 2002; Rumble et al., 2007). Literature data on MORB and NBS-28 suggest that the TFL passes through the origin within analytical uncertainty (Kusakabe and Matsuhisa, 2008; Robert et al., 1992), i.e. VSMOW falls on the TFL. Therefore, all $\Delta^{17} \mathrm{O}$ analyses were corrected relative to NBS-28 quartz with $\Delta^{17} \mathrm{O}_{\mathrm{TFL}}$ $=0 \%$. Errors of $\Delta^{17} \mathrm{O}$ are given as standard errors of the mean (SEM) multiplied by Student's $\mathrm{t}$ factor for a $95 \%$ confidence limit.

\subsubsection{Isotope exchange experiments between $\mathrm{CO}_{2}$ and water}

The $\mathrm{CO}_{2}$-water equilibration experiments were carried out at 2,23 and $37{ }^{\circ} \mathrm{C}$ within a bottle-shaped equilibration apparatus as shown in Fig. 3-1. The apparatus consists of a glass jar $(\sim 60 \mathrm{ml})$ for the water and a volume of about $350 \mathrm{ml}$ for the $\mathrm{CO}_{2}$ gas. The $\mathrm{CO}_{2}$ and the water can be separated using a ball valve. The apparatus can be connected to a vacuum system. During the equilibration process, the molar $\mathrm{H}_{2} \mathrm{O}_{(1)} / \mathrm{CO}_{2}$ ratio exceeds 200, so that the oxygen isotopic composition of the water largely controls the triple oxygen isotope ratios of the $\mathrm{CO}_{2}$. For the equilibration experiments, we used deionized tap water, which had been filled in a two-liter water tank, so that all experiments were conducted with isotopically identical water. The initial $\delta^{18} \mathrm{O}_{\text {VSMOW }}$ value of the $\mathrm{CO}_{2}$ gas varied between 15 and 28\%o. We tested attainment of isotopic equilibrium by performing a set of time-dependent $\delta^{18} \mathrm{O}$ analysis of equilibrated $\mathrm{CO}_{2}$. 


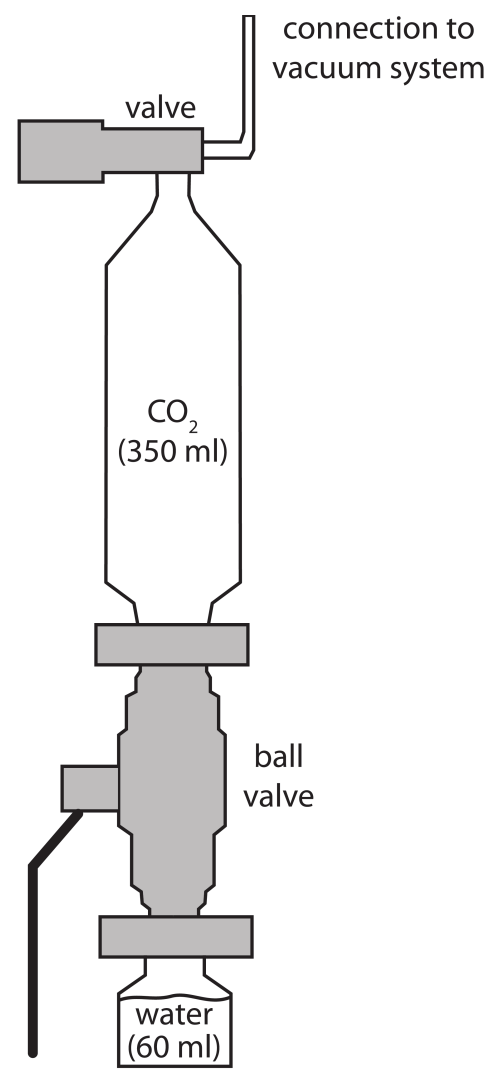

Fig. 3-1: The $\mathrm{CO}_{2}$-water equilibration apparatus.

The experiments were conducted according to the following procedure: We first filled the bottom reservoir with $60 \mathrm{ml}$ of water. The water was then frozen with liquid nitrogen. The freezing step took about $1 \mathrm{~h}$. Next, the apparatus was evacuated to $3 \times 10^{-3}$ mbar. We then closed the ball valve and expanded the $\mathrm{CO}_{2}$ into the top part of the apparatus. The $\mathrm{CO}_{2}$ pressure in the top part was $\sim 1$ bar in all experiments. Subsequent, we thawed the ice and brought the apparatus to the equilibration temperature. We then opened the ball valve to allow the $\mathrm{CO}_{2}$ to equilibrate with the water. The $2{ }^{\circ} \mathrm{C}$ experiments were conducted in a fridge with a temperature stability of $\pm 2{ }^{\circ} \mathrm{C}$. The $23{ }^{\circ} \mathrm{C}$ experiments were conducted in a temperature-controlled room with a stability of $\pm 2{ }^{\circ} \mathrm{C}$. The $37^{\circ} \mathrm{C}$ experiments were conducted in a drying oven with a stability of $\pm 3{ }^{\circ} \mathrm{C}$.

After equilibration, we closed the ball valve and isolated the $\mathrm{CO}_{2}$ from the water reservoir. The $\mathrm{CO}_{2}$ was isolated from water vapor and other gaseous impurities using a Russian doll type cryogenic trap (Brenninkmeijer, 1991; Brenninkmeijer and Röckmann, 1996). An important issue was that the $\mathrm{CO}_{2}$ had to be dried in order to avoid exchange of the sample $\mathrm{CO}_{2}$ with condensed water. Therefore, sample $\mathrm{CO}_{2}$ was passed through $\mathrm{Mg}\left(\mathrm{ClO}_{4}\right)_{2}$ before entering the cryogenic trap. For final drying, the $\mathrm{CO}_{2}$ gas was brought in contact with $\mathrm{P}_{2} \mathrm{O}_{5}$ as drying agent for about $30 \mathrm{~min}$. 


\subsubsection{Triple oxygen isotope analyses of $\mathrm{CO}_{2}$ and water}

The $\delta^{18} \mathrm{O}$ analyses of $\mathrm{CO}_{2}$ were carried out in dual inlet mode on a Finnigan Delta plus mass spectrometer. The $\delta^{18} \mathrm{O}$ values were standardized by comparison with $\mathrm{CO}_{2}$ generated by phosphoric acid decomposition of NBS-19 $\left(\delta^{18} \mathrm{O}_{\mathrm{VSMOW}}=+28.65 \% ; \delta^{13} \mathrm{C}_{\mathrm{PDB}}=+1.95 \%\right.$ ). The carbonate was reacted at $70{ }^{\circ} \mathrm{C}$ and the acid fractionation factor for calcite $\alpha_{\mathrm{CO} 2}$ calcite $=1.00871$ (Kim et al., 2007) was used. The mass spectrometric uncertainty in $\delta^{18} \mathrm{O}$ is in the range of $\pm 0.03 \%$ ( $(1 \sigma, \mathrm{SD})$.

The $\Delta^{17} \mathrm{O}$ analyses of $\mathrm{CO}_{2}$ were performed using a $\mathrm{CO}_{2}-\mathrm{CeO}_{2}$ equilibration technique (Hofmann and Pack, 2010). For this purpose, about $13 \mathrm{mmol}$ of $\mathrm{CO}_{2}$ was equilibrated with 6 to $10 \mathrm{mg} \mathrm{CeO}_{2}$ powder $(0.04-0.06 \mathrm{mmol})$ at $685^{\circ} \mathrm{C}$. Subsequently, the $\mathrm{CeO}_{2}$ was decomposed by infrared-laser fluorination and the liberated molecular oxygen was analyzed using a MAT 253 gas source mass spectrometer (details on the mass spectrometric analyses are given below). One analytical session generally contained 8-10 $\mathrm{CeO}_{2}$ samples (0.6-3 mg per sample) and 5-8 NBS-28 quartz reference samples $(0.2-1 \mathrm{mg}$ per sample). The $\delta^{18} \mathrm{O}$ and $\Delta^{17} \mathrm{O}$ analyses of $\mathrm{CeO}_{2}$ were corrected relative to NBS-28 quartz analyzed the same day $\left(\delta^{18} \mathrm{O}=+9.6 \%\right.$ (Dargie et al., 2007), $\Delta^{17} \mathrm{O}_{\mathrm{TFL}}=0 \%$ ). In this way, $\Delta^{17} \mathrm{O}$ analyses are recorded with high accuracy and precision relative to the TFL. The $\Delta{ }^{17} \mathrm{O}$ values of $\mathrm{CO}_{2}$ were inferred from the $\Delta^{17} \mathrm{O}$ values of $\mathrm{CeO}_{2}$, with $\Delta^{17} \mathrm{O}_{\mathrm{CO} 2}=$ $\Delta^{17} \mathrm{O}_{\mathrm{CeO} 2}+\left(\theta_{\mathrm{CO} 2-\mathrm{CeO} 2}-\lambda_{\mathrm{TFL}}\right) \times 1000 \ln { }^{18} \alpha_{\mathrm{CO} 2-\mathrm{CeO} 2}$, where ${ }^{18} \alpha_{\mathrm{CO} 2-\mathrm{CeO} 2}$ and $\theta_{\mathrm{CO} 2-\mathrm{CeO} 2}$ denote the fractionation factors for triple oxygen isotope exchange between $\mathrm{CO}_{2}$ and $\mathrm{CeO}_{2}(\mathrm{Hofmann}$ and Pack, 2010).

Recently, (Cao and Liu, 2011) pointed out that the triple oxygen isotope fractionation exponent $\theta_{\mathrm{CO} 2-\mathrm{CeO} 2}$ published by Hofmann and Pack (2010) deviates significantly from their theoretical estimate for $\mathrm{CO}_{2}-\mathrm{CeO}_{2}$ exchange at $685^{\circ} \mathrm{C}$. Thus, it is important to note that the fractionation factor ${ }^{18} \alpha_{\mathrm{CO} 2-\mathrm{CeO} 2}$ and the corresponding triple oxygen isotope fractionation exponent $\theta_{\mathrm{CO} 2-\mathrm{CeO} 2}$ given by Hofmann and Pack (2010) are steady-state values specific for the design of our apparatus and the experimental procedure. The temperature at the center of the equilibration tube, where the $\mathrm{CeO}_{2}$ is placed, is $685{ }^{\circ} \mathrm{C}$, whereas the two ends of the tube remain at room temperature. The thermal gradient within the tube leads to an isotope fractionation in the distribution of the $\mathrm{CO}_{2}$ molecules: Light $\mathrm{CO}_{2}$ isotopologues are enriched in the heated center part of the tube, whereas heavy $\mathrm{CO}_{2}$ isotopologues are enriched near the tube ends (see Jones and Furry, 1946 and references therein). The fractionation related to thermal diffusion affects the triple oxygen isotope composition of the $\mathrm{CO}_{2}$ that equilibrates with the $\mathrm{CeO}_{2}$ because the diffusion process most likely proceeds with a $\theta$ value of $\sim 0.509$ (Young et al., 2002). 
We redetermined the instrumental $\mathrm{CO}_{2}-\mathrm{CeO}_{2}$ fractionation for the design of our equilibration apparatus and obtained $1000 \ln { }^{18} \alpha_{\mathrm{CO} 2-\mathrm{CeO} 2}=11.7 \pm 1.5$ (SD) and $\theta_{\mathrm{CO} 2-}$ $\mathrm{CeO}_{2}=0.523 \pm 0.001$ (SD) for a $\mathrm{CO}_{2}$ pressure of $\sim 600 \mathrm{mbar}$ in the equilibration tube. For the calibration experiments, carbon dioxide with a known triple oxygen isotope composition was produced by combustion of carbon with $\mathrm{O}_{2}\left(\delta^{18} \mathrm{O}_{\text {VSMOW }}=13.473 \%\right.$ o, $\delta^{17} \mathrm{O}_{\text {VSMOW }}=$ $6.649 \%$ ) that was calibrated relative to VSMOW by E. Barkan (Institute of Earth Sciences, Hebrew University of Jerusalem). The current results on ${ }^{18} \alpha_{\mathrm{CO} 2-\mathrm{CeO} 2}$ and $\theta_{\mathrm{CO} 2-\mathrm{CeO} 2}$ confirm previous results reported in Hofmann and Pack (2010).

The triple oxygen isotope analyses on the released $\mathrm{O}_{2}$ were carried out on a Thermo MAT 253 mass spectrometer in continuous flow mode relative to an in-house reference $\mathrm{O}_{2}$ gas. The in-house reference $\mathrm{O}_{2}$ gas was calibrated relative to VSMOW by E. Barkan (Institute of Earth Sciences, Hebrew University of Jerusalem) with $\delta^{18} \mathrm{O}_{\text {VSMOW }}=+13.473 \%$ and $\delta^{17} \mathrm{O}_{\text {VSMOW }}=+6.649 \%$. The reference gas peaks were $15-25 \mathrm{~V}$ and the sample peaks 20 $30 \mathrm{~V}(\mathrm{~m} / \mathrm{z}=32)$ high. The analytical uncertainty of $\Delta^{17} \mathrm{O}$ for a single analysis is $\pm 0.05 \%$ $(1 \sigma, \mathrm{SD})$.

The triple oxygen isotope analyses of water were conducted by Amaelle Landais (Laboratoire des Sciences du Climat et de l'Environnement, Paris) using the $\mathrm{CoF}_{3}$ fluorination method coupled with dual inlet mass spectrometry of $\mathrm{O}_{2}$ (Baker et al., 2002; Barkan and Luz, 2005). The oxygen isotopic composition of the water was analyzed relative to a working standard that had been calibrated to VSMOW. The analytical uncertainty in $\delta^{18} \mathrm{O}$ and $\Delta^{17} \mathrm{O}$ is in the range of $\pm 0.05 \%$ (SD) and $\pm 0.006 \%$ (SD), respectively. A subsample of the water reservoir was analyzed before and after equilibration with $\mathrm{CO}_{2}$ in order to verify that the $\mathrm{CO}_{2}$-water equilibration process did not affect the isotopic composition of the water.

\subsection{Results}

First, we conducted three sets of time-dependent experiments at 2, 23 and $37{ }^{\circ} \mathrm{C}$ (Fig. 3-2). At $2{ }^{\circ} \mathrm{C}$, the $\delta^{18} \mathrm{O}$ value of equilibrated $\mathrm{CO}_{2}$ converges to a limit value of $+37.7 \%$ after $300 \mathrm{~h}$ of equilibration. This shows that isotopic equilibrium is reached within $300 \mathrm{~h}$. At 23 and $37{ }^{\circ} \mathrm{C}$, the equilibrium values of $+33.0 \%$ and $+30.0 \%$ are reached within $200 \mathrm{~h}$. In order to ensure that isotopic equilibrium is reached in the subsequent experiments, we have chosen equilibration times of $312 \mathrm{~h}$ at $2{ }^{\circ} \mathrm{C}$ and $216 \mathrm{~h}$ at 23 and $37^{\circ} \mathrm{C}$.

The triple oxygen isotope composition of equilibrated $\mathrm{CO}_{2}$ was analyzed for $12 \mathrm{CO}_{2}$-water equilibration experiments (Table 3-1). The $\Delta^{17} \mathrm{O}_{\mathrm{TFL}}$ value of the water-equilibrated $\mathrm{CO}_{2}$ 
was determined with high precision to be $-0.17 \pm 0.03 \%$ o $\left(\mathrm{t}_{0.95} \times \mathrm{SEM}\right)$ at $2{ }^{\circ} \mathrm{C},-0.08 \pm 0.02 \%$ o $\left(\mathrm{t}_{0.95} \times \mathrm{SEM}\right)$ at $23{ }^{\circ} \mathrm{C}$ and $-0.10 \pm 0.03 \%$ ( $\left.\mathrm{t}_{0.95} \times \mathrm{SEM}\right)$ at $37^{\circ} \mathrm{C}($ Fig. 3-3).

The deionized tap water had a $\delta^{18} \mathrm{O}$ value of $-8.52 \%$ and a $\Delta^{17} \mathrm{O}_{\mathrm{TFL}}$ value of $+0.010 \pm 0.006 \%$ prior to equilibration with $\mathrm{CO}_{2}$ (Fig. 3-3). Recalculating the triple oxygen isotope composition relative to the global meteoric water line (GMWL) with $\delta^{\prime 17} \mathrm{O}=0.528 \times \delta^{\prime 18} \mathrm{O}+0.033 \%$ (Luz and Barkan, 2010) gives $\Delta^{17} \mathrm{O}_{\mathrm{GMWL}}=+0.002 \pm 0.006 \%$, i.e. the deionized tap water falls on the GMWL suggesting that it inherits its triple oxygen isotope signature from local meteoric water. For one equilibration experiment (Table 3-1, no. 1), the water was also analyzed after equilibration with $\mathrm{CO}_{2}$ and these data indicate that the equilibration process did not affect the triple oxygen isotope composition of the water $\left(\delta^{18} \mathrm{O}=-8.44 \%\right.$ o, $\left.\Delta^{17} \mathrm{O}_{\mathrm{TFL}}=+0.019 \pm 0.006 \% 0\right)$.

Combining the oxygen isotope data of $\mathrm{CO}_{2}$ and water, $\theta_{\mathrm{CO} 2-\text { water }}$ is equal to $0.5211 \pm 0.0015$ $\left(\mathrm{t}_{0.95} \times \mathrm{SEM}\right)$ at $2{ }^{\circ} \mathrm{C}, \quad 0.5229 \pm 0.0015\left(\mathrm{t}_{0.95} \times \mathrm{SEM}\right)$ at $23{ }^{\circ} \mathrm{C}$ and $0.5223 \pm 0.0016$ $\left(\mathrm{t}_{0.95} \times \mathrm{SEM}\right)$ at $37^{\circ} \mathrm{C}$. The weighted mean of $\theta_{\mathrm{CO} 2 \text {-water }}$ is $0.522 \pm 0.002\left(\mathrm{t}_{0.95} \times \mathrm{SEM}\right)$ in the temperature range of 2 to $37^{\circ} \mathrm{C}$. In addition, we calculated the fractionation factor ${ }^{18} \alpha_{\mathrm{CO} 2}$ water for these equilibration experiments and found that $1000 \ln { }^{18} \alpha_{\mathrm{CO} 2 \text {-water }}$ is equal to $45.3 \pm 0.5(\mathrm{SD}), 41.2 \pm 0.8$ and $38.5 \pm 0.5$ at 2,23 and $37^{\circ} \mathrm{C}$. 


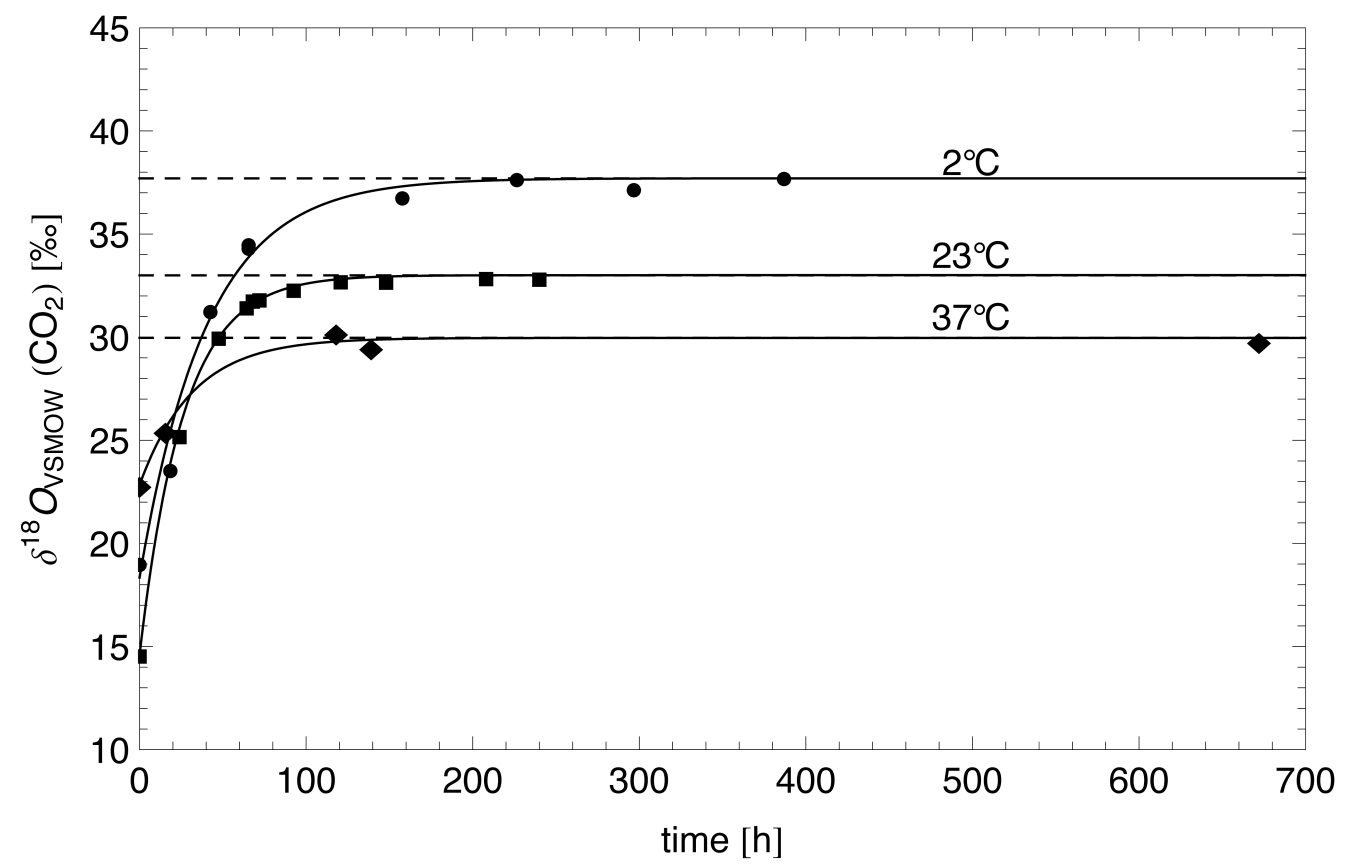

Fig. 3-2: Plot of $\delta^{18} \mathrm{O}$ of $\mathrm{CO}_{2}$ vs. equilibration time. Three sets of time-dependent equilibration experiments between $\mathrm{CO}_{2}$ and water $\left(\delta^{18} \mathrm{O}=-8.5 \%\right)$ at 2,23 and $37{ }^{\circ} \mathrm{C}$ show that the $\delta^{18} \mathrm{O}$ value of $\mathrm{CO}_{2}$ reaches a limit value for an equilibration time $>300 \mathrm{~h}$ at $2{ }^{\circ} \mathrm{C}$ and $>200 \mathrm{~h}$ at 23 and $37{ }^{\circ} \mathrm{C}$ indicating that isotopic equilibrium is reached.

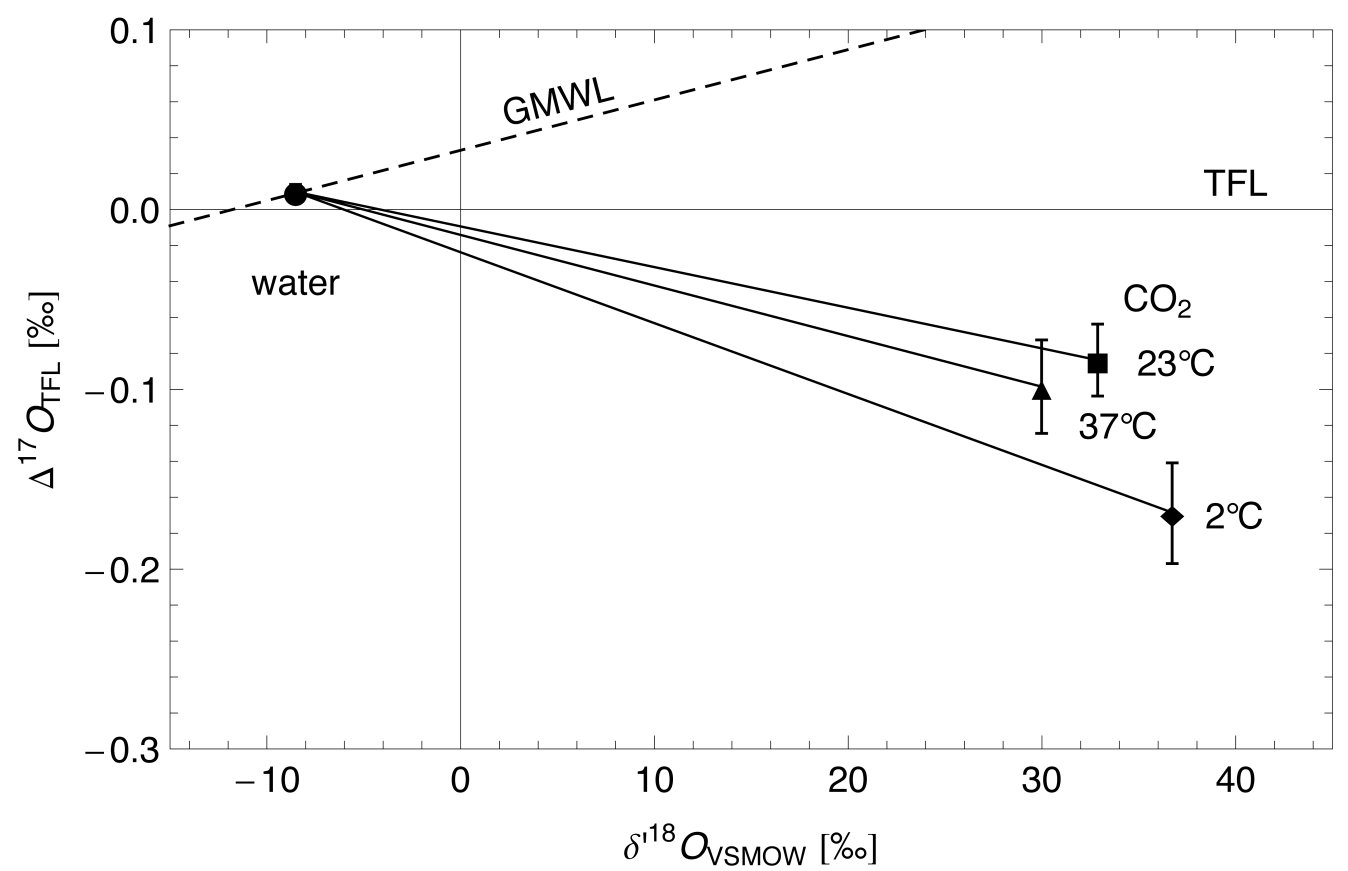

Fig. 3-3: Experimental determination of $\theta_{\mathrm{CO} 2 \text {-water. }}$ The diamond, square and triangle represent triple oxygen isotope data of $\mathrm{CO}_{2}$ equilibrated with water $(\bullet)$ at 2,23 and $37{ }^{\circ} \mathrm{C}$. Error bars represent the standard error of the mean multiplied by Student's t-factor for a $95 \%$ confidence limit. The dashed line illustrates the global meteoric water line (GMWL) determined by Luz and Barkan (2010). 
Table 3-1: Isotopic data of water equilibrated $\mathrm{CO}_{2}$ (12 equilibration experiments). The $\Delta^{17} \mathrm{O}$ analyses are based on a $\mathrm{CO}_{2}-\mathrm{CeO}_{2}$ equilibration technique (Hofmann and Pack, 2010). Subsequent to the $\mathrm{CO}_{2}-\mathrm{CeO}_{2}$ equilibration, the $\mathrm{CeO}_{2}$ is decomposed by infrared-laser fluorination and the liberated molecular oxygen is analyzed on a mass spectrometer. No systematic shift in $\delta^{18} \mathrm{O}$ of the $\mathrm{CO}_{2}$ was observed before and after equilibration with $\mathrm{CeO}_{2}$.

\begin{tabular}{|c|c|c|c|c|c|c|c|c|}
\hline \multirow[t]{2}{*}{ No. } & \multirow{2}{*}{\multicolumn{2}{|c|}{$\mathbf{T}\left[{ }^{\circ} \mathbf{C}\right]$}} & \multirow{2}{*}{$\begin{array}{l}\delta^{18} \mathbf{O}_{\mathrm{CeO} 2} \\
{[\% 0]}\end{array}$} & \multirow{2}{*}{$\begin{array}{l}\delta^{17} \mathbf{O}_{\mathrm{CeO} 2} \\
{[\% 0]}\end{array}$} & $\delta^{18} \mathbf{O}_{\mathrm{CO} 2}[\% 0]$ & $\delta^{18} \mathbf{O}_{\mathrm{CO} 2}[\% 0]$ & \multirow{2}{*}{$\begin{array}{l}\Delta^{17} \mathrm{O}_{\mathrm{CO} 2} \\
{[\% \text { o] }}\end{array}$} & \multirow[t]{2}{*}{$\theta_{\text {CO2-water }}$} \\
\hline & & & & & $\begin{array}{l}\text { (before } \mathrm{CeO}_{2} \\
\text { equilibration) }\end{array}$ & $\begin{array}{l}\text { (after } \mathrm{CeO}_{2} \\
\text { equilibration) }\end{array}$ & & \\
\hline \multirow[t]{5}{*}{1} & \multirow{5}{*}{\multicolumn{2}{|c|}{2}} & 27.325 & 14.096 & 38.6 & 37.4 & -0.18 & \\
\hline & & & 27.444 & 14.146 & & & -0.19 & \\
\hline & & & 27.781 & 14.28 & & & -0.24 & \\
\hline & & & 27.815 & 14.308 & & & -0.22 & \\
\hline & & & 27.851 & 14.34 & & & -0.21 & \\
\hline \multirow[t]{5}{*}{2} & \multirow{5}{*}{\multicolumn{2}{|c|}{2}} & 24.548 & 12.686 & 37.0 & 36.9 & -0.15 & \\
\hline & & & 24.558 & 12.686 & & & -0.16 & \\
\hline & & & 24.646 & 12.76 & & & -0.13 & \\
\hline & & & 24.477 & 12.575 & & & -0.23 & \\
\hline & & & 23.685 & 12.345 & & & -0.05 & \\
\hline \multirow[t]{5}{*}{3} & \multirow{5}{*}{\multicolumn{2}{|c|}{2}} & 24.439 & 12.68 & 37.2 & 37.2 & -0.10 & \\
\hline & & & 24.53 & 12.656 & & & -0.17 & \\
\hline & & & 23.762 & 12.247 & & & -0.18 & \\
\hline & & & 24.253 & 12.538 & & & -0.15 & \\
\hline & & & 24.376 & 12.595 & & & -0.16 & \\
\hline \multicolumn{3}{|c|}{ Aver. $\pm \mathrm{t}_{0.95} \times \mathrm{SEM}$} & & & & & $-0.17 \pm 0.03$ & $\begin{array}{l}0.5211 \\
\pm 0.0015\end{array}$ \\
\hline \multirow[t]{3}{*}{4} & \multirow{3}{*}{\multicolumn{2}{|c|}{23}} & 19.677 & 10.177 & 32.1 & - & -0.13 & \\
\hline & & & 19.708 & 10.173 & & & -0.15 & \\
\hline & & & 19.678 & 10.265 & & & -0.05 & \\
\hline \multirow[t]{4}{*}{5} & \multirow{4}{*}{\multicolumn{2}{|c|}{23}} & 20.997 & 10.926 & 33.5 & 34.2 & -0.07 & \\
\hline & & & 21.04 & 10.964 & & & -0.05 & \\
\hline & & & 20.822 & 10.843 & & & -0.06 & \\
\hline & & & 21.136 & 10.936 & & & -0.13 & \\
\hline \multirow[t]{3}{*}{6} & \multirow{3}{*}{\multicolumn{2}{|c|}{23}} & 20.495 & 10.643 & 32.5 & 32.5 & -0.09 & \\
\hline & & & 20.097 & 10.443 & & & -0.08 & \\
\hline & & & 20.204 & 10.516 & & & -0.07 & \\
\hline \multirow[t]{3}{*}{7} & & 23 & 20.184 & 10.428 & 34 & 33.4 & -0.14 & \\
\hline & & & 20.531 & 10.696 & & & -0.06 & \\
\hline & & & 20.509 & 10.707 & & & -0.04 & \\
\hline \multirow[t]{4}{*}{8} & & 23 & 21.623 & 11.241 & 33.7 & 33.6 & -0.08 & \\
\hline & & & 21.617 & 11.198 & & & -0.12 & \\
\hline & & & 21.652 & 11.294 & & & -0.04 & \\
\hline & & & 21.711 & 11.313 & & & -0.05 & \\
\hline \multicolumn{5}{|c|}{ Aver. $\pm \mathrm{t}_{0.95} \times \mathrm{SEM}$} & & & $\begin{array}{l}-0.08 \\
\pm 0.02\end{array}$ & $\begin{array}{l}0.5229 \\
\pm 0.0015\end{array}$ \\
\hline
\end{tabular}




\begin{tabular}{|c|c|c|c|c|c|c|c|}
\hline \multirow[t]{2}{*}{ No. } & \multirow[t]{2}{*}{$\mathbf{T}\left[{ }^{\circ} \mathbf{C}\right]$} & \multirow{2}{*}{$\begin{array}{l}\delta^{18} \mathrm{O}_{\mathrm{CeO} 2} \\
{[\% 0]}\end{array}$} & \multirow{2}{*}{$\begin{array}{l}\boldsymbol{\delta}^{17} \mathbf{O}_{\mathrm{CeO} 2} \\
{[\% 0]}\end{array}$} & $\delta^{18} \mathbf{O}_{\mathrm{CO} 2}[\% 0]$ & $\delta^{18} \mathbf{O}_{\mathrm{CO} 2}[\% 0]$ & \multirow{2}{*}{$\begin{array}{l}\Delta^{17} \mathbf{O}_{\mathrm{CO} 2} \\
{[\% 0]}\end{array}$} & \multirow[t]{2}{*}{$\theta_{\text {CO2-water }}$} \\
\hline & & & & $\begin{array}{l}\text { (before } \mathrm{CeO}_{2} \\
\text { equilibration) }\end{array}$ & $\begin{array}{l}\text { (after } \mathrm{CeO}_{2} \\
\text { equilibration) }\end{array}$ & & \\
\hline \multirow[t]{2}{*}{9} & 37 & 18.932 & 9.846 & 29.9 & 30 & -0.08 & \\
\hline & & 19.09 & 9.9 & & & -0.10 & \\
\hline \multirow[t]{4}{*}{10} & 37 & 16.607 & 8.546 & 30.6 & 30.7 & -0.16 & \\
\hline & & 16.712 & 8.684 & & & -0.08 & \\
\hline & & 16.702 & 8.646 & & & -0.11 & \\
\hline & & 16.633 & 8.628 & & & -0.10 & \\
\hline \multirow[t]{5}{*}{11} & 37 & 18.528 & 9.66 & 31.1 & 30.9 & -0.05 & \\
\hline & & 18.564 & 9.668 & & & -0.06 & \\
\hline & & 18.455 & 9.633 & & & -0.04 & \\
\hline & & 18.529 & 9.633 & & & -0.08 & \\
\hline & & 18.53 & 9.64 & & & -0.07 & \\
\hline \multirow[t]{3}{*}{12} & 37 & 21.483 & 11.04 & 30.3 & 30 & -0.21 & \\
\hline & & 21.413 & 11.097 & & & -0.11 & \\
\hline & & 21.65 & 11.219 & & & -0.12 & \\
\hline \multicolumn{2}{|c|}{ Aver. $\pm \mathrm{t}_{0.95} \times \mathrm{SEM}$} & & & & & $\begin{array}{l}-0.10 \\
\pm 0.03\end{array}$ & $\begin{array}{l}0.5223 \\
\pm 0.0016\end{array}$ \\
\hline
\end{tabular}




\subsection{Discussion}

\subsubsection{The triple oxygen isotope equilibrium fractionation exponent $\theta_{\mathrm{CO} \text {-water }}$ in the context of experimental and theoretical literature data}

Our results show that the equilibrium fractionation exponent $\theta$ for $\mathrm{CO}_{2}$-water exchange at low temperatures is significantly lower than the high-temperature limit of 0.530 (Cao and Liu, 2011; Young et al., 2002). We found that the equilibrium $\theta_{\mathrm{CO} 2 \text {-water }}$ value, within experimental uncertainty, is not temperature dependent in the temperature range between 2 and $37^{\circ} \mathrm{C}$, and thus, we suggest that $\mathrm{CO}_{2}$-water exchange in the bio-, hydro- and

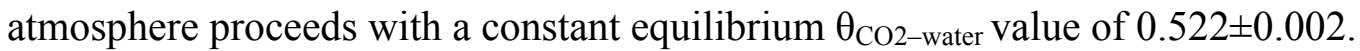

The fractionation in ${ }^{18} \mathrm{O} /{ }^{16} \mathrm{O}$ between $\mathrm{CO}_{2}$ and water agrees well with literature data (Brenninkmeijer et al., 1983; O'Neil and Adami, 1969), see Fig. 3-4. This confirms that we have reached isotopic equilibrium in our experiments.

In order to test internal agreement between published data and our result on $\theta_{\mathrm{CO} 2 \text {-water, we }}$ consider the relationship of $1000 \ln { }^{18} \alpha$ and $\theta$ for isotope exchange between $\mathrm{CO}_{2}$ gas, water vapor and water. In a $\Delta^{17} \mathrm{O}$ vs. $\delta^{\prime 18} \mathrm{O}$ plot, the equilibrium fractionation factors between these three phases must form a triangle as illustrated in Fig. 3-5. The temperaturedependent equilibrium fractionation factor $1000 \ln ^{18} \alpha$ is experimentally known for the systems $\mathrm{CO}_{2}$-water (e.g. Brenninkmeijer et al., 1983) and water-water vapor (Friedman and $\mathrm{O}^{\prime} \mathrm{Neil}, 1977$ ) and theoretically predicted for water vapor- $\mathrm{CO}_{2}$ exchange (Richet et al., 1977). Barkan and Luz (2005) experimentally determined the equilibrium $\theta$ value for water-water vapor exchange and Matsuhisa et al. (1978) theoretically estimated the exponent $\theta$ for $\mathrm{CO}_{2}$-water vapor equilibrium. Combining these literature data, we estimate that $\theta_{\mathrm{CO} 2 \text {-water }}$ should equal to 0.522 in the temperature range of 2 to $37^{\circ} \mathrm{C}$. The precision of this estimate is in the order of \pm 0.001 because it mainly depends on the uncertainty of the

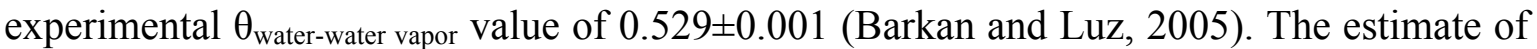
$\theta_{\mathrm{CO} 2-\text { water }}$ is in excellent agreement with our experimentally determined $\theta$ value of $0.522 \pm 0.002$.

Recently, Cao and Liu (2011) presented a data set on theoretical equilibrium $\theta$ values for oxygen isotope exchange. In Fig. 3-5, the light gray triangle illustrates their results on equilibrium $\theta$ values for the system $\mathrm{CO}_{2}$-water-water vapor. The difference between their theoretical equilibrium $\theta$ value for $\mathrm{CO}_{2}$-water vapor exchange and the previously published $\theta$ value from Matsuhisa et al. (1978) results from the calculation of the reduced partition function ratios of $\mathrm{CO}_{2}$. Matsuhisa et al. (1978) applied the 'rule of geometric 
mean', where one would assume that the difference in bond energy between ${ }^{18} \mathrm{O}-{ }^{18} \mathrm{O}$ and ${ }^{16} \mathrm{O}-{ }^{16} \mathrm{O}$ is twice than the difference in bond energy between ${ }^{18} \mathrm{O}-{ }^{16} \mathrm{O}$ and ${ }^{16} \mathrm{O}-{ }^{16} \mathrm{O}$ (Bigeleisen, 1955; Eiler, 2007). In contrast, Cao and Liu (2011) conclude that the 'rule of geometric mean' is not a valid assumption for the calculation of equilibrium $\theta$ values at low temperatures, and as a consequence, calculate slightly different reduced partition

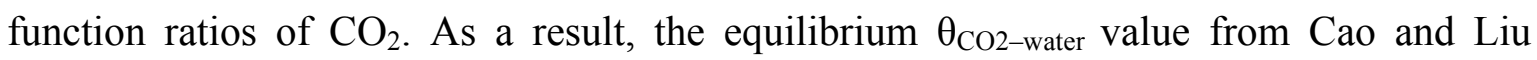
(2011) of $\sim 0.5245$ in the temperature range from 2 to $37^{\circ} \mathrm{C}$ is higher than what can be deduced from the reduced partition function ratios of carbon dioxide given by Matsuhisa et al. (1978). Our experimental value for $\theta_{\mathrm{CO} 2 \text {-water, however, suggests that the theoretical }}$ estimate by Cao and Liu (2011) is slightly too high. ${ }^{1}$

Theory suggests that equilibrium $\theta$ values at low temperatures show only a slight, if any temperature dependence (Cao and Liu, 2011; Matsuhisa et al., 1978). Cao and Liu (2011)

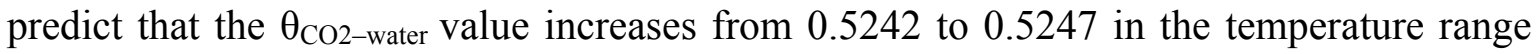
from 2 to $37{ }^{\circ} \mathrm{C}$ as shown in Fig. 3-6. Our experimental data on the $\theta_{\mathrm{CO} 2 \text {-water value cannot }}$ resolve this small temperature dependence. For water-water vapor exchange, the experimental and theoretical equilibrium $\theta$ values do not show any temperature dependence at low temperatures, but coincide with the high temperature limit of 0.530 (Barkan and Luz, 2005; Cao and Liu, 2011), see Fig. 3-6.

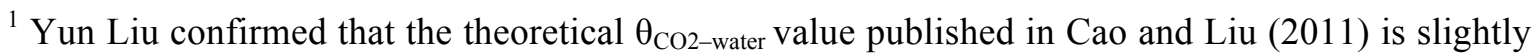
too high and he calculated a revised $\theta_{\mathrm{CO} 2 \text {-water }}$ value of 0.523 at $25{ }^{\circ} \mathrm{C}$ (Y. Liu, pers. comm.).
} 


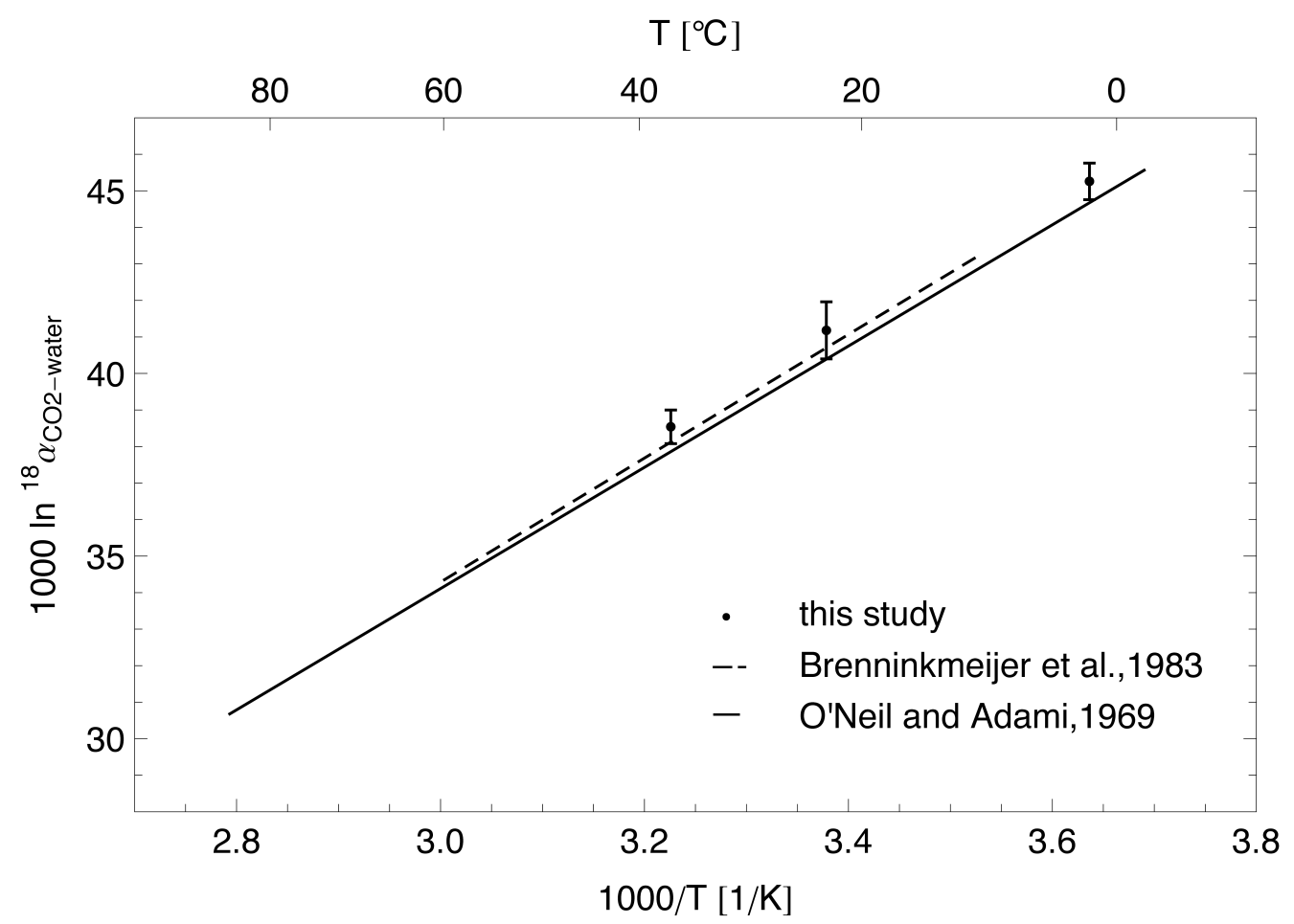

Fig. 3-4: Experimental determination of the fractionation factor $1000 \ln { }^{18} \alpha_{\mathrm{CO} 2 \text {-water. The }}$ fractionation factor ${ }^{18} \alpha$ determined in this study for 2,23 and $37{ }^{\circ} \mathrm{C}$ agrees well with literature data on $\mathrm{CO}_{2}$-water isotope exchange (Brenninkmeijer et al., 1983; O'Neil and Adami, 1969). Error bars denote the standard deviation. 


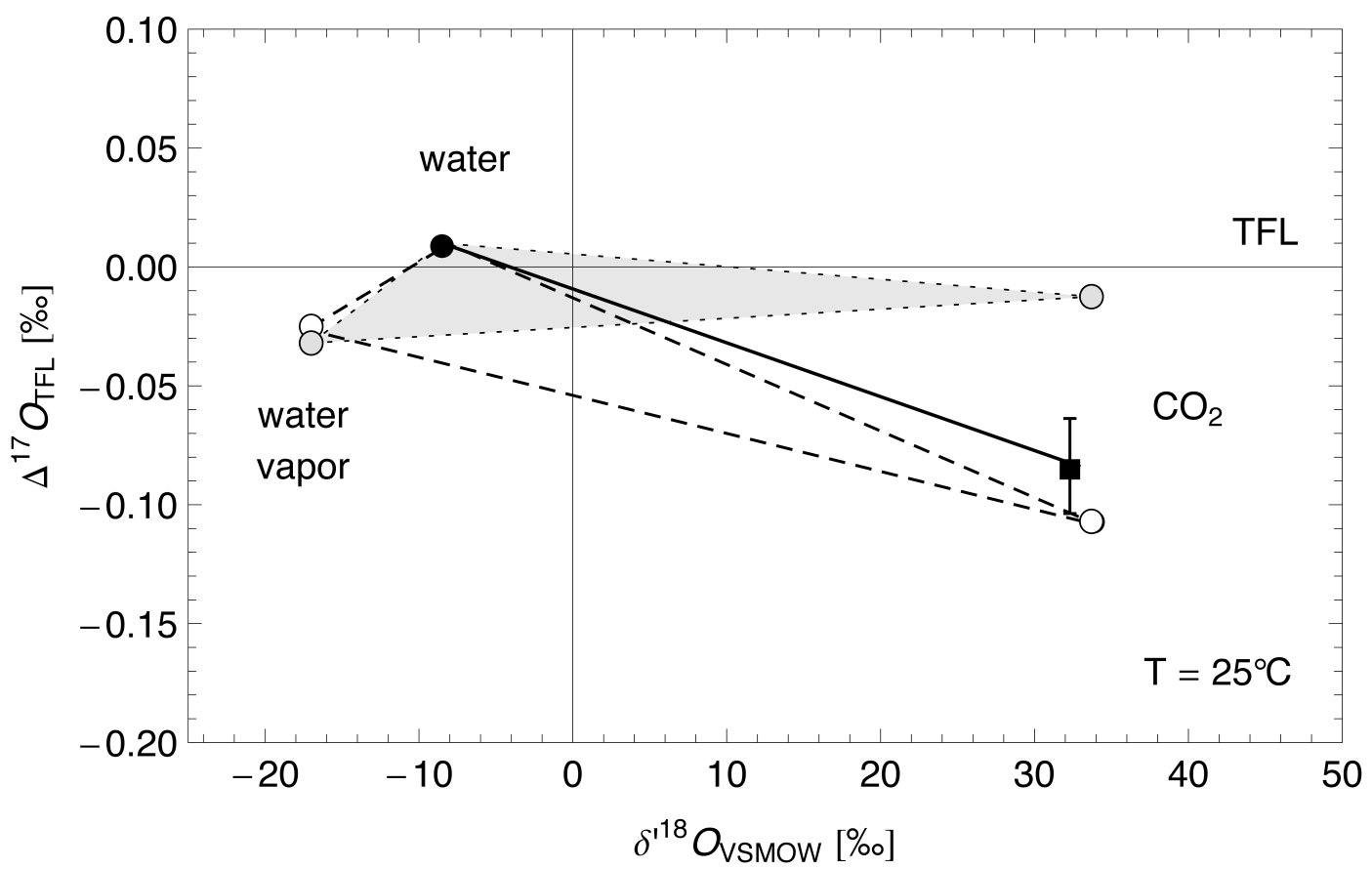

Fig. 3-5: Illustration of the equilibrium fractionation factors $1000 \ln { }^{18} \alpha$ and $\theta$ between $\mathrm{CO}_{2}$ gas, water vapor and water at $25{ }^{\circ} \mathrm{C}$. In a $\Delta^{17} \mathrm{O}$ vs. $\delta^{\prime 18} \mathrm{O}$ plot, the equilibrium fractionation factors between the three phases must form a triangle. Such a triangle can be used to test internal agreement between published data. Our experimental data on the triple oxygen isotope equilibrium fractionation between $\mathrm{CO}_{2}$ and water are illustrated as a black line. The dashed triangle is based on compiled experimental and theoretical literature data: the fractionation factor ${ }^{18} \alpha_{\mathrm{CO} 2 \text {-water }}$ was taken from Brenninkmeijer et al. (1983), the fractionation factor ${ }^{18} \alpha_{\text {water-water vapor }}$ was taken from Friedman

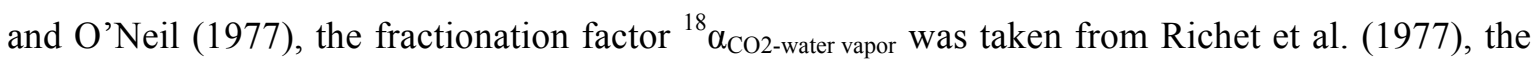

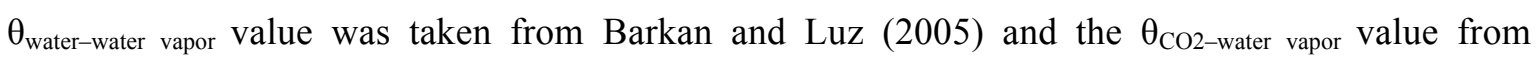
Matsuhisa et al. (1978). From these literature data one can estimate a $\theta_{\mathrm{CO} 2 \text {-water value }}$ of $0.522 \pm 0.001$ $\left(2{ }^{\circ} \mathrm{C} \leq \mathrm{T} \leq 37{ }^{\circ} \mathrm{C}\right)$. The dotted, light gray triangle illustrates theoretical equilibrium fractionation factors from Cao and Liu (2011). Our data on water equilibrated $\mathrm{CO}_{2}$ at $25^{\circ} \mathrm{C}$ are consistent with theoretical data from Matsuhisa et al. (1978), but there is a slight discrepancy between our experimental $\theta_{\mathrm{CO} 2 \text {-water }}$ value and the theoretical estimate from Cao and Liu (2011). 


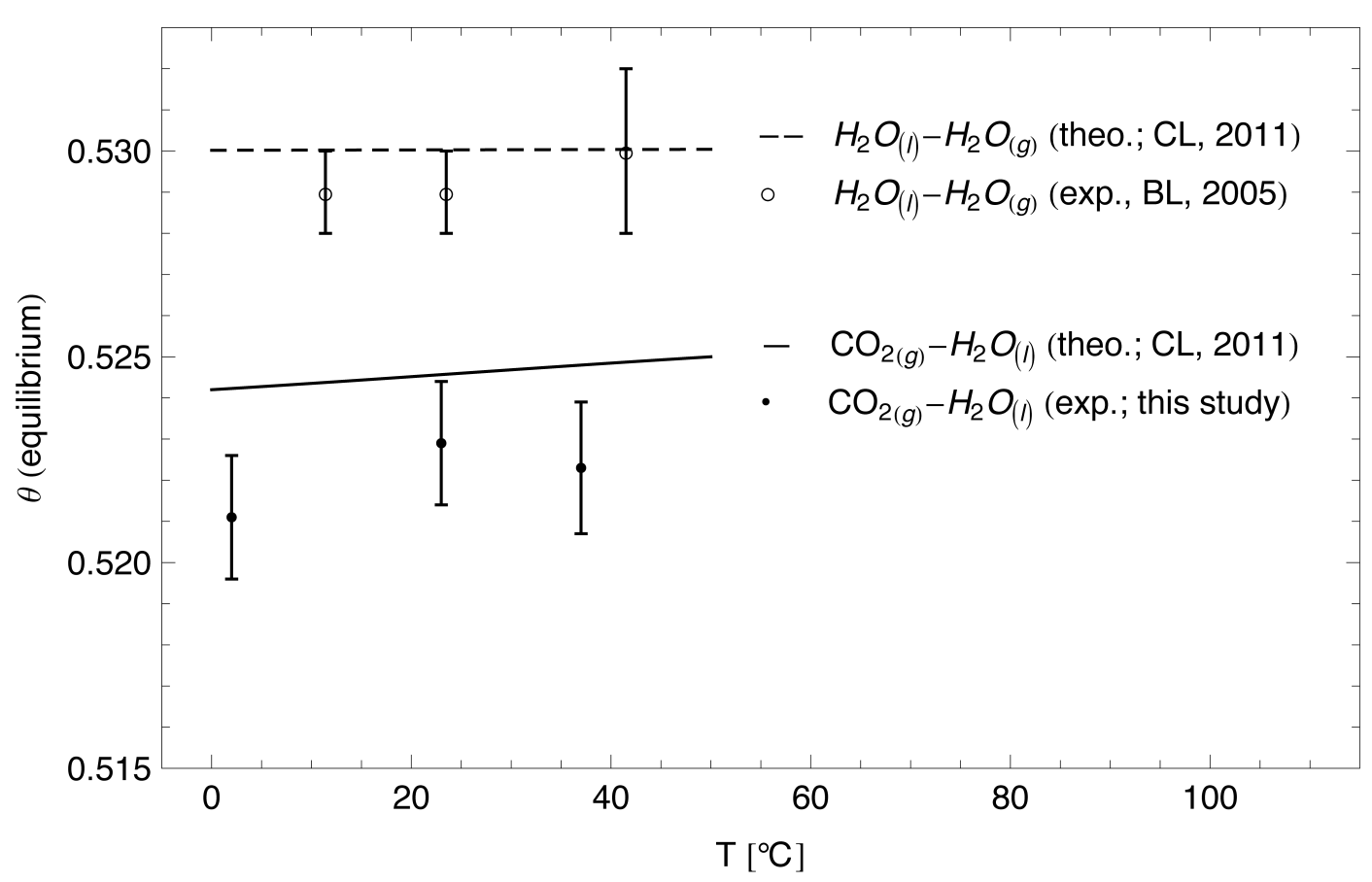

Fig. 3-6: Comparison of experimental and theoretical equilibrium $\theta$ values for water-water vapor and $\mathrm{CO}_{2}$-water exchange at low temperatures. The theoretical $\theta$ value for water-water vapor exchange from Cao and Liu (2011) agrees well with experimental data from Barkan and Luz (2005). However, the theoretical $\theta$ value for $\mathrm{CO}_{2}$-water exchange from Cao and Liu (2011) is slightly higher than experimental data determined in this study. Error bars denote the standard error of the mean multiplied by Student's t-factor for a $95 \%$ confidence limit.

\subsubsection{Relevance of the $\theta_{\mathrm{CO} 2 \text {-water }}$ value for the identification of major $\mathrm{CO}_{2}$ sources to the troposphere}

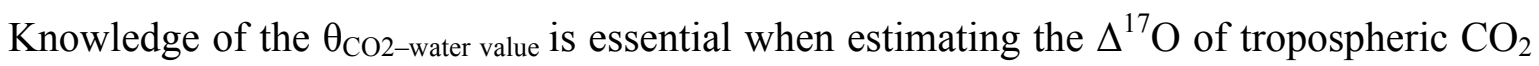
(Hoag et al., 2005). This is because the triple oxygen isotope composition of tropospheric $\mathrm{CO}_{2}$ is largely controlled by isotope exchange with water in the bio- and hydrosphere.

The main exchange reservoirs for tropospheric $\mathrm{CO}_{2}$ are land plants (leaf water), soil water and the ocean surface waters. For leaf and ocean water exchange, an equilibrium fractionation exponent of $\theta_{\mathrm{CO} 2-\text { water }}=0.522$ is relevant. This value deviates significantly from the previously assumed $\theta_{\mathrm{CO} 2-\text { water }}$ value of 0.516 (Hoag et al., 2005). For carbon dioxide emissions from soils, both equilibrium and kinetic fractionation play a role (Miller et al., 1999a); requiring a more complex model for understanding the $\Delta^{17} \mathrm{O}$ of soil $\mathrm{CO}_{2}$.

Isotope exchange between $\mathrm{CO}_{2}$ and water in leaves and soils is catalyzed by the enzyme carbonic anhydrase (Gillon and Yakir, 2001; Gillon and Yakir, 2000; Seibt et al., 2006; Wingate et al., 2009). The influence of carbonic anhydrase on the $\theta_{\mathrm{CO} 2 \text {-water value is not }}$ 
known. But as carbonic anhydrase has no influence on the ${ }^{18} \mathrm{O} /{ }^{16} \mathrm{O}$ fractionation, we suggest that it also does not have an influence on the ${ }^{17} \mathrm{O} /{ }^{16} \mathrm{O}$ fractionation, i.e. the $\theta_{\mathrm{CO} 2}$ water. It is part of an ongoing study to verify this assumption.

To assess the potential of $\Delta^{17} \mathrm{O}$ of tropospheric $\mathrm{CO}_{2}$ as a tracer for the global carbon cycle, comprehensive model predictions on the $\Delta^{17} \mathrm{O}$ value of tropospheric $\mathrm{CO}_{2}$ should refine the model predictions from Hoag et al. (2005). We suggest that these model predictions should implement the experimentally determined equilibrium $\theta$ value for $\mathrm{CO}_{2}$-water exchange. In doing so, the models could investigate both the gross carbon exchange between the bioand hydrosphere and the influx of mass-independently fractionated $\mathrm{CO}_{2}$ from the stratosphere to the troposphere more precisely.

\subsection{Acknowledgment}

We thank A. Landais for analyzing the triple oxygen isotope composition of our water samples and we thank E. Barkan for the calibration of our inhouse reference $\mathrm{O}_{2}$ gas relative to VSMOW. We also thank two anonymous reviewers for helpful comments. This study was funded by the German Science Foundation (AP, project PA909/6-1, PA909/62). 


\subsection{References}

Baker, L., Franchi, I. A., Maynard, J., Wright, I. P., Pillinger, C. T., 2002. A technique for the determination of ${ }^{18} \mathrm{O} /{ }^{16} \mathrm{O}$ and ${ }^{17} \mathrm{O} /{ }^{16} \mathrm{O}$ isotopic ratios in water from small liquid and solid samples. Anal. Chem. 74, 1665-1673.

Barkan, E., Luz, B., 2005. High precision measurements of ${ }^{17} \mathrm{O} /{ }^{16} \mathrm{O}$ and ${ }^{18} \mathrm{O} /{ }^{16} \mathrm{O}$ ratios in $\mathrm{H}_{2} \mathrm{O}$. Rapid Commun. Mass Spec. 19, 3737-3742.

Bigeleisen, J., 1955. Statistical mechanics of isotopic systems with small quantum corrections. I. General considerations and the rule of the geometric mean. J. Chem. Phys. 23, 2264-2267.

Brenninkmeijer, C. A. M., 1991. Robust, high-efficiency, high-capacity cryogenic trap. Anal. Chem. 63, 1182-1184.

Brenninkmeijer, C. A. M., Kraft, P., Mook, W. G., 1983. Oxygen isotope fractionation between $\mathrm{CO}_{2}$ and $\mathrm{H}_{2} \mathrm{O}$. Isot. Geosci. 1, 181-190.

Brenninkmeijer, C. A. M., Röckmann, T., 1996. Russian doll type cryogenic traps: improved design and isotope separation effects. Anal. Chem. 68, 3050-3053.

Cao, X., Liu, Y., 2011. Equilibrium mass-dependent fractionation relationships for triple oxygen isotopes. Geochim. Cosmochim. Acta 75, 7435-7445.

Ciais, P., Denning, A. S., Tans, P. P., Berry, J. A., Randall, D., Collatz, J. G., Sellers, P. J., White, J. W., Trolier, M., Meijer, H. A. J., Francey, R. J., Monfray, P., Heimann, M., 1997. A three-dimensional synthesis study of $\delta^{18} \mathrm{O}$ in atmospheric $\mathrm{CO}_{2}$ : Part 1 Surface fluxes. J. Geophys. Res. 102, 5857-5872.

Dargie, M., Winckler, G., Gröning, M., 2007. Reference sheet for reference materials. International Atomic Energy Agency (IAEA), Vienna.

Eiler, J. M., 2007. "Clumped-isotope" geochemistry - The study of naturally-occurring, multiply-substituted isotopologues. Earth Planet. Sci. Lett. 262, 309-327.

Farquhar, G. D., Lloyd, J., Taylor, J. A., Flanagan, L. B., Syvertsen, J. P., Hubick, K. T., Wong, S. C., Ehleringer, J. R., 1993. Vegetation effects on the isotope composition of oxygen in atmospheric $\mathrm{CO}_{2}$. Nature 363, 439-443.

Francey, R. J., Tans, P. P., 1987. Latitudinal variation in oxygen-18 of atmospheric $\mathrm{CO}_{2}$. Nature 327, 495-497.

Friedli, H., Siegenthaler, U., Rauber, D., Oeschger, H., 1987. Measurements of concentration, ${ }^{13} \mathrm{C} /{ }^{12} \mathrm{C}$ and ${ }^{18} \mathrm{O} /{ }^{16} \mathrm{O}$ ratios of tropospheric carbon dioxide over Switzerland. Tellus B 39B, 80-88. 
Friedman, I., O'Neil, J. R., 1977. Compilation of stable isotope fractionation factors of geochemical interest. U.S. Geological Survey Prof. Paper 440-KK.

Gillon, J., Yakir, D., 2001. Influence of carbonic anhydrase activity in terrestrial vegetation on the ${ }^{18} \mathrm{O}$ content of atmospheric $\mathrm{CO}_{2}$. Science 291, 2584-2587.

Gillon, J. S., Yakir, D., 2000. Naturally low carbonic anhydrase activity in $\mathrm{C}_{4}$ and $\mathrm{C}_{3}$ plants limits discrimination against $\mathrm{C}^{18} \mathrm{OO}$ during photosynthesis. Plant Cell Environ. 23, 903-915.

Hoag, K. J., Still, C. J., Fung, I. Y., Boering, K. A., 2005. Triple oxygen isotope composition of tropospheric carbon dioxide as a tracer of terrestrial gross carbon fluxes. Geophys. Res. Lett. 32, 1-5.

Hofmann, M. E. G., Pack, A., 2010. Technique for high-precision analysis of triple oxygen isotope ratios in carbon dioxide. Anal. Chem. 82, 4357-4361.

Hulston, J. R., Thode, H. G., 1965. Variations in the $\mathrm{S}^{33}, \mathrm{~S}^{34}$, and $\mathrm{S}^{36}$ contents of meteorites and their relation to chemical and nuclear effects. J. Geophys. Res. 70, 3475-3484.

Jones, R. C., Furry, W. H., 1946. The separation of isotopes by thermal diffusion. Rev. Mod. Phys. 18, 151-224.

Kim, S.-T., Mucci, A., Taylor, B. E., 2007. Phosphoric acid fractionation factors for calcite and aragonite between 25 and $75^{\circ} \mathrm{C}$ : Revisited. Chem. Geol. 246, 135-146.

Kusakabe, M., Matsuhisa, Y., 2008. Oxygen three-isotope ratios of silicate reference materials determined by direct comparison with VSMOW-oxygen. Geochem. J. 42, 309-317.

Lämmerzahl, P., Röckmann, T., Brenninkmeijer, C. A. M., Krankowsky, D., Mauersberger, K., 2002. Oxygen isotope composition of stratospheric carbon dioxide. Geophys. Res. Lett. 29, 1582.

Luz, B., Barkan, E., 2010. Variations of ${ }^{17} \mathrm{O} /{ }^{16} \mathrm{O}$ and ${ }^{18} \mathrm{O} /{ }^{16} \mathrm{O}$ in meteoric waters. Geochim. Cosmochim. Acta 74, 6276-6286.

Matsuhisa, Y., Goldsmith, J. R., Clayton, R. N., 1978. Mechanisms of hydrothermal crystallization of quartz at $250^{\circ} \mathrm{C}$ and $15 \mathrm{kbar}$. Geochim. Cosmochim. Acta $42,173-$ 182.

Miller, J. B., Yakir, D., White, J. W. C., Tans, P. P., 1999a. Measurement of ${ }^{18} \mathrm{O} /{ }^{16} \mathrm{O}$ in the soil-atmosphere $\mathrm{CO}_{2}$ flux. Global Biogeochem. Cy. 13, 761-774.

Miller, M. F., 2002. Isotopic fractionation and the quantification of ${ }^{17} \mathrm{O}$ anomalies in the oxygen three-isotope system: an appraisal and geochemical significance. Geochim. Cosmochim. Acta 66, 1881-1889. 
O'Neil, J. R., Adami, L. H., 1969. Oxygen isotope partition function ratio of water and the structure of liquid water. J. Phys. Chem. 73, 1553-1558.

Richet, P., Bottinga, Y., Javoy, M., 1977. A review of hydrogen, carbon, nitrogen, oxygen, sulphur, and chlorine stable isotope fractionation among gaseous molecules. Annu. Rev. Earth Planet. Sci. 5, 65-110.

Robert, F., Rejou-Michel, A., Javoy, M., 1992. Oxygen isotopic homogeneity of the Earth: new evidence. Earth Planet. Sci. Lett. 108, 1-9.

Rumble, D., Miller, M. F., Franchi, I. A., Greenwood, R. C., 2007. Oxygen three-isotope fractionation lines in terrestrial silicate minerals: An inter-laboratory comparison of hydrothermal quartz and eclogitic garnet. Geochim. Cosmochim. Acta 71, 35923600 .

Seibt, U., Wingate, L., Lloyd, J., Berry, J. A., 2006. Diurnally variable $\delta^{18} \mathrm{O}$ signatures of soil $\mathrm{CO}_{2}$ fluxes indicate carbonic anhydrase activity in a forest soil. J. Geophys. Res. 111, G04005.

Thiemens, M., Jackson, T., Brenninkmeijer, C. A. M., 1995a. Observation of a mass independent oxygen isotopic composition in terrestrial stratospheric $\mathrm{CO}_{2}$, the link to ozone chemistry, and the possible occurrence in the Martian atmosphere. Geophys. Res. Lett. 22, 255-257.

Thiemens, M. H., Jackson, T., 1991. Oxygen isotope fractionation in stratospheric $\mathrm{CO}_{2}$. Geophys. Res. Lett. 18, 669-672.

Wingate, L., Ogée, J., Cuntz, M., Genty, B., Reiter, I., Seibt, U., Yakir, D., Maseyk, K., Pendall, E. G., Barbour, M. M., Mortazavi, B., Burlett, R. g., Peylin, P., Miller, J., Mencuccini, M., Shim, J. H., Hunt, J., Grace, J., 2009. The impact of soil microorganisms on the global budget of $\delta^{18} \mathrm{O}$ in atmospheric $\mathrm{CO}_{2}$. Proc. Natl. Acad. Sci. 106, 22411-22415.

Yakir, D., Wang, X. F., 1996. Fluxes of $\mathrm{CO}_{2}$ and water between terrestrial vegetation and the atmosphere estimated from isotope measurements. Nature 380, 515-517.

Young, E. D., Galy, A., Nagahara, H., 2002. Kinetic and equilibrium mass-dependent isotope fractionation laws in nature and their geochemical and cosmochemical significance. Geochim. Cosmochim. Acta 66, 1095-1104. 


\title{
4 On the triple oxygen isotope composition of carbon dioxide from some combustion processes
}

\author{
Horváth, B., Hofmann, M.E.G. and Pack, A., \\ On the triple oxygen isotope composition of carbon dioxide from some combustion \\ processes, Geochim. Cosmochim. Acta, in press.
}

\subsection{Abstract}

The triple oxygen isotope composition $\left(\Delta^{17} \mathrm{O}\right)$ of $\mathrm{CO}_{2}$ from different sources is gaining in importance as possible tracer of gross carbon exchanges between major reservoirs. Here we present the $\Delta^{17} \mathrm{O}$ of $\mathrm{CO}_{2}$ from natural gas and propane-butane combustion, wood chips burning, car exhaust and human breath. All investigated $\mathrm{CO}_{2}$ samples had negative $\Delta^{17} \mathrm{O}$ value compared to the $\mathrm{CO}_{2}$-water equilibration line (slope $\theta=0.522$; zero intercept), which was inherited from the oxidant air $\mathrm{O}_{2}$. However, for all combustion experiments, the $\Delta{ }^{17} \mathrm{O}$ value of $\mathrm{CO}_{2}$ was significantly higher than the $\Delta^{17} \mathrm{O}$ value of air $\mathrm{O}_{2}$. The oxygen isotope composition of $\mathrm{CO}_{2}$ from natural gas $\left(\delta^{18} \mathrm{O}=21.6 \pm 0.7 \%\right.$; $\Delta^{17} \mathrm{O}=-0.30 \pm 0.02 \%$ ) and from propane-butane $\left(\delta^{18} \mathrm{O}=22.5 \pm 0.8 \%\right.$; $\Delta^{17} \mathrm{O}=-0.32 \pm 0.02 \%$ ) combustion is explained by kinetic fractionation of ambient air $\mathrm{O}_{2}$. In case of wood chips burning $\left(\delta^{18} \mathrm{O}=19.4 \pm 1.0 \% ; \Delta^{17} \mathrm{O}=-0.21 \pm 0.02 \%\right.$ o $)$ the wood inherent $\mathrm{O}$ also affected the triple oxygen isotope composition of the $\mathrm{CO}_{2}$. Car exhaust $\mathrm{CO}_{2} \quad\left(\delta^{18} \mathrm{O}=32.6 \pm 3.0 \%\right.$; $\Delta \Delta^{17} \mathrm{O}=-0.32 \pm 0.03 \%$ ) might have likely equilibrated with the condensed water in the exhaust line. The isotope composition of breath $\mathrm{CO}_{2} \quad\left(\delta^{18} \mathrm{O}=35.1 \pm 1.0 \%\right.$; $\Delta^{17} \mathrm{O}=-0.03 \pm 0.03 \%$ ) was controlled by equilibration with body water. We assess the $\Delta^{17} \mathrm{O}$ value of $\mathrm{CO}_{2}$ as a potential tracer for anthropogenic $\mathrm{CO}_{2}$ emission.

\subsection{Introduction}

In order to predict possible consequences of anthropogenic carbon dioxide $\left(\mathrm{CO}_{2}\right)$ emissions it is important to understand the global carbon cycle. One powerful tool for investigating the interactions between the major carbon reservoirs (geosphere, hydrosphere, biosphere) is the stable isotope geochemistry. The ${ }^{13} \mathrm{C} /{ }^{12} \mathrm{C}$ and ${ }^{18} \mathrm{O} /{ }^{16} \mathrm{O}$ isotope ratios of tropospheric $\mathrm{CO}_{2}$ are established tracers in studies on the global carbon cycles (e.g. Cuntz et al., 2003b; Francey and Tans, 1987; Gruber, 2001; Keeling, 1958; Keeling, 1961). 
The carbon isotope composition of atmospheric $\mathrm{CO}_{2}$ (expressed in form of the $\delta^{13} \mathrm{C}$ value, see section 4.3) gives information on the net carbon exchange between atmosphere and biosphere (e.g. Ciais et al., 1995). The oxygen isotope composition of tropospheric $\mathrm{CO}_{2}$ (expressed as $\delta^{18} \mathrm{O}$ for the ${ }^{18} \mathrm{O} /{ }^{16} \mathrm{O}$ ratio) is controlled by isotope exchange with different water reservoirs; namely leaf, soil and surface water (e.g. Francey and Tans, 1987). The $\delta^{18} \mathrm{O}$ value of $\mathrm{CO}_{2}$ that has equilibrated with leaf water is different from the $\delta^{18} \mathrm{O}$ of $\mathrm{CO}_{2}$ that has equilibrated with soil water (e.g. Cuntz et al., 2003b). Thus, the $\delta^{18} \mathrm{O}$ value of tropospheric $\mathrm{CO}_{2}$ can be used as a tracer for the gross flux of carbon between troposphere and biosphere (e.g. Ciais et al., 1997; Farquhar et al., 1993).

Hoag et al. (2005) suggested that the triple oxygen isotope composition of $\mathrm{CO}_{2}$ (expressed in form of $\Delta^{17} \mathrm{O}$, which is the deviation in $\delta^{17} \mathrm{O}$ from a reference line; for definition see section 4.3) provides a more robust tracer for the global carbon cycle than $\delta^{18} \mathrm{O}$ alone. The $\Delta{ }^{17} \mathrm{O}$ value of tropospheric $\mathrm{CO}_{2}$ is controlled by the influx of stratospheric $\mathrm{CO}_{2}$ with a large $\Delta^{17} \mathrm{O}$ excess and resetting of the $\Delta^{17} \mathrm{O}$ excess by exchange with water in oceans, in soil and most importantly in leaves. Assuming a constant flux and a constant $\Delta^{17} \mathrm{O}$ value of stratospheric $\mathrm{CO}_{2}$ and a constant exchange with ocean water, the $\Delta^{17} \mathrm{O}$ value of tropospheric $\mathrm{CO}_{2}$ has been suggested as a tracer for global primary production (Hoag et al., 2005).

Apart from stratospheric $\mathrm{CO}_{2}$, the $\mathrm{CO}_{2}$ from the combustion of fossil and modern organic matter (fossil fuels, wood) is likely also a source of $\mathrm{CO}_{2}$ with non-zero $\Delta^{17} \mathrm{O}$. Hoag et al. (2005) proposed that $\mathrm{CO}_{2}$ from combustion is another source of "anomalous" oxygen with a deficit in ${ }^{17} \mathrm{O}$. The deficit is thought to be inherited from tropospheric $\mathrm{O}_{2}$, which carries a negative $\Delta^{17} \mathrm{O}$ value (Barkan and Luz, 2005; Pack et al., 2007). It is hypothesized that during combustion, the anomaly is transferred from the $\mathrm{O}_{2}$ to $\mathrm{CO}_{2}$ making combustion $\mathrm{CO}_{2}$ clearly distinguishable from ambient background $\mathrm{CO}_{2}$. According to Hoag et al. (2005) "anomalous" $\mathrm{CO}_{2}$ from anthropogenic sources has little effect on a global scale, but can be an important source in urban regions (Newman et al., 2008; Pataki et al., 2007; Widory and Javoy, 2003; Yanes and Yapp, 2010).

The ${ }^{13} \mathrm{C} /{ }^{12} \mathrm{C}$ and ${ }^{18} \mathrm{O} /{ }^{16} \mathrm{O}$ ratios of $\mathrm{CO}_{2}$ alone are insufficient for unambiguous determination of different fluxes (e.g. Demény and Haszpra, 2002; Djuricin, 2010). For example, $\mathrm{CO}_{2}$ from soil respiration has a similar $\delta^{13} \mathrm{C}$ value to $\mathrm{CO}_{2}$ from fossil fuel combustion. Other tracers were also tested. Levin et al. (2003) successfully applied cost intensive ${ }^{14} \mathrm{C}$ analyses for determination of the mixing ratio of $\mathrm{CO}_{2}$ from fossil fuel 
combustion. In a promising approach, Affek et al. (2007) suggested using the mass-47 anomaly of $\mathrm{CO}_{2}\left(\Delta_{47}\right)$ for tracing combustion $\mathrm{CO}_{2}$ in air.

In this contribution, we present the first data on the triple oxygen isotope composition of $\mathrm{CO}_{2}$ from combustion processes. We test the hypothesis from Hoag et al. (2005) that the $\Delta^{17} \mathrm{O}$ value of combustion $\mathrm{CO}_{2}$ is inherited from tropospheric $\mathrm{O}_{2}$.

\subsection{Materials and methods}

\subsubsection{Definitions}

Variations in stable isotope ratios are expressed in form of the $\delta$ notation relative to a standard. The $\delta^{13} \mathrm{C}$ value is defined as:

$$
\delta^{13} C=\frac{\left(\frac{{ }^{13} C}{{ }^{12} C}\right)_{\text {sample }}}{\left(\frac{{ }^{13} C}{{ }^{12} C}\right)}-1
$$

with VPDB as standard. The variations in the ${ }^{17} \mathrm{O} /{ }^{16} \mathrm{O}$ and ${ }^{18} \mathrm{O} /{ }^{16} \mathrm{O}$ ratios are expressed in the same way with the only difference that VSMOW is used as standard. For correct description of the effect of fractionation processes on the ${ }^{17 / 16} \mathrm{O}$ to ${ }^{18 / 16} \mathrm{O}$ relation, the linearized version of $\delta$ ' notation was introduced. The $\delta$ ' values are defined as $\delta^{, 17} \mathrm{O}=\ln \left(\delta^{17} \mathrm{O}+1\right)$ and $\delta^{, 18} \mathrm{O}=\ln \left(\delta^{18} \mathrm{O}+1\right)$ (Hulston and Thode, 1965; Miller, 2002; Young et al., 2002).

The triple oxygen isotope composition is given as $\Delta^{17} \mathrm{O}$ values, which denote the deviation from a reference line (RL) with: $\Delta^{17} \mathrm{O}=\delta{ }^{, 17} \mathrm{O}-\lambda_{\mathrm{RL}} \times \delta{ }^{18} \mathrm{O}-\gamma_{\mathrm{RL}}$

We use the equilibrium slope for $\mathrm{CO}_{2}$-water equilibration of 0.522 (Hofmann et al., $2012 b)$ as $\lambda_{R L}$ and a zero intercept $\left(\gamma_{R L}=0\right)$ for our study. We point out, however, that any other line could be chosen, as long as it is well defined and as long as it is helpful for the scientific problem being addressed (Assonov and Brenninkmeijer, 2005).

\subsubsection{Sampling}

We have produced $\mathrm{CO}_{2}$ by combustion of four different combustibles: (i) In-house laboratory gas (natural gas) originated from production sites in Russia and Norway (according to information from the local supplier, the Stadtwerke Göttingen AG). It is composed of $>90 \mathrm{~mol} \%$ methane. (ii) A propane-butane gas mixture was supplied in small 
(220 g), pressurized bottles (Apragas, France) for use in a camping stove. (iii) Air dried wood chips were prepared from dry Norway spruce (Picea abies) wood from Göttingen. The chips were $2-8 \mathrm{~cm}$ long, ca. $1 \mathrm{~cm}$ wide, and $0.5 \mathrm{~mm}$ thin. (iv) $\mathrm{The}^{\mathrm{CO}_{2}}$ in the exhaust gas of a gasoline engine car (VW POLO, 2010, $1400 \mathrm{~cm}^{3}$ engine displacement) was sampled. The samples were taken after the engine reached the normal operating temperature of $90^{\circ} \mathrm{C}$ for the cooling water.

In addition to the inorganic combustion processes, we studied $\mathrm{CO}_{2}$ exhaled by two humans (female, 25; male, 35).

Ambient air oxygen was the oxidant in all cases.

\subsubsection{Experimental procedures}

Natural gas was combusted by means of a laboratory Bunsen burner. The bottled propanebutane mixture was combusted using a Markill "Devil" camping stove with pre-adjusted and optimized air/fuel ratios. Wood chips were dried at $60{ }^{\circ} \mathrm{C}$ for $24 \mathrm{~h}$ before using. They were burned in an open fire under a fume hood. The temperature of the natural gas and propane butane flame were above the measurement range of the thermometer, i.e., $>1200{ }^{\circ} \mathrm{C}$. The temperature of the wood chips flame was between 600 and $700{ }^{\circ} \mathrm{C}$. The flame temperatures were measured with a digital thermometer (Extech Instruments, 421501) with a K-Type thermocouple, and an accuracy of $\pm 3 \mathrm{~K}$. The combustion gases were collected directly above the flame, through a $1 / 4$ " stainless steel tube. The sampling rate was set to $\sim 0.3 \mathrm{~L} \mathrm{~min}^{-1}$. The combustion gases were first pumped through a $2 \mu \mathrm{m}$ particle filter (Swagelok) and then dried at sub-atmospheric pressure by pumping through a $20 \mathrm{~cm}$ long tube with an inner diameter of $1 \mathrm{~cm}$, which was filled with magnesium perchlorate $\left(\mathrm{Mg}\left(\mathrm{ClO}_{4}\right)_{2}\right)$. As combustion gases were pumped through the filter and the $\mathrm{Mg}\left(\mathrm{ClO}_{4}\right)_{2}$ trap within a second and no condensed water was observed in any of the experiments, we exclude that the isotope composition of $\mathrm{CO}_{2}$ was modified by exchange with liquid water. After filtering and drying, sample $\mathrm{CO}_{2}$ was isolated from the noncondensable gases with a "Russian doll"-type cryogenic trap (Brenninkmeijer and Röckmann, 1996) that was submerged in liquid nitrogen $\left(-196^{\circ} \mathrm{C}\right)$. Any remaining water was removed from the sample $\mathrm{CO}_{2}$ in a second drying step by expanding the gas for 30 60 min into a glass volume that contained a few grams of $\mathrm{P}_{2} \mathrm{O}_{5}$.

The exhaust gas of the Volkswagen Polo was sampled at a flow rate of $0.2 \mathrm{~L} \mathrm{~min}^{-1}$ through a $2 \mu \mathrm{m}$ particle filter (Swagelok) and a $\mathrm{Mg}\left(\mathrm{ClO}_{4}\right)_{2}$ water trap into a pre-evacuated $3.5 \mathrm{~L}$ glass flask. The $1 / 4$ " stainless steel sampling tube was inserted 5-10 cm into the tail pipe, where the temperature was $55-65{ }^{\circ} \mathrm{C}$. The $\mathrm{CO}_{2}$ was extracted from the pre-dried gas 
mixture as described above. As for the gas and wood combustibles, no liquid water was observed in the sampling apparatus at any of the experiments.

Human breath was sampled by exhaling through a $\mathrm{Mg}\left(\mathrm{ClO}_{4}\right)_{2}$ water trap directly into the cryogenic trap. After deep inhalation, air was exhaled for $\sim 30-40 \mathrm{~s}$. The flow into the trap was $\sim 0.3 \mathrm{~L} \mathrm{~min}^{-1}$. About $7 \mathrm{~L}$ of respired breath was collected for one sample.

\subsubsection{Analytical procedures}

The $\mathrm{CO}_{2}$ concentration in the combustion gases was measured with an electronic pressure gauge in a calibrated volume. The concentrations ranged between 1.5 (exhaled breath) and 15 vol.\% (car exhaust). Open flame combustion yielded $2.5-17$ vol.\% $\mathrm{CO}_{2}$. Contamination by air from the laboratory was negligible as the laboratory was kept well-vented during the experiments.

The $\delta^{13} \mathrm{C}$ and $\delta^{18} \mathrm{O}$ values of the extracted $\mathrm{CO}_{2}$ were measured by dual inlet gas source mass spectrometry using a Finnigan Delta Plus isotope ratio mass spectrometer. The inhouse reference $\mathrm{CO}_{2}$ was calibrated relative to $\mathrm{CO}_{2}$ generated by phosphoric acid decomposition of NBS-19 $\left(\mathrm{T}=70{ }^{\circ} \mathrm{C} ; \delta^{18} \mathrm{O}_{\text {VSMOW }}=+28.65 \% ; \delta^{13} \mathrm{C}_{\mathrm{PDB}}=+1.95 \%\right.$ (Coplen et al., 2002)). We applied the acid fractionation factor ${ }^{18} \alpha_{\mathrm{CO} 2 \text {-calcite }}=1.00871$ (Kim et al., 2007 ) to calculate the composition of the $\mathrm{CO}_{2}$ gas.

The external reproducibility for $\delta^{13} \mathrm{C}$ and $\delta^{18} \mathrm{O}$ was $\pm 0.1 \%$. We measured the $\mathrm{N}_{2} \mathrm{O}$ mixing ratios on $\mathrm{He}$ diluted subsamples with a gas chromatograph (Carlo Erba, Hofheim, Germany). As the measured $\mathrm{N}_{2} \mathrm{O} / \mathrm{CO}_{2}$ ratios were $<1 / 10,000$ in all cases, no correction for $\mathrm{N}_{2} \mathrm{O}$ was necessary (Assonov and Brenninkmeijer, 2006).

The $\Delta^{17} \mathrm{O}$ value of the $\mathrm{CO}_{2}$ was measured with the $\mathrm{CO}_{2}-\mathrm{CeO}_{2}$ equilibration method (Hofmann et al., 2012b; Hofmann and Pack, 2010). An excess of $\mathrm{CO}_{2}$ was equilibrated with $\mathrm{CeO}_{2}$ powder at $685^{\circ} \mathrm{C}$. It was shown by Assonov and Brenninkmeijer (2001) and confirmed by Hofmann and Pack (2010) and Hofmann et al. (2012b) that $\mathrm{CO}_{2}$ and $\mathrm{CeO}_{2}$ fully exchange at these conditions. The equilibrated $\mathrm{CeO}_{2}$ was analyzed for its triple oxygen isotope ratios by infrared-laser fluorination coupled with continuous flow gas chromatograph isotope ratio monitoring mass spectrometry (CF-GCirmMS). Samples were loaded along with NBS-28 quartz into an 18-pit Ni sample holder. One analytical session generally contained 8-12 $\mathrm{CeO}_{2}$ samples (0.6-3 mg per sample) and 6-8 NBS-28 quartz standards (0.2-1 mg per sample). Purified $\mathrm{F}_{2}$ gas was used as oxidation agent. The sample $\mathrm{O}_{2}$ was cleaned from excess $\mathrm{F}_{2}$ by passing through a $\mathrm{NaCl}$ trap. The liberated $\mathrm{Cl}_{2}$ was trapped in a cold trap at $-196{ }^{\circ} \mathrm{C}$. The interfering $\mathrm{NF}_{3}$ (Pack et al., 2007) was separated in a 
$5 \AA$ molecular sieve type GC Column (Thermo Gasbench II) before introduction of the sample gas into the source of a Thermo MAT 253 gas mass spectrometer. The in-house reference $\mathrm{O}_{2}$ gas was calibrated relative to VSMOW by E. Barkan (Institute of Earth Sciences, Hebrew University of Jerusalem) with $\delta^{18} \mathrm{O}_{\mathrm{VSMOW}}=13.473 \pm 0.015 \%$ ( $\left.\mathrm{t}_{0.95} \times \mathrm{SEM}\right)$ and $\delta^{17} \mathrm{O}_{\mathrm{vSMOW}}=6.649 \pm 0.009 \%\left(\mathrm{t}_{0.95} \times \mathrm{SEM}\right)$. The $\Delta{ }^{17} \mathrm{O}$ value of $\mathrm{CO}_{2}$ was calculated as follows:

$$
\Delta^{17} O_{\mathrm{CO}_{2}}=\Delta^{17} \mathrm{O}_{\mathrm{CeO}_{2}}+\left(\lambda_{\mathrm{CO}_{2}-\mathrm{CeO}_{2}}-\lambda_{\mathrm{RL}}\right) \times 10^{3} \ln ^{18} \alpha_{\mathrm{CO}_{2}-\mathrm{CeO}_{2}}
$$

where ${ }^{18} \alpha_{\mathrm{CO}_{2}-\mathrm{CeO}_{2}}$ and $\lambda_{\mathrm{CO}_{2}-\mathrm{CeO}_{2}}$ are the fractionation factor and the triple oxygen isotope fractionation exponent for oxygen isotope exchange between $\mathrm{CO}_{2}$ and $\mathrm{CeO}_{2}$ in our apparatus. Note that $\alpha$ and $\lambda$ are not equilibrium values of a simple equilibration reaction between $\mathrm{CO}_{2}$ and $\mathrm{CeO}_{2}$. Instead, they are due to equilibrium and kinetic fractionation and are a function of the geometry of the equilibration apparatus and the $\mathrm{CO}_{2}$ pressure in the equilibration tube. The data presented here were obtained using the same apparatus and pressure range as calibration experiments with $\mathrm{CO}_{2}$ with known isotope composition (Hofmann et al., 2012b; Hofmann and Pack, 2010).

Each $\mathrm{CO}_{2}$-equilibrated $\mathrm{CeO}_{2}$ sample was divided into 2-6 aliquots, which were measured separately. The $\Delta^{17} \mathrm{O}$ values of $\mathrm{CeO}_{2}$ were corrected relative to NBS-28 analyzed the same day. The analytical uncertainty of $\Delta^{17} \mathrm{O}$ for a single analysis was $\leq \pm 0.05 \%$ ( $1 \sigma$, SD). This value was calculated based on the error propagation for Eq. 4-2 (Gehler et al., 2011; Hofmann et al., 2012b; Hofmann and Pack, 2010). An example for the precision of the measurements from one analytical session is displayed in Fig. 4-1. 


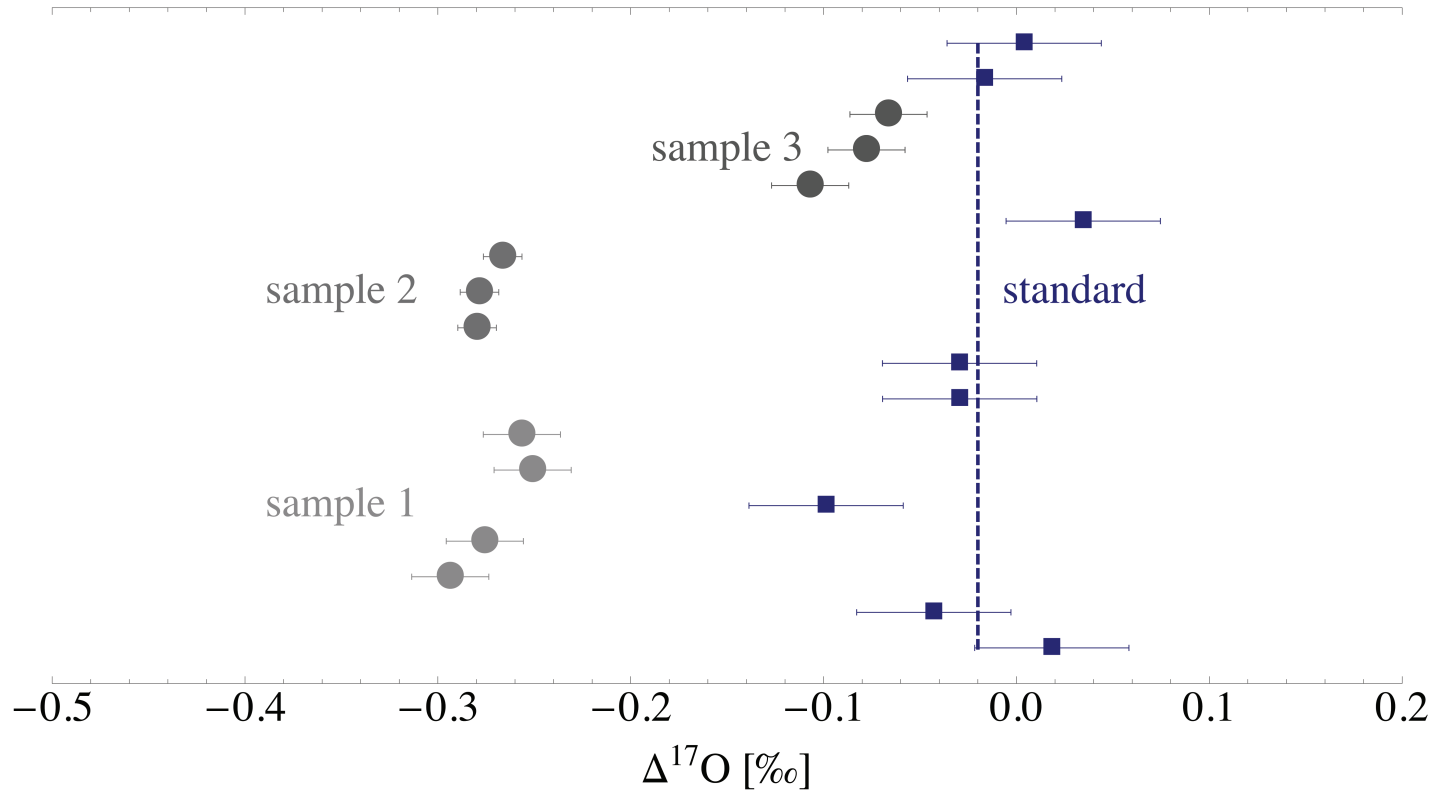

Fig. 4-1: With the method described by Hofmann and Pack (2010), the $\Delta^{17} \mathrm{O}$ value of $\mathrm{CO}_{2}$ can be measured with a precision of $0.05 \%$ (SD) or better. This variation diagram depicts the results of $\Delta \Delta^{17} \mathrm{O}$ measurements for one analytical session. The data points are vertically arranged in the order they have been obtained (from bottom to top). The bars indicate the $1 \sigma$ standard deviation. Solid squares indicate the silicate and rock standards (NBS-28 quartz and mid-ocean ridge basalt). The standard deviation of the measured values was $0.04 \%(\mathrm{n}=8$, SE $0.015 \%)$. Three $\mathrm{CO}_{2}$ equilibrated $\mathrm{CeO}_{2}$ samples (dots) were analyzed. The standard deviations of the measurements were $0.02 \%$, $0.01 \%$ and $0.02 \%$, respectively.

\subsection{Results}

Carbon and oxygen isotope ratios of $\mathrm{CO}_{2}$ from the experiments are listed in Table 4-1.

The $\delta^{13} \mathrm{C}$ value of $\mathrm{CO}_{2}$ from our natural gas combustion was $-29.6 \pm 0.8 \%$ and $-30.7 \pm 0.1 \%$ from the propane-butane combustion. The oxygen isotope composition of $\mathrm{CO}_{2}$ from combustion of natural gas and propane-butane were similar in $\delta^{18} \mathrm{O} \sim 22 \%$ (Table 4-1). The $\Delta^{17} \mathrm{O}$ values showed a significant deficit in ${ }^{17} \mathrm{O}$ with $\Delta^{17} \mathrm{O}=-0.30 \pm 0.02 \%$ for natural gas and $-0.32 \pm 0.02 \%$ for the propane-butane mixture.

The $\delta^{13} \mathrm{C}$ value of $\mathrm{CO}_{2}$ that was extracted from the wood combustion gases was $-26.4 \pm 1.0 \%$. The corresponding $\delta^{18} \mathrm{O}$ and $\Delta^{17} \mathrm{O}$ values were $19.4 \pm 1.0 \%$ and $-0.21 \pm 0.02 \%$, respectively.

The oxygen isotope composition of $\mathrm{CO}_{2}$ from the car exhaust gases was $\delta^{18} \mathrm{O}=32.6 \pm 3.0 \%$. The $\Delta^{17} \mathrm{O}$ value of the car exhaust gas was $-0.32 \pm 0.03 \%$. 
The $\delta^{13} \mathrm{C}$ value of human breath $\mathrm{CO}_{2}$ was $-24.5 \pm 1.0 \%$ and the $\delta^{18} \mathrm{O}$ value was $35.1 \pm 1.0 \%$. The corresponding $\Delta^{17} \mathrm{O}$ value was $-0.03 \pm 0.03 \%$. No significant difference was observed between $\mathrm{CO}_{2}$ from the two individuals (Table 4-1). 
Table 4-1: Carbon and oxygen isotope compositions of $\mathrm{CO}_{2}$ from different anthropogenic sources. For the mean values $95 \%$ confidence limits are given (standard error of the mean multiplied by Student's t-factor).

\begin{tabular}{|c|c|c|c|c|}
\hline Sample & $\mathbf{N}^{\mathbf{a}}$ & $\delta^{13} \mathrm{C}_{\text {VPDB }}$ & $\delta^{18} O_{\text {VSMow }}$ & $\Delta^{17} \mathbf{O}_{\mathrm{RL}}{ }^{\mathrm{b}}$ \\
\hline & & & $-[\%$ ] & 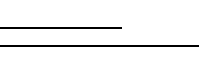 \\
\hline \multirow[t]{13}{*}{ Natural gas } & 1 & -29.6 & 22.2 & -0.29 \\
\hline & & & & -0.25 \\
\hline & & & & -0.25 \\
\hline & & & 21.3 & \\
\hline & 2 & -29.1 & & -0.33 \\
\hline & & & & -0.33 \\
\hline & & & & -0.34 \\
\hline & & & & -0.32 \\
\hline & 3 & -29.4 & 21.5 & -0.27 \\
\hline & & & & -0.31 \\
\hline & 4 & -30.2 & 21.4 & -0.31 \\
\hline & & & & -0.33 \\
\hline & & & & -0.29 \\
\hline Average $\pm \mathrm{t}_{0.95} \times \mathrm{SEM}$ & & $-29.6 \pm 0.8$ & $21.6 \pm 0.7$ & $-0.30 \pm 0.02$ \\
\hline \multirow[t]{10}{*}{ Propane-butane } & 1 & -30.6 & 22.4 & -0.31 \\
\hline & & & & -0.38 \\
\hline & 2 & -30.7 & 22.5 & -0.30 \\
\hline & & & & -0.29 \\
\hline & & & & -0.32 \\
\hline & 3 & -30.6 & 22.0 & -0.32 \\
\hline & & & & -0.34 \\
\hline & 4 & -30.8 & 23.2 & -0.32 \\
\hline & & & & -0.30 \\
\hline & & & & -0.32 \\
\hline Average $\pm \mathrm{t}_{0.95} \times \mathrm{SEM}$ & & $-30.7 \pm 0.1$ & $22.5 \pm 0.8$ & $-0.32 \pm 0.02$ \\
\hline \multirow[t]{13}{*}{ Wood chips } & 1 & -25.5 & 19.3 & -0.23 \\
\hline & & & & -0.21 \\
\hline & & & & -0.19 \\
\hline & & & & -0.18 \\
\hline & 2 & -26.5 & 18.6 & -0.21 \\
\hline & & & & -0.21 \\
\hline & & & & -0.19 \\
\hline & 3 & -26.6 & 19.9 & -0.27 \\
\hline & & & & -0.17 \\
\hline & & & & -0.18 \\
\hline & 4 & -26.9 & 19.9 & -0.21 \\
\hline & & & & -0.22 \\
\hline & & & & -0.23 \\
\hline Average $\pm \mathrm{t}_{0.95} \times \mathrm{SEM}$ & & $-26.4 \pm 1.0$ & $19.4 \pm 1.0$ & $-0.21 \pm 0.02$ \\
\hline
\end{tabular}




\begin{tabular}{|c|c|c|c|c|}
\hline Sample & $\mathbf{N}^{\mathbf{a}}$ & $\delta^{13} \mathbf{C}_{\text {VPDB }}$ & $\delta^{18} \mathbf{O}_{\text {VSMow }}$ & $\Delta^{17} \mathbf{O}_{\mathrm{RL}}^{\mathrm{b}}$ \\
\hline \multirow[t]{15}{*}{ Car exhaust } & 1 & -27.7 & 35.4 & -0.27 \\
\hline & & & & -0.29 \\
\hline & & & & -0.30 \\
\hline & 2 & -27.7 & 31.5 & -0.31 \\
\hline & & & & -0.43 \\
\hline & & & & -0.38 \\
\hline & & & & -0.28 \\
\hline & 3 & -27.8 & 31.4 & -0.36 \\
\hline & & & & -0.30 \\
\hline & & & & -0.37 \\
\hline & & & & -0.34 \\
\hline & 4 & -28.9 & 32.1 & -0.31 \\
\hline & & & & -0.32 \\
\hline & & & & -0.33 \\
\hline & & & & -0.24 \\
\hline Average $\pm \mathrm{t}_{0.95} \times \mathrm{SEM}$ & & $-28.0 \pm 0.9$ & $32.6 \pm 3.0$ & $-0.32 \pm 0.03$ \\
\hline \multirow[t]{9}{*}{ Human breath } & 1 & -25.5 & 35.2 & -0.01 \\
\hline & & & & -0.07 \\
\hline & 2 & -24.3 & 34.9 & 0.04 \\
\hline & & & & -0.07 \\
\hline & & & & -0.07 \\
\hline & 3 & -24.0 & 36.0 & 0.04 \\
\hline & & & & -0.06 \\
\hline & 4 & -24.3 & 34.5 & -0.01 \\
\hline & & & & -0.04 \\
\hline Average $\pm \mathrm{t}_{0.95} \times \mathrm{SEM}$ & & $-24.5 \pm 1.0$ & $35.1 \pm 1.0$ & $-0.03 \pm 0.03$ \\
\hline
\end{tabular}

${ }^{a} \mathrm{~N}$ denotes the number of independent experiments. The $\delta^{13} \mathrm{C}$ and $\delta^{18} \mathrm{O}$ values were measured once per experiment in dual-inlet mode ( 5 cycles). In contrast, the $\Delta^{17} \mathrm{O}$ values were determined on $2-6$ aliquots in continuous flow mode (see section 4.3).

${ }^{\mathrm{b}} \Delta{ }^{17} \mathrm{O}$ values are given as a deviation from the reference line, with a slope $(\lambda) 0.522$ and 0 intercept $(\gamma) . \lambda$ refers to the $\mathrm{CO}_{2}-$ water equilibration line, determined by Hofmann et al. (2012b). 


\subsection{Discussion}

\subsubsection{Carbon isotope ratios}

The carbon isotope composition of the $\mathrm{CO}_{2}$ samples from different combustion processes was within the range of literature data given for the respective combustibles. This is expected as the entire carbon is converted to $\mathrm{CO}_{2}$.

The $\delta^{13} \mathrm{C}$ value of $\mathrm{CO}_{2}$ from our natural gas combustion $(-29.6 \pm 0.8 \%$ ) is within the range reported for natural methane of $-20 \%$ to $-75 \%$ o (Yakir, 2003). It agrees well with the range measured recently by Schumacher et al. (2011) for natural gas combustion $\mathrm{CO}_{2}$ $(-31.8$ to $-29.7 \%$ o).

The $\delta^{13} \mathrm{C}$ value of $\mathrm{CO}_{2}$ from the propane-butane combustion was $-30.7 \pm 0.1 \%$, which is consistent with the range given by Rooney et al. (1995) for propane ( $-26 \%$ to $-32 \%$ ). The $\delta^{13} \mathrm{C}$ value of $\mathrm{CO}_{2}$ that was extracted from the wood combustion gases $(-26.4 \pm 1.0 \%)$ is in the range of $-22 \%$ to $-28 \%$ reported for wood by Craig (1953). Our values are very similar to the values measured on spruce wood from Switzerland (-25\%) (Jäggi et al., 2002 ) and from Norway (-25\%) (Saurer et al., 2004). For comparison, Schumacher et al. (2011) measured a $\delta^{13} \mathrm{C}$ value of $-27.1 \%$ for $\mathrm{CO}_{2}$ from spruce wood combustion.

The $\delta^{13} \mathrm{C}$ value of $\mathrm{CO}_{2}$ from car exhaust $(-28.0 \pm 0.9 \%)$ is consistent with the values reported by Pataki et al. (2003) (-28\%) and Newman (2008) (-26\%) for gasoline. The $\delta^{13} \mathrm{C}$ of $\mathrm{CO}_{2}$ from the car exhaust agrees with the measured value of Schumacher et al. (2011) (-27\%). Affek and Eiler (2006) reported a $\delta^{13} \mathrm{C}$ value of $-25 \%$ or $\mathrm{CO}_{2}$ from car exhausts.

Our data and the data by Schumacher et al. (2011) and Affek and Eiler (2006) demonstrate that no large fractionation in $\delta^{13} \mathrm{C}$ occurs between the fuels and the combustion $\mathrm{CO}_{2}$.

\subsubsection{Oxygen isotope ratios}

\section{$\operatorname{Air} \mathrm{O}_{2}$}

Air $\mathrm{O}_{2}$ was the oxidant in all experiments. The isotope composition of air $\mathrm{O}_{2}$ has been analyzed relative to VSMOW to $\delta^{18} \mathrm{O}=23.88 \%$ and $\delta^{17} \mathrm{O}=12.08 \%$ with $\Delta^{17} \mathrm{O}=-0.31 \%$ o (Barkan and Luz, 2005). This value has been suggested of being incorrect and has recently been revised to $\Delta^{17} \mathrm{O}=-0.37 \%$ (letter to the editor, Barkan and Luz (2011)). Pack et al. (2007) report the isotope composition of technical $\mathrm{O}_{2}$. Their dataset includes a number of 
gases with $\delta^{18} \mathrm{O}$ values equal to air $\mathrm{O}_{2}$. As technical $\mathrm{O}_{2}$ is made of air $\mathrm{O}_{2}$, it is assumed to be unfractionated in $\Delta^{17} \mathrm{O}$ relative to air $\mathrm{O}_{2}$ as well. Pack et al. (2007) reported their data with respect to the terrestrial fractionation line with a slope of 0.5237 and zero intercept with NBS-28 quartz having $\Delta^{17} \mathrm{O}=0 \%$. Recent high-precision analyses of NBS-28 quartz relative to VSMOW give $\Delta^{17} \mathrm{O}=0 \%$ when using a line with a slope of 0.527 and an intercept of $-0.07 \%$ (Tanaka and Nakamura, 2012). Recalculating the data reported in Pack et al. (2007) and taking in account the newly reported $\Delta^{17} \mathrm{O}$ of NBS-28 from Tanaka and Nakamura (2012) with respect to a reference line with slope 0.522 and zero intercept gives a $\Delta^{17} \mathrm{O}$ of air $\mathrm{O}_{2}$ of $-0.34 \%$.

Combustion $\mathrm{CO}_{2}$ obtains its oxygen from air $\mathrm{O}_{2}$. Thus combustion $\mathrm{CO}_{2}$ should have an oxygen isotope composition that is related to the composition of air $\mathrm{O}_{2}$.

\section{Natural gas combustion}

The $\delta^{18} \mathrm{O}$ of $\mathrm{CO}_{2}$ from the open-flame combustion experiments for natural gas were $\sim 2 \%$ lower than the $\delta^{18} \mathrm{O}$ of air $\mathrm{O}_{2}$. The small fractionation in $\delta^{18} \mathrm{O}$ may be explained by means of a slight preference of ${ }^{16} \mathrm{O}$ relative to ${ }^{18} \mathrm{O}$ during the combustion process. Isotope exchange between $\mathrm{CO}_{2}$ and water at $\mathrm{T}<100{ }^{\circ} \mathrm{C}$ is unlikely to have occurred because one would expect higher $\delta^{18} \mathrm{O}$ of $\mathrm{CO}_{2}$. If $\mathrm{CO}_{2}$ and water initially inherited the isotope composition of air $\mathrm{O}_{2}(+23.88 \%)$, exchange between these reservoirs at any temperature would lead to $\delta^{18} \mathrm{O}>23.88 \%$ in the $\mathrm{CO}_{2}$ and $\delta^{18} \mathrm{O}<23.88 \%$ for the $\mathrm{H}_{2} \mathrm{O}$ (see fractionation factors, e.g. in Brenninkmeijer et al., 1983). Instead, a $\delta^{18} \mathrm{O}$ value slightly lower than $23.88 \%$ was measured for the combustion $\mathrm{CO}_{2}$. Also, no water was observed in any part of the extraction apparatus during sampling and storage. We therefore conclude that equilibration between $\mathrm{CO}_{2}$ and water did not play any role.

We calculated the kinetic fractionation factor for $\mathrm{O}_{2}$ according to Craig (1954) and Young et al. (2002):

$$
\lambda_{O_{2}}^{k i n}=\frac{\ln ^{17} \alpha_{O_{2}}^{k i n}}{\ln ^{18} \alpha_{O_{2}}^{k i n}}=\frac{\ln \left[\frac{29 \times 32}{29+32} \times \frac{29+33}{29 \times 33}\right]}{\ln \left[\frac{29 \times 32}{29+32} \times \frac{29+34}{29 \times 34}\right]}=0.512
$$


$\mathrm{A}-2 \%$ shift in $\delta^{18} \mathrm{O}$ results in a $0.02 \%$ shift in $\Delta^{17} \mathrm{O}$, giving an expected value for the $\mathrm{CO}_{2}$ of $-0.32 \%$, which is close to the observed $\Delta^{17} \mathrm{O}$ value of $-0.30 \pm 0.02 \%$ for $\mathrm{CO}_{2}$ from natural gas combustion (Fig. 4-2).

Schumacher et al. (2011) measured in natural gas combustion $\mathrm{CO}_{2}$ a $\delta^{18} \mathrm{O}$ depletion between $13.5 \%$ and $16.8 \%$ compared to the oxidant, which is in stark contrast to the depletion of $2.4 \%$ measured in this study. We assume that this difference partially arises from the difference in the oxidant. Schumacher et al. (2011) used pure oxygen, where ${ }^{18} \alpha^{\mathrm{kin}} \mathrm{O}_{2}$ is 0.970 , while in this study the oxygen source was air, where the ${ }^{18} \alpha^{\mathrm{kin}} \mathrm{O}_{2}$ is 0.986 .

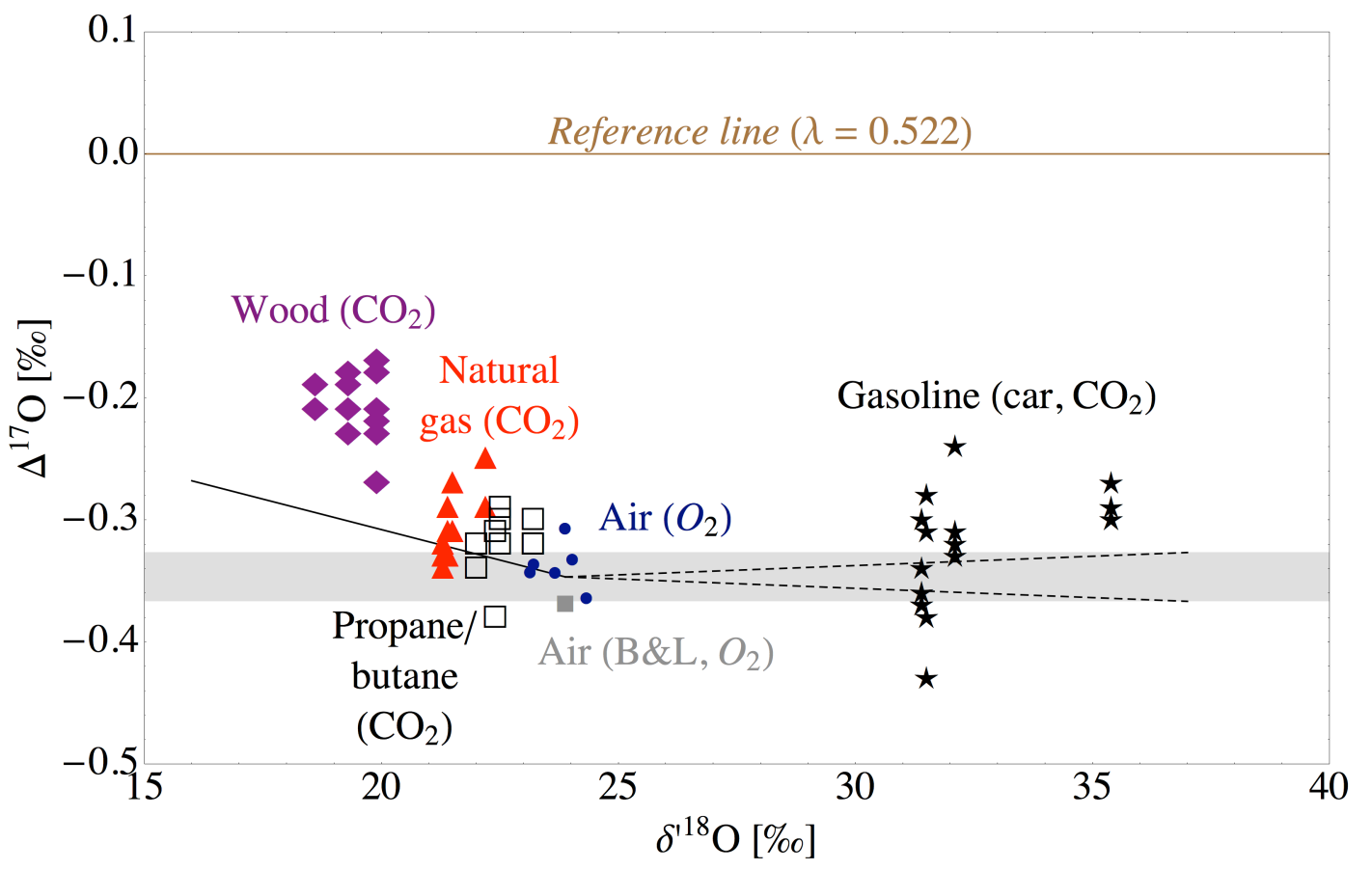

Fig. 4-2: The triple oxygen isotope compositions of $\mathrm{CO}_{2}$ from fossil fuel combustion reflect a small fractionation in diffusion of $\mathrm{O}_{2}$ to the combustion site $\left({ }^{18} \mathrm{O}\right.$ depletion). Triangles and open squares depict $\mathrm{CO}_{2}$ from natural gas and propane-butane combustion, respectively. In case of biomass combustion (diamonds) intrinsic $\mathrm{O}$, in case of car exhaust $\mathrm{CO}_{2}$ (stars) equilibration between condensed water and $\mathrm{CO}_{2}$ plays a significant role, too. Dots depict the triple oxygen isotope composition of air $\mathrm{O}_{2}$ measured by Pack et al. (2007); the gray band represents the $95 \%$ confidence interval of these measurements. The solid gray square shows air $\mathrm{O}_{2}$ measured by Barkan and Luz (2011). Black line indicates the kinetic fractionation trajectory for diffusion of $\mathrm{O}_{2}$ in air $\left(\lambda_{\mathrm{O}_{2}}^{\mathrm{kin}}=0.512\right)$; dashed lines show the $95 \%$ confidence interval of the $\mathrm{CO}_{2}$-water equilibration line (0.522 \pm 0.002 , Hofmann et al., 2012b). 


\section{Propane-butane combustion}

For the propane-butane mixture, a $\delta^{18} \mathrm{O}$ value was observed that was only $1.4 \%$ lower than the $\delta^{18} \mathrm{O}$ of air $\mathrm{O}_{2}$. This demonstrates that very little fractionation occurs during the combustion process. The corresponding $\Delta^{17} \mathrm{O}$ value is $-0.32 \%$. Considering a kinetic diffusive effect on $\Delta^{17} \mathrm{O}$ of $0.01 \%$ o (Eq. 4-3) the expected $\Delta^{17} \mathrm{O}$ value of $\mathrm{CO}_{2}$ is $-0.33 \%$, which is in agreement with our observation of $-0.32 \pm 0.02 \%$ (Fig. 4-2).

The gas combustion experiments show that only very little oxygen isotope fractionation occurs between $\mathrm{O}_{2}$ in the educts and $\mathrm{CO}_{2}$ in the products in the flame and that postcombustion exchange with vapor is negligible. A small kinetic effect may be suggested by the observed slightly lower $\delta^{18} \mathrm{O}$ value of combustion $\mathrm{CO}_{2}$ relative to the $\delta^{18} \mathrm{O}$ value of air $\mathrm{O}_{2}$.

\section{Wood combustion}

Unlike fossil fuels, a considerable amount of oxygen is contained in wood. Average spruce contains $70 \mathrm{~mol} \%$ cellulose and hemi cellulose $\left(\left[\mathrm{C}_{6} \mathrm{H}_{10} \mathrm{O}_{5}\right]_{\mathrm{n}}\right)$ and $30 \mathrm{~mol} \%$ lignin $\left(\mathrm{C}_{10} \mathrm{H}_{12} \mathrm{O}\right)$ (Sjostrom, 1993). Assuming combustion of water-free wood, $22 \%$ of the oxygen in the combustion is intrinsic oxygen and only $78 \%$ sources from ambient air $\mathrm{O}_{2}$.

Therefore, at least $\sim 22 \%$ of the oxygen in combustion gases $\left(\mathrm{CO}_{2}, \mathrm{H}_{2} \mathrm{O}\right)$ originated not from isotopically anomalous air $\mathrm{O}_{2}$, but from intrinsic "normal" oxygen cellulose, hemi cellulose, and lignin. The $\Delta^{17} \mathrm{O}$ value of $\mathrm{CO}_{2}$ from our wood combustion experiments clearly indicates the presence of an isotopically "normal" (i.e., without large negative anomaly as air $\mathrm{O}_{2}$ ) component in the combustion gases as the $\Delta^{17} \mathrm{O}$ value of $\mathrm{CO}_{2}$ is higher than the $\Delta^{17} \mathrm{O}$ value of air $\mathrm{O}_{2}$ (Fig. 4-2).

The $\delta^{18} \mathrm{O}$ value of spruce wood (i.e., cellulose, hemi cellulose and lignin) grown in a similar environment is $25 \%$ (Jäggi et al., 2003). The high $\delta^{18} \mathrm{O}$ value of wood is due to equilibrium fractionation between leaf water and cellulose, which is $\sim 27 \%$ o (DeNiro and Epstein, 1979; Yakir and DeNiro, 1990). Leaf water in temperate regions is enriched in $\delta^{18} \mathrm{O}$ relative to meteoric water $\left(\delta^{18} \mathrm{O} \sim-8 \%\right.$ ) by $\sim 8 \pm 5 \%$ (Landais et al., 2006) giving a $\delta^{18} \mathrm{O}$ of leaf water of $\sim 0 \pm 5 \%$. The $\Delta^{17} \mathrm{O}$ value of wood has not yet been analyzed. Assuming that a triple oxygen isotope fractionation exponent for cellulose-water falls within the range of the published low-T oxygen isotope equilibrium exponents (Barkan and Luz, 2005; Hofmann et al., 2012b) $0.522 \leq \lambda_{\text {cellulose-water }} \leq 0.529$, a $\Delta^{17}$ O of cellulose of $\sim 0 \pm 0.1 \%$ is estimated (Fig. $4-3$ ). Remaining moisture in wood is assumed to be kinetically 
fractionated relative to the original stem water with $\lambda=0.516$ (see Landais et al., 2006) resulting in $\delta^{18} \mathrm{O} \approx 0 \%$ and $\Delta^{17} \mathrm{O} \approx-0.06 \%$ (Fig. 4-3).

Our rough estimate on the triple isotope composition of possible oxygen sources in the combustion gases of wood show that $\sim 2 / 3$ of oxygen in combustion $\mathrm{CO}_{2}$ sources from air $\mathrm{O}_{2}$ and $\sim 1 / 3$ sources from oxygen intrinsic to wood, i.e., cellulose, hemi cellulose and remaining moisture.

In case of wood chips combustion, Schumacher et al. (2011) measured a $\delta^{18} \mathrm{O}$ depletion of $15.5 \%$ compared to the oxidant. This value is in contrast to our measured depletion of $4.4 \%$. Similar to natural gas combustion, we assume that this difference arises from the different oxidant (pure $\mathrm{O}_{2}$ vs. $\mathrm{O}_{2}$ in air) and different experimental set up (closed chamber with ignition through heating vs. open flame). Open flame combustion of charcoal and peat coal by Schumacher et al. (2011) resulted in a much smaller (1.3 and 4.5\%o) $\delta^{18} \mathrm{O}$ depletion of the oxygen source, similar to our observations.

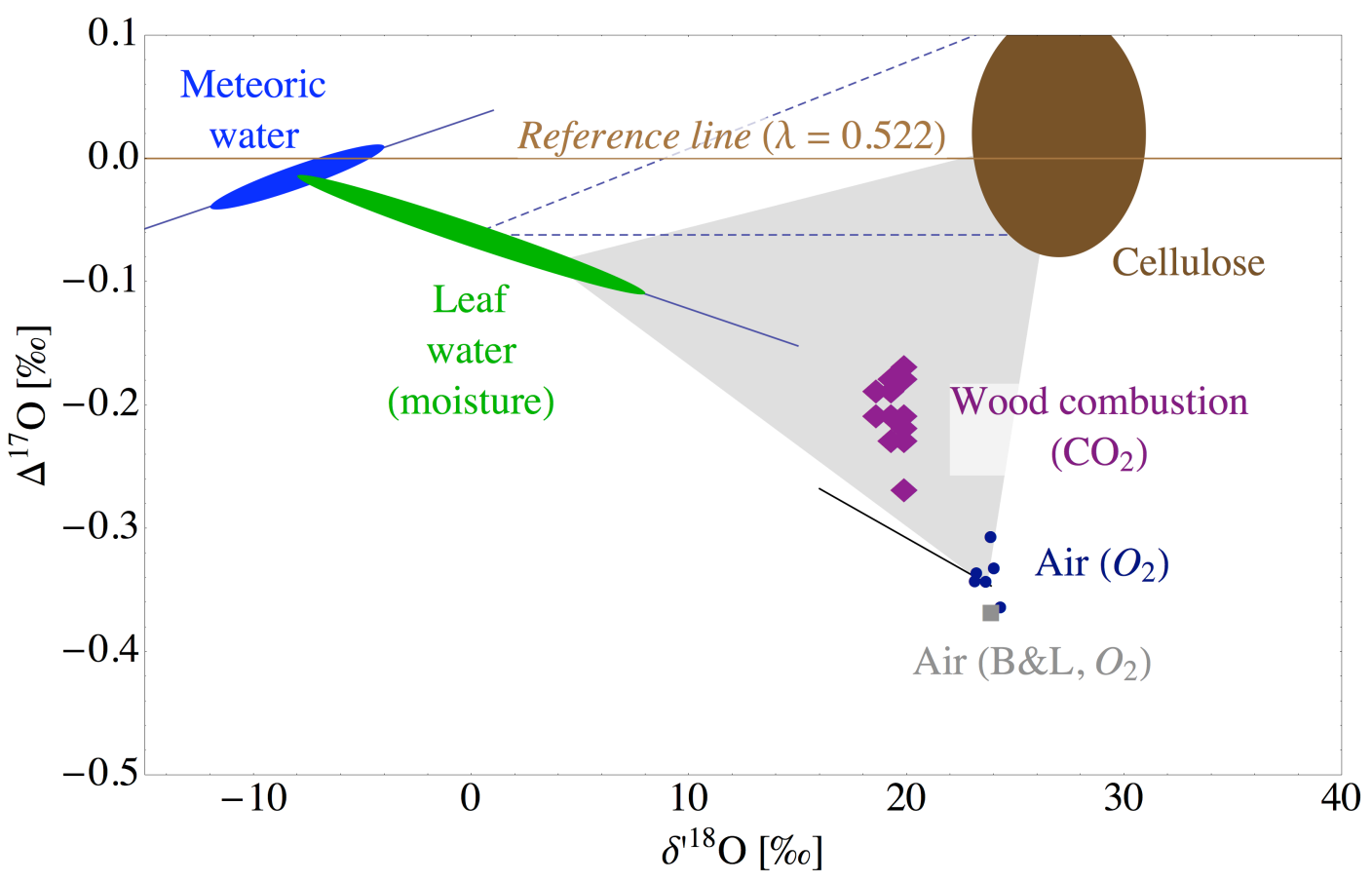

Fig. 4-3: The $\mathrm{CO}_{2}$ from wood combustion may have three sources of $\mathrm{O}$ : (i) tropospheric $\mathrm{O}_{2}$ (small dots, measurements from Pack et al., 2007; solid gray square from Barkan and Luz, 2011) which can be depleted along a kinetic fractionation trajectory (black line) (ii) intrinsic O from cellulose (brown ellipse) (iii) remaining moisture in wood. (See text for details on estimates for each oxygen source). Global meteoric water line (GMWL, $\lambda=0.528$ and $\gamma=0.033 \%$, Luz and Barkan, 2010) and the evaporation line of water $(\lambda=0.516$, Landais et al., 2006) are depicted. 


\section{Car exhaust}

The $\delta^{18} \mathrm{O}$ value of $\mathrm{CO}_{2}$ collected from the car exhaust is by $\sim 9 \%$ higher than the $\delta^{18} \mathrm{O}$ value of air $\mathrm{O}_{2}$. The $\mathrm{CO}_{2}$ was sampled from the exhaust pipe where temperatures were about $60{ }^{\circ} \mathrm{C}$ and $\mathrm{CO}_{2}$-water oxygen isotope exchange may be the cause for the observed $\delta^{18} \mathrm{O}$ value.

The $\Delta^{17} \mathrm{O}$ value of the $\mathrm{CO}_{2}$ from the exhaust pipe $(-0.32 \pm 0.03 \%)$ is only slightly higher than the $\Delta^{17} \mathrm{O}$ of air $\mathrm{O}_{2}(-0.37 \%$, by Barkan and Luz, $2011 ;-0.34 \%$ oy Pack et al., 2007). Hofmann et al. (2012b) gave an uncertainty $\left(\mathrm{t}_{0.95} \times \mathrm{SEM}\right)$ of \pm 0.002 for the $\mathrm{CO}_{2}$-water equilibrium isotope fractionation exponent. Considering the fractionation in $\delta^{18} \mathrm{O}$ of $9 \%$, this uncertainty introduces an intrinsic uncertainty of $0.02 \%$, giving an expected $\Delta^{17} \mathrm{O}$ of $\mathrm{CO}_{2}$ of $-0.37 \pm 0.02 \%$ (for $\Delta^{17} \mathrm{O}$ of $\mathrm{O}_{2}$ from Barkan and Luz, 2011) and of $-0.34 \pm 0.02 \%$ (for $\Delta^{17} \mathrm{O}$ of $\mathrm{O}_{2}$ from Pack et al., 2007), respectively. As in the case of gas combustion, our $\Delta^{17} \mathrm{O}$ of $\mathrm{CO}_{2}$ is slightly higher than expected when using the revised value for air $\mathrm{O}_{2}$, but is in good agreement when using the value $\Delta^{17} \mathrm{O}$ of air $\mathrm{O}_{2}$ measured by Pack et al. (2007) (Fig. 4-2).

Alternatively, $\mathrm{CO}_{2}$ may have exchanged with vapor within the exhaust pipe as suggested by the clumped isotope analyses by Affek and Eiler (2006). In such a scenario, metal walls within the pipe, large surfaces within the silencers or the Pt coated surface in the catalysts may have catalyzed the exchange reaction. There is no strong evidence, however, for fast oxygen isotope exchange between $\mathrm{CO}_{2}$ and water vapor, thus the partial equilibration between $\mathrm{CO}_{2}$ and the condensed water in the exhaust pipe line seems to be a more plausible explanation for our results.

\section{Human respiration $\mathrm{CO}_{2}$}

We demonstrate that the triple oxygen isotope composition of $\mathrm{CO}_{2}$ from abiotic combustion processes is partly controlled by the isotope composition of air $\mathrm{O}_{2}$, and thus, shows significant negative $\Delta^{17} \mathrm{O}$ values. Exchange with water is the second important factor controlling $\delta^{18} \mathrm{O}$ and $\Delta^{17} \mathrm{O}$ of combustion $\mathrm{CO}_{2}$. Although $\mathrm{CO}_{2}$ from human breath does not influence the isotope composition of atmospheric $\mathrm{CO}_{2}$, it is a model for biogenic "combustion" $\mathrm{CO}_{2}$ that has extensively exchanged with water. Exchange with water is expected for $\mathrm{CO}_{2}$ that is emitted by any kind of heterotrophic organisms, e.g. in soils. Soil $\mathrm{CO}_{2}$ is an important source of $\mathrm{CO}_{2}$ in the atmosphere. $\mathrm{CO}_{2}$ that equilibrated with seawater is another important source for the atmosphere. 
The $\delta^{13} \mathrm{C}$ value of $\mathrm{CO}_{2}$ from human respiration of two individuals was $-24.5 \pm 1.0 \%$. This value largely reflects the $\delta^{13} \mathrm{C}$ of the diet. Both individuals live in Germany and have similar $\delta^{13} \mathrm{C}$ as the individuals from France that were studied by Widory and Javoy (2003) $\left(\delta^{13} \mathrm{C}=-24.5 \%\right)$. In contrast, respired $\mathrm{CO}_{2}$ of US Americans had $\delta^{13} \mathrm{C}$-values that were 1 to $6 \%$ higher than in our study (Affek and Eiler, 2006; Epstein and Zeiri, 1988; Yanes and Yapp, 2010). As noted by Affek and Eiler (2006), a possible explanation is the larger contribution of $\mathrm{C}_{4}$ plants (e.g. corn) with a higher $\delta^{13} \mathrm{C}$ value to the diet of people from North America compared to the Mid-European individuals.

We observed a mean $\delta^{18} \mathrm{O}$ value of $35.1 \pm 1.0 \%$ in the exhaled breath $\mathrm{CO}_{2}$. This is similar to the value of exhaled $\mathrm{CO}_{2}$ reported by Affek and Eiler (2006) $\left(34.3 \pm 0.3 \%\right.$ ). The $\delta^{18} \mathrm{O}$ value of exhaled $\mathrm{CO}_{2}$ is controlled by equilibration with body water (Luz et al., 1984), which, in turn, is largely controlled by drinking water (Longinelli, 1984). According to Brenninkmeijer et al. (1983) the ${ }^{18} \mathrm{O} /{ }^{16} \mathrm{O}$ fractionation of $\mathrm{CO}_{2}$ relative to water is ${ }^{18} \alpha_{\mathrm{CO}_{2} \text {-water }}=1.03865$ at $37^{\circ} \mathrm{C}$. This gives a $\delta^{18} \mathrm{O}$ value of $-3.4 \%$ or the body water of the two individuals in this study (Fig. 4-4). This value is somewhat lower than the value $(-2.6 \%)$ measured by Luz et al. (1984).

As for $\delta^{18} \mathrm{O}$, the $\Delta^{17} \mathrm{O}$ value of exhaled $\mathrm{CO}_{2}$ of $-0.03 \%$ is also controlled by the composition of body water. Hofmann et al. (2012b) experimentally determined a $\theta_{\mathrm{CO}_{2} \text {-water }}$ value of $0.522 \pm 0.002\left(\mathrm{t}_{0.95} \times \mathrm{SE}\right)$ for a temperature range of $2-37^{\circ} \mathrm{C}$. This, along with the

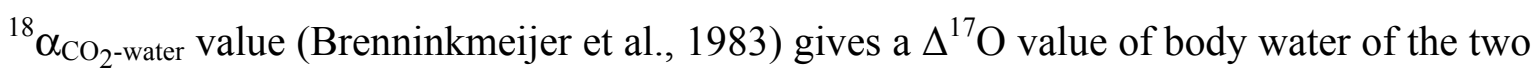
individuals of $-0.03 \pm 0.08 \%$ (Fig. 4-4). Local drinking water has $\delta^{18} \mathrm{O}=-8.5 \%$ and a $\Delta^{17} \mathrm{O}$ value of $-0.02 \%$ o (Hofmann et al., 2012b). Considering that the isotope composition of body water of medium sized mammals (e.g. humans) is largely controlled by drinking water, our data are in good agreement with the expectation. 


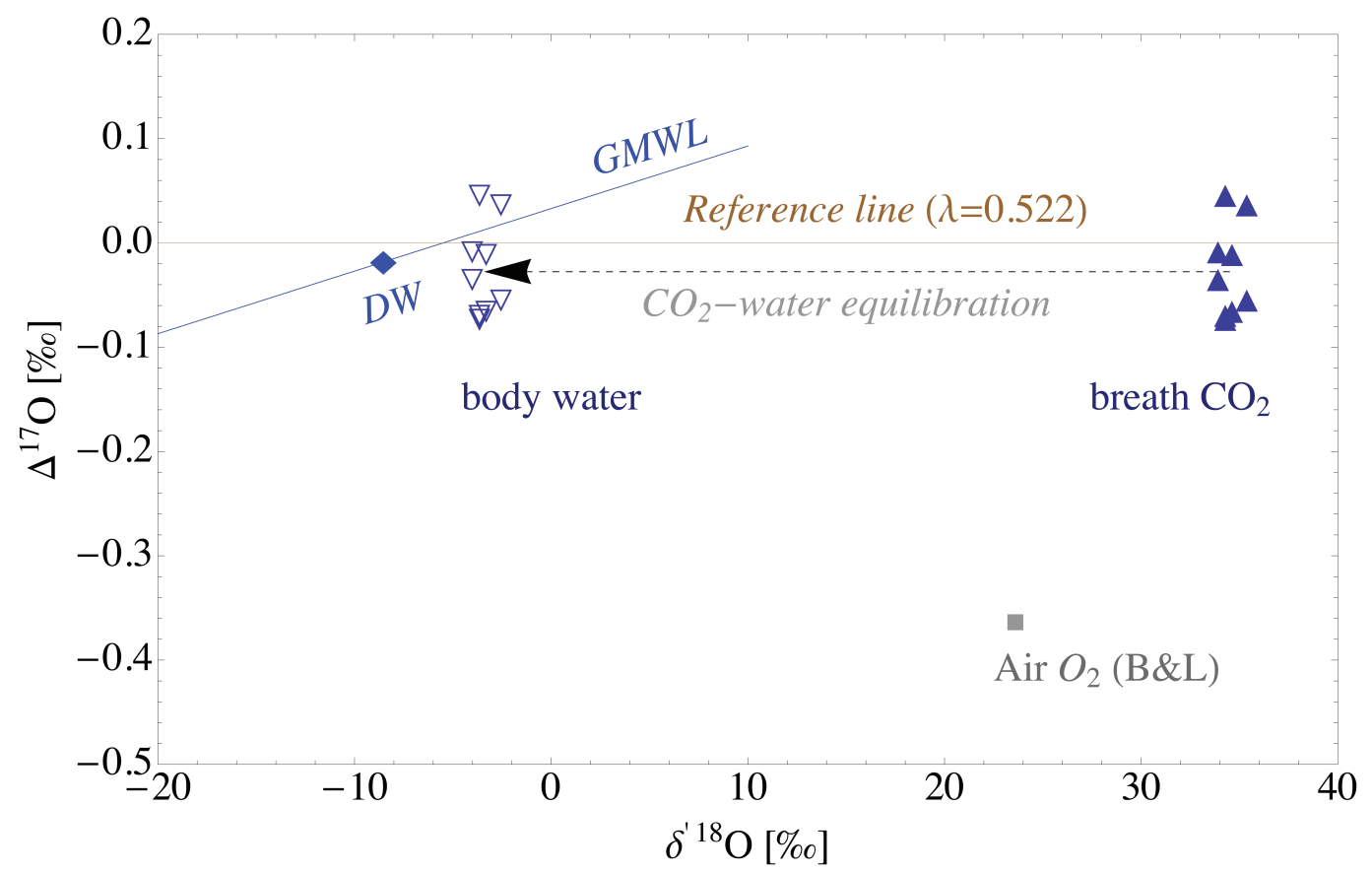

Fig. 4-4: From the triple oxygen isotope composition of $\mathrm{CO}_{2}$ from human respiration (filled triangles) the isotopic composition of body water (open triangles) can be inferred. The $\theta_{\mathrm{CO}_{2} \text {-water }}$ is 0.522 (Hofmann et al., 2012b), the fractionation factor ${ }^{18} \alpha_{\mathrm{CO}_{2} \text {-water }}$ at $37^{\circ} \mathrm{C}$ is 1.03879 (Brenninkmeijer et al., 1983). The two main O sources of human body water are displayed: local drinking water (DW, diamond) (Hofmann et al., 2012b) and air $\mathrm{O}_{2}$ (solid gray square) (Barkan and Luz, 2011). The line labeled with GMWL represents the global meteoric water line $(\lambda=0.528$ and $\gamma=0.033 \%$, Luz and Barkan, 2010).

\subsubsection{Can the $\Delta^{17} \mathrm{O}$ value of $\mathrm{CO}_{2}$ be used as a tracer to distinguish between different $\mathrm{CO}_{2}$ sources?}

Our data show that with our current technique, $\Delta^{17} \mathrm{O}$ value of $\mathrm{CO}_{2}$ from gas combustion, combustion of wood and from respiration can be well distinguished.

The background $\mathrm{CO}_{2}$ concentration level is $390 \mathrm{ppm}$ (NOAA, 2012). The $\delta^{18} \mathrm{O}$ value of background $\mathrm{CO}_{2}$ is $\sim 41.5 \%$ (e.g. Francey and Tans, 1987) and the $\Delta^{17} \mathrm{O}$ is $0.01 \%$ (Hofmann et al., 2012a). We assume an average $\Delta^{17} \mathrm{O}$ value of anthropogenic $\mathrm{CO}_{2}$ of $-0.33 \%$. Considering a necessary analytical resolution of $\pm 0.05 \%$, a detection limit for anthropogenic $\mathrm{CO}_{2}$ is at $\sim 60 \mathrm{ppm}$ above background level. Such levels can, indeed, be observed in urban environments (Affek and Eiler, 2006; Pataki et al., 2007; Widory and Javoy, 2003) making identification of anthropogenic $\mathrm{CO}_{2}$ on basis of $\Delta^{17} \mathrm{O}$ conceivable. For the case of anthropogenic emissions in urban environment, however, $\delta^{13} \mathrm{C}$ may be a better proxy than $\Delta^{17} \mathrm{O}$. 
For cases, where high atmospheric $\mathrm{CO}_{2}$ levels are either due to anthropogenic emissions or soil respiration, $\Delta^{17} \mathrm{O}$ can be used as an additional proxy to $\delta^{13} \mathrm{C}$ and $\delta^{18} \mathrm{O}$ values, because the traditional tracers $\left(\delta^{13} \mathrm{C}\right.$ and $\left.\delta^{18} \mathrm{O}\right)$ cannot distinguish between anthropogenic and soil emissions (Djuricin, 2010).

\subsection{Conclusions}

We demonstrate that $\mathrm{CO}_{2}$ from combustion of natural gas and propane-butane gas largely inherits the isotope composition of air $\mathrm{O}_{2}$ and has an anomaly of $\Delta^{17} \mathrm{O}=-0.30$ to $-0.32 \%$. Carbon dioxide from wood combustion contains a mixture of oxygen from atmospheric $\mathrm{O}_{2}$ and oxygen intrinsic to wood with a $\Delta^{17} \mathrm{O}=-0.21 \%$. The isotope composition of $\mathrm{CO}_{2}$ from car exhaust inherits the $\Delta^{17} \mathrm{O}$ of air $\mathrm{O}_{2}$, but has likely exchanged with similarly anomalous combustion water at $\mathrm{T}<100{ }^{\circ} \mathrm{C}$. Our experiments demonstrate that the isotope composition of respired $\mathrm{CO}_{2}$ is controlled by ambient water and does not carry a large anomaly in $\Delta^{17} \mathrm{O}$.

We have given constraints on the $\Delta^{17} \mathrm{O}$ value of selected $\mathrm{CO}_{2}$ sources that may be used as additional proxy when modeling the isotope composition of tropospheric $\mathrm{CO}_{2}$.

\subsection{Acknowledgments}

We thank E. Barkan for the calibration of our in-house reference $\mathrm{O}_{2}$ gas relative to VSMOW. We thank two reviewers (S. S. Assonov and an anonymous reviewer) whose comments led to considerable improvement of the manuscript. The German Science Foundation supported this project financially (AP, project PA909/6-1, PA909/6-2). 


\subsection{References}

Affek, H. P., Eiler, J. M., 2006. Abundance of mass $47 \mathrm{CO}_{2}$ in urban air, car exhaust, and human breath. Geochim. Cosmochim. Acta 70, 1-12.

Affek, H. P., Xu, X., Eiler, J. M., 2007. Seasonal and diurnal variations of ${ }^{13} \mathrm{C}^{18} \mathrm{O}^{16} \mathrm{O}$ in air: Initial observations from Pasadena, CA. Geochim. Cosmochim. Acta 71, 50335043.

Assonov, S., Brenninkmeijer, C., 2006. On the $\mathrm{N}_{2} \mathrm{O}$ correction used for mass spectrometric analysis of atmospheric $\mathrm{CO}_{2}$. Rapid Commun. Mass Spec. 20, 1809-1819.

Assonov, S. S., Brenninkmeijer, C. A. M., 2001. A new method to determine the ${ }^{17} \mathrm{O}$ isotopic abundance in $\mathrm{CO}_{2}$ using oxygen isotope exchange with a solid oxide. Rapid Commun. Mass Spec. 15, 2426-2437.

Assonov, S. S., Brenninkmeijer, C. A. M., 2005. Reporting small $\Delta^{17} \mathrm{O}$ values: existing definitions and concepts. Rapid Commun. Mass Spec. 19, 627-636.

Barkan, A., Luz, B., 2011. The relationship among the three stable isotopes of oxygen in air, seawater and marine photosynthesis. Rapid Commun. Mass Spec. 25, 23672369.

Barkan, E., Luz, B., 2005. High precision measurements of ${ }^{17} \mathrm{O} /{ }^{16} \mathrm{O}$ and ${ }^{18} \mathrm{O} /{ }^{16} \mathrm{O}$ ratios in $\mathrm{H}_{2}$ O. Rapid Commun. Mass Spec. 19, 3737-3742.

Brenninkmeijer, C. A. M., Kraft, P., Mook, W. G., 1983. Oxygen isotope fractionation between $\mathrm{CO}_{2}$ and $\mathrm{H}_{2} \mathrm{O}$. Isot. Geosci. 1, 181-190.

Brenninkmeijer, C. A. M., Röckmann, T., 1996. Russian doll type cryogenic traps: improved design and isotope separation effects. Anal. Chem. 68, 3050-3053.

Ciais, P., Denning, A. S., Tans, P. P., Berry, J. A., Randall, D., Collatz, J. G., Sellers, P. J., White, J. W., Trolier, M., Meijer, H. A. J., Francey, R. J., Monfray, P., Heimann, M., 1997. A three-dimensional synthesis study of $\delta^{18} \mathrm{O}$ in atmospheric $\mathrm{CO}_{2}$ : Part 1 Surface fluxes. J. Geophys. Res. 102, 5857-5872.

Ciais, P., Tans, P. P., Trolier, M., White, J. W. C., Francey, R. J., 1995. A large northern hemisphere terrestrial $\mathrm{CO}_{2}$ sink indicated by the ${ }^{13} \mathrm{C} /{ }^{12} \mathrm{C}$ ratio of atmospheric $\mathrm{CO}_{2}$. Science 269, 1098-1102.

Coplen, T. B., Hopple, J. A., Böhlke, J. K., Peiser, H. S., Rieder, S. E., Krouse, H. R., Rosman, K. J. R., Ding, T., Jr. Vocke, R. D., Révész, K. M., Lamberty, A., Taylor, P., De Bièvre, P., 2002. Compilation of minimum and maximum isotope ratios of selected elements in naturally occurring terrestrial materials and reagents.WaterResources Investigations Report U.S. Geological Survey, Reston, Virginia. 
Craig, H., 1953. The geochemistry of the stable carbon isotopes. Geochim. Cosmochim. Acta 3, 53-92.

Craig, H., 1954. Carbon 13 in plants and the relationships between carbon 13 and carbon 14 variations in nature. The Journal of Geology 62, 115-149.

Cuntz, M., Ciais, P., Hoffmann, G., Knorr, W., 2003b. A comprehensive global threedimensional model of $\delta^{18} \mathrm{O}$ in atmospheric $\mathrm{CO}_{2}: 1$. Validation of surface processes. J. Geophys. Res. 108, ACH1-ACH23.

Demény, A., Haszpra, L., 2002. Stable isotope compositions of $\mathrm{CO}_{2}$ in background air and at polluted sites in Hungary. Rapid Commun. Mass Spectrom. 16, 797-804.

DeNiro, M. J., Epstein, S., 1979. Relationship between the oxygen isotope ratios of terrestrial plant cellulose, carbon dioxide, and water. Science 204, 51-53.

Djuricin, S., 2010. A comparison of tracer methods for quantifying $\mathrm{CO}_{2}$ sources in an urban region. J. Geophys. Res. 115, D11303.

Epstein, S., Zeiri, L., 1988. Oxygen and Carbon Isotopic Compositions of Gases Respired by Humans. Proc. Natl. Acad. Sci. USA 85, 1727-1731.

Farquhar, G. D., Lloyd, J., Taylor, J. A., Flanagan, L. B., Syvertsen, J. P., Hubick, K. T., Wong, S. C., Ehleringer, J. R., 1993. Vegetation effects on the isotope composition of oxygen in atmospheric $\mathrm{CO}_{2}$. Nature 363, 439-443.

Francey, R. J., Tans, P. P., 1987. Latitudinal variation in oxygen-18 of atmospheric $\mathrm{CO}_{2}$. Nature 327, 495-497.

Gehler, A., Tütken, T., Pack, A., 2011. Triple oxygen isotope analysis of bioapatite as tracer for diagenetic alteration of bones and teeth. Palaeogeography, Palaeoclimatology, Palaeoecology 310, 84-91.

Gruber, N., 2001. An improved estimate of the isotopic air-sea disequilibrium of $\mathrm{CO}_{2}$ : Implications for the oceanic uptake of anthropogenic $\mathrm{CO}_{2}$. Geophys. Res. Lett. 28, 555.

Hoag, K. J., Still, C. J., Fung, I. Y., Boering, K. A., 2005. Triple oxygen isotope composition of tropospheric carbon dioxide as a tracer of terrestrial gross carbon fluxes. Geophys. Res. Lett. 32, 1-5.

Hofmann, M. E. G., Horváth, B., Pack, A., 2012a. Global long-term mean triple oxygen isotope composition of tropospheric $\mathrm{CO}_{2}$. Sixth International Symposium on Isotopomers, Washington DC. 
Hofmann, M. E. G., Horváth, B., Pack, A., 2012b. Triple oxygen isotope equilibrium fractionation between carbon dioxide and water. Earth Planet. Sci. Lett. 319-320, 159-164.

Hofmann, M. E. G., Pack, A., 2010. Technique for high-precision analysis of triple oxygen isotope ratios in carbon dioxide. Anal. Chem. 82, 4357-4361.

Hulston, J. R., Thode, H. G., 1965. Variations in the $\mathrm{S}^{33}, \mathrm{~S}^{34}$, and $\mathrm{S}^{36}$ contents of meteorites and their relation to chemical and nuclear effects. J. Geophys. Res. 70, 3475-3484.

Jäggi, M., Saurer, M., Fuhrer, J., Siegwolf, R., 2003. Seasonality of $\delta^{18} \mathrm{O}$ in needles and wood of Picea abies. New Phytologist 158, 51-59.

Jäggi, M. J., Saurer, M. S., Fuhrer, J. F., Siegwolf, R. S., 2002. The relationship between the stable carbon isotope composition of needle bulk material, starch, and tree rings in Picea abies. Oecologia 131, 325-332.

Keeling, C. D., 1958. The concentration and isotopic abundances of atmospheric carbon dioxide in rural areas. Geochim. Cosmochim. Acta 13, 322-334.

Keeling, C. D., 1961. The concentration and isotopic abundances of carbon dioxide in rural and marine air. Geochim. Cosmochim. Acta 24, 277-298.

Kim, S.-T., Mucci, A., Taylor, B. E., 2007. Phosphoric acid fractionation factors for calcite and aragonite between 25 and $75^{\circ} \mathrm{C}$ : Revisited. Chem. Geol. 246, 135-146.

Landais, A., Barkan, E., Yakir, D., Luz, B., 2006. The triple isotopic composition of oxygen in leaf water. Geochim. Cosmochim. Acta 70, 4105-4115.

Levin, I., 2003. A novel approach for independent budgeting of fossil fuel $\mathrm{CO}_{2}$ over Europe by ${ }^{14} \mathrm{CO}_{2}$ observations. Geophys. Res. Lett. 30, 2194.

Longinelli, A., 1984. Oxygen isotopes in mammal bone phosphate: A new tool for paleohydrological and paleoclimatological research? Geochim. Cosmochim. Acta 48, 385-390.

Luz, B., Barkan, E., 2010. Variations of ${ }^{17} \mathrm{O} /{ }^{16} \mathrm{O}$ and ${ }^{18} \mathrm{O} /{ }^{16} \mathrm{O}$ in meteoric waters. Geochim. Cosmochim. Acta 74, 6276-6286.

Luz, B., Kolodny, Y., Horowitz, M., 1984. Fractionation of oxygen isotopes between mammalian bone-phosphate and environmental drinking water. Geochim. Cosmochim. Acta 48, 1689-1693.

Miller, M. F., 2002. Isotopic fractionation and the quantification of ${ }^{17} \mathrm{O}$ anomalies in the oxygen three-isotope system: an appraisal and geochemical significance. Geochim. Cosmochim. Acta 66, 1881-1889. 
Newman, S., Xu, X., Affek, H. P., Stolper, E., Epstein, S., 2008. Changes in mixing ratio and isotopic composition of $\mathrm{CO}_{2}$ in urban air from the Los Angeles basin, California, between 1972 and 2003. J. Geophys. Res. 113, D23304.

NOAA, U. S. D. o. C., National Oceanic and Atmospheric Administration, Earth System Research Laboratory, Global Monitoring Division 2012. Mauna Loa, Hawaii United States (MLO). In-situ $\mathrm{CO}_{2}$ monthly averages.

Pack, A., Toulouse, C., Przybilla, R., 2007. Determination of oxygen triple isotope ratios of silicates without cryogenic separation of $\mathrm{NF}_{3}$ - technique with application to analyses of technical $\mathrm{O}_{2}$ gas and meteorite classification. Rapid Commun. Mass Spec. 21, 3721-3728.

Pataki, D., Xu, T., Luo, Y., Ehleringer, J., 2007. Inferring biogenic and anthropogenic carbon dioxide sources across an urban to rural gradient. Oecologia 152, 307-322.

Pataki, D. E., Bowling, D. R., Ehleringer, J. R., 2003. Seasonal cycle of carbon dioxide and its isotopic composition in an urban atmosphere: Anthropogenic and biogenic effects. J. Geophys. Res. 108, 4735.

Rooney, M. A., Claypool, G. E., Moses Chung, H., 1995. Modeling thermogenic gas generation using carbon isotope ratios of natural gas hydrocarbons. Chem. Geol. $126,219-232$.

Saurer, M., Siegwolf, R. T. W., Schweingruber, F. H., 2004. Carbon isotope discrimination indicates improving water-use efficiency of trees in northern Eurasia over the last 100 years. Global Change Biology 10, 2109-2120.

Schumacher, M., Werner, R. A., Meijer, H. A. J., Jansen, H. G., Brand, W. A., Geilmann, H., Neubert, R. E. M., 2011. Oxygen isotopic signature of $\mathrm{CO}_{2}$ from combustion processes. Atmos. Chem. Phys. 11, 1473-1490.

Sjostrom, E., 1993. Wood Chemistry. Fundamentals and Applications. Academic press., San Diego.

Tanaka, R., Nakamura, E., 2012. Kinetic isotope fractionation effect observed in oxygen triple isotope ratios in terrestrial silicate minerals. Sixth International Symposium on Isotopomers, Washington DC.

Widory, D., Javoy, M., 2003. The carbon isotope composition of atmospheric $\mathrm{CO}_{2}$ in Paris. Earth Planet. Sci. Lett. 215, 289-298.

Yakir, D., 2003. The stable isotopic composition of atmospheric $\mathrm{CO}_{2}$. In: Keeling, R. F. (Ed.), The Atmosphere. Elsevier-Pergamon, Oxford.

Yakir, D., DeNiro, M. J., 1990. Oxygen and hydrogen isotope fractionation during cellulose metabolism in Lemna gibba L. Plant Physiology 93, 325. 
Yanes, Y., Yapp, C. J., 2010. Indoor and outdoor urban atmospheric $\mathrm{CO}_{2}$ : Stable carbon isotope constraints on mixing and mass balance. Appl. Geochem. 25, 1339-1349.

Young, E. D., Galy, A., Nagahara, H., 2002. Kinetic and equilibrium mass-dependent isotope fractionation laws in nature and their geochemical and cosmochemical significance. Geochim. Cosmochim. Acta 66, 1095-1104. 


\title{
5 Triple oxygen isotope composition of tropospheric $\mathrm{CO}_{2}$ : Observational data and model simulation
}

\author{
Hofmann, M.E.G., Horváth, B. and Pack, A., \\ Triple oxygen isotope composition of tropospheric $\mathrm{CO}_{2}$ : Observational data and model \\ simulation, in preparation
}

\subsection{Abstract}

In recent years, modeling results suggested that the triple oxygen isotope composition of tropospheric $\mathrm{CO}_{2}$ might be a promising new tracer for terrestrial gross carbon fluxes. Here, we present high-precision triple oxygen isotope data of ambient air $\mathrm{CO}_{2}$ sampled in Göttingen (NW Germany) over the course of 2 years and on top of the Brocken Mountain (1140 m, NW Germany). We compare our observational data to a revised triple oxygen isotope mass balance model of tropospheric $\mathrm{CO}_{2}$ where we reconcile both ${ }^{18} \mathrm{O} /{ }^{16} \mathrm{O}$ and ${ }^{17} \mathrm{O} /{ }^{16} \mathrm{O}$ fractionation processes. All triple oxygen isotope data are reported as $\Delta^{17} \mathrm{O}$ values relative to a $\mathrm{CO}_{2}$-water equilibration line with $\Delta^{17} \mathrm{O}=\ln \left(\delta^{17} \mathrm{O}+1\right)-0.522 \times \ln \left(\delta^{18} \mathrm{O}+1\right)$. Carbon dioxide sampled in Göttingen has a long-term mean triple oxygen isotope composition with $\delta^{18} \mathrm{O}_{\text {VSMOW }}=41.6 \pm 0.9 \%$ (SD) and $\Delta^{17} \mathrm{O}=-0.03 \pm 0.07 \%$ (SD). The $\Delta^{17} \mathrm{O}$ signal shows a temporal variation with a peak-to-peak range of about $0.25 \%$ that parallels the seasonal $\delta^{18} \mathrm{O}$ cycle from summer 2010 to winter 2011, but deviates from the seasonal pattern in 2012. Three samples from the Brocken Mountain fall within the range observed in Göttingen. Overall, the observational data are slightly lower than the prediction for the global troposphere of $+0.06 \%$. A Monte Carlo simulation gives an uncertainty estimate intrinsic to our model of $\pm 0.05 \%$ (SD). The revised global mass balance model shows a sensitivity of $\Delta^{17} \mathrm{O}$ of tropospheric $\mathrm{CO}_{2}$ to variations in the terrestrial gross primary production, which is only slightly lower than previously predicted. However, the discrepancy between the observed and predicted mean $\Delta^{17} \mathrm{O}$ and the large interannual variation in $\Delta^{17} \mathrm{O}$ requires future investigations. 


\subsection{Introduction}

The triple oxygen isotope composition of strato- and mesospheric $\mathrm{CO}_{2}$ is characterized by a large oxygen isotope anomaly (Boering et al., 2004; Kawagucci et al., 2008; Lämmerzahl et al., 2002; Thiemens et al., 1995b). This anomaly has its origin in the formation of ozone in the stratosphere and is passed on to stratospheric $\mathrm{CO}_{2}$ via exchange with $\mathrm{O}\left({ }^{1} \mathrm{D}\right.$ ) (Yung et al., 1991). As stratospheric $\mathrm{CO}_{2}$ enters the troposphere, the anomaly is lost due to dilution with mass-dependently fractionated $\mathrm{CO}_{2}$ and isotopic exchange with water in the hydroand biosphere.

To date, extensive data on the triple oxygen isotope composition of stratospheric $\mathrm{CO}_{2}$ were reported in the literature (Boering et al., 2004; Kawagucci et al., 2008; Lämmerzahl et al., 2002; Thiemens et al., 1995b), but no high-precision data on tropospheric $\mathrm{CO}_{2}$ have been published so far. The lack of high-precision data on $\Delta^{17} \mathrm{O}$ of tropospheric $\mathrm{CO}_{2}$ motivated Hoag et al. (2005) to set up a model that characterizes the triple oxygen isotope composition of tropospheric $\mathrm{CO}_{2}$. The authors predict that tropospheric $\mathrm{CO}_{2}$ should have an oxygen isotope anomaly of $\sim 0.15 \%$ relative to a reference line with a slope of 0.516 in a $\delta^{18} \mathrm{O}$ vs. $\delta^{17} \mathrm{O}$ plot (corresponding to $\Delta^{17} \mathrm{O}=0.11 \%$ relative to a reference line with a slope of 0.522 in a $\ln \left(\delta^{18} \mathrm{O}+1\right)$ vs. $\ln \left(\delta^{17} \mathrm{O}+1\right)$ plot, see section 5.3.1 for definition of $\delta$ and $\Delta{ }^{17} \mathrm{O}$ values) and they postulate that high-precision $\Delta^{17} \mathrm{O}$ analyses of tropospheric $\mathrm{CO}_{2}$ should constrain estimates on terrestrial gross primary productivity. However, the model prediction is based on several simplified assumptions for biosphere-atmosphere interaction, e.g. the authors assume that the exponent $\theta$, where $\alpha^{17 / 16}=\left(\alpha^{18 / 16}\right)^{\theta}$, for $\mathrm{CO}_{2^{-}}$ water equilibrium isotope exchange is 0.516. Recently, Hofmann et al. (2012b) determined an exponent of $0.522 \pm 0.002$ for $\mathrm{CO}_{2}$-water equilibrium exchange, and thus, a revised model prediction of $\Delta^{17} \mathrm{O}$ of tropospheric $\mathrm{CO}_{2}$ becomes necessary.

Here, we present a revised global mass balance model for the triple oxygen isotope composition of tropospheric $\mathrm{CO}_{2}$, where we reconcile the assumptions for ${ }^{18} \mathrm{O} /{ }^{16} \mathrm{O}$ and ${ }^{17} \mathrm{O} /{ }^{16} \mathrm{O}$ fractionation of atmospheric $\mathrm{CO}_{2}$ : (i) we implement the experimental results for the exponent $\theta$ for $\mathrm{CO}_{2}$-water equilibrium (Hofmann et al., 2012b), (ii) we take into account that the main water reservoirs that exchange with atmospheric $\mathrm{CO}_{2}$ (ocean, soil and leaf water) have a distinct triple oxygen isotope signature (Landais et al., 2006; Luz and Barkan, 2010) and (iii) we assume that $\mathrm{CO}_{2}$ sinks can also fractionate the triple oxygen isotope composition. 
Subsequent, we compare the revised model prediction to high-precision triple oxygen isotope data of tropospheric $\mathrm{CO}_{2}$ from Göttingen, a medium-sized town located in the center of Germany, and triple oxygen isotope data of $\mathrm{CO}_{2}$ sampled on top of the nearby Brocken Mountain.

\subsection{Method}

\subsubsection{Triple oxygen isotope notation}

Oxygen isotope ratios $\left({ }^{17} \mathrm{O} /{ }^{16} \mathrm{O}\right.$ and $\left.{ }^{18} \mathrm{O} /{ }^{16} \mathrm{O}\right)$ are traditionally reported as $\delta$-values relative to VSMOW:

$$
\delta^{17} O=\left[\frac{\left({ }^{17} \mathrm{O} /{ }^{16} O\right)_{\text {sample }}}{\left({ }^{17} \mathrm{O} /{ }^{16} O\right)_{\text {VSMOW }}}-1\right]
$$

and

$$
\delta^{18} O=\left[\frac{\left({ }^{18} \mathrm{O} /{ }^{16} O\right)_{\text {sample }}}{\left({ }^{18} \mathrm{O} /{ }^{16} \mathrm{O}\right)_{\text {VSMOW }}}-1\right]
$$

Small variations in the triple oxygen isotope composition are reported as deviations from a mass-dependent reference line in a triple oxygen isotope plot with logarithmic $\delta$ coordinates (Hulston and Thode, 1965; Miller, 2002; Young et al., 2002):

$$
\Delta^{17} \mathrm{O}_{R L}=\ln \left(\delta^{17} \mathrm{O}+1\right)-\lambda_{R L} \times \ln \left(\delta^{18} \mathrm{O}+1\right)-\gamma_{R L}
$$

In this study, we take a $\mathrm{CO}_{2}$-water equilibration line as reference line (RL) with a slope $\lambda_{\mathrm{RL}}=0.522$ and zero intercept, e.g. $\gamma_{\mathrm{RL}}=0 \%$. The slope is based on the exponent $\theta$ for equilibrium exchange between $\mathrm{CO}_{2}$ and water (Hofmann et al., 2012b); the zero intercept was chosen for simplicity. The logarithmic $\delta$-values are abbreviated as $\delta$ '-values with $\delta^{, 17} \mathrm{O}=\ln \left(\delta^{17} \mathrm{O}+1\right)$ and $\delta^{18} \mathrm{O}=\ln \left(\delta^{18} \mathrm{O}+1\right)$. For the ${ }^{18} \mathrm{O} /{ }^{16} \mathrm{O}$ mass balance calculation, all oxygen isotope ratios are reported as $\delta^{18} \mathrm{O}$ values. 


\subsubsection{Model description}

Various $\mathrm{CO}_{2}$ sources and sinks characterize the triple oxygen isotope signature of tropospheric $\mathrm{CO}_{2}$. We consider the following gross fluxes $\mathrm{F}$ that affect the tropospheric $\mathrm{CO}_{2}$ reservoir:

$d M / d t=F_{A}(t)+F_{r e s p}(t)+F_{O A}(t)+F_{A O}(t)+F_{S A}(t)+F_{A S}(t)+F_{S I A}(t)+F_{A S I}(t)+F_{f f}+F_{\text {fire }}$

with

$$
\begin{aligned}
& \mathrm{dM} / \mathrm{dt}=\text { rate of increase of tropospheric } \mathrm{CO}_{2} \text { reservoir (in } \mathrm{PgC} / \mathrm{yr} \text { ) } \\
& \mathrm{F}_{\mathrm{A}} \quad=\text { terrestrial assimilation flux (in } \mathrm{PgC} / \mathrm{yr} \text { ) } \\
& \mathrm{F}_{\text {resp }} \quad=\mathrm{CO}_{2} \text { emitted from terrestrial respiration (in } \mathrm{PgC} / \mathrm{yr} \text { ) } \\
& \mathrm{F}_{\mathrm{OA}} \quad=\mathrm{CO}_{2} \text { emitted from the oceans (in } \mathrm{PgC} / \mathrm{yr} \text { ) } \\
& \mathrm{F}_{\mathrm{AO}} \quad=\mathrm{CO}_{2} \text { taken up by oceans (in } \mathrm{PgC} / \mathrm{yr} \text { ) } \\
& \mathrm{F}_{\mathrm{SA}} \quad=\text { stratospheric } \mathrm{CO}_{2} \text { entering the troposphere (in } \mathrm{PgC} / \mathrm{yr} \text { ) } \\
& \mathrm{F}_{\mathrm{AS}} \quad=\text { tropospheric } \mathrm{CO}_{2} \text { entering the stratosphere (in } \mathrm{PgC} / \mathrm{yr} \text { ) } \\
& \mathrm{F}_{\mathrm{SIA}} \quad=\text { soil invasion flux to troposphere (in } \mathrm{PgC} / \mathrm{yr} \text { ) } \\
& \mathrm{F}_{\mathrm{ASI}} \quad=\text { soil invasion flux from troposphere (in } \mathrm{PgC} / \mathrm{yr} \text { ) } \\
& \mathrm{F}_{\mathrm{ff}} \quad=\mathrm{CO}_{2} \text { emitted from fossil fuel burning (in } \mathrm{PgC} / \mathrm{yr} \text { ) } \\
& \mathrm{F}_{\text {fire }} \quad=\mathrm{CO}_{2} \text { emitted from biomass burning (in } \mathrm{PgC} / \mathrm{yr} \text { ) }
\end{aligned}
$$

We use an initial size of $830 \mathrm{PgC}\left(=\mathrm{M}_{0}\right)$ for the tropospheric $\mathrm{CO}_{2}$ reservoir and an increase rate of $4 \mathrm{PgC} / \mathrm{yr}(=\mathrm{dM} / \mathrm{dt})$ (Canadell et al., 2007; Le Quéré et al., 2009). Note that the size of the $\mathrm{CO}_{2}$ fluxes (except $\mathrm{F}_{\mathrm{ff}}$ and $\mathrm{F}_{\text {fire }}$ ) increases as the $\mathrm{CO}_{2}$ concentration in the atmosphere increases. The initial magnitudes of the carbon sources and sinks are listed in Table 5-1 and will be discussed in detail below. 
In order to model the global $\delta^{18} \mathrm{O}$ composition of tropospheric $\mathrm{CO}_{2}\left(=\delta_{\mathrm{a}}\right)$, we consider the following global mass balance equation according to previous studies (e.g. Ciais et al., 1997; Cuntz et al., 2003a; Cuntz et al., 2003b; Welp et al., 2011):

$$
\begin{aligned}
\frac{d \delta_{a}}{d t}= & \frac{1}{M_{0}+(d M / d t) t} \times \\
& {\left[F_{A}(t) D_{A}+F_{\text {resp }}(t)\left(\delta_{\text {resp }}-\delta_{a}\right)+F_{O A}(t)\left(\delta_{O}-\delta_{a}\right)+F_{S A}(t)\left(\delta_{\text {strat }}-\delta_{a}\right)\right.} \\
& \left.+F_{S I A}(t)\left(\delta_{S I}-\delta_{a}\right)+F_{f f}\left(\delta_{f f}-\delta_{a}\right)+F_{\text {fire }}\left(\delta_{\text {fire }}-\delta_{a}\right)\right]
\end{aligned}
$$

with

$$
\begin{aligned}
& \mathrm{M}_{0} \quad=\text { initial size of tropospheric } \mathrm{CO}_{2} \text { reservoir (in } \mathrm{PgC} \text { ) } \\
& \mathrm{D}_{\mathrm{A}} \quad=\delta^{18} \mathrm{O} \text { isotope discrimination due to assimilation (in \%o), i.e. kinetic }
\end{aligned}
$$
fractionation during diffusion into and out of leaf stomata and $\mathrm{CO}_{2}$-water equilibration in the stomata

$\delta_{\text {resp }}=\delta^{18} \mathrm{O}$ value of $\mathrm{CO}_{2}$ emitted from terrestrial respiration (in \%o)

$\delta_{\mathrm{O}} \quad=\delta^{18} \mathrm{O}$ value of $\mathrm{CO}_{2}$ emitted from the ocean (in \%o)

$\delta_{\text {strat }}=\delta^{18} \mathrm{O}$ value of $\mathrm{CO}_{2}$ from the lower stratosphere (in \%o)

$\delta_{\mathrm{SI}} \quad=\delta^{18} \mathrm{O}$ value of $\mathrm{CO}_{2}$ in equilibrium with soil water (in \%o)

$\delta_{\mathrm{ff}} \quad=\delta^{18} \mathrm{O}$ value of $\mathrm{CO}_{2}$ from fossil fuel burning (in \%o)

$\delta_{\text {fire }} \quad=\delta^{18} \mathrm{O}$ value of $\mathrm{CO}_{2}$ from biomass burning (in \%o)

For the mass balance equations we abbreviate $\delta^{18} \mathrm{O}$ values with $\delta$. The isotopic signatures are listed in Table 5-2 and will also be discussed in detail below. In Eq. 5-5, we can omit the carbon sinks $\mathrm{F}_{\mathrm{AO}}, \mathrm{F}_{\mathrm{AS}}$ and $\mathrm{F}_{\mathrm{ASI}}$ because the $\delta$-values of the transported $\mathrm{CO}_{2}$ are identical to $\delta_{\mathrm{a}}$. 
In accordance with the global budget equation for the $\delta^{18} \mathrm{O}$ composition of the troposphere (Eq. 5-5), we calculate the $\Delta^{17} \mathrm{O}$ signature of tropospheric $\mathrm{CO}_{2}\left(=\Delta^{17}{ }_{\mathrm{a}}\right)$ :

$$
\begin{aligned}
\frac{d \Delta_{a}^{17}}{d t}= & \frac{1}{M_{0}+(d M / d t) t} \times \\
& {\left[F_{A}(t) D_{A}^{17}+F_{\text {resp }}(t)\left(\Delta_{\text {resp }}^{17}-\Delta_{a}^{17}\right)+F_{O A}(t)\left(\Delta_{O}^{17}-\Delta_{a}^{17}\right)+F_{S A}(t)\left(\Delta_{\text {strat }}^{17}-\Delta_{a}^{17}\right)+\right.} \\
& \left.F_{S I A}(t)\left(\Delta_{S I}^{17}-\Delta_{a}^{17}\right)+F_{f f}\left(\Delta_{f f}^{17}-\Delta_{a}^{17}\right)+F_{\text {fire }}\left(\Delta_{\text {fire }}^{17}-\Delta_{a}^{17}\right)\right]
\end{aligned}
$$

with

$\mathrm{D}^{17}{ }_{\mathrm{A}}=\Delta^{17} \mathrm{O}$ isotope discrimination due to assimilation (in \%o), i.e. kinetic fractionation during diffusion into and out of leaf stomata and $\mathrm{CO}_{2}$-water equilibration in the stomata

$\Delta^{17}{ }_{\text {resp }}=\Delta^{17} \mathrm{O}$ value of $\mathrm{CO}_{2}$ emitted from terrestrial respiration (in \%o)

$\Delta^{17} \mathrm{O}=\Delta^{17} \mathrm{O}$ value of $\mathrm{CO}_{2}$ in equilibrium with ocean water (in \%o)

$\Delta^{17}{ }_{\text {strat }}=\Delta^{17} \mathrm{O}$ value of $\mathrm{CO}_{2}$ from the lower stratosphere (in \%o)

$\Delta^{17} \mathrm{SI}=\Delta{ }^{17} \mathrm{O}$ value of $\mathrm{CO}_{2}$ in equilibrium with soil water (in \%o)

$\Delta^{17}$ ff $=\Delta^{17} \mathrm{O}$ value of $\mathrm{CO}_{2}$ from fossil fuel burning (in \%o)

$\Delta^{17}$ fire $=\Delta^{17} \mathrm{O}$ value of $\mathrm{CO}_{2}$ from biomass burning (in \%o)

$\lambda_{\text {kinetic }}=$ triple oxygen isotope exponent for kinetic fractionation

For the model description, we abbreviate $\Delta^{17} \mathrm{O}$ values with $\Delta^{17}$. Both mass balance equations reach a quasi steady-state after a few years, and thus, all model results are given for $\mathrm{t}=50 \mathrm{yr}$.

Note that strictly speaking the $\Delta^{17} \mathrm{O}$ mass balance formulation gives only an approximation for $\Delta^{17}$ a. To be precise, a $\delta^{17} \mathrm{O}$ mass balance equation would be more appropriate, however, our approximation with $\Delta^{17} \mathrm{O}$ values changes the final outcome by less than $0.002 \%$.

\section{Terrestrial assimilation}

The terrestrial biosphere fixes about $120 \mathrm{PgC}$ per year (Beer et al., 2010). This rate of carbon fixation by the biosphere is generally termed gross primary production (GPP). Ciais et al. (1997) estimate that about $12 \%$ of the annual GPP are consumed by leaf respiration. Furthermore, we assume that the rate of assimilation increases as the $\mathrm{CO}_{2}$ concentration increases: 


$$
F_{A}(t)=0.88 G P P\left(1+\frac{d M / d t}{M_{0}} t\right)
$$

The assimilation rate of the terrestrial biosphere is driven by the difference in $\mathrm{CO}_{2}$ concentration in the leaf stomata $\left(C_{c s}\right)$ and the atmosphere $\left(C_{a}\right)$ (Farquhar et al., 1993):

$$
F_{A}=\frac{C_{a}}{C_{a}-C_{c s}} F_{A}-\frac{C_{c s}}{C_{a}-C_{c s}} F_{A}=-\left(F_{L A}+F_{A L}\right)
$$

where $\mathrm{F}_{\mathrm{LA}}$ denotes the amount of $\mathrm{CO}_{2}$ that is released per year from the stomata to the atmosphere and $\mathrm{F}_{\mathrm{AL}}$ is the amount of $\mathrm{CO}_{2}$ diffusing into terrestrial leaf stomata. The $\mathrm{C}_{\mathrm{cs}} / \mathrm{C}_{\mathrm{a}}$ ratio varies between $\mathrm{C}_{3}$ and $\mathrm{C}_{4}$ plants because the latter fix carbon dioxide more effectively due to a different photosynthetic pathway (Pearcy and Ehleringer, 1984). For the mass balance calculation we assume an overall $\mathrm{C}_{\mathrm{cs}} / \mathrm{C}_{\mathrm{a}}$ ratio of 0.70 (Ciais et al., 1997; Cuntz et al., 2003a; Cuntz et al., 2003b), which takes into account that about $77 \%$ of the global GPP can be traced back to $\mathrm{C}_{3}$ plants $\left(\mathrm{f}_{\mathrm{C} 3}\right)$ and the remaining to $\mathrm{C}_{4}$ plants $\left(\mathrm{f}_{\mathrm{C} 4}\right)$ (Lloyd and Farquhar, 1994; Still et al., 2003).

The $\mathrm{CO}_{2}$ diffusing into the leaf stomata rapidly exchanges its oxygen isotopes with the leaf water. For $\mathrm{C}_{3}$ plants, about $93 \%$ of the $\mathrm{CO}_{2}$ diffusing out of the stomata is in isotopic equilibrium with leaf water $\left(\Theta_{\mathrm{C} 3}=0.93\right)$ and for $\mathrm{C}_{4}$ plants about $38 \%$ of the $\mathrm{CO}_{2}$ is in isotopic equilibrium $\left(\Theta_{\mathrm{C} 4}=0.38\right)$ (Gillon and Yakir, 2001; Gillon and Yakir, 2000). Thus, we can estimate the fraction of $\mathrm{CO}_{2}$ that is in equilibrium with leaf water $\left(\mathrm{F}_{\text {LAequ }}\right)$ and the fraction of $\mathrm{CO}_{2}$ that is not affected by exchange with leaf water $\left(\mathrm{F}_{\mathrm{LAnonequ}}\right)$ :

$$
F_{\text {LAequ }}=\left(f_{C 3} \times \Theta_{C 3}+f_{C 4} \times \Theta_{C 4}\right) \times F_{L A}
$$

and

$$
F_{\text {LAnonequ }}=\left(f_{C 3} \times\left(1-\Theta_{C 3}\right)+f_{C 4} \times\left(1-\Theta_{C 4}\right)\right) \times F_{L A}
$$

The ${ }^{18} \mathrm{O} /{ }^{16} \mathrm{O}$ ratio of $\mathrm{CO}_{2}$ in equilibrium with leaf water $\left(\delta_{\mathrm{L}}\right)$ depends on (i) the isotopic composition of the soil and stem water $\left(\delta_{\mathrm{SW}}=-7.5 \%\right.$, Ciais et al. 1997), (ii) the degree of kinetic fractionation due to evapotranspiration in the leaves $\left(\alpha_{\text {transpiration }}=0.9917\right.$, West et al., 2008) and (iii) the equilibration temperature $\left(\mathrm{T}_{\text {leaf }}=285 \mathrm{~K}\right.$, Ciais et al., 1997):

$$
\delta_{L}=\left(\delta_{S W}+1\right) \frac{\alpha_{C O 2-\text { water }}\left(T_{\text {leaf }}\right)}{\alpha_{\text {transpiration }}}
$$


where $\alpha_{\mathrm{CO} 2 \text {-water }}$ is the temperature dependent ${ }^{18} \mathrm{O} /{ }^{16} \mathrm{O}$ fractionation factor for $\mathrm{CO}_{2}$-water exchange according to Brenninkmeijer et al. (1983).

The ${ }^{18} \mathrm{O} /{ }^{16} \mathrm{O}$ isoflux for carbon assimilation during photosynthesis (in $\% \mathrm{PgC} / \mathrm{yr}$ ) can then be expressed as:

$$
F_{A} \times D_{A}=\left(\alpha_{L}-1\right) \times\left(F_{A L}+F_{\text {LAnonequ }}\right)+\left(\left(\delta_{L}+1\right) \times \alpha_{L}-1-\delta^{\prime}{ }_{a}\right) \times F_{\text {LAequ }}
$$

where $\alpha_{L}=0.9926$ describes the kinetic fractionation factor for diffusion into and out of the stomata (Farquhar et al., 1993).

Similar to ${ }^{18} \mathrm{O} /{ }^{16} \mathrm{O}$, the triple oxygen isotope composition of $\mathrm{CO}_{2}$ emitted from plants depends on the oxygen isotope signature of soil water. We assume that the triple oxygen isotope composition of soil water $\left(\Delta^{17} \mathrm{sw}\right)$ at the depth where plant roots take up water is not affected by evaporation and that it falls on the global meteoric water line (GMWL) with a slope $\lambda_{\mathrm{GMWL}}=0.528$ and an intercept $\gamma_{\mathrm{GMWL}}=0.033 \%$ (Luz and Barkan, 2010):

$$
\Delta_{S W}^{17}=\left(\lambda_{G M W L}-\lambda_{R L}\right) \times \ln \left(\delta_{S W}+1\right)+\gamma_{G M W L}
$$

Given this relationship, soil water with $\delta_{\mathrm{SW}}=-7.5 \%$ has a $\Delta^{17}$ Sw value of $-0.01 \%$.

The triple oxygen isotope composition of $\mathrm{CO}_{2}$ in equilibrium with leaf water $\left(\Delta^{17}\right)$ depends on (i) the isotopic composition of the soil water, (ii) the degree of evapotranspiration and (iii) the oxygen isotope exchange between $\mathrm{CO}_{2}$ and water in the stomata (see Fig. 5-1):

$$
\Delta_{L}^{17}=\Delta_{S W}^{17}+\left(\lambda_{R L}-\lambda_{\text {transpiration }}\right) \times \ln \left(\alpha_{\text {transpiration }}\right)+\left(\lambda_{R L}-\theta_{\text {CO2-water }}\right) \times \ln \left(\alpha_{\text {CO2-water }}\left(T_{\text {leaf }}\right)\right) \quad \text { Eq. }
$$

where $\theta_{\mathrm{CO} 2 \text {-water }}$ is the exponent for triple oxygen isotope exchange between $\mathrm{CO}_{2}$ and water and $\lambda_{\text {transpiration }}$ the exponent for transpiration in plant leaves. In a previous study, we determined an exponent $\theta_{\mathrm{CO} 2 \text {-water }}$ of $0.522 \pm 0.002$ for the temperature range of 2 to $37^{\circ} \mathrm{C}$ (Hofmann et al., 2012b). For the exponent $\lambda_{\text {transpiration, Landais et al. (2006) showed that it }}$ depends on the mean humidity $\mathrm{h}$ above the leaf stomata: $\lambda_{\text {transpiration }}=0.522-0.008 \times \mathrm{h}$. Note that the slope of the reference line $\lambda_{\mathrm{RL}}$ is equal to the exponent $\theta_{\mathrm{CO} 2 \text {-water }}$ and for this particular case the last term becomes zero. 
The ${ }^{17} \mathrm{O} /{ }^{16} \mathrm{O}$ isoflux for photosynthetic activity of terrestrial plants (in $\%{ }_{0} \mathrm{PgC} / \mathrm{yr}$ ) can be calculated according to the ${ }^{18} \mathrm{O} /{ }^{16} \mathrm{O}$ isoflux (see Eq. 5-12):

$$
\begin{aligned}
F_{A} \times \Delta_{A}^{17}= & \left(\ln \left(\alpha_{L}\right) \times\left(\lambda_{\text {kinetic }}-\lambda_{R L}\right)\right) \times\left(F_{A L}+F_{\text {LAnonequ }}\right) \\
& +\left(\Delta_{L}^{17}+\left(\lambda_{\text {kinetic }}-\lambda_{R L}\right) \times \ln \left(\alpha_{L}\right)-\Delta_{a}^{17}\right) \times F_{\text {LAequ }}
\end{aligned}
$$

Equation 5-15 illustrates that all the $\mathrm{CO}_{2}$ diffusing into and out of the stomata is kinetically fractionated, but only a part of the $\mathrm{CO}_{2}$ equilibrates with leaf water before retro-diffusing into the atmosphere.

\section{Respiration and soil invasion}

Most of the carbon assimilated by terrestrial photosynthesis is eventually released back to the atmosphere as $\mathrm{CO}_{2}$ due to soil respiration. The net carbon sink due to terrestrial carbon assimilation is about $3 \mathrm{PgC} / \mathrm{yr}$ (Canadell et al., 2007; Le Quéré et al., 2009):

$$
F_{\text {resp }}(t)=A(t)-3 \mathrm{PgC} / \mathrm{yr}
$$

Based on our assumption on GPP and the relationship given above, the flux from terrestrial respiration is $102.6 \mathrm{PgC} / \mathrm{yr}$.

Carbon dioxide produced by soil respiration rapidly equilibrates with soil water at a global mean temperature of $12^{\circ} \mathrm{C}$ (Ciais et al., 1997). Subsequently, it is kinetically fractionated during the diffusion process out of the soil column with $\alpha_{\mathrm{S}}=0.9928$ (Miller et al., 1999a):

$$
\delta_{\text {resp }}=\left(\delta_{S W}+1\right) \alpha_{\text {CO2-water }}\left(T_{\text {soil }}\right) \alpha_{S}-1
$$

Analogous to $\delta_{\text {resp }}$, we estimate the triple oxygen isotope composition of soil respired $\mathrm{CO}_{2}$ :

$$
\Delta_{\text {resp }}^{17}=\Delta_{S W}^{17}-\left(\lambda_{R L}-\theta_{C O 2-\text { water }}\right) \times \ln \left(\alpha_{\text {CO2-water }}\left(T_{\text {soil }}\right)\right)-\left(\lambda_{R L}-\lambda_{\text {kinetic }}\right) \times \ln \left(\alpha_{S}\right) \quad \text { Eq. 5-18 }
$$

$\mathrm{CO}_{2}$ diffusing into the uppermost soil column equilibrates with soil water and diffuses back to the atmosphere. This process is known as the soil invasion flux (Miller et al., 1999a; Tans, 1998). We take a soil invasion flux $\mathrm{F}_{\mathrm{SI}}$ of $30 \mathrm{PgC}$ per year (Stern et al., 2001). Recently, Wingate et al. (2009) suggested that the soil invasion flux might account for up to $450 \mathrm{PgC} / \mathrm{yr}$ and we considered this estimate as an upper limited for the soil invasion flux in the Monte Carlo simulation (see below section on the Monte Carlo simulation). 
The isotopic composition of the soil invasion flux depends on the global mean soil water isotope composition and on the equilibration temperature in the soils:

$$
\delta_{S I}=\left(\delta_{S W}+1\right) \times \alpha_{C O 2-\text { water }}\left(T_{\text {soil }}\right)-1
$$

Analog to $\delta_{\mathrm{SI}}$, we estimate the triple oxygen isotope signature of the soil invasion flux:

$$
\Delta_{S I}^{17}=\Delta_{S W}^{17}-\left(\lambda_{R L}-\theta_{C O 2-\text { water }}\right) \times \ln \left(\alpha_{C O 2-\text { water }}\left(T_{\text {soil }}\right)\right)
$$

\section{Ocean gross fluxes}

We assume that the gross $\mathrm{CO}_{2}$ flux from the oceans to the troposphere is about $90 \mathrm{PgC} / \mathrm{yr}$ (Heimann and Maier-Reimer, 1996):

$$
F_{O A}(t)=90 \mathrm{PgC} / \mathrm{yr}\left(1+\frac{d M / d t}{M_{0}} t\right)
$$

Global carbon models generally consider a constant net ocean sink of $2 \mathrm{PgC} / \mathrm{yr}$ (Canadell et al., 2007; Le Quéré et al., 2009). However, we omit the carbon sink flux for triple oxygen isotope calculations because the oxygen isotope fractionation occurring at the airsea interface is negligible (e.g. Ciais et al., 2005).

The mean oxygen isotope composition of ocean water is $\delta_{\text {ocean }}=0 \%$ and $\Delta^{17}{ }_{\text {ocean }}=-0.005 \%$ (Luz and Barkan, 2010). The $\mathrm{CO}_{2}$ diffusing into the ocean surface water equilibrates rapidly with the ocean water at a global mean temperature of $18^{\circ} \mathrm{C}$ (Ciais et al., 1997). It follows from the above that

$$
\delta_{O}=\left(\delta_{\text {ocean }}+1\right) \times \alpha_{\text {CO2-water }}\left(T_{\text {ocean }}\right)-1
$$

and

$$
\Delta_{O}^{17}=\Delta_{\text {ocean }}^{17}-\left(\lambda_{R L}-\theta_{\text {CO2-water }}\right) \times \ln \left(\alpha_{\text {CO2-water }}\left(T_{\text {soil }}\right)\right)
$$




\section{Stratosphere-troposphere exchange fluxes}

The $\mathrm{CO}_{2}$ fluxes from the troposphere into the stratosphere and vice versa are $100 \mathrm{PgC} / \mathrm{yr}$ and $-100 \mathrm{PgC} / \mathrm{yr}$, respectively (Appenzeller et al., 1996). Because the $\mathrm{CO}_{2}$ flux leaving the troposphere is not fractionated, we only have to consider the $\mathrm{CO}_{2}$ source entering the troposphere:

$$
F_{S A}(t)=100 \operatorname{PgC} / \mathrm{yr}\left(1+\frac{d M / d t}{M_{0}} t\right)
$$

Carbon dioxide from the stratosphere is enriched in ${ }^{18} \mathrm{O}$ due to isotopic exchange with stratospheric ozone (Gamo et al., 1989). Kawagucci et al. (2008) estimate the oxygen isotope fluxes for stratospheric carbon dioxide to the troposphere based on a linear correlation between the $\mathrm{N}_{2} \mathrm{O}$ mixing ratio and the $\delta^{18} \mathrm{O}$ composition of $\mathrm{CO}_{2}$. For $\delta^{18} \mathrm{O}$, the authors give $+38 \%$ ogC/yr. Combining their data with an estimate for the $\mathrm{CO}_{2}$ flux size of $100 \mathrm{PgC} / \mathrm{yr}$ (Appenzeller et al., 1996), we assume that stratospheric $\mathrm{CO}_{2}$ is enriched relative to tropospheric $\mathrm{CO}_{2}$ by $0.4 \%$ :

$$
\delta_{\text {strat }}=\delta_{a}+0.4 \%
$$

Similar to $\delta^{18} \mathrm{O}$, the ${ }^{17} \mathrm{O}$ enrichment of the stratospheric $\mathrm{CO}_{2}$ flux to the troposphere can be estimated on combined $\Delta^{17} \mathrm{O}\left(\mathrm{CO}_{2}\right)$ and $\mathrm{N}_{2} \mathrm{O}$ measurements of stratospheric air masses (Boering et al., 2004; Kawagucci et al., 2008). Boering et al. (2004) determined a net $\mathrm{CO}_{2}$ flux from the stratosphere of $42.9 \% \mathrm{PgC} / \mathrm{yr}$ and Kawagucci et al. (2008) determined a value of $48 \% \mathrm{PgC} / \mathrm{yr}$. Recasting these literature data relative to our reference line with $\lambda_{\mathrm{RL}}=0.522$ in a triple oxygen isotope plot with logarithmic $\delta$-coordinates gives $42 \% \mathrm{PgC} / \mathrm{yr}$ and $47 \% \mathrm{PgC} / \mathrm{yr}$, respectively. We take an average value of $44.5 \% \mathrm{ogC} / \mathrm{yr}$ and combine it with the stratospheric flux size of $100 \mathrm{PgC} / \mathrm{yr}$ (Appenzeller et al., 1996) to estimate the $\Delta^{17} \mathrm{O}$ value of stratospheric $\mathrm{CO}_{2}$ entering the troposphere:

$$
\Delta_{\text {strat }}^{17}=\Delta_{a}^{17}+0.445 \% \text { o }
$$




\section{Anthropogenic emissions and biomass burning}

Carbon dioxide from anthropogenic emissions and biomass burning are minor carbon fluxes on a global scale compared to the large gross carbon fluxes from the terrestrial biosphere. Anthropogenic $\mathrm{CO}_{2}$ emissions from fossil fuel burning amount to about 8 PgC/yr (Canadell et al., 2007; Le Quéré et al., 2009). Global fire emissions are estimated to contribute about $1 \mathrm{PgC} / \mathrm{yr}$ to global $\mathrm{CO}_{2}$ sources (Canadell et al., 2007; Le Quéré et al., 2009; van der Werf et al., 2004).

It may be assumed that $\mathrm{CO}_{2}$ from fossil fuel combustion or biomass burning largely inherits its triple oxygen isotope composition from atmospheric $\mathrm{O}_{2}$. Barkan and Luz (2011) determined the triple oxygen isotope composition of tropospheric $\mathrm{O}_{2}$ with $\delta^{18} \mathrm{O}=23.881 \%$ and $\Delta^{17} \mathrm{O}=-0.365 \%$ (relative to a reference line with $\lambda_{\mathrm{RL}}=0.522$ ). Horváth et al. (in press) show that $\mathrm{CO}_{2}$ from high-temperature combustion, indeed, produces $\mathrm{CO}_{2}$ with a triple oxygen isotope composition that is close to that of ambient air $\mathrm{O}_{2}\left(\delta^{18} \mathrm{O} \approx \sim 22 \%\right.$ and $\Delta{ }^{17} \mathrm{O} \approx-0.31 \%$ ). However, car exhaust is significantly enriched in ${ }^{18} \mathrm{O}\left(\delta^{18} \mathrm{O}=33 \%\right.$ ), but it also inherits the oxygen isotope anomaly of air $\mathrm{O}_{2}\left(\Delta^{17} \mathrm{O}=-0.32 \%\right.$ ) (Horváth et al., in press). For this study, we assume that anthropogenic $\mathrm{CO}_{2}$ from fossil fuel burning has $\delta_{\mathrm{ff}}=25 \%$ and $\Delta^{17}{ }_{\mathrm{ff}}=-0.32 \%$. The triple oxygen isotope composition of carbon dioxide from low temperature combustion, such as wood combustion, is affected by equilibration with water or other oxygen sources, e.g. wood inherent oxygen (Horváth et al., in press). Thus, we assume that $\mathrm{CO}_{2}$ produced from biomass burning has $\delta_{\text {fire }}=19 \%$ and $\Delta^{17}$ fire $=$ $-0.21 \%$ (Horváth et al., in press).

\section{Monte Carlo simulation}

We carried out a Monte Carlo simulation in order to obtain an uncertainty estimate of the $\delta^{18} \mathrm{O}$ and $\Delta^{17} \mathrm{O}$ mass balance output. The input parameters that were considered for the Monte Carlo simulation are listed in Table 5-3. The parameters were independently varied using a random function that produces values according to a normal distribution. The mean, standard deviation and maximum-minimum values were chosen according to the literature. For all parameters, the range of variation represents the broadest reasonable distribution. The simulation was carried out with 500 random numbers for each variable. Additionally, we tested the sensitivity of $\Delta^{17} \mathrm{O}$ of tropospheric $\mathrm{CO}_{2}$ to the size of terrestrial gross primary productivity. 


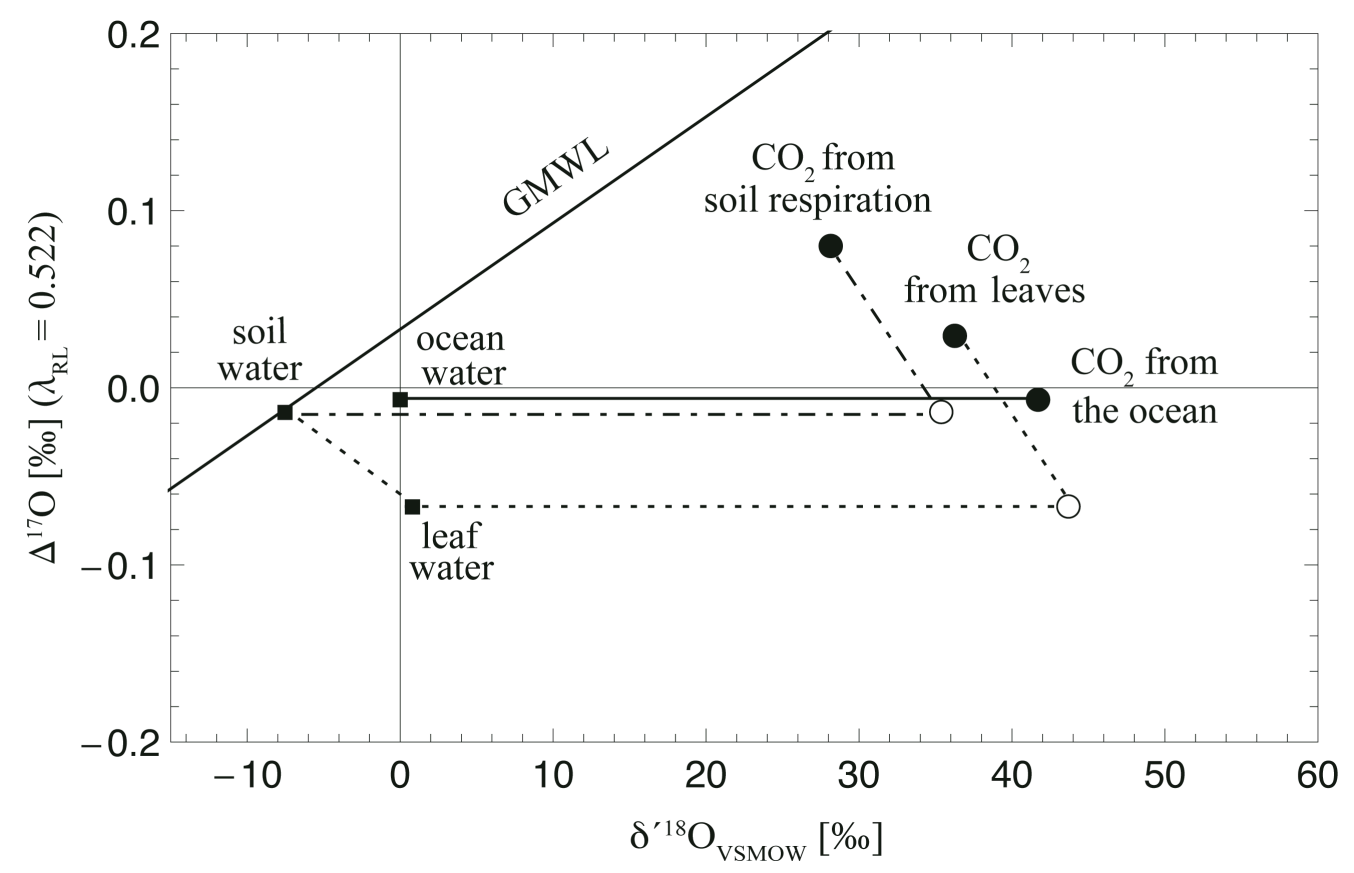

Fig. 5-1: Triple oxygen isotope signature of the main mass-dependently fractionated $\mathrm{CO}_{2}$ sources to the troposphere. The closed squares illustrate the triple oxygen isotope composition of the main water reservoirs (ocean, soil and leaf water); the closed circles illustrate the isotopic composition of the $\mathrm{CO}_{2}$ emitted from ocean, soils and terrestrial plants. We assume that equilibration between carbon dioxide and the three water reservoirs takes place with $\theta_{\mathrm{CO} 2 \text {-water }}=0.522 \pm 0.002$ (Hofmann et al., 2012b), i.e. parallel to the slope of our reference line $\lambda_{\mathrm{RL}}$. Carbon dioxide released from the oceans is in isotopic equilibrium with ocean surface water. Carbon dioxide released from plant leaves is in isotopic equilibrium with leaf water which deviates from the global meteoric water line (GMWL, Luz and Barkan, 2010) due to kinetic fractionation during evapotranspiration (Landais et al., 2006). Carbon dioxide produced in soils equilibrates with soil water (open circle), but subsequently the $\mathrm{CO}_{2}$ is kinetically fractionated due to diffusion out of the soil column (Miller et al., 1999a). 
Table 5-1: Mass balance variables: carbon fluxes and related parameters.

\begin{tabular}{|c|c|c|c|c|}
\hline Parameter & Description & Estimate & Units & References \\
\hline $\mathrm{M}_{0}$ & $\mathrm{CO}_{2}$ inventory troposphere & 830 & $\mathrm{PgC}$ & $\begin{array}{l}\text { (Canadell et al., 2007; } \\
\text { Le Quéré et al., 2009) }\end{array}$ \\
\hline $\mathrm{dM} / \mathrm{dt}$ & $\begin{array}{l}\text { rate of increase of } \\
\text { tropospheric } \mathrm{CO}_{2} \text { reservoir }\end{array}$ & 4 & $\mathrm{PgC} / \mathrm{yr}$ & $\begin{array}{l}\text { (Canadell et al., 2007; } \\
\text { Le Quéré et al., 2009) }\end{array}$ \\
\hline GPP & gross primary production & 120 & $\mathrm{PgC} / \mathrm{yr}$ & (Beer et al., 2010) \\
\hline $\mathrm{F}_{\mathrm{A}}=0.88 \times \mathrm{GPP}$ & terrestrial assimilation rate & 106 & $\mathrm{PgC} / \mathrm{yr}$ & (Ciais et al., 1997) \\
\hline $\mathrm{F}_{\mathrm{LA}}$ & from leaves & 246 & $\mathrm{PgC} / \mathrm{yr}$ & (Farquhar et al., 1993) \\
\hline$=\mathrm{A} \times \mathrm{C}_{\mathrm{cs}} /\left(\mathrm{C}_{\mathrm{a}}-\mathrm{C}_{\mathrm{cs}}\right)$ & & & & \\
\hline $\begin{array}{l}F_{\text {LAequ }} \\
=\Theta \times F_{L A}\end{array}$ & $\begin{array}{l}\mathrm{CO}_{2} \text { fraction from leaves } \\
\text { that is in equilibrium with } \\
\text { leaf water }\end{array}$ & 197 & $\mathrm{PgC} / \mathrm{yr}$ & $\begin{array}{l}\text { (Gillon and Yakir, } \\
\text { 2001; Gillon and } \\
\text { Yakir, 2000) }\end{array}$ \\
\hline $\begin{array}{l}\mathrm{F}_{\text {LAnonequ }} \\
=(1-\Theta) \times \mathrm{F}_{\mathrm{LA}}\end{array}$ & $\begin{array}{l}\mathrm{CO}_{2} \text { fraction from leaves } \\
\text { that is not in equilibrium } \\
\text { with leaf water }\end{array}$ & 49 & $\mathrm{PgC} / \mathrm{yr}$ & $\begin{array}{l}\text { (Gillon and Yakir, } \\
\text { 2001; Gillon and } \\
\text { Yakir, 2000) }\end{array}$ \\
\hline $\mathrm{F}_{\mathrm{AL}}$ & to leaves & -352 & $\mathrm{PgC} / \mathrm{yr}$ & (Farquhar et al., 1993) \\
\hline$=-\mathrm{A} \times \mathrm{C}_{\mathrm{a}} /\left(\mathrm{C}_{\mathrm{a}}-\mathrm{C}_{\mathrm{cs}}\right.$ & & & & \\
\hline $\mathrm{F}_{\text {resp }}$ & from terrestrial respiration & 103 & $\mathrm{PgC} / \mathrm{yr}$ & $\begin{array}{l}\text { (Canadell et al., 2007; } \\
\text { Le Quéré et al., 2009) }\end{array}$ \\
\hline$=\mathrm{A}-3$ & & & & \\
\hline $\mathrm{F}_{\mathrm{SA}}$ & from stratosphere & 100 & $\mathrm{PgC} / \mathrm{yr}$ & $\begin{array}{l}\text { (Appenzeller et al., } \\
\text { 1996) }\end{array}$ \\
\hline $\mathrm{F}_{\mathrm{AS}}$ & to stratosphere & -100 & $\mathrm{PgC} / \mathrm{yr}$ & $\begin{array}{l}\text { (Appenzeller et al., } \\
\text { 1996) }\end{array}$ \\
\hline $\mathrm{F}_{\mathrm{OA}}$ & from ocean & 90 & $\mathrm{PgC} / \mathrm{yr}$ & $\begin{array}{l}\text { (Heimann and Maier- } \\
\text { Reimer, 1996) }\end{array}$ \\
\hline
\end{tabular}




\begin{tabular}{|c|c|c|c|c|}
\hline Parameter & Description & Estimate & Units & References \\
\hline $\mathrm{F}_{\mathrm{AO}}$ & to ocean & -92 & $\mathrm{PgC} / \mathrm{yr}$ & $\begin{array}{l}\text { (Canadell et al., 2007; } \\
\text { Le Quéré et al., 2009) }\end{array}$ \\
\hline $\mathrm{F}_{\mathrm{SIA}}$ & soil invasion $\left(\mathrm{CO}_{2}\right.$ source $)$ & 30 & $\mathrm{PgC} / \mathrm{yr}$ & (Stern et al., 2001) \\
\hline $\mathrm{F}_{\mathrm{ASI}}$ & soil invasion $\left(\mathrm{CO}_{2}\right.$ sink $)$ & -30 & $\mathrm{PgC} / \mathrm{yr}$ & (Stern et al., 2001) \\
\hline $\mathrm{F}_{\mathrm{ff}}$ & fossil fuels & 8 & $\mathrm{PgC} / \mathrm{yr}$ & (Boden et al., 2011) \\
\hline$F_{\text {fire }}$ & fire emissions & 1 & $\mathrm{PgC} / \mathrm{yr}$ & $\begin{array}{l}\text { (Canadell et al., 2007; } \\
\text { Le Quéré et al., 2009; } \\
\text { van der Werf et al., } \\
2004 \text { ) }\end{array}$ \\
\hline$\Theta$ & $\begin{array}{l}\text { degree of } \mathrm{CO}_{2} \text {-water } \\
\text { equilibration in plant leaves }\end{array}$ & 0.80 & - & $\begin{array}{l}\text { (Gillon and Yakir, } \\
\text { 2001; Gillon and }\end{array}$ \\
\hline$=\mathrm{f}_{\mathrm{C} 3} \Theta_{\mathrm{C} 3}+\mathrm{f}_{\mathrm{C} 4} \Theta_{\mathrm{C} 4}$ & & & & Yakir, 2000) \\
\hline$\Theta_{\mathrm{C} 3}$ & $\begin{array}{l}\text { degree of } \mathrm{CO}_{2} \text {-water } \\
\text { equilibration in } \mathrm{C}_{3} \text { plants }\end{array}$ & 0.93 & - & $\begin{array}{l}\text { (Gillon and Yakir, } \\
\text { 2001; Gillon and } \\
\text { Yakir, 2000) }\end{array}$ \\
\hline$\Theta_{\mathrm{C} 4}$ & $\begin{array}{l}\text { degree of } \mathrm{CO}_{2} \text {-water } \\
\text { equilibration in } \mathrm{C}_{4} \text { plants }\end{array}$ & 0.38 & - & $\begin{array}{l}\text { (Gillon and Yakir, } \\
\text { 2001; Gillon and } \\
\text { Yakir, 2000) }\end{array}$ \\
\hline $\mathrm{f}_{\mathrm{C} 3}$ & fraction of $\mathrm{C}_{3}$ plants & 0.77 & - & (Still et al., 2003) \\
\hline $\mathrm{f}_{\mathrm{C} 4}=\left(1-\mathrm{f}_{\mathrm{C} 3}\right)$ & fraction of $\mathrm{C}_{4}$ plants & 0.23 & - & (Still et al., 2003) \\
\hline $\mathrm{C}_{\mathrm{cs}} / \mathrm{C}_{\mathrm{a}}$ & $\begin{array}{l}\mathrm{CO}_{2} \text { concentration gradient } \\
\text { between chloroplasts and } \\
\text { atmosphere }\end{array}$ & 0.70 & - & $\begin{array}{l}\text { (Ciais et al., 1997; } \\
\text { Cuntz et al., 2003a; } \\
\text { Cuntz et al., 2003b) }\end{array}$ \\
\hline
\end{tabular}


Table 5-2: Mass balance variables: isotopic signatures, fractionation factors and related parameters. For the model description, $\delta^{18} \mathrm{O}$ values are abbreviated with $\delta$ and $\Delta{ }^{17} \mathrm{O}$ values are abbreviated with $\Delta^{17}$.

\begin{tabular}{|c|c|c|c|c|}
\hline Parameter & Description & Estimate & Units & References \\
\hline$\delta_{\mathrm{a}}$ & $\begin{array}{l}\text { modeled } \delta^{18} \mathrm{O} \text { value of global } \\
\text { tropospheric } \mathrm{CO}_{2}\end{array}$ & & $\%$ & \\
\hline $\mathrm{D}_{\mathrm{A}}$ & $\begin{array}{l}\delta^{18} \mathrm{O} \text { isotope discrimination of } \mathrm{CO}_{2} \text { due } \\
\text { to assimilation }\end{array}$ & & $\%$ & \\
\hline$\delta_{\mathrm{L}}$ & $\begin{array}{l}\delta^{18} \mathrm{O} \text { value of } \mathrm{CO}_{2} \text { in equilibrium with } \\
\text { leaf water }\end{array}$ & 44.7 & $\%$ & $\begin{array}{l}\text { (Ciais et al., } \\
\text { 1997) }\end{array}$ \\
\hline$\delta_{\mathrm{SW}}$ & $\delta^{18} \mathrm{O}$ value of soil water & -7.5 & $\%$ & $\begin{array}{l}\text { (Ciais et al., } \\
\text { 1997) }\end{array}$ \\
\hline$\delta_{\text {resp }}$ & $\begin{array}{l}\delta^{18} \mathrm{O} \text { value of } \mathrm{CO}_{2} \text { emitted from } \\
\text { terrestrial respiration }\end{array}$ & 28.6 & $\%$ & $\begin{array}{l}\text { (Ciais et al., } \\
\text { 2005; Ciais et } \\
\text { al., 1997; Cuntz } \\
\text { et al., 2003a; } \\
\text { Cuntz et al., } \\
\text { 2003b) }\end{array}$ \\
\hline$\delta_{\text {ocean }}$ & $\delta^{18} \mathrm{O}$ value of ocean surface water & 0 & $\%$ & \\
\hline$\delta_{\mathrm{O}}$ & $\begin{array}{l}\delta^{18} \mathrm{O} \text { value of } \mathrm{CO}_{2} \text { in equilibrium with } \\
\text { ocean water }\end{array}$ & 42.6 & $\%$ & $\begin{array}{l}\text { (Ciais et al., } \\
\text { 2005; Ciais et } \\
\text { al., 1997; Cuntz } \\
\text { et al., 2003a; } \\
\text { Cuntz et al., } \\
\text { 2003b) }\end{array}$ \\
\hline$\delta_{\text {strat }}$ & $\begin{array}{l}\delta^{18} \mathrm{O} \text { value of } \mathrm{CO}_{2} \text { from the lower } \\
\text { stratosphere }\end{array}$ & $\delta_{\mathrm{a}}+0.4 \% \mathrm{o}$ & $\%$ & $\begin{array}{l}\text { (Kawagucci et } \\
\text { al., 2008) }\end{array}$ \\
\hline$\delta_{\mathrm{SI}}$ & $\begin{array}{l}\delta^{18} \mathrm{O} \text { value of } \mathrm{CO}_{2} \text { in equilibrium with } \\
\text { soil water }\end{array}$ & 36.0 & $\%$ & $\begin{array}{l}\text { (Wingate et al., } \\
\text { 2009) }\end{array}$ \\
\hline$\delta_{\mathrm{ff}}$ & $\begin{array}{l}\delta^{18} \mathrm{O} \text { value of } \mathrm{CO}_{2} \text { from fossil fuel } \\
\text { burning }\end{array}$ & 25 & $\%$ & $\begin{array}{l}\text { (Horváth et al., } \\
\text { in press) }\end{array}$ \\
\hline
\end{tabular}




\begin{tabular}{|c|c|c|c|c|}
\hline Parameter & Description & Estimate & Units & References \\
\hline$\delta_{\text {fire }}$ & $\begin{array}{l}\delta^{18} \mathrm{O} \text { value of } \mathrm{CO}_{2} \text { from biomass } \\
\text { burning }\end{array}$ & 19 & $\%$ & $\begin{array}{l}\text { (Horváth et al., } \\
\text { in press) }\end{array}$ \\
\hline$\Delta_{a}^{17}$ & $\begin{array}{l}\text { modeled } \Delta^{17} \mathrm{O} \text { value of global } \\
\text { tropospheric } \mathrm{CO}_{2}\end{array}$ & & $\%$ & \\
\hline $\mathrm{D}^{17}{ }_{\mathrm{A}}$ & $\begin{array}{l}\Delta^{17} \mathrm{O} \text { isotope discrimination due to } \\
\text { assimilation }\end{array}$ & & $\%$ & \\
\hline$\Delta^{17}{ }_{L}^{17}$ & $\begin{array}{l}\Delta^{17} \mathrm{O} \text { value of } \mathrm{CO}_{2} \text { in equilibrium with } \\
\text { leaf water }\end{array}$ & -0.07 & $\%$ & \\
\hline$\Delta^{17} \mathrm{SW}$ & $\Delta{ }^{17} \mathrm{O}$ value of soil water & -0.01 & $\%$ & \\
\hline$\Delta^{17}{ }_{\text {resp }}$ & $\begin{array}{l}\Delta^{17} \mathrm{O} \text { value of } \mathrm{CO}_{2} \text { emitted from } \\
\text { terrestrial respiration }\end{array}$ & 0.08 & $\%$ & \\
\hline$\Delta^{17}$ ocean & $\Delta^{17} \mathrm{O}$ value of ocean surface water & -0.01 & $\%$ & $\begin{array}{l}\text { (Luz and } \\
\text { Barkan, 2010) }\end{array}$ \\
\hline$\Delta^{17}{ }_{\mathrm{O}}$ & $\begin{array}{l}\Delta{ }^{17} \mathrm{O} \text { value of } \mathrm{CO}_{2} \text { in equilibrium with } \\
\text { ocean water }\end{array}$ & -0.01 & $\%$ & \\
\hline$\Delta_{\text {strat }}^{17}$ & $\begin{array}{l}\Delta^{17} \mathrm{O} \text { value of } \mathrm{CO}_{2} \text { from the lower } \\
\text { stratosphere }\end{array}$ & $\begin{array}{l}\Delta^{17}{ }^{+}+ \\
0.445 \% 0\end{array}$ & $\%$ & $\begin{array}{l}\text { (Boering et al., } \\
2004 \text {; } \\
\text { Kawagucci et } \\
\text { al., 2008) }\end{array}$ \\
\hline$\Delta^{17}{ }_{\mathrm{SI}}$ & $\begin{array}{l}\Delta{ }^{17} \mathrm{O} \text { value of } \mathrm{CO}_{2} \text { in equilibrium with } \\
\text { soil water }\end{array}$ & -0.01 & $\%$ & \\
\hline$\Delta^{17}{ }_{\mathrm{ff}}$ & $\begin{array}{l}\Delta^{17} \mathrm{O} \text { value of } \mathrm{CO}_{2} \text { from fossil fuel } \\
\text { burning }\end{array}$ & -0.32 & $\%$ & $\begin{array}{l}\text { (Horváth et al., } \\
\text { in press) }\end{array}$ \\
\hline$\Delta_{\text {fire }}^{17}$ & $\begin{array}{l}\Delta^{17} \mathrm{O} \text { value of } \mathrm{CO}_{2} \text { from biomass } \\
\text { burning }\end{array}$ & -0.21 & $\%$ & $\begin{array}{l}\text { (Horváth et al., } \\
\text { in press) }\end{array}$ \\
\hline$\alpha_{\mathrm{CO} 2 \text {-water }}$ & $\begin{array}{l}\text { temperature dependent equilibrium } \\
\text { fractionation factor for }{ }^{18} \mathrm{O} /{ }^{16} \mathrm{O} \text { isotope } \\
\text { exchange between } \mathrm{CO}_{2} \text { and water }\end{array}$ & $\begin{array}{l}(17.604 / \mathrm{T}- \\
0.01793)+1\end{array}$ & - & $\begin{array}{l}\text { (Brenninkmeijer } \\
\text { et al., 1983) }\end{array}$ \\
\hline
\end{tabular}




\begin{tabular}{|c|c|c|c|c|}
\hline Parameter & Description & Estimate & Units & References \\
\hline$\theta_{\mathrm{CO} 2 \text {-water }}$ & $\begin{array}{l}\text { triple oxygen isotope equilibrium } \\
\text { fractionation factor }\end{array}$ & 0.522 & - & $\begin{array}{l}\text { (Hofmann et al., } \\
\text { 2012b) }\end{array}$ \\
\hline & $\left(2^{\circ} \mathrm{C} \leq \mathrm{T} \leq 37^{\circ} \mathrm{C}\right)$ & & & \\
\hline$\alpha_{\text {transpiration }}$ & $\begin{array}{l}\text { leaf water enrichment in }{ }^{18} \mathrm{O} \text { due to } \\
\text { evapotranspiration }\end{array}$ & 0.9917 & - & $\begin{array}{l}\text { (West et al., } \\
\text { 2008) }\end{array}$ \\
\hline$\lambda_{\text {transpiration }}$ & $\begin{array}{l}\text { triple oxygen isotope fractionation } \\
\text { factor for transpiration in plant leaves }\end{array}$ & $\begin{array}{l}0.522- \\
0.008 \times h\end{array}$ & - & $\begin{array}{l}\text { (Landais et al., } \\
\text { 2006) }\end{array}$ \\
\hline $\mathrm{h}$ & mean humidity above leaf stomata & 0.8 & - & $\begin{array}{l}\text { (Ciais et al., } \\
\text { 1997) }\end{array}$ \\
\hline$\alpha_{\mathrm{L}}$ & $\begin{array}{l}\text { kinetic fractionation factor }\left({ }^{18} \mathrm{O} /{ }^{16} \mathrm{O}\right) \text { for } \\
\text { diffusion into and out of stomata }\end{array}$ & 0.9926 & - & $\begin{array}{l}\text { (Farquhar et al., } \\
1993 \text { ) }\end{array}$ \\
\hline$\alpha_{\mathrm{S}}$ & $\begin{array}{l}\text { kinetic fractionation factor }\left({ }^{18} \mathrm{O} /{ }^{16} \mathrm{O}\right) \text { for } \\
\text { diffusion out of soils }\end{array}$ & 0.9928 & - & $\begin{array}{l}\text { (Miller et al., } \\
\text { 1999a) }\end{array}$ \\
\hline$\lambda_{\text {kinetic }}$ & $\begin{array}{l}\text { triple oxygen isotope factor for kinetic } \\
\text { fractionation }\end{array}$ & 0.509 & - & $\begin{array}{l}\text { (Young et al., } \\
\text { 2002) }\end{array}$ \\
\hline$\lambda_{\mathrm{RL}}$ & $\begin{array}{l}\text { slope of reference line }\left(\mathrm{CO}_{2} \text {-water }\right. \\
\text { equilibration line })\end{array}$ & 0.522 & - & $\begin{array}{l}\text { (Hofmann et al., } \\
\text { 2012b) }\end{array}$ \\
\hline$\lambda_{\mathrm{GMWL}}$ & slope of the global meteoric water line & 0.528 & - & $\begin{array}{l}\text { (Luz and } \\
\text { Barkan, 2010) }\end{array}$ \\
\hline$\gamma_{\mathrm{GMWL}}$ & $\begin{array}{l}\text { intercept of the global meteoric water } \\
\text { line }\end{array}$ & 0.033 & $\%$ & $\begin{array}{l}\text { (Luz and } \\
\text { Barkan, 2010) }\end{array}$ \\
\hline $\mathrm{T}_{\text {soil }}$ & global mean soil temperature & 285 & $\mathrm{~K}$ & $\begin{array}{l}\text { (Ciais et al., } \\
\text { 1997) }\end{array}$ \\
\hline $\mathrm{T}_{\text {leaf }}$ & global mean leaf temperature & 285 & $\mathrm{~K}$ & $\begin{array}{l}\text { (Ciais et al., } \\
\text { 1997) }\end{array}$ \\
\hline $\mathrm{T}_{\text {ocean }}$ & global mean sea surface temperature & 291 & $\mathrm{~K}$ & $\begin{array}{l}\text { (Ciais et al., } \\
\text { 1997) }\end{array}$ \\
\hline
\end{tabular}


Table 5-3: Input parameters for the Monte Carlo simulation.

\begin{tabular}{|c|c|c|c|c|c|c|}
\hline Parameter & Mean & SD & Min & $\operatorname{Max}$ & Units & References \\
\hline GPP & 120 & 30 & 100 & 180 & $\mathrm{PgC} / \mathrm{yr}$ & $\begin{array}{l}\text { (Beer et al., 2010; Welp et al., } \\
\text { 2011) }\end{array}$ \\
\hline $\mathrm{C}_{\mathrm{CS}} / \mathrm{C}_{\mathrm{a}}$ & 0.70 & 0.13 & 0.56 & 0.77 & - & $\begin{array}{l}\text { (Ciais et al., 1997; Cuntz et al., } \\
\text { 2003b; Welp et al., 2011) }\end{array}$ \\
\hline$\Theta$ & 0.8 & 0.1 & 0.6 & 1 & - & $\begin{array}{l}\text { (Gillon and Yakir, 2001; Gillon } \\
\text { and Yakir, 2000) }\end{array}$ \\
\hline$\alpha_{\mathrm{L}}$ & 0.9926 & 0.0030 & 0.9912 & 0.9941 & - & (Farquhar et al., 1993) \\
\hline$\alpha_{\mathrm{S}}$ & 0.9928 & 0.0030 & 0.9912 & 0.9941 & - & (Miller et al., 1999a) \\
\hline $\mathrm{T}_{\text {soil }}$ & 288 & 2 & 285 & 293 & $\mathrm{~K}$ & $\begin{array}{l}\text { (Ciais et al., 1997; Cuntz et al., } \\
\text { 2003b) }\end{array}$ \\
\hline $\mathrm{T}_{\text {leaf }}$ & 291 & 2 & 286 & 296 & $\mathrm{~K}$ & $\begin{array}{l}\text { (Ciais et al., 1997; Cuntz et al., } \\
\text { 2003b) }\end{array}$ \\
\hline $\mathrm{T}_{\text {ocean }}$ & 291 & 2 & 286 & 296 & $\mathrm{~K}$ & $\begin{array}{l}\text { (Ciais et al., 1997; Cuntz et al., } \\
\text { 2003b) }\end{array}$ \\
\hline$\delta_{\mathrm{SW}}$ & -7.5 & 3 & -9 & 0 & $\%$ & $\begin{array}{l}\text { (Ciais et al., 1997; Cuntz et al., } \\
\text { 2003b) }\end{array}$ \\
\hline$\alpha_{\text {transpiration }}$ & 0.9917 & 0.0010 & 0.9900 & 0.9940 & - & (West et al., 2008) \\
\hline $\mathrm{h}$ & 0.8 & 0.1 & 0.6 & 1 & - & (Ciais et al., 1997) \\
\hline$\theta_{\mathrm{CO} 2 \text {-water }}$ & 0.522 & 0.001 & 0.50 & 0.53 & - & (Hofmann et al., 2012b) \\
\hline$\lambda_{\text {kinetic }}$ & 0.509 & 0.001 & 0.50 & 0.53 & - & (Young et al., 2002) \\
\hline $\mathrm{F}_{\mathrm{OA}}$ & 90 & 10 & 70 & 100 & $\mathrm{PgC} / \mathrm{yr}$ & (Naegler et al., 2006) \\
\hline $\mathrm{F}_{\mathrm{SA}}$ & 100 & 30 & 25 & 175 & $\mathrm{PgC} / \mathrm{yr}$ & (Appenzeller et al., 1996) \\
\hline $\mathrm{F}_{\mathrm{SI}}$ & 30 & 120 & 0 & 450 & $\mathrm{PgC} / \mathrm{yr}$ & (Wingate et al., 2009) \\
\hline
\end{tabular}




\subsubsection{Sampling of tropospheric $\mathrm{CO}_{2}$ and isotope analyses}

We sampled ambient air $\mathrm{CO}_{2}$ in two-week intervals from June 2010 to July 2012 from the fourth floor of the Geoscience Department in Göttingen. The department is situated at the outskirts of the medium-sized town Göttingen with moderate traffic density $(130,000$ inhabitants, $\left.51.5569^{\circ} \mathrm{N}, 9.9468^{\circ} \mathrm{E}\right)$.

Additionally, we sampled two air samples on top of the nearby Brocken Mountain, the highest peak of the Harz Mountain range with an elevation of about $1140 \mathrm{~m}\left(51.7987^{\circ} \mathrm{N}\right.$, $\left.10.6185^{\circ} \mathrm{E}\right)$. The mountain range stands out of the surrounding lowlands and the Mt. Brocken is mostly exposed to low tropospheric winds from west/southwest. The Brocken air was sampled on $2^{\text {nd }}$ and $28^{\text {th }}$ March and $17^{\text {th }}$ July 2012 in order to check if the air samples from Göttingen were significantly affected by elevated anthropogenic $\mathrm{CO}_{2}$ influx (Horváth et al., in press) or local $\mathrm{CO}_{2}$ sources from the biosphere.

In Göttingen, the $\mathrm{CO}_{2}$ was directly extracted from ambient air using a Russian doll type cryogenic trap with borosilicate-glass filters (Brenninkmeijer, 1991; Brenninkmeijer and Röckmann, 1996). A tube was installed at the building so that ambient air was collected with 1-2 meter distance to the building. First, the ambient air passed through magnesium perchlorate, $\mathrm{Mg}\left(\mathrm{ClO}_{4}\right)_{2}$, to remove water vapor. Then, the $\mathrm{CO}_{2}$ was separated from all noncondensable gases by means of the cryogenic trap at a flow rate of 2-3 L/min. In order to analyze the $\Delta^{17} \mathrm{O}$ of $\mathrm{CO}_{2}$ we use our $\mathrm{CO}_{2}-\mathrm{CeO}_{2}$ equilibration technique which requires at least $3.5 \mathrm{mmol}$ of $\mathrm{CO}_{2}$ (corresponding to about $400 \mathrm{~L}$ of ambient air at STP) (Hofmann et al., 2012b; Hofmann and Pack, 2010).

Subsequent to the collection of $\mathrm{CO}_{2}$ in the Russian doll type cryogenic trap, the cold trap is slowly warmed to room temperature. Simultaneously, a second trap is held at $-70^{\circ} \mathrm{C}$ (with a mixture of liquid nitrogen and ethanol) to hold back remaining water vapor. Next, the $\mathrm{CO}_{2}$ gas is exposed for about 30 minutes to $\mathrm{P}_{2} \mathrm{O}_{5}$ for final drying. A subsample of the $\mathrm{CO}_{2}$ $(\sim 50 \mu \mathrm{mol})$ is separated for conventional $\delta^{13} \mathrm{C}$ and $\delta^{18} \mathrm{O}$ analyses. The remaining $\mathrm{CO}_{2}$ sample is then immediately transferred to the $\mathrm{CO}_{2}-\mathrm{CeO}_{2}$ equilibration apparatus, so that no storage of the sample $\mathrm{CO}_{2}$ becomes necessary.

Air sampling on top of the Brocken Mountain was carried out with an oil-free, highpressure compressor from Rix Industries with a gas engine drive (model SA-3G). The air inlet was held at about $4 \mathrm{~m}$ above ground. The air stream passed through two $\operatorname{Mg}\left(\mathrm{ClO}_{4}\right)_{2}$ 
units in order to effectively remove water vapor. Before entering the compressor, the flow rate was controlled with a mass flow controller, which was set to $2-3 \mathrm{~L} / \mathrm{min}$. The dried air was compressed into a $5 \mathrm{~L}$ pressure cylinder, which was filled up to 100 bar. A $3 \mathrm{~m}$ long exhaust pipe was attached to the compressor to ensure that the exhaust fumes were directed away from the air inlet system. Additionally, the compressor and the exhaust pipe were placed downwind so that the air samples were not contaminated with exhaust gases. The $\mathrm{CO}_{2}$ extraction from the compressed air and the sample preparation was carried out analog to the procedure described above.

The $\delta^{18} \mathrm{O}$ analyses of $\mathrm{CO}_{2}$ were carried out on a Finnigan Delta plus mass spectrometer. The $\delta^{18} \mathrm{O}$ values were standardized by comparison with $\mathrm{CO}_{2}$ generated by phosphoric acid decomposition of NBS-19 $\left(\delta^{18} \mathrm{O}_{\text {VSMOW }}=+28.65 \%\right)$. The carbonate was reacted at $70{ }^{\circ} \mathrm{C}$ and the acid fractionation factor for calcite $\alpha_{\mathrm{CO} 2 \text {-calcite }}=1.00871$ (Kim et al., 2007) was used. The mass spectrometric uncertainty in $\delta^{18} \mathrm{O}$ is in the range of $\pm 0.03 \%$ o $(1 \sigma, \mathrm{SD})$.

We measured $\mathrm{CO}_{2}$ and $\mathrm{N}_{2} \mathrm{O}$ concentrations of the air samples with a gas chromatograph (Carlo Erba) in order to correct the $\delta^{18} \mathrm{O}$ values for interferences with $\mathrm{N}_{2} \mathrm{O}$ (Assonov et al., 2009). All $\delta^{18} \mathrm{O}$ data of ambient air $\mathrm{CO}_{2}$ were corrected with $-0.29 \pm 0.03 \%$ (SD).

The $\Delta^{17} \mathrm{O}$ analyses were carried out using the $\mathrm{CO}_{2}-\mathrm{CeO}_{2}$ exchange method (Hofmann et al., 2012b; Hofmann and Pack, 2010). The method was calibrated by producing $\mathrm{CO}_{2}$ with a known triple oxygen isotope composition by combustion of graphite with $\mathrm{O}_{2}$ $\left(\delta^{18} \mathrm{O}_{\mathrm{VSMOW}}=13.473 \%\right.$ o, $\left.\delta^{17} \mathrm{O}_{\mathrm{VSMOW}}=6.649 \%\right)$ that was analyzed relative to VSMOW by E. Barkan (Institute of Earth Sciences, Hebrew University of Jerusalem). 


\subsection{Results and discussion}

\subsubsection{Modeled triple oxygen isotope composition of tropospheric $\mathrm{CO}_{2}$}

The mass balance calculation and the Monte Carlo simulation give a global annual mean of tropospheric $\mathrm{CO}_{2}$ of $\Delta^{17} \mathrm{O}=+0.06 \pm 0.05 \%$ (SD). The model prediction is slightly lower than the former prediction from Hoag et al. (2005) with $\Delta^{17} \mathrm{O} \approx+0.11 \%$ (relative to a reference line with a slope of 0.522 in a $\ln \left(\delta^{18} \mathrm{O}+1\right)$ vs. $\ln \left(\delta^{17} \mathrm{O}+1\right)$ plot $)$. Our model prediction is the most sensitive to assumption on the exponent $\theta_{\mathrm{CO} 2 \text {-water, the magnitude of }}$ stratospheric $\mathrm{CO}_{2}$ influx, the $\mathrm{C}_{\mathrm{cs}} / \mathrm{C}_{\mathrm{a}}$ ratio (the ratio of $\mathrm{CO}_{2}$ concentration in chloroplasts to atmospheric $\mathrm{CO}_{2}$ concentration), the magnitude of the soil invasion flux and the magnitude of the terrestrial gross primary production (see section 5.4.2 and 5.4.3).

For the $\delta^{18} \mathrm{O}$ mass balance calculation, the base scenario (see Table 5-1 and Table 5-2) results in $\delta^{18} \mathrm{O}=41.3 \%$ and the Monte Carlo simulation (see Table 5-3) in $\delta^{18} \mathrm{O}=$ $40.9 \pm 1.9 \%$ o (SD). The modeled mean $\delta^{18} \mathrm{O}$ value is in good agreement with the observed global mean of about $41.5 \%$ (e.g. Farquhar et al., 1993). The large uncertainty in the $\delta^{18} \mathrm{O}$ model prediction gives a very conservative estimate for the global troposphere, in order to test the maximum effect of the model assumptions on the $\Delta^{17} \mathrm{O}$ prediction of tropospheric $\mathrm{CO}_{2}$.

\subsubsection{Impact of the major $\mathrm{CO}_{2}$ sources and sinks on the global mean $\Delta^{17} \mathrm{O}$ value of tropospheric $\mathrm{CO}_{2}$}

The effect of the various carbon sources and sinks on the global triple oxygen isotope composition of tropospheric $\mathrm{CO}_{2}$ is best illustrated by comparing the $\delta^{18} \mathrm{O}$ and $\Delta^{17} \mathrm{O}$ isofluxes (Fig. 5-2). The term isoflux refers to the multiplication of the carbon flux size F and the difference in the isotopic composition of the respective carbon flux and the isotopic composition of tropospheric $\mathrm{CO}_{2}$, e.g. $\mathrm{F}_{\mathrm{SA}}\left(\delta^{18} \mathrm{O}_{\mathrm{SA}}-\delta^{18} \mathrm{O}_{\mathrm{a}}\right)$.

The $\delta^{18} \mathrm{O}$ isofluxes of our mass balance model were chosen in accordance with previous modeling studies (see e.g. Ciais et al., 2005). In doing so, the ${ }^{18} \mathrm{O} /{ }^{16} \mathrm{O}$ ratio of tropospheric $\mathrm{CO}_{2}$ is mainly controlled by assimilation and respiration but the range for the assimilation and respiration isoflux was slightly extended compared to the ranges given by Ciais et al. (2005), see Fig. 5-2a. This is mainly due to the large variation in the $\mathrm{CO}_{2}$ concentration gradient between chloroplasts and atmosphere $\left(0.56<\mathrm{C}_{\mathrm{cs}} / \mathrm{C}_{\mathrm{a}}<0.77\right)$ and in the terrestrial 
gross primary production $(100 \mathrm{PgC} / \mathrm{yr}<\mathrm{GPP}<180 \mathrm{PgC} / \mathrm{yr})$ that were considered for the Monte Carlo simulation.

It is well known that stratospheric $\mathrm{CO}_{2}$ is enriched in ${ }^{18} \mathrm{O}$ relative to tropospheric $\mathrm{CO}_{2}$, and as a consequence, the influx of stratospheric $\mathrm{CO}_{2}$ must go along with a positive $\delta^{18} \mathrm{O}$ isoflux. However, $\delta^{18} \mathrm{O}$ modeling studies generally neglect the influx of stratospheric $\mathrm{CO}_{2}$ (Cuntz et al., 2003a; Cuntz et al., 2003b; Peylin et al., 1996; Welp et al., 2011). Here, we consider the estimate of stratospheric $\mathrm{CO}_{2}$ influx from Kawagucci et al. (2008) and conclude that stratospheric $\mathrm{CO}_{2}$ influx indeed does not have a significant impact on the $\delta^{18} \mathrm{O}$ composition of tropospheric $\mathrm{CO}_{2}$ (see Fig. 5-2a).

For the soil invasion flux, we considered recent findings from Wingate et al. (2009) that the abiotic $\mathrm{CO}_{2}$ flux from soils might have a much larger effect on the oxygen isotope composition of tropospheric $\mathrm{CO}_{2}$ than previously assumed $\left(0 \mathrm{PgC} / \mathrm{yr}<\mathrm{F}_{\mathrm{SI}}<450 \mathrm{PgC} / \mathrm{yr}\right)$.

The large scatter in $\delta^{18} \mathrm{O}$ isofluxes illustrates that modeling the $\delta^{18} \mathrm{O}$ value of tropospheric $\mathrm{CO}_{2}$ is very sensitive to various assumptions. Thus, comprehensive bio- and atmosphere models are required to simulate spatial and temporal variations in $\delta^{18} \mathrm{O}$ of tropospheric $\mathrm{CO}_{2}$ (Ciais et al., 1997; Cuntz et al., 2003a; Cuntz et al., 2003b; Peylin et al., 1996; Welp et al., 2011). That is why Hoag et al. (2005) suggested that $\Delta^{17} \mathrm{O}$ of tropospheric $\mathrm{CO}_{2}$ might be a more straightforward tracer of variations in assimilation and respiration.

The modeled $\Delta^{17} \mathrm{O}$ isofluxes suggest that the $\Delta^{17} \mathrm{O}$ value of tropospheric $\mathrm{CO}_{2}$ is mainly controlled by terrestrial assimilation, respiration, stratospheric influx and soil invasion (see Fig. 5-2b). However, in contrast to the previous $\Delta^{17} \mathrm{O}$ model from Hoag et al. (2005), assimilation has a negative effect on $\Delta^{17} \mathrm{O}$ of tropospheric $\mathrm{CO}_{2}$, whereas both respiratory $\mathrm{CO}_{2}$ and stratospheric influx have a positive effect on $\Delta^{17} \mathrm{O}$ of tropospheric $\mathrm{CO}_{2}$. The negative $\Delta^{17} \mathrm{O}$ isoflux for assimilation is mainly a result of kinetic fractionation during $\mathrm{CO}_{2}$ diffusion into the stomata. The positive effect of respiratory $\mathrm{CO}_{2}$ on the $\Delta^{17} \mathrm{O}$ composition of tropospheric $\mathrm{CO}_{2}$ results from the kinetic fractionation during diffusion out of the soil column (see Fig. 5-1). For the stratospheric $\mathrm{CO}_{2}$ influx, we combine the estimates from Boering et al. (2004) and Kawagucci et al. (2008) on the ${ }^{17} \mathrm{O}$ enrichment of stratospheric $\mathrm{CO}_{2}$ influx, and thus, we obtain a slightly higher $\Delta^{17} \mathrm{O}$ isoflux for stratospheric $\mathrm{CO}_{2}$ compared to the previous $\Delta^{17} \mathrm{O}$ model from Hoag et al. (2005). The assumption on the size of the soil invasion flux also has a considerable effect on the modeled $\Delta^{17} \mathrm{O}$ value, whereas fossil fuel emissions and biomass burning do not have a significant impact on the $\Delta^{17} \mathrm{O}$ composition of global tropospheric $\mathrm{CO}_{2}$. 
a)

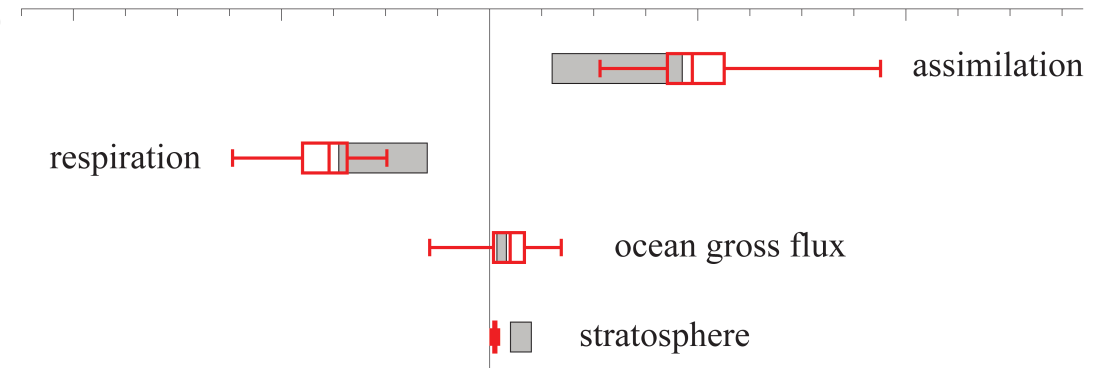

fossil fuel

biomass burning |

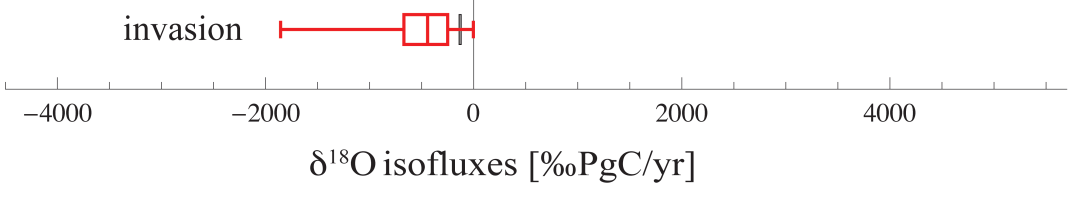

b)

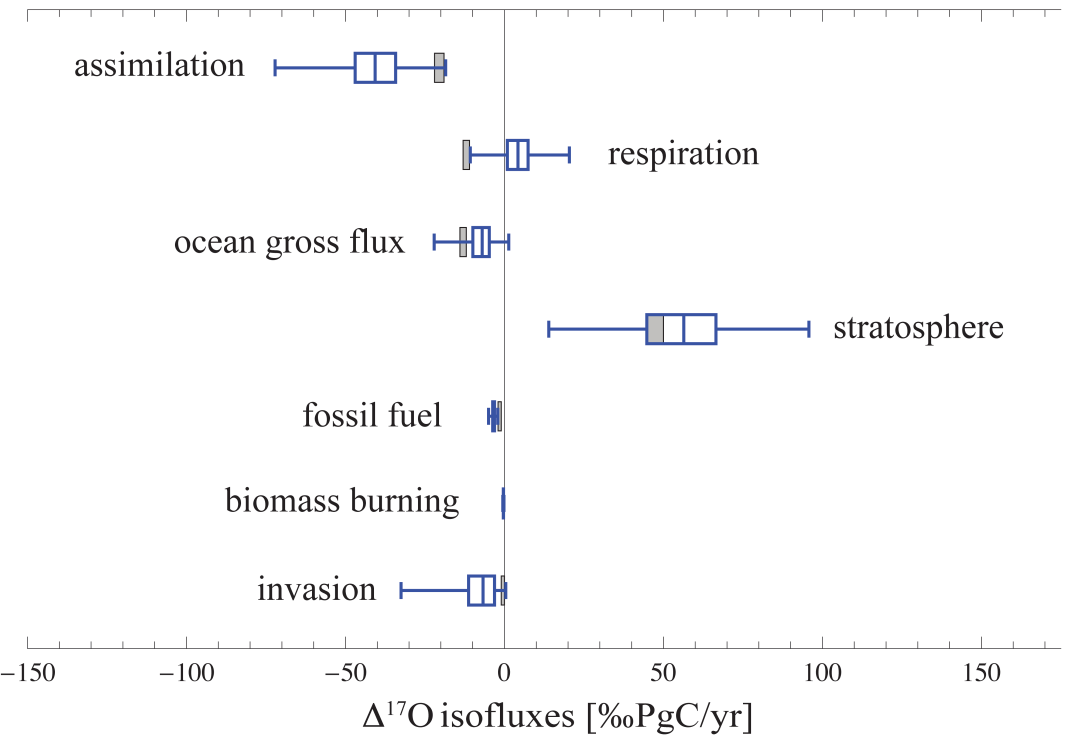

Fig. 5-2: Box plots showing the main isofluxes controlling the triple oxygen isotope composition of tropospheric $\mathrm{CO}_{2}$. The boxes indicate the median, 25th and 75th percentiles of the Monte Carlo simulation. The whisker caps indicate 5 th and 95 th percentiles. a) $\delta^{18} \mathrm{O}$ isofluxes: The $\delta^{18} \mathrm{O}$ composition of tropospheric $\mathrm{CO}_{2}$ is mainly controlled by two opponents: assimilation and respiration. Our $\delta^{18} \mathrm{O}$ model assumptions are in good agreement with previous $\delta^{18} \mathrm{O}$ isofluxes from Ciais et al. (2005) (gray rectangles). The only major modification is the assumption on the soil invasion flux: We implemented a mean of $30 \mathrm{PgC} / \mathrm{yr}$ in the Monte Carlo simulation, but extended the possible range up to $450 \mathrm{PgC} / \mathrm{yr}$ as suggested by Wingate et al. (2009). b) $\Delta^{17} \mathrm{O}$ isofluxes: The model suggests that the $\Delta^{17} \mathrm{O}$ value of tropospheric $\mathrm{CO}_{2}$ is mainly controlled by assimilation, respiration, soil invasion and stratospheric influx. However, in contrast to the model from Hoag et al. (2005) (gray rectangles), our modeling results suggest that both respiratory $\mathrm{CO}_{2}$ and stratospheric influx have a positive effect on $\Delta^{17} \mathrm{O}$ of tropospheric $\mathrm{CO}_{2}$ and the soil invasion flux might also significantly affect the triple oxygen isotope composition of tropospheric $\mathrm{CO}_{2}$. 


\subsubsection{Is $\Delta^{17} \mathrm{O}$ of tropospheric $\mathrm{CO}_{2}$ a potential tracer for the terrestrial gross primary production?}

We tested the sensitivity of $\Delta^{17} \mathrm{O}$ of tropospheric $\mathrm{CO}_{2}$ to GPP. The model predicts that a 3fold change from 50 to $150 \mathrm{PgC} / \mathrm{yr}$ results in a $\Delta^{17} \mathrm{O}$ decrease of about $-0.08 \%$ (Fig. 5-3). This sensitivity to GPP is slightly lower than the prediction of $-0.11 \%$ for a decrease from 50 to $150 \mathrm{PgC} / \mathrm{yr}$ from Hoag et al. (2005). However, the $\Delta^{17} \mathrm{O}$ composition of tropospheric $\mathrm{CO}_{2}$ is also significantly affected by the $\mathrm{C}_{\mathrm{cs}} / \mathrm{C}_{\mathrm{a}}$ ratio, and as a consequence by the distribution of $\mathrm{C}_{3}$ and $\mathrm{C}_{4}$ plants, the magnitude of stratospheric $\mathrm{CO}_{2}$ influx and soil invasion $\mathrm{CO}_{2}$. Thus, in order to use $\Delta^{17} \mathrm{O}$ of $\mathrm{CO}_{2}$ as a tracer for GPP better constrains for these parameters are required.

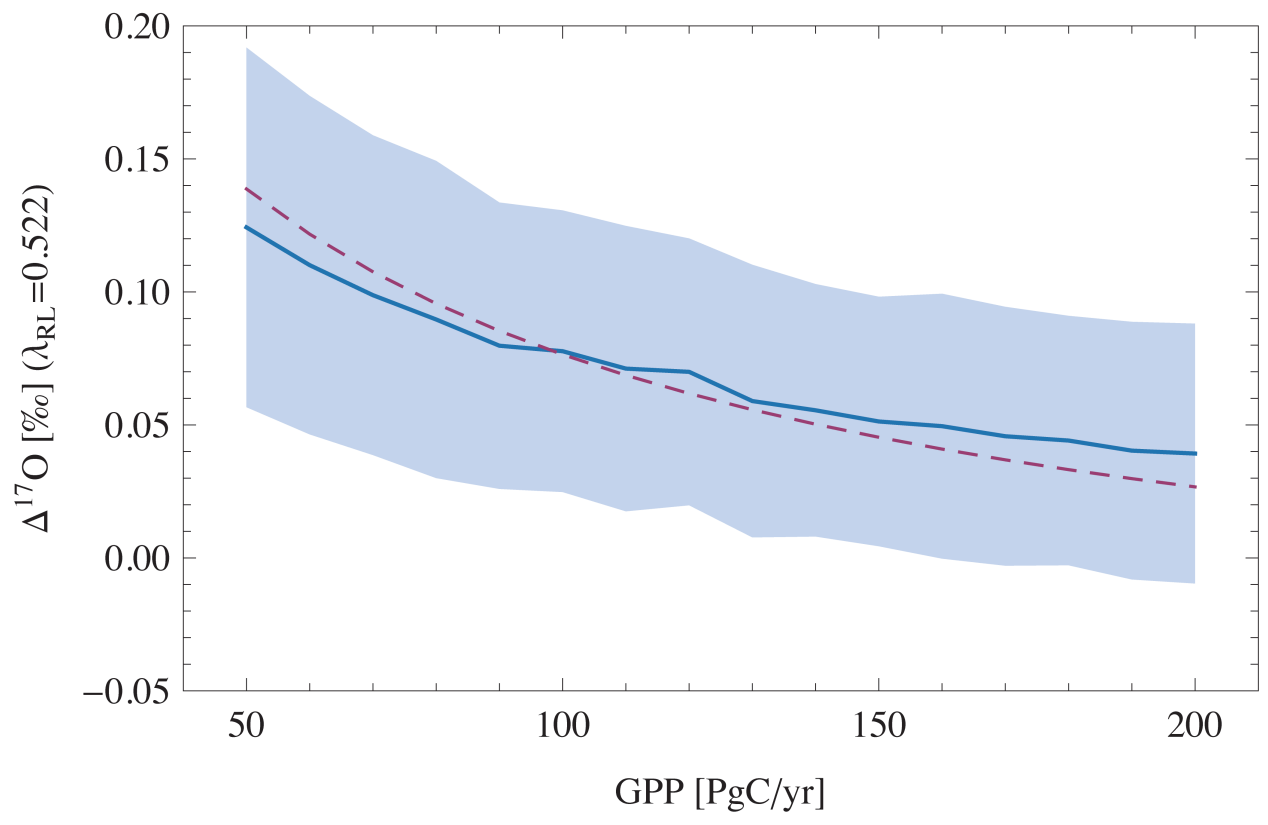

Fig. 5-3: Modeled sensitivity of $\Delta^{17} \mathrm{O}$ of tropospheric $\mathrm{CO}_{2}$ to variations in the terrestrial gross primary production (GPP). The dashed curve shows the sensitivity of $\Delta^{17} \mathrm{O}$ for the base scenario (see Table 5-1 and Table 5-2) and the solid curve shows the result from the Monte Carlo simulation (see Table 5-3). The error envelope denotes the standard deviation obtained from the Monte Carlo simulation and reflects all uncertainties in $\Delta{ }^{17} \mathrm{O}$ modeling, most notably, the $\mathrm{C}_{\mathrm{cs}} / \mathrm{C}_{\mathrm{a}}$ ratio, the magnitude of stratospheric $\mathrm{CO}_{2}$ influx and the amount of soil invasion $\mathrm{CO}_{2}$. 


\subsubsection{Observational triple oxygen isotope data of tropospheric $\mathrm{CO}_{2}$}

Ambient air $\mathrm{CO}_{2}$ sampled in Göttingen has a mean $\Delta^{17} \mathrm{O}$ value of $-0.03 \pm 0.07 \%$ o $(\mathrm{SD})$ and a corresponding $\delta^{18} \mathrm{O}$ value of $41.6 \pm 0.9 \%$ (SD). In contrast to stratospheric $\mathrm{CO}_{2}$, the observational data do not show any correlation between $\delta^{18} \mathrm{O}$ and $\Delta^{17} \mathrm{O}$ (Fig. 5-4).

The Mt. Brocken $\mathrm{CO}_{2}$ data fall within the range observed in Göttingen: The $\mathrm{CO}_{2}$ sampled on $2^{\text {nd }}$ and $28^{\text {th }}$ March and on $17^{\text {th }}$ July 2012 have $\Delta^{17} \mathrm{O}$ values of $0.00 \pm 0.02 \%$ (SE), $-0.08 \pm 0.02 \%$ o (SE) and $-0.06 \pm 0.03 \%$ o (SE) and $\delta^{18} \mathrm{O}$ values of $40.4 \%$, $40.7 \%$ ond $40.6 \%$ (Fig. 5-4 and Fig. 5-5). Thus, the triple oxygen isotope composition of ambient air $\mathrm{CO}_{2}$ from Göttingen is not significantly affected by local anthropogenic $\mathrm{CO}_{2}$ emissions.

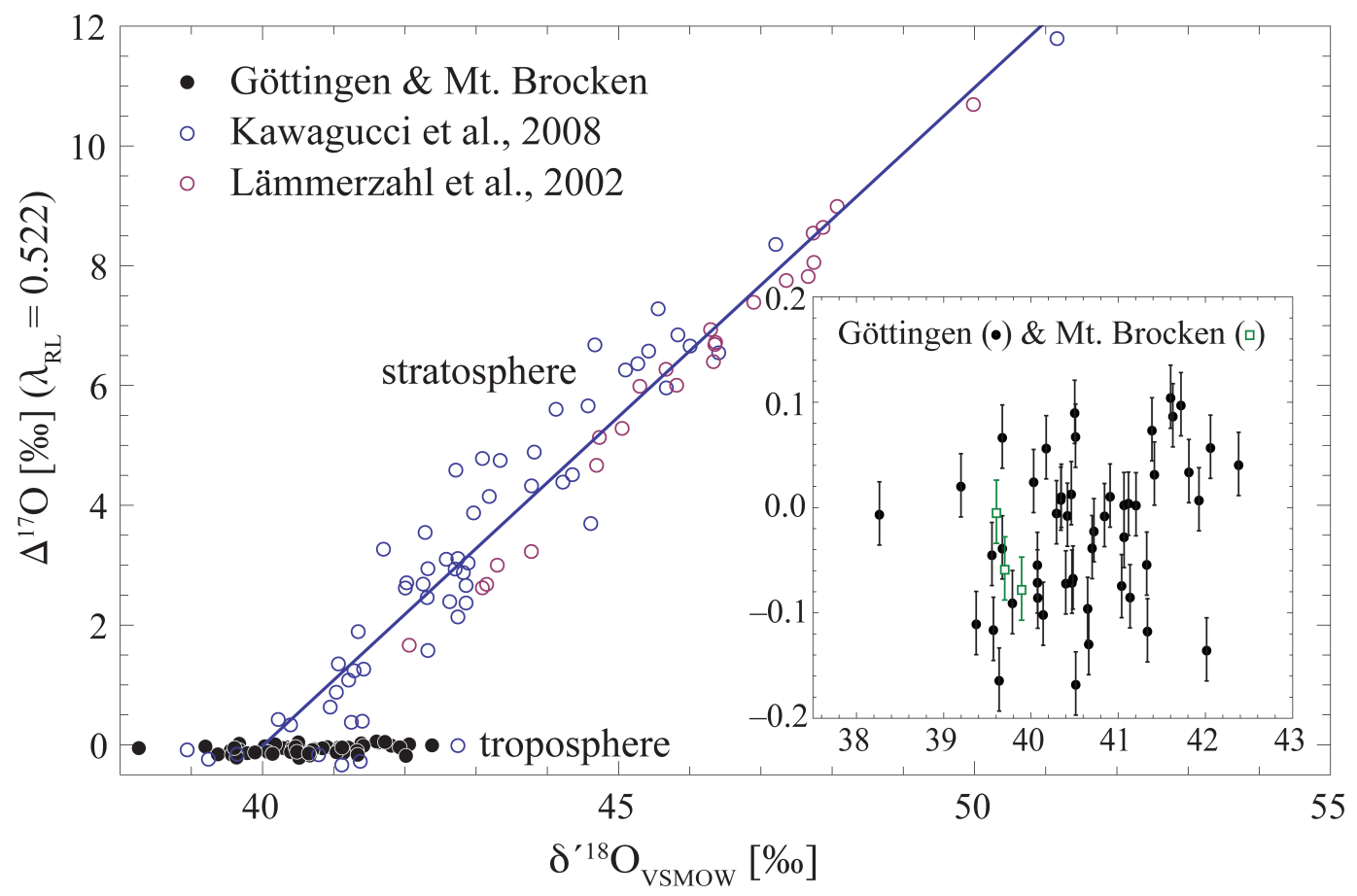

Fig. 5-4: Triple oxygen isotope composition of tropospheric and stratospheric $\mathrm{CO}_{2}$. Tropospheric $\mathrm{CO}_{2}$ from Göttingen and from Mt. Brocken plot on or close to the $\mathrm{CO}_{2}$-water equilibration line, i.e. $\Delta{ }^{17} \mathrm{O} \approx 0 \%$. These near-surface $\mathrm{CO}_{2}$ data fall on the lower end of a stratosphere-troposphere mixing line (Kawagucci et al., 2008; Lämmerzahl et al., 2002), but do not show any correlation between $\delta^{, 18} \mathrm{O}$ and $\Delta^{17} \mathrm{O}$. The Mt. Brocken $\mathrm{CO}_{2}$ was sampled on $2^{\text {nd }}$ and $28^{\text {th }}$ March and $17^{\text {th }} \mathrm{July}$ 2012, the Göttingen $\mathrm{CO}_{2}$ was sampled between June 2010 and July 2012. Error bars show standard errors. 
The $\delta^{18} \mathrm{O}$ values of ambient air $\mathrm{CO}_{2}$ sampled in Göttingen show a clear variation with time (Fig. 5-5). The variability in $\delta^{18} \mathrm{O}$ is due to the seasonal variation in plant activity with an amplitude of about $1.5 \%$. The seasonality in $\delta^{18} \mathrm{O}$ is about double the size than the seasonality observed at the continental background station Schauinsland (SW Germany) (see Cuntz et al., 2003a) due to local $\mathrm{CO}_{2}$ sources from the biosphere.

The $\Delta^{17} \mathrm{O}$ values of $\mathrm{CO}_{2}$ sampled in Göttingen also show a temporal variation with a peakto-peak range of about $0.25 \%$. From June 2010 to December 2011, the $\Delta^{17} \mathrm{O}$ variation parallels the seasonal cycle of the measured $\delta^{18} \mathrm{O}$ values (Fig. 5-5), e.g. maximum $\Delta^{17} \mathrm{O}$ values ( $\sim 0.08 \%$ ) during spring/summer 2010 and 2011 and a local minimum $(\sim-0.05 \%$ ) during winter 2010/2011. During the first half of 2012, however, the $\Delta^{17} \mathrm{O}$ values scatter around $-0.1 \%$ and do no longer parallel the seasonal cycle of $\delta^{18} \mathrm{O}$.

Our $\Delta^{17} \mathrm{O}$ model prediction for the global troposphere of $+0.06 \pm 0.05 \%$ agrees well with the observational data for Göttingen $\mathrm{CO}_{2}$ sampled during summer 2010 and 2011 (see Fig. 5-5). However, the global prediction deviates significantly from the mean $\Delta^{17} \mathrm{O}$ value of $-0.08 \pm 0.05 \%$ o (SD) analyzed for Göttingen $\mathrm{CO}_{2}$ sampled between July 2011 and July 2012.

It is beyond the scope of this study to investigate in detail the observed temporal variation in $\Delta^{17} \mathrm{O}$ of ambient air $\mathrm{CO}_{2}$ from Göttingen. However, it is apparent from the assimilation isofluxes (described in section 5.4.2 and shown in Fig. 5-2) that an increase in plant activity during spring and summer leads to an increase in the observed $\delta^{18} \mathrm{O}$ values of tropospheric $\mathrm{CO}_{2}$. At the same time, this should decrease the $\Delta^{17} \mathrm{O}$ values of tropospheric $\mathrm{CO}_{2}$ during spring and summer because of the predicted negative $\Delta^{17} \mathrm{O}$ isoflux for assimilation. However, this is in contrast to the observational data, which show maximum $\Delta^{17} \mathrm{O}$ values during early summer 2010 and 2011. Thus, it may be that the influx of stratospheric $\mathrm{CO}_{2}$ significantly affects the temporal variation of $\Delta{ }^{17} \mathrm{O}$ values of Göttingen $\mathrm{CO}_{2}$. A similar pattern was observed for atmospheric $\mathrm{N}_{2} \mathrm{O}$, where the seasonal cycle of $\mathrm{N}_{2} \mathrm{O}$ mixing ratios in the troposphere is also significantly influenced by the influx of stratospheric air masses (Nevison et al., 2011).

To conclude, future investigations are required to clarify the cause for the temporal variation of $\Delta^{17} \mathrm{O}$ of ambient air $\mathrm{CO}_{2}$ from Göttingen. On the one hand, these studies should focus on the relevance of stratospheric influx, on the other hand, they should investigate experimentally the triple oxygen isotope composition of local $\mathrm{CO}_{2}$ sources from the biosphere. 

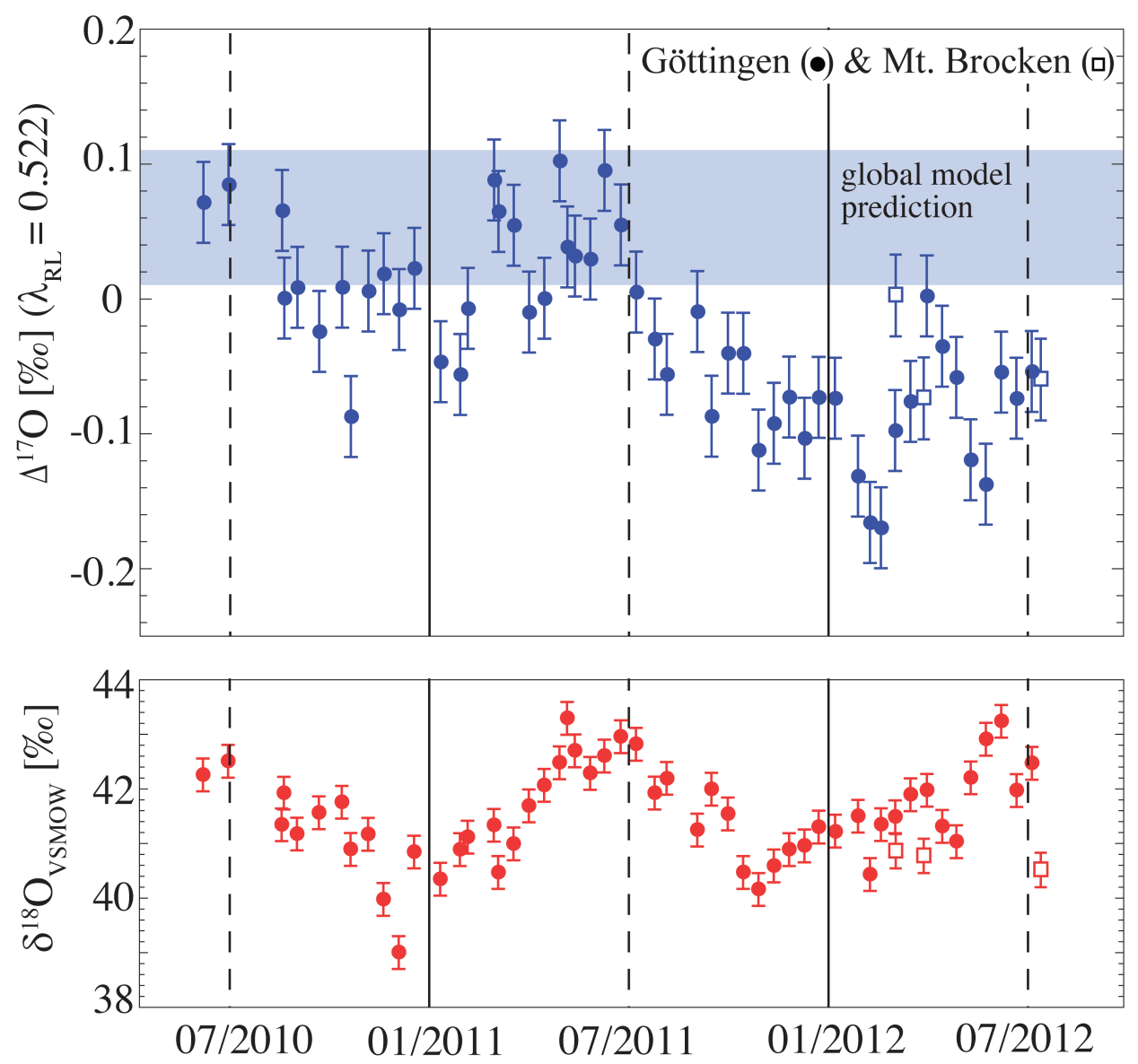

Fig. 5-5: Time series of the triple oxygen isotope composition of ambient air $\mathrm{CO}_{2}$ from Göttingen. The $\Delta^{17} \mathrm{O}$ composition of tropospheric $\mathrm{CO}_{2}$ shows a temporal variation: From June 2010 to December 2011, the $\Delta^{17} \mathrm{O}$ variation parallels the seasonal cycle of the measured $\delta^{18} \mathrm{O}$ values. However, in 2012, the $\Delta^{17} \mathrm{O}$ signal does no longer run parallel to the seasonal $\delta^{18} \mathrm{O}$ cycle. The model prediction for the global troposphere $\left(\Delta^{17} \mathrm{O}=+0.06 \pm 0.05 \%\right.$, see section 5.4.1) agrees well with the $\Delta^{17} \mathrm{O}$ measurements in the first year, however, the model cannot explain the strong decrease in $\Delta^{17} \mathrm{O}$ in 2012. It may be that the influx of stratospheric $\mathrm{CO}_{2}$ has a significant impact on the observed temporal variation in $\Delta^{17} \mathrm{O}$ of ambient air $\mathrm{CO}_{2}$ from Göttingen. 


\subsection{Conclusions}

Here, we present a refined model prediction for the global triple oxygen isotope composition of tropospheric $\mathrm{CO}_{2}$. We predict a global mean $\Delta^{17} \mathrm{O}$ composition of $+0.06 \%$ and estimate an uncertainty of $\pm 0.05 \%$ o (SD) based on a Monte Carlo simulation. Despite the various refined assumptions on the biosphere-atmosphere interaction, we confirm the sensitivity of $\Delta^{17} \mathrm{O}$ of tropospheric $\mathrm{CO}_{2}$ to the terrestrial gross primary production. However, we suggest that the global mean of $+0.06 \%$ is slightly lower than the previous estimate from Hoag et al. (2005) of $+0.11 \%$.

Moreover, we present the first set of high-precision triple oxygen isotope data of tropospheric $\mathrm{CO}_{2}$. Ambient air $\mathrm{CO}_{2}$ sampled in Göttingen between June 2010 and July 2012 has a mean $\Delta^{17} \mathrm{O}$ value of $-0.03 \pm 0.07 \%$ o (SD). The triple oxygen isotope data of background $\mathrm{CO}_{2}$ sampled on top of the Brocken Mountain $\left(\Delta^{17} \mathrm{O}=-0.04 \pm 0.04 \%\right.$ (SD)) fall within the range observed in Göttingen. Thus, the observational data only in part overlap with the model prediction for the global troposphere. The discrepancy between the observed and predicted mean $\Delta^{17} \mathrm{O}$ value and the large interannual variation in $\Delta^{17} \mathrm{O}$ needs further investigations. Future studies should focus on the relevance of stratospheric influx and the experimental determination of the triple oxygen isotope composition of local $\mathrm{CO}_{2}$ sources from the biosphere in order to clarify the observed temporal variation in $\Delta^{17} \mathrm{O}$ of ambient air $\mathrm{CO}_{2}$.

\subsection{Acknowledgments}

We thank M. Cuntz and J. Kaiser for very helpful comments on the mass balance calculation. We also thank E. Barkan for calibration of our inhouse reference $\mathrm{O}_{2}$ gas relative to VSMOW. This project was partly funded by the German Science Foundation (AP, project PA909/6-2). 


\subsection{References}

Appenzeller, C., Holton, J. R., Rosenlof, K. H., 1996. Seasonal variation of mass transport across the tropopause. J. Geophys. Res.-Atmos. 101, 15071-15078.

Assonov, S. S., Brenninkmeijer, C. A. M., Koeppel, C., Röckmann, T., 2009. $\mathrm{CO}_{2}$ isotope analyses using large air samples collected on intercontinental flights by the CARIBIC Boeing 767. Rapid Commun. Mass Spec. 23, 822-830.

Barkan, A., Luz, B., 2011. The relationship among the three stable isotopes of oxygen in air, seawater and marine photosynthesis. Rapid Commun. Mass Spec. 25, 23672369.

Beer, C., Reichstein, M., Tomelleri, E., Ciais, P., Jung, M., Carvalhais, N., Rödenbeck, C., Arain, M. A., Baldocchi, D., Bonan, G. B., Bondeau, A., Cescatti, A., Lasslop, G., Lindroth, A., Lomas, M., Luyssaert, S., Margolis, H., Oleson, K. W., Roupsard, O., Veenendaal, E., Viovy, N., Williams, C., Woodward, F. I., Papale, D., 2010. Terrestrial gross carbon dioxide uptake: global distribution and covariation with climate. Science 329, 834-838.

Boden, T. A., Marland, G., Andreas, R. J., 2011. Global, regional, and national fossil-fuel $\mathrm{CO}_{2}$ emissions. Carbon Dioxide Information Analysis Center, Oak Ridge National Laboratory, U.S. Department of Energy, Oak Ridge, Tenn., U.S.A.

Boering, K. A., Jackson, T., Hoag, K. J., Cole, A. S., Perri, M. J., Thiemens, M., Atlas, E., 2004. Observations of the anomalous oxygen isotopic composition of carbon dioxide in the lower stratosphere and the flux of the anomaly to the troposphere. Geophys. Res. Lett. 31.

Brenninkmeijer, C. A. M., 1991. Robust, high-efficiency, high-capacity cryogenic trap. Anal. Chem. 63, 1182-1184.

Brenninkmeijer, C. A. M., Kraft, P., Mook, W. G., 1983. Oxygen isotope fractionation between $\mathrm{CO}_{2}$ and $\mathrm{H}_{2} \mathrm{O}$. Isot. Geosci. 1, 181-190.

Brenninkmeijer, C. A. M., Röckmann, T., 1996. Russian doll type cryogenic traps: improved design and isotope separation effects. Anal. Chem. 68, 3050-3053.

Canadell, J. G., Le Quéré, C., Raupach, M. R., Field, C. B., Buitenhuis, E. T., Ciais, P., Conway, T. J., Gillett, N. P., Houghton, R. A., Marland, G., 2007. Contributions to accelerating atmospheric $\mathrm{CO}_{2}$ growth from economic activity, carbon intensity, and efficiency of natural sinks. Proc. Natl. Acad. Sci. 104, 18866-18870.

Ciais, P., Cuntz, M., Scholze, M., Mouillot, F., Peylin, P., Gitz, V., 2005. Remarks on the use of ${ }^{13} \mathrm{C}$ and ${ }^{18} \mathrm{O}$ isotopes in atmospheric $\mathrm{CO}_{2}$ to quantify biospheric carbon fluxes. In: Flanagan, L. B., Ehleringer, J. R., and Pataki, D. E. Eds.), Stable 
Isotopes and Biosphere - Atmosphere Interactions : Processes and Biological Controls. Elsevier.

Ciais, P., Denning, A. S., Tans, P. P., Berry, J. A., Randall, D., Collatz, J. G., Sellers, P. J., White, J. W., Trolier, M., Meijer, H. A. J., Francey, R. J., Monfray, P., Heimann, M., 1997. A three-dimensional synthesis study of $\delta^{18} \mathrm{O}$ in atmospheric $\mathrm{CO}_{2}$ : Part 1 Surface fluxes. J. Geophys. Res. 102, 5857-5872.

Cuntz, M., Ciais, P., Hoffmann, G., Allison, C. E., Francey, R. J., Knorr, W., Tans, P. P., White, J. W. C., Levin, I., 2003a. A comprehensive global three-dimensional model of $\delta^{18} \mathrm{O}$ in atmospheric $\mathrm{CO}_{2}: 2$. Mapping the atmospheric signal. J. Geophys. Res. 108, ACH2.1-ACH2.19.

Cuntz, M., Ciais, P., Hoffmann, G., Knorr, W., 2003b. A comprehensive global threedimensional model of $\delta^{18} \mathrm{O}$ in atmospheric $\mathrm{CO}_{2}: 1$. Validation of surface processes. J. Geophys. Res. 108, ACH1-ACH23.

Farquhar, G. D., Lloyd, J., Taylor, J. A., Flanagan, L. B., Syvertsen, J. P., Hubick, K. T., Wong, S. C., Ehleringer, J. R., 1993. Vegetation effects on the isotope composition of oxygen in atmospheric $\mathrm{CO}_{2}$. Nature 363, 439-443.

Gamo, T., Tsutsumi, M., Sakai, H., Nakazawa, T., Tanaka, M., Honda, H., Kubo, H., Itoh, T., 1989. Carbon and oxygen isotopic ratios of carbon dioxide of a stratospheric profile over Japan. Tellus B 41B, 127-133.

Gillon, J., Yakir, D., 2001. Influence of carbonic anhydrase activity in terrestrial vegetation on the ${ }^{18} \mathrm{O}$ content of atmospheric $\mathrm{CO}_{2}$. Science 291, 2584-2587.

Gillon, J. S., Yakir, D., 2000. Naturally low carbonic anhydrase activity in $\mathrm{C}_{4}$ and $\mathrm{C}_{3}$ plants limits discrimination against $\mathrm{C}^{18} \mathrm{OO}$ during photosynthesis. Plant Cell Environ. 23, 903-915.

Heimann, M., Maier-Reimer, E., 1996. On the relations between the oceanic uptake of $\mathrm{CO}_{2}$ and its carbon isotopes. Global Biogeochem. Cy. 10, 89-110.

Hoag, K. J., Still, C. J., Fung, I. Y., Boering, K. A., 2005. Triple oxygen isotope composition of tropospheric carbon dioxide as a tracer of terrestrial gross carbon fluxes. Geophys. Res. Lett. 32, 1-5.

Hofmann, M. E. G., Horváth, B., Pack, A., 2012b. Triple oxygen isotope equilibrium fractionation between carbon dioxide and water. Earth Planet. Sci. Lett. 319-320, 159-164.

Hofmann, M. E. G., Pack, A., 2010. Technique for high-precision analysis of triple oxygen isotope ratios in carbon dioxide. Anal. Chem. 82, 4357-4361. 
Horváth, B., Hofmann, M. E. G., Pack, A., in press. On the triple oxygen isotope composition of carbon dioxide from some combustion processes. Geochim. Cosmochim. Acta.

Hulston, J. R., Thode, H. G., 1965. Variations in the $\mathrm{S}^{33}, \mathrm{~S}^{34}$, and $\mathrm{S}^{36}$ contents of meteorites and their relation to chemical and nuclear effects. J. Geophys. Res. 70, 3475-3484.

Kawagucci, S., Tsunogai, U., Kudo, S., Nakagawa, F., Honda, H., Aoki, S., Nakazawa, T., Tsutsumi, M., Gamo, T., 2008. Long-term observation of mass-independent oxygen isotope anomaly in stratospheric $\mathrm{CO}_{2}$. Atmos. Chem. Phys. 8, 6189-6197.

Kim, S.-T., Mucci, A., Taylor, B. E., 2007. Phosphoric acid fractionation factors for calcite and aragonite between 25 and $75^{\circ} \mathrm{C}$ : Revisited. Chem. Geol. 246, 135-146.

Lämmerzahl, P., Röckmann, T., Brenninkmeijer, C. A. M., Krankowsky, D., Mauersberger, K., 2002. Oxygen isotope composition of stratospheric carbon dioxide. Geophys. Res. Lett. 29, 1582.

Landais, A., Barkan, E., Yakir, D., Luz, B., 2006. The triple isotopic composition of oxygen in leaf water. Geochim. Cosmochim. Acta 70, 4105-4115.

Le Quéré, C., Raupach, M. R., Canadell, J. G., Marland, G., et al., 2009. Trends in the sources and sinks of carbon dioxide. Nature Geosci. 2, 831-836.

Lloyd, J., Farquhar, G. D., 1994. $\mathrm{C}^{13}$ discrimination during $\mathrm{CO}_{2}$ assimilation by the terrestrial biosphere. Oecologia 99, 201-215.

Luz, B., Barkan, E., 2010. Variations of ${ }^{17} \mathrm{O} /{ }^{16} \mathrm{O}$ and ${ }^{18} \mathrm{O} /{ }^{16} \mathrm{O}$ in meteoric waters. Geochim. Cosmochim. Acta 74, 6276-6286.

Miller, J. B., Yakir, D., White, J. W. C., Tans, P. P., 1999a. Measurement of ${ }^{18} \mathrm{O} /{ }^{16} \mathrm{O}$ in the soil-atmosphere $\mathrm{CO}_{2}$ flux. Global Biogeochem. Cy. 13, 761-774.

Miller, M. F., 2002. Isotopic fractionation and the quantification of ${ }^{17} \mathrm{O}$ anomalies in the oxygen three-isotope system: an appraisal and geochemical significance. Geochim. Cosmochim. Acta 66, 1881-1889.

Naegler, T., Ciais, P., Rodgers, K., Levin, I., 2006. Excess radiocarbon constraints on airsea gas exchange and the uptake of $\mathrm{CO}_{2}$ by the oceans. Geophys. Res. Lett. 33.

Nevison, C. D., Dlugokencky, E., Dutton, G., Elkins, J. W., Fraser, P., Hall, B., Krummel, P. B., Langenfelds, R. L., O'Doherty, S., Prinn, R. G., Steele, L. P., Weiss, R. F., 2011. Exploring causes of interannual variability in the seasonal cycles of tropospheric nitrous oxide. Atmos. Chem. Phys. 11, 3713-3730.

Pearcy, R. W., Ehleringer, J., 1984. Comparative ecophysiology of $\mathrm{C}_{3}$ and $\mathrm{C}_{4}$ plants. Plant Cell Environ. 7, 1-13. 
Peylin, P., Ciais, P., Tans, P. P., Six, K., Berry, J. A., Denning, A. S., $1996 .{ }^{18}$ O in atmospheric $\mathrm{CO}_{2}$ simulated by a 3-D transport model: A sensitivity study to vegetation and soil fractionation factors. Phys. Chem. Earth 21, 463-469.

Stern, L. A., Amundson, R., Baisden, W. T., 2001. Influence of soils on oxygen isotope ratio of atmospheric $\mathrm{CO}_{2}$. Global Biogeochem. Cy. 15, 753-759.

Still, C. J., Berry, J. A., Collatz, G. J., DeFries, R. S., 2003. Global distribution of $\mathrm{C}_{3}$ and $\mathrm{C}_{4}$ vegetation: Carbon cycle implications. Global Biogeochem. Cy. 17, -.

Tans, P. P., 1998. Oxygen isotopic equilibrium between carbon dioxide and water in soils. Tellus B 50, 163-178.

Thiemens, M. H., Jackson, T., Zipf, E. C., Erdman, P. W., van Egmond, C., 1995b. Carbon dioxide and oxygen isotope anomalies in the mesosphere and stratosphere. Science 270, 969-972.

van der Werf, G. R., Randerson, J. T., Collatz, G. J., Giglio, L., Kasibhatla, P. S., Arellano, A. F., Olsen, S. C., Kasischke, E. S., 2004. Continental-scale partitioning of fire emissions during the 1997 to 2001 El Niño/La Niña period. Science 303, 73-76.

Welp, L. R., Keeling, R. F., Meijer, H. A. J., Bollenbacher, A. F., Piper, S. C., Yoshimura, K., Francey, R. J., Allison, C. E., Wahlen, M., 2011. Interannual variability in the oxygen isotopes of atmospheric $\mathrm{CO}_{2}$ driven by El Nino. Nature 477, 579-582.

West, J. B., Sobek, A., Ehleringer, J. R., 2008. A simplified GIS approach to modeling global leaf water isoscapes. Plos One 3, e2447.

Wingate, L., Ogée, J., Cuntz, M., Genty, B., Reiter, I., Seibt, U., Yakir, D., Maseyk, K., Pendall, E. G., Barbour, M. M., Mortazavi, B., Burlett, R. g., Peylin, P., Miller, J., Mencuccini, M., Shim, J. H., Hunt, J., Grace, J., 2009. The impact of soil microorganisms on the global budget of $\delta^{18} \mathrm{O}$ in atmospheric $\mathrm{CO}_{2}$. Proc. Natl. Acad. Sci. 106, 22411-22415.

Young, E. D., Galy, A., Nagahara, H., 2002. Kinetic and equilibrium mass-dependent isotope fractionation laws in nature and their geochemical and cosmochemical significance. Geochim. Cosmochim. Acta 66, 1095-1104.

Yung, Y. L., Demore, W. B., Pinto, J. P., 1991. Isotopic exchange between carbon dioxide and ozone via $\mathrm{O}\left({ }^{1} \mathrm{D}\right)$ in the stratosphere. Geophys. Res. Lett. 18, 13-16. 


\section{Conclusions and outlook}

This thesis evaluates the potential of triple oxygen isotope analysis in $\mathrm{CO}_{2}$ as a new tracer for the global carbon cycle. It was an integral part of this study to show that high-precision analysis of tropospheric $\mathrm{CO}_{2}$ allows detecting small variations in $\Delta^{17} \mathrm{O}$ in natural and anthropogenic carbon dioxide. This is a prerequisite for establishing $\Delta^{17} \mathrm{O}$ in tropospheric $\mathrm{CO}_{2}$ as a new tracer to complement conventional $\delta^{18} \mathrm{O}$ and $\delta^{13} \mathrm{C}$ analyses.

The new analytical technique described in chapter 2 has an analytical uncertainty in $\Delta^{17} \mathrm{O}$ measurements of at least $\pm 0.05 \%$ for a single measurement (standard deviation). Due to multiple analyses, the analytical uncertainty was generally reduced to $\pm 0.02 \%$ o to $\pm 0.03 \%$. Thus, until today, this technique is probably the most precise method to analyze the triple oxygen isotope composition of carbon dioxide. However, the method requires a large amount of sample $\mathrm{CO}_{2}$ : At the beginning, about $3.5 \mathrm{mmol}$ of $\mathrm{CO}_{2}(\sim 70 \mathrm{ml}, \mathrm{STP})$ were used for one analysis (see chapter 2), but over the course of the project the sample size was reduced to about one-fifth (see chapter 3, 4 and 5).

The method described here for triple oxygen isotope analysis in atmospheric $\mathrm{CO}_{2}$ can also be applied to carbonate samples. For this purpose, the carbonate sample has to be decomposed by reaction with phosphoric acid. The released $\mathrm{CO}_{2}$ can then be analyzed according to the procedure described in Chapter 2. First high-precision analyses of terrestrial carbonates were carried out during the time of this PhD study (Hofmann et al., 2012c), but it was beyond the scope of this study to explore in detail the potential of ${ }^{17} \mathrm{O}$ analyses in biogenic and abiotic carbonates as a tracer for their formation process. Thus, in principle, the technique for ${ }^{17} \mathrm{O}$ analysis in $\mathrm{CO}_{2}$ also opens up a new field for isotope analysis in carbonates, but the preliminary results showed that further enhancements in measurement precision are required so that this new tool may be used as a new tracer for paleoclimate reconstruction (Hofmann et al., 2012c).

In chapter 3, experimental results on the triple oxygen isotope equilibrium fractionation between $\mathrm{CO}_{2}$ and water are presented. These laboratory studies showed that the triple oxygen isotope exponent $\theta_{\mathrm{CO} 2 \text {-water }}$ is equal to $0.522 \pm 0.002$ for $2{ }^{\circ} \mathrm{C}<\mathrm{T}<37^{\circ} \mathrm{C}$. Subsequent to these laboratory studies, this exponent for $\mathrm{CO}_{2}$-water equilibrium was also confirmed by theoretical studies (pers. comm. Yun Liu, also see footnote 1 in chapter 3). The knowledge of this exponent was essential for meaningful interpretation of the combustion data presented in chapter 4 and it was also of great importance for the global mass balance model presented in chapter 5 . 
In chapter 4, it was shown that combustion $\mathrm{CO}_{2}$ can inherit a distinct triple oxygen isotope signature from ambient air $\mathrm{O}_{2}$, and thus, anthropogenic $\mathrm{CO}_{2}$ can clearly be distinguished from natural $\mathrm{CO}_{2}$ sources to the troposphere. Combustion of natural gas and propanebutane produces carbon dioxide with a $\Delta^{17} \mathrm{O}$ value of $-0.32 \%$ to $-0.30 \%$ (relative to $\lambda_{\mathrm{RL}}=0.522$ and $\gamma=0 \%$ ). Carbon dioxide from car exhaust also inherits the distinct triple oxygen isotope composition of ambient air $\mathrm{O}_{2}$ with $\Delta^{17} \mathrm{O}=-0.34 \%$, but it might have exchanged with similarly anomalous combustion water in the car exhaust. For carbon dioxide from wood combustion, the ${ }^{17} \mathrm{O}$ depletion is less pronounced with a mean $\Delta{ }^{17} \mathrm{O}$ value of $-0.21 \%$, due to $\mathrm{CO}_{2}$-water equilibration and wood inherent oxygen. In contrast, the triple oxygen isotope composition of carbon dioxide in human breath is solely controlled by the isotopic composition of ambient water and does not carry a large oxygen isotope anomaly.

In chapter 5 , the first high-precision triple oxygen isotope data of tropospheric $\mathrm{CO}_{2}$ are presented. Tropospheric $\mathrm{CO}_{2}$ sampled in Göttingen has a mean $\Delta^{17} \mathrm{O}$ value of $-0.03 \pm 0.07 \%$ o (standard deviation) and shows a temporal variation with a peak-to-peak range of $\sim 0.25 \%$. The tropospheric $\mathrm{CO}_{2}$ data from the Brocken Mountain fall within the range observed in Göttingen. The observational data only in part overlap with the revised global model prediction of $+0.06 \pm 0.05 \%$ o (standard deviation). The modeling results suggest that the observed temporal variation in $\Delta^{17} \mathrm{O}$ cannot be attributed to seasonal variations in plant activity, but it may be that the influx of stratospheric $\mathrm{CO}_{2}$ significantly affects the temporal $\Delta^{17} \mathrm{O}$ variations of tropospheric $\mathrm{CO}_{2}$. Thus, future studies are required to explain the interannual variability of $\Delta^{17} \mathrm{O}$ observed for Göttingen $\mathrm{CO}_{2}$ and to explain the discrepancy between the predicted global mean and the observational $\Delta^{17} \mathrm{O}$ data. 


\section{References}

Hofmann, M. E. G., Horváth, B., Pack, A., 2012c. Triple oxygen isotope exponent for phosphoric acid decomposition of carbonates. Sixth International Symposium on Isotopomers, Washington DC. 


\section{List of publications}

The following summary gives a list of all publications that were released during the time of the $\mathrm{PhD}$ thesis.

\section{Peer-review journals:}

- Hofmann, M. E. G., Horváth, B. and Pack, A., Triple oxygen isotope composition of tropospheric $\mathrm{CO}_{2}$ : Observational data and model simulation, in preparation

- Horváth, B., Hofmann, M. E. G., and Pack, A., 2012, On the triple oxygen isotope composition of carbon dioxide from some combustion processes, Geochim. Cosmochim. Acta, in press

- Hofmann, M. E. G., Horváth, B., and Pack, A., 2012. Triple oxygen isotope equilibrium fractionation between carbon dioxide and water. Earth Planet. Sci. Lett. 319-320, 159-164

- Hofmann, M. E. G. and Pack, A., 2010. Technique for high-precision analysis of triple oxygen isotope ratios in carbon dioxide. Anal. Chem. 82, 4357-4361

\section{Conference abstracts:}

- Hofmann, M. E. G., Horváth, B., and Pack, A., 2012. Global long-term mean triple oxygen isotope composition of tropospheric $\mathrm{CO}_{2}$, European Mineralogical Conference, Frankfurt

- Pack, A., Albrecht, N., Hofmann, M. E. G., Bultmann, E. M., Horváth, B., and Gehler, A., 2012. Variations in triple isotope fractionation exponents, European Mineralogical Conference, Frankfurt

- Horváth, B., Hofmann, M. E. G., and Pack, A., 2012. Triple oxygen isotope variations in ambient air $\mathrm{CO}_{2}$ from Göttingen, JESIUM, Leipzig

- Hofmann, M. E. G., Horváth, B., and Pack, A., 2012, Global long-term mean triple oxygen isotope composition of tropospheric $\mathrm{CO}_{2}$, International Symposium on Isotopomers, Washington D.C. 
- Hofmann, M. E. G., Horváth, B., and Pack, A., 2012, Triple oxygen isotope exponent for phosphoric acid decomposition of carbonates, International Symposium on Isotopomers, Washington D.C.

- Horváth, B., Hofmann, M. E. G., and Pack, A., 2012. Seasonal triple oxygen isotope variations in ambient air $\mathrm{CO}_{2}$ from Göttingen, International Symposium on Isotopomers, Washington D.C.

- Pack, A., Albrecht, N., Hofmann, M. E. G., Horváth, B., Gehler, A., 2012. Experimental data on variations in triple oxygen isotope equilibrium fractionation exponents, International Symposium on Isotopomers, Washington D.C.

- Hofmann, M. E. G., Horváth, B., and Pack, A., 2011. Triple oxygen isotope composition of tropospheric carbon dioxide and terrestrial carbonates, AGU, San Francisco.

- Horváth, B., Hofmann, M. E. G., and Pack, A., 2011. Triple oxygen isotope composition of $\mathrm{CO}_{2}$ as a tracer for global carbon fluxes and for regional $\mathrm{CO}_{2}$ sources, Annual Meeting of the German Association for Stable Isotope Research, Villigen-PSI.

- Horváth, B., Hofmann, M. E. G., and Pack, A., 2011. Triple oxygen isotope composition as a potential tracer for mixing ratios of carbon dioxide sources in urban air, XI. Isotope Workshop, Budapest.

- Hofmann, M. E. G., Horváth, B. and Pack, A., 2011. Triple oxygen isotope equilibrium fractionation between $\mathrm{CO}_{2}$ and water and its implication on tropospheric $\mathrm{CO}_{2}$, Tenth Informal Conference on Atmospheric and Molecular Science, Copenhagen.

- Horváth, B., Hofmann, M. E. G. and Pack, A., 2011. Triple oxygen isotope composition as a potential tracer for mixing ratios of carbon dioxide sources in urban air, Tenth Informal Conference on Atmospheric and Molecular Science, Copenhagen.

- Hofmann, M. E. G., Horváth, B., Hinrichsen, S. and Pack, A., 2011. Temperature dependence of the triple oxygen isotope equilibrium fractionation between carbon dioxide and water and its implication on the triple oxygen isotope signature of tropospheric carbon dioxide, EGU, Vienna. 
- Horváth, B., Hofmann, M. E. G., Hinrichsen, S. and Pack, A., 2011. Triple oxygen isotope composition of carbon dioxide from various anthropogenic sources and in urban air, EGU, Vienna.

- Pack, A., Horváth, B., Hofmann, M. E. G., Goldmann, A., Albrecht, N., Gellissen, M., Zipfel, J., and Palme, H., 2011. Defining the terrestrial oxygen isotope fractionation line and observed oxygen isotopic heterogeneity within the Allende meteorite, Lunar and Planetary Science Conference, Houston.

- Hofmann, M. E. G., Horváth, B. and Pack, A., 2010. Triple oxygen isotope composition of $\mathrm{CO}_{2}$ from the biosphere, the troposphere and from combustion. International Symposium on Isotopomers, Amsterdam.

- Horváth, B., Hofmann, M. E. G., Gehler, A. and Pack, A., 2010. Triple oxygen composition of $\mathrm{CO}_{2}$ from fossil fuel combustion and human respiration, International Symposium on Isotopomers, Amsterdam.

- Hofmann, M. E. G., Horváth, B. and Pack, A., 2010. Experimental determination of the exponent $\beta$ for oxygen triple isotope fractionation between carbon dioxide and water, EGU, Vienna.

- Horváth, B., Hofmann, M. E. G. and Pack, A., 2010. Triple oxygen composition of carbon dioxide from fossil fuel combustion. EGU, Vienna. 